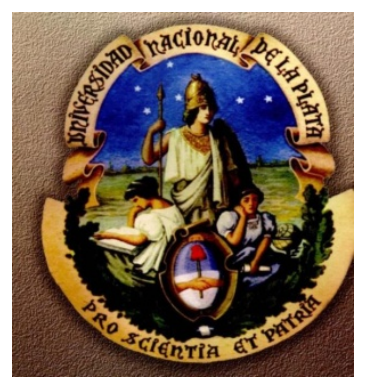

UNIVERSIDAD NACIONAL DE LA PLATA

FACULTAD DE CIENCIAS EXACTAS

DEPARTAMENTO DE CIENCIAS BIOLÓGICAS

Trabajo de Tesis Doctoral

\title{
ROL DE GALECTINA-1 EN LA FISIOPATOLOGÍA DE LAS ENFERMEDADES INFLAMATORIAS INTESTINALES
}

Autor: Lic. Rodrigo Papa Gobbi

Director: Dr. Guillermo Docena

Co-directora: Dra. Cecilia Muglia

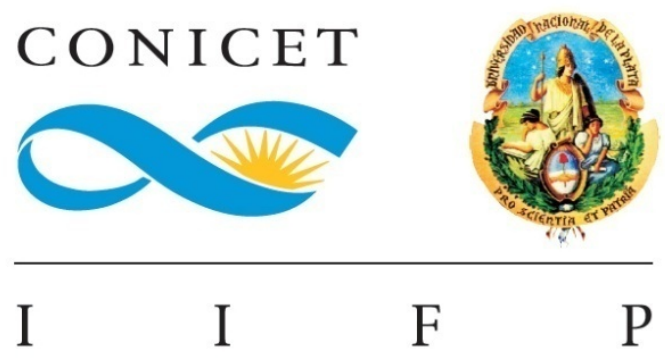

Instituto de Estudios Inmunológicos y Fisiopatológicos 

Que el fin del mundo te pille bailando Joaquín Sabina 

A Maxi

A Miriam, Ricardo y Marcelo 



\section{Agradecimientos}

Las palabras que puedo escribir en estas páginas son sólo un tenue reflejo del agradecimiento que tengo por toda la gente que, desde su lugar, contribuyó al desarrollo de este trabajo. Seguramente me olvide de nombrar a más de uno, a quienes pido perdón $y$, al mismo tiempo, les agradezco enormemente por su ayuda.

A mis directores Guille y Ceci. Por creer en mí y apostar a este proyecto, por formarme durante estos años y darme la libertad con la que trabajo.

A mis viejos. La vida hizo que tenga 3 , dos de ellos me trajeron a éste mundo, el tercero me enseño que eso no es requisito imprescindible para el cargo. Son quienes bancan cada uno de mis proyectos, por más que éstos nos pongan un montón de kilómetros entre medio.

A mis hermanos, Maxi, Alfo, Nico y Davi. El primero vino de fabrica, a los otros 3 me los tope por la vida y nuestros caminos se entrelazaron de manera tan fuerte que no compartir padres paso a ser un hecho insignificante. A pesar de la distancia están siempre cerca, con la palabra justa y el hombro listo.

A mi familia, Abuelo, Tio Mario, Primos, por su cariño y apoyo.

A "los tíos": Juan, Susana, Maria Elena, Patricio, Pedro, Axel, Horacio, Estela, Dani. Porque mucho de lo que soy se los debo a ustedes.

A mis amigos del pago: May, Ani, Glo, Lara, Facu y Luji. Por hacer que cada reencuentro este lleno de risas y alegría.

A la FAMILIA LISIN: Pao, Nico, Juan, Costy, Romi A, Romi C, Belu, Agus E, Agus Z, David, Gri, Reni, Fer Trejo, Kari, Lu, Martin R, Alberto, Fer Chirdo, Paula, JC, Vani, Vicky, Loli, Yani, Pablo S, Male, Coqui, Ezequiel R y Andre. Por hacer que el lab rebalse de alegría.

Dentro del increíble grupo de gente con la que trabajo quiero agradecer particularmente a Juan, Paolin y Nico, porque su paciencia y entusiasmo fueron infinitos cada una de las muuuuchass vez que acudí a ellos en busca de un consejo. 
A Gabriel Rabinovich y Marta Toscano, por su enorme generosidad a la hora de compartir tanto recursos como sabiduría. Sin su ayuda nada de lo que aquí muestro hubiera sido posible. Sus consejos y experiencia despertaron en mí un particular interés por el mundo de la glicobiología.

A Lu por su enorme aporte a este tesis a través del modelo de colitis. A Vero Allo por los ELISA de Gal-1. A Reni, Paolo, Antonio y Tom por su aporte con los fibroblastos. A Romi, quien a pesar de la distancia y todos los imaginables impedimentos tecnológicos leyó y corrigió este trabajo con una increíble dedicación y rapidez.

A la banda del Rocodromo, pero en especial al Flaco Santi y Panchito, por ser mis compañeros de vida platense.

Al GEMaRI (Amalia, Maga, Gustavo, Patricio, El chino, Santi, May y el amariyo) por recibirme durante parte de la escritura de esta tesis y compartir mates, charlas y consejos durante todo ese tiempo.

Al personal del Hospital Udaondo, San Martin y Sor María Ludovica. Por su compromiso y dedicación con este trabajo: Ivan, Arturo, Alejandro, Agustina, Martin, Olga, Maricel, Ricardo Drut, Pablo Tirado, Anibal Gil y Silvia Negreira. En especial quiero agradecer a Alicia Sambuelli y Andrés Rocca, en quienes no sólo encontré eminencias de su profesión, sino personas con una calidez humana tan grande que hizo que nuestra labor conjunta fuese una experiencia enriquecedora tanto en lo profesional como en lo personal.

A la Facultad de Ciencias Exactas y la Universidad Nacional de La Plata, por darme el lugar de trabajo.

A CONICET por otorgarme las becas que permitieron el desarrollo de esta tesis. 


\section{ÍNDICE GENERAL}

$\begin{array}{ll}\text { Agradecimientos } & 5\end{array}$

$\begin{array}{ll}\text { ÍNDICE GENERAL } & 7\end{array}$

$\begin{array}{ll}\text { ABREVIATURAS } & 11\end{array}$

$\begin{array}{ll}\text { ÍNDICE DE FIGURAS } & 13\end{array}$

$\begin{array}{ll}\text { RESUMEN } & 15\end{array}$

$\begin{array}{ll}\text { INTRODUCCIÓN GENERAL } & 17\end{array}$

Las Enfermedades Inflamatorias Intestinales $\quad 20$

$\begin{array}{ll}\text { Galectinas } & 28\end{array}$

HIPÓTESIS DE TRABAJO Y OBJETIVOS GENERALES 33

MATERIALES Y MÉTODOS

$\begin{array}{ll}\text { 1. MUESTRAS BIOLÓGICAS } & 37\end{array}$

$\begin{array}{ll}\text { 1.1 Provenientes de pacientes } & 37\end{array}$

$\begin{array}{ll}1.2 \text { Provenientes de ratones } & 39\end{array}$

$\begin{array}{ll}1.3 \text { Línea celular } & 39\end{array}$

2. PROCESAMIENTO DE MUESTRAS 40

2.1 Conservación y transporte $\quad 40$

2.2 Aislamiento de células epiteliales y de células de la lámina propia $\quad 40$

2.3 Aislamiento de células $\mathrm{CD}^{+}$de la lámina propia $\quad 41$

3. CULTIVO DE ÓRGANO Y MODELOS IN VITRO E IN VIVO

3.1 Cultivo de órgano $\quad 41$

3.2 Cultivo de líneas celulares $\quad 42$

3.3 Modelo de colitis $\quad 42$

4. EXPRESIÓN DE GENES, PROTEÍNAS Y MARCADORES DE SUPERFICIE 43 
4.1 Aislamiento de ARN y RT-PCR en tiempo real

4.2 Histología e inmunohistoquímica

4.3 SDS PAGE y Western Blot

4.4 Análisis del glicofenotipo celular y capacidad de unión a Gal-1

5. ENSAYOS DE MUERTE CELULAR

5.1 Tinción con Anexina V/ioduro de propidio

5.2 Ensayo de TUNEL por microscopía confocal

5.3 Análisis fluorométrico de la actividad caspasas-3, -8 y -9

5.4 Análisis del potencial de membrana mitocondrial

5.5 Expresión de Bad, Bax y Bcl-2

6. ANÁLISIS ESTADÍSTICOS

CAPITULO I: Análsis de galectinas como biomarcadores de actividad en las

Enfermedades Inflamatorias Intestinales

INTRODUCCIÓN

OBJETIVOS ESPECÍFICOS

RESULTADOS Y CONCLUSIONES PARCIALES

La expresión de las galectinas está desregulada en las zonas inflamadas de pacientes con Ell

La expresión conjunta de Gal-1, -3, -4 y -9 refleja el grado de actividad de la mucosa

La expresión de ARNm de las galectinas no permite discriminar entre inflamación en EC y CU

Las galectinas se expresan diferencialmente dependiendo del tipo de inflamación intestinal

DISCUSIÓN 
RESULTADOS Y CONCLUSIONES PARCIALES

Gal-1 está diferencialmente expresada en las zonas inflamadas de la mucosa colónica de los pacientes con Ell

Los niveles de Gal-1 aumentan en un modelo de colitis inducida por TNBS

TNF- $\alpha$ induce la expresión de Gal-1 en la mucosa colónica humana, pero las proteasas secretadas por los miofibroblastos ejercen una acción proteolítica sobre esta lectina

DISCUSIÓN

CAPITULO III: Modulación del efecto pro-apoptótico de galectina-1 en las sobrevida de los linfocitos T en el entorno inflamatorio de las Ell

INTRODUCCIÓN

OBJETIVOS ESPECÍFICOS

RESULTADOS Y CONCLUSIONES PARCIALES

Gal-1 controla la sobrevida de los linfocitos T de la lámina propia en homeostasis

Las células T de la lámina propia muestran una capacidad diferencial de unir Gal-1

Las células T de la lámina propia expresan un glicofenotipo diferencial en pacientes con Ell

CAPITULO IV: Galectina-1 controla la sobrevida de las células epiteliales en el intestino

INTRODUCCIÓN

OBJETIVOS ESPECÍFICOS 
El entorno inflamatorio modula la capacidad de los enterocitos de unir Gal-1, así como su susceptibilidad a la muerte celular

El entorno inflamatorio promueve in vivo un glicofenotipo permisivo para el reconocimiento de Gal-1 en los enterocitos y favorece la inducción de apoptosis

La capacidad de unir Gal-1 y la susceptibilidad a la muerte celular inducida por esta lectina está incrementada en pacientes con enfermedad inflamatoria intestinal

DISCUSIÓN

DISCUSIÓN Y CONCLUSIONES FINALES

DISCUSIÓN FINAL

CONCLUSIONES FINALES 


\section{ABREVIATURAS}

AD: análisis discriminante.

LTLP: linfocito $\mathrm{T}$ de la lámina ADC: área debajo de la curva. propia.

C2GnT:

$1,6-\mathrm{N}-$

acetilglucosaminiltransferasa.

CD: cluster de diferenciación.

CDAl: índice de actividad de la enfermedad de Crohn.

CEI: célula epitelial intestinal.

CU: colitis ulcerosa.

DSS: dextran de sodio y sulfato.

EC: enfermedad de Crohn.

Ell: enfermedad inflamatoria intestinal.

FSC: Forward scatter.

Gal: galectina.

GATA3: proteína de unión a

\section{GATA 3.}

GDI: gen de interés.

IAE: índice de actividad de la enfermedad.

IAH: índice de actividad histológico.

IFN-p: interferon gama.

IL: interleuquina.

INF: inflamado.

LP: lámina propia.

LT: linfocito T.
MMPs: metaloproteasas.

NO INF: no inflamado.

PBMC: células mononucleares de sangre periférica.

PCR: reacción en cadena de la polimerasa.

PNA: aglutinina de mani.

qPCR: PCR cuantitativa.

rh: recombinante humano.

ROC: característica operativa del receptor.

SNA: aglutinina de Sambucus nigra.

SSC: side scatter.

ST3Gal1: $\alpha 2-3$ sialiltransferasa.

ST6Gal1: $\alpha 2-6$ sialiltransferasa.

STAT4: traductor de señales y activador de la transcripción 4.

T-bet: factor de transcripción de T-box 21.

TIMP: inhibidor de las metaloproteasas.

TNBS: ácido sulfónico 2, 4, 6trinitrobenceno. 
TNF- $\boldsymbol{\alpha}$ : factor de necrosis

tumoral alfa.

Treg: célula T regulatoria.

u.a: unidades arbitrarias.
UCAl: índice de actividad de la colitis ulcerosa.

VC: validación cruzada. 


\section{ÍNDICE DE FIGURAS}

Fig. 1: Incidencia de las Ell a nivel mundial e hipótesis de la higiene 22

Fig. 2: Marco conceptual de las Ell.

Fig. 3: Diferencias entre las lesiones producidas por la CU y la EC. 25

Fig. 4: Citoquinas en las Ell. $\quad 27$

Fig. 5: Clasificación y esquema estructural de las Gals. 29

Fig. 6: Formación de redes entre las Gals y sus ligandos. 30

Fig. 7: Rol de las Gals en las Ell. 32

Fig. 1.1: Niveles de expresión de LGALS1 en la mucosa colónica. 66

Fig. 1.2: Niveles de expresión de LGALS3, 4, y 9 en la mucosa colónica. $\quad 69$

Fig. 1.3: Análisis de sensibilidad y especificidad de las Gals como indicadores $\begin{array}{ll}\text { de inflamación. } & \mathbf{7 0}\end{array}$

Fig. 1.4: Análisis discriminante de la expresión de las diferentes Gals en muestras de colon en pacientes control y pacientes con Ell.

Fig. 1.5: Análisis discriminante de la expresión de las diferentes Gals según el grado de inflamación.

Fig. 1.6: Análisis discriminante de la expresión de las Gals y marcadores inmunológicos asociados a células $\mathrm{T}$.

Fig. 1.7: Análisis discriminante de la expresión de Gals en pacientes con diferentes patologías inflamatorias intestinales.

Fig. 1.8: Análisis discriminante de la expresión de Gals en pacientes control, pacientes con Ell y pacientes con rechazo al trasplante de intestino. $\quad 80$

Fig. 2.1: Rol de Gal-1 en la regulación de la respuesta inmune. 94

Fig. 2.2: Expresión de Gal-1 en la mucosa colónica de pacientes control. 98

Fig. 2.3: Expresión de Gal-1 en biopsias de pacientes con Ell. 99

Fig. 2.4: Modelo murino de colitis inducido por TNBS. 101

Fig. 2.5: Expresión de Gal-1 en el colon de ratones del modelos de colitis inducido por TNBS. 
Fig. 2.6: TNF- $\alpha$ induce la expresión de Gal-1 mientras que las proteasas presentes en sobrenadantes de fibroblastos la degradan.

Fig. 3.1: Las células epiteliales intestinales están expuestas a numerosos estímulos pro y anti- inflamatorios durante los procesos crónicos de las Ell. 115 Fig. 3.2: La sobre-exposición a citoquinas pro-inflamatorias estimula el desarrollo de cáncer en pacientes con Ell.

Fig. 3.3: Biosíntesis de O-glicanos y sitios de unión de las diferentes lectinas. 120 Fig. 3.4: Análisis del efecto pro-apoptótico de Gal-1 sobre los LTLP del colon humano.

Fig. 3.5: Unión de Gal-1 a células T provenientes de la mucosa colónica de pacientes control.

Fig. 3.6: Análisis de la capacidad de unión de Gal-1 por los LTLP de pacientes con ElI.

Fig. 3.7: Glicofenotipo de los linfocitos $\mathrm{T}$ de la lámina propia en pacientes control.

Fig. 3.8: Unión de PNA y SNA en LTLP provenientes de pacientes con Ell.

Fig. 3.9: El ambiente inflamatorio de las Ell modula la expresión de las enzimas que ramifican los ligandos de Gal-1.

Fig. 3.10: Expresión de C2GnT-1 y capacidad de los LT de unir Gal-1 en ensayos in vitro.

Fig. 4.1: Análisis de la capacidad de unión de Gal-1 e inducción de apoptosis en enterocitos frente a estímulos pro-inflamatorios.

Fig. 4.2: Análisis de los mecanismos de apoptosis inducidos por Gal-1 en enterocitos murinos.

Fig. 4.3: Análisis del reconocimiento de Gal-1 e inducción de apoptosis en enterocitos aislados de ratones con colitis.

Fig. 4.4: Análisis de la capacidad de unión de Gal-1 de enterocitos aislados de pacientes control y pacientes con Ell, y de la presencia de células apoptóticas en la mucosa colónica luego de la incubación con Gal-1. 


\section{RESUMEN}

Las Enfermedades Inflamatorias Intestinales (EII) son un conjunto de patologías crónicas multifactoriales en las cuales se produce una respuesta inmune aberrante contra componentes de la microbiota intestinal. Dentro de las Ell, la colitis ulcerosa (CU) y la enfermedad de Crohn (EC) son las dos formas más estudiadas. Si bien existen diferencias en la presentación clínica de estas patologías, en ambos casos los linfocitos T (LT) de la mucosa sobre-expresan citoquinas pro-inflamatorias del perfil Th1. La cronicidad de este proceso desencadena complicaciones tales como la formación de abscesos, fístulas, estenosis e inclusive la necesidad de resección quirúrgica de diversos segmentos del intestino debido a lo extenso del daño.

Galectina-1 (Gal-1) es una lectina endógena con propiedades antiinfamatorias ampliamente documentadas. Entre los distintos efectos descriptos para esta proteína podríamos mencionar el control de la sobrevida de los LT Th1 y la modulación en la producción de citoquinas.

En el presente trabajo de tesis se propuso estudiar la expresión de Gal-1 en la mucosa colónica humana y murina en situaciones fisiológicas y patológicas; analizar la correlación entre la producción de esta lectina y la actividad inflamatoria del tejido y su capacidad de modular la sobrevida de los LT y de las células epiteliales intestinales (CEI) en dichos entornos.

Pudimos demostrar que el análisis conjunto de la expresión intestinal de diferentes galectinas permite distinguir entre pacientes con Ell activa $y$ pacientes control, Ell inactiva o en remisión. Además, concluimos que este análisis es una herramienta eficiente para determinar el grado de inflamación de dicha mucosa y distinguirla de otras patologías inflamatorias intestinales agudas y crónicas. Por lo tanto, podría constituir un marcador de la historia de la patología en el paciente.

En cuanto a su rol en la fisiología intestinal, en homeostasis Gal-1 ejerce un efecto pro-apoptótico sobre los LT de la lámina propia colónica, efecto que 
permite controlar la activación celular frente al constante desafío antigénico por parte de la microbiota. Además, comprobamos que la respuesta fisiológica del intestino frente a un estímulo inflamatorio consiste en inducir un aumento en los niveles de expresión de esta lectina. Sin embargo, este mecanismo compensatorio resulta inefectivo dado que los LT de la lámina propia alteran su maquinaria de glicosilacióin, inhibiendo la expresión de los ligandos específicos para Gal-1. Asimismo, las proteasas presentes en el entorno inflamatorio tisular degradan a esta proteína. Ambos efectos en la lámina propia favorecen la persistencia del foco inflamatorio y la no resolución del daño tisular. Por otra parte, la inflamación sostenida incrementa el porcentaje de CEI que expresan los ligandos para esta lectina. Este fenómeno intensifica el efecto proapoptótico que Gal-1 ejerce sobre dichas células. Este mecanismo contribuye a la perdida de la integridad epitelial, la alteración de la permeabilidad intestinal y propicia la traslocación de los antígenos del lumen a la lámina propia.

Por lo tanto, en condiciones de homeostasis, Gal-1 contribuiría a la normal fisiología del intestino. Sin embargo, en procesos inflamatorios crónicos, dicho rol se vería alterado, hecho que propiciaría la continuidad de la enfermedad. Una mejor comprensión de los mecanismos que gobiernan la expresión de los ligandos específicos de esta lectina, y el rol que ésta ejerce sobre otras células del sistema inmune, permitirá plantear nuevas terapias o procedimientos para restablecer el glicofenotipo de los LT y de las CEI y, de esta manera, controlar la inflamación intestinal. 
INTRODUCCIÓN GENERAL 

La mucosa gastrointestinal es la principal vía de ingreso de la mayoría de los antígenos que el sistema inmune debe enfrentar. Estas superficies están recubiertas por una monocapa de células epiteliales que cumplen dos funciones principales: actúan como barrera física que separa el lumen del medio interno y como un elemento esencial del sistema inmune.

En este escenario tan particular, el sistema inmune de la mucosa intestinal es el encargado de discernir entre inducir los mecanismos de tolerancia frente a la microbiota y antígenos dietarios, o activar una respuesta inmunológica a fin de erradicar los microorganismos potencialmente perjudiciales. Este hecho conlleva a que en el intestino exista la mayor cantidad de células inmunes (principalmente linfocitos B y T) del organismo. Este conjunto de células es un componente esencial del sistema inmune de mucosas y el responsable de mantener la homeostasis intestinal.

En los últimos años se han logrado importantes avances en la comprensión de los complejos mecanismos que gobiernan la tolerancia oral. A través de los mismos, la mucosa intestinal se mantiene en un estado basal de inflamación controlada frente a aquellos antígenos que se necesitan preservar 
(antígenos de la dieta y de la microbiota, esta última compuesta por más de 2000 especies de bacterias, y 10 veces más células procariotas que todas las células del organismo) (Hooper \& Gordon, 2001; Mowat y col., 2004; Strober y col., 2003). Pero, al mismo tiempo, permite iniciar una rápida y efectiva respuesta frente a patógenos, a fin de controlarlos o erradicarlos.

Por lo tanto, a fin de mantener la homeostasis intestinal, el sistema inmune de mucosas debe permanentemente montar mecanismos de activación y de tolerancia frente a un diverso conjunto de antígenos (Mowat y col., 2004; Strober y col, 2003). Estos complejos mecanismos no han sido completamente dilucidados, por lo cual es necesario profundizar los estudios que permitan un mejor entendimiento de la interacción microorganismos-mucosa en situaciones fisiológicas y patológicas.

\section{Las Enfermedades Inflamatorias Intestinales}

Las enfermedades inflamatorias intestinales (EII) engloban a un conjunto de patologías inflamatorias crónicas que alternan periodos de remisión y de actividad. Dentro de este grupo la colitis ulcerosa (CU) y la enfermedad de Crohn (EC) son las dos formas más estudiadas (Baumgart \& Sandborn, 2007). Si bien estas patologías se presentan principalmente en países desarrollados (Fig. $1 \mathrm{~A}$ ), en los últimos años ha habido un incremento en su incidencia a nivel mundial (Fig. 1 B) y la prevalencia de las Ell está alcanzando cifras importantes en otras regiones en el mundo. Tal es el caso de nuestro país, considerado típicamente como una de las regiones con baja incidencia para estas enfermedades (Fig. 1 A) (Cosnes y col., 2011), pero donde actualmente se está observando un cambio en la presentación de la patología. Este hecho ha sido interpretado a partir de la elaboración de la Hipótesis de la Higiene (Strachan, 1989), que luego fue re-formulada por J-F Bach (Bach, 2002). Según estos autores, los hábitos de vida "occidentalizados", caracterizados por una menor exposición a microorganismos intracelulares patógenos (debido a mejores planes de vacunación, mayor uso de antibióticos y menor contacto con la naturaleza, entre otros factores), y una mayor exposición a alérgenos (a 
causa de hábitos de vida mayormente intra-domiciliarios) propicia la activación de mecanismos inmunológicos Th2-dependientes. Por lo tanto, originalmente esta hipótesis permitió comprender la alta incidencia de las enfermedades Th2dependiente, como las alergias, frente al control de las enfermedades infecciosas, mediadas por de mecanismos Th1-dependiente (Fig 1 B). Sin embargo, posteriormente J-F Bach describió valores de incidencia similarmente elevados para patologías del tipo Th1. Este hecho, sumado a la creciente descripción de fallas a nivel de tolerancia en la mayoría de las inmunopatologías llevó a la reformulación de la misma. Actualmente se considera que las fallas en los diferentes mecanismos que modulan la tolerancia son los responsables de la mayor incidencia de las inmunopatologías mediadas por mecanismos tanto Th1 como Th2 (Bach, 2002). Como planteó Strachan en un comienzo (1989), este hecho estaría relacionado con los hábitos de vida "ocidentalizados". Sin embargo, a diferencia del postulado original, la hipótesis actual sostiene que el contacto alterado con microorganismos durante las etapas tempranas de la niñez afecta el desarrollo de los mecanismos de tolerancia inmune.

Si bien, no existen estudios epidemiológicos publicados sobre las Ell en Argentina, las estadísticas indican una prevalencia de 50 casos cada 100000 habitantes (Sambuelli, comunicación personal). A diferencia de los países donde estas enfermedades han tenido una larga evolución, en Argentina se observa el doble de casos de CU en relación a EC (Sambuelli, comunicación personal). Esto presenta una diferencia notable en comparación con los países desarrollados, donde la prevalencia de la EC duplica en número de casos a la CU (Baumgart \& Sandborn, 2007). 


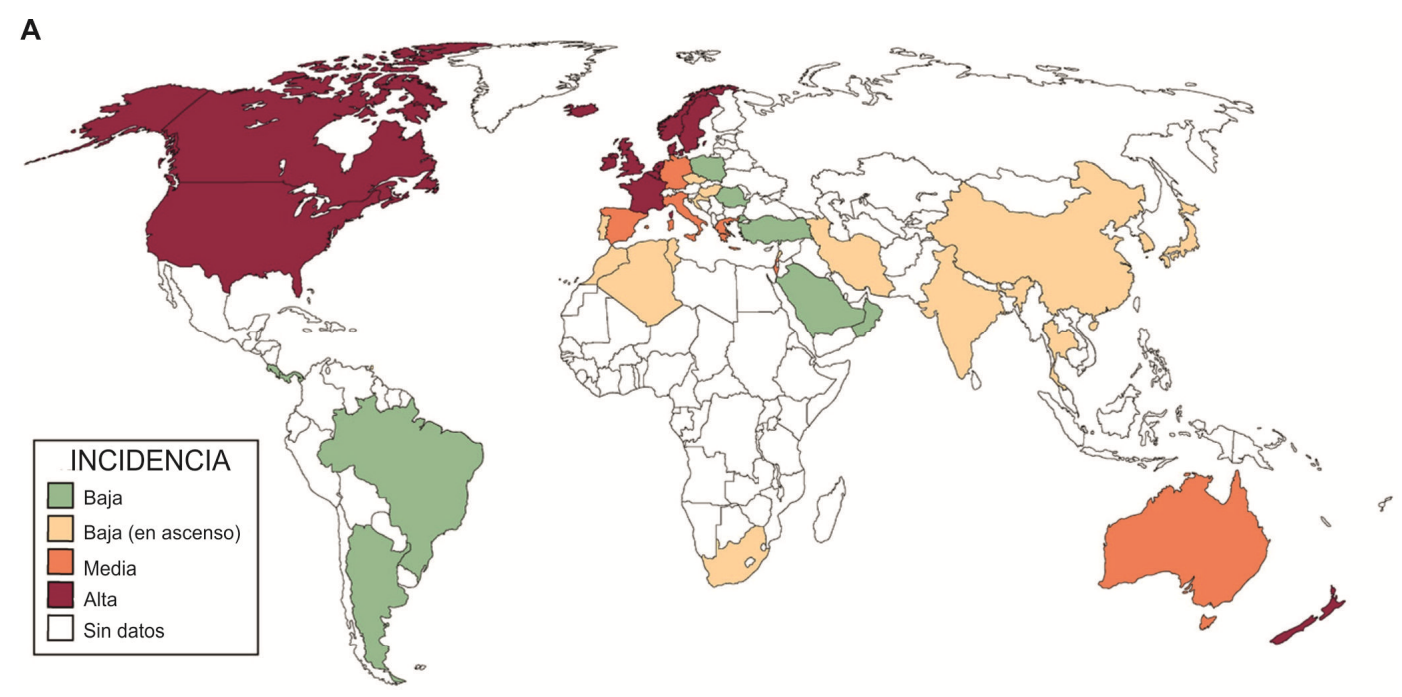

B
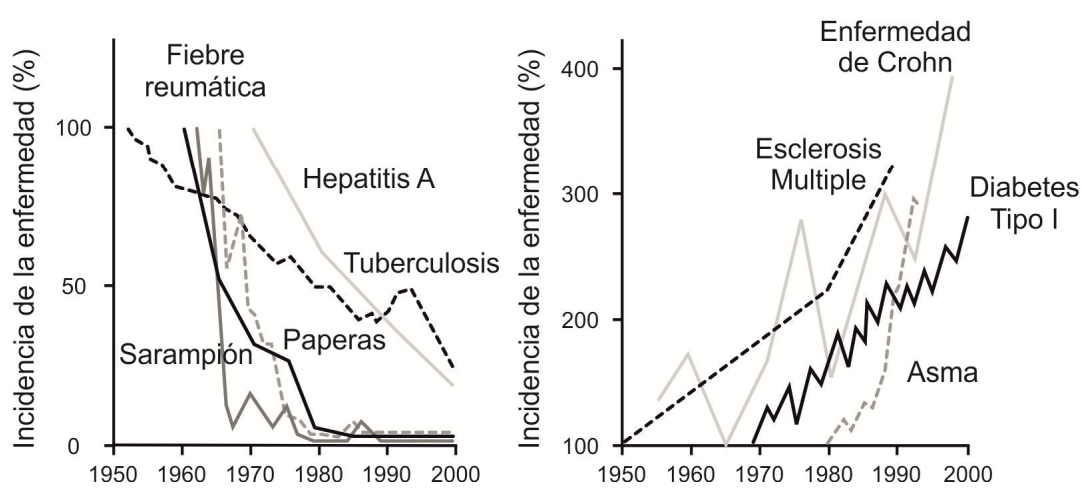

Fig. 1: Incidencia de las Ell a nivel mundial e hipótesis de la higiene

Modificado a partir de Cosnes y col., 2011, y Bach, 2002.

Aunque la etiología de las Ell es aún desconocida, en los últimos años se ha comprobado la contribución tanto de factores ambientales como genéticos e inmunológicos en la etiopatogenia de estas enfermedades (Fig. 2) (Neurath, 2014; Baumgart \& Carding, 2007). La combinación de dichos factores de susceptibilidad generaría alteraciones en la funcionalidad de la barrera epitelial, posibilitando la traslocación de antígenos luminales al interior de la pared intestinal (Neurath, 2014).

En condiciones de homeostasis el sistema inmune asociado a la mucosa intestinal puede distinguir entre los antígenos derivados de la dieta, la flora comensal y los patógenos, permitiendo montar una respuesta inmune acotada y efectiva cuando es necesaria (Garrett y col., 2010; Xavier \& Podolsky, 2007). 
Sin embargo, en las Ell se genera una producción excesiva y aberrante de citoquinas. Se postula que el origen de este proceso crónico es la respuesta inmune sostenida frente a componentes de la microbiota (Baumgart \& Carding, 2007). Con el tiempo este proceso ocasiona alteraciones histológicas y fisiológicas del tracto gastrointestinal (Fig. 2.) (Geremia y col., 2014; Neurath, 2014; Strober \& Fuss, 2011). A su vez, la expresión crónica de mediadores inflamatorios ha sido asociada con manifestaciones extra intestinales, siendo la piel (eritema noduloso, pioderma gangrenoso y estomatitis aftosa), las articulaciones (artritis periférica), los ojos (uveítis anterior y epiescleritis) y el hígado (colangitis esclerosante primaria) los órganos principalmente afectados (Neurath, 2014). 
Etapa previa a la enfermedad

\begin{tabular}{|l|}
\hline Factores Genéticos \\
Péptidos antimi-crobianos \\
Autofagia \\
Citoquinas \\
Quimoquinas \\
\hline
\end{tabular}

\section{Factores Ambientales}

Microorganismos

Dieta

Infecciones

Apendicectomía

Antibióticos

Anti-inflamatorios no esteroideos

Estrés

Humo de cigarrillo

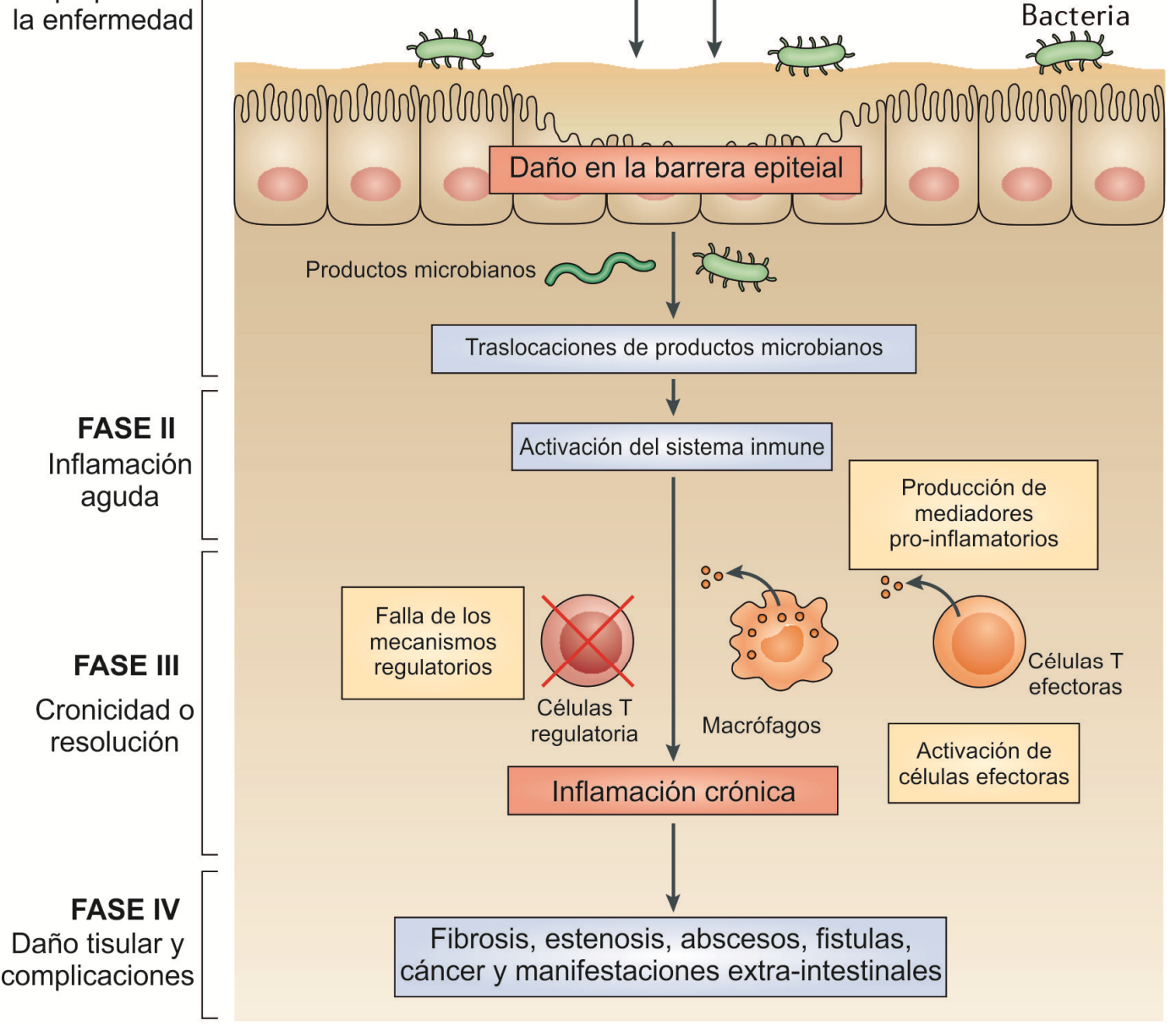

Fig. 2: Marco conceptual de las Ell.

La integridad de la mucosa intestinal puede ser alterada tanto por factores genéticos como ambientales (Fase I/estado previo a la enfermedad) y favorece la traslocación de bacterias comensales y antígenos microbianos desde el lumen hacia la pared del intestino. Esto conduce a un estado de inflamación aguda, con activación de células del sistema inmune y liberación de citoquinas pro-inflamatorias (Fase II/inflamación aguda). Si esta fase no puede ser resuelta por medio de los mecanismos anti-inflamatorios se establece un proceso crónico (Fase III/ cronicidad o resolución de la inflamación). Con el tiempo la respuesta inmune crónica puede causar fibrosis, estenosis, abscesos, cáncer y manifestaciones extra-intestinales (Fase IV/ destrucción de tejido y complicaciones. Modificado a partir de Neurath 2014. 
La presentación de las Ell es muy diferente en EC y CU. De hecho, las lesiones típicas observadas en la CU y en la EC difieren en su localización e histología (Fig. 3) (Baumgart \& Sandborn, 2007). Mediante el examen endoscópico e histológico se puede apreciar que en la CU las lesiones afectan al colon, y principalmente al recto (Fig. 3A), mientras que en la EC las mismas pueden situarse en cualquier segmento del tracto gastrointestinal (desde la boca hasta el ano) (Fig. 3D). Además, la lesión clásica en la CU es continua y simétrica (Fig. 3 B) y está restringida a la mucosa (Fig. 3C). Por otra parte, en la EC las lesiones son discontinuas o "parcheadas", alternando zonas inflamadas con zonas no inflamadas (Fig. $3 \mathrm{D}$ y E). Aquí el daño es transmural, afectando desde el compartimento epitelial hasta la capa muscular (Fig. 3 F) (Baumgart \& Sandborn, 2007).

Estas diferencias en la presentación de la CU y la EC probablemente reflejan que se trata de entidades clínicas independientes, con distintos mecanismos inmunopatogénicos subyacentes (Neurath, 2014). Sin embargo, en un $8-10 \%$ de los casos el análisis endoscópico e histológico no logra distinguir la identidad de la patología. Este conjunto de pacientes es agrupado dentro de las “colitis indeterminada”(Royero Gútierrez, 2003) .
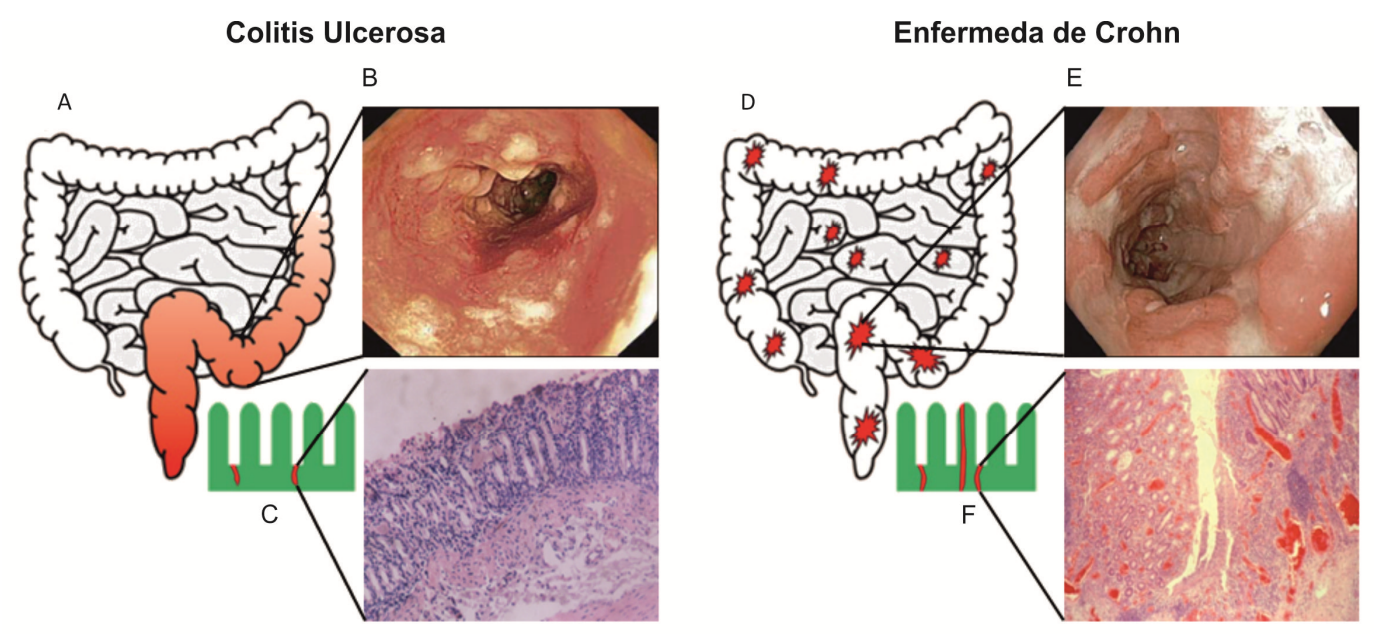

Fig. 3: Diferencias entre las lesiones producidas por la CU y la EC.

A) Esquema de las zonas del colon mayormente afectadas en la CU. B) Fotografía de una lesión continua y simétrica, típica de la CU. C) Izquierda: Esquema de una lesión típica de CU. Derecha: Tinción con hematoxilina-eosina. Se observa como el infiltrado inflamatorio está restringido a la 
mucosa. D) Esquema del tipo de lesión y ubicación de la misma en la EC. E) Fotografía de una lesión típica de EC, se puede observar mucosa sana alternada con mucosa enferma. F) Izquierda: Esquema de una lesión típica de EC. Derecha: Tinción con hematoxilina-eosina. El daño es transmural, abarcando tanto la mucosa como la capa muscular. Modificado a partir de Baumgart \& Sandborn, 2007.

Si bien en un momento se intentó diferenciar a estas dos patologías a través de las citoquinas presentes en el tejido, (Geremia y col, 2014; Heller y col., 2005), en los últimos años han surgido numerosas evidencias que demuestran que dicha clasificación es más compleja de lo supuesto en un principio (Fig.4) (Geremia y col., 2014; Neurath, 2014; Strober \& Fuss, 2011). La hipótesis surgió de la observación que células T aisladas de la mucosa de pacientes con EC producen mayores niveles de IL-2 e IFN- $\gamma$ y, además, muestran elevados niveles de T-bet, en comparación a linfocitos T (LT) de pacientes con CU. A su vez, los LT aislados a partir de la mucosa de pacientes con CU secretan más IL-5 e IL-13 que los derivados de paciente con EC, y muestran niveles elevados de Gata-3 (Beck \& Wallace, 1997; Geremia y col., 2014; Neurath, 2014).

Estos hallazgos llevaron a definir a la EC como una patología inflamatoria del tipo Th1, y a la CU como una Th2. Sin embargo, estudios recientes han mostrado que el perfil de citoquinas expresado en estas patologías no es fácilmente encasillable dentro del paradigma Th1/Th2. De hecho, en pacientes con CU no se observan niveles apreciables de IL-4 (Geremia y col., 2014; Neurath, 2014; Strober \& Fuss, 2011) y son muy pocos los grupos que han caracterizado niveles elevados de citoquinas Th2.

Por medio de cultivos ex vivo de biopsias, Geremia y colaboradores (2014) observaron que tanto las muestras provenientes de pacientes con CU, como aquellas de pacientes con EC, producen niveles elevados y comparables de IFN- $\gamma$ e IL-6. Utilizando esta misma metodología se observó que los niveles de IL-13 son 10 veces menores que los de IFN- $\gamma$, y que no hay diferencias entre pacientes con CU/EC y pacientes control (Geremia y col., 2014). A su vez, los niveles de IL-17A e IL-17F están incrementados tanto en pacientes con CU como 
en pacientes con EC (Christophi y col., 2012; Geremia y col., 2014; Neurath, 2014). De hecho, la aparición de esta citoquina ha sido postulada como un hecho natural en la evolución de estas patologías, siendo mayores sus niveles cuando la enfermedad entra en su etapa crónica tardía (Strober \& Fuss, 2011).

En conjunto, estos resultados estarían indicando que los pacientes con CU no expresan todo el repertorio característico de un perfil Th2, sino más bien una respuesta "tipo" Th2, y que ambas patologías poseen un componente Th1/Th17 (Geremia y col., 2014; Neurath, 2014; Strober \& Fuss, 2011). Lo que sí ha quedado claramente establecido es que en ambos casos existe una sobreproducción de citoquinas pro-inflamatorias (IL-1 $\beta$, IL-6 y TNF- $\alpha$, entre otras). Este hecho, junto a fallas en los circuitos regulatorios, conduce a un proceso que no se auto-limita y progresa en el tiempo (Neurath, 2014; Xu y col., 2014).

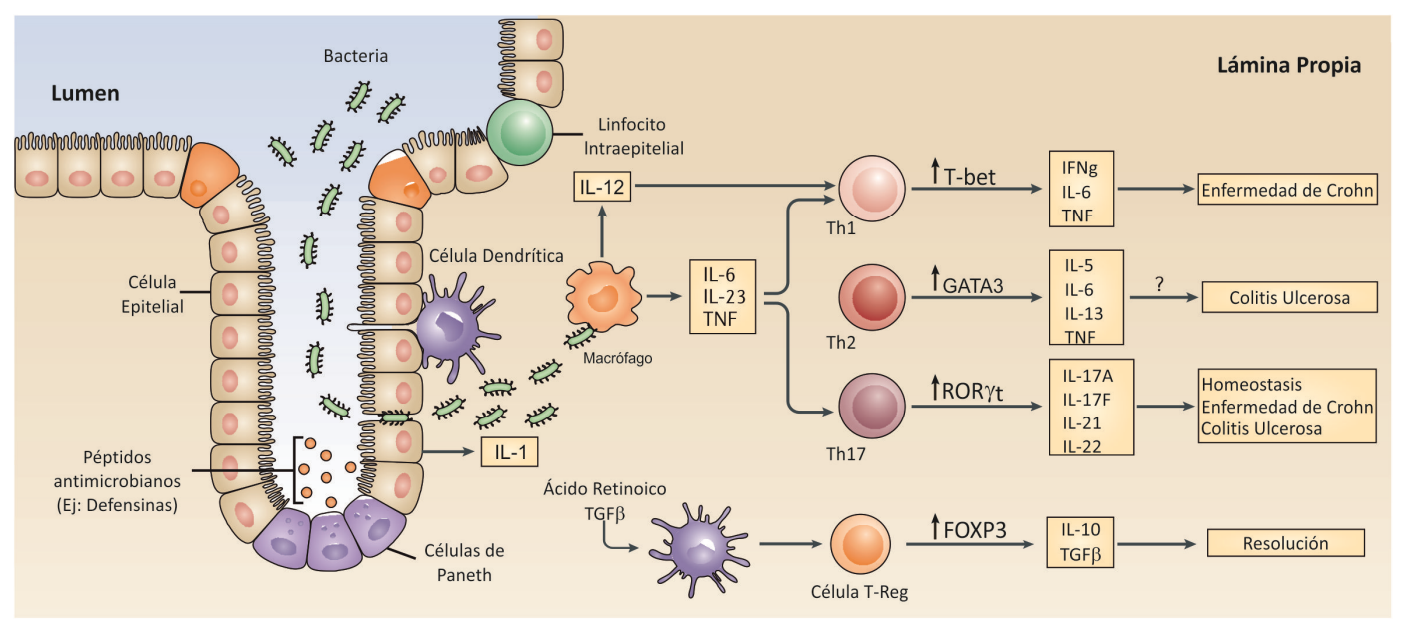

Fig. 4: Citoquinas en las Ell.

Se ha demostrado, tanto en pacientes con Ell como en modelos experimentales de colitis, que las citoquinas pro- $\mathrm{y}$ anti-inflamatorias son generadas por diversos tipos celulares (células epiteliales, macrófagos, dendríticas y linfocitos $\mathrm{T}$, entre otras) en respuesta a estímulos ambientales, entre ellos componentes de la microbiota. El balance en la producción de estas citoquinas pro y anti-inflamatorias en la mucosa regula el desarrollo y perpetuación del foco inflamatorio intestinal. Modificado a partir de Neurath 2014.

Entre las múltiples y variadas consecuencias asociadas a la persistencia de este foco inflamatorio se encuentra el desbalance entre la producción de 
metaloproteasas (MMPs) y sus inhibidores (TIMPs) por parte de los fibroblastos y miofibroblastos, ocasionando daños en el tejido (Biancheri y col., 2014). A su vez, otro factor que contribuye con la pérdida de la integridad de la mucosa es la sobre-expresión de TNF- $\alpha$, IL-13 e IFN- $\gamma$. Estas citoquinas son producidas tanto por células de la inmunidad innata como adaptativa, y han sido asociadas a la inducción de apoptosis en células epiteliales del intestino (Geremia y col., 2014; Goretsky y col., 2012). La sobre-producción sostenida de MMPs y citoquinas pro-inflamatorias, junto a la sub-producción de TIMP y las fallas en los circuitos regulatorios de la mucosa inducen el daño en la pared intestinal. Dicho daño genera complicaciones severas como la estenosis intestinal, formación de abscesos, fístulas y desarrollo de neoplasias (Neurath, 2014; Baumgart \& Sandborn, 2007; Biancheri y col., 2014; Ullman \& Itzkowitz, 2011).

Por lo tanto, la interacción de factores genéticos, ambientales y otros desencadenantes (humo de cigarrillo, stress, etc.) determinan que, en ciertos individuos con susceptibilidad, haya una respuesta aberrante del sistema inmune. Este proceso inflamatorio crónico genera la activación y transformación de ciertos tipos celulares (LT y fibroblastos, entre otros), los cuales serían los responsables del daño tisular.

\section{Galectinas}

Las galectinas (Gals) constituyen una familia de proteínas con capacidad de unirse a residuos glucídicos presentes en diferentes componentes celulares del citoplasma, membrana plasmática y matriz extracelular. Estas proteínas reconocen en forma específica unidades repetitivas [Galß1-4-NAcGIc] presentes en $N$ - y $O$-glicanos a través de un dominio altamente conservado de 135 aminoácidos, denominado "dominio de reconocimiento de carbohidratos" (DRC) (Cooper, 2002).

Hasta el momento se han identificado 15 Gals en mamíferos, las cuales se clasifican de acuerdo a su estructura en Gals "prototipo", "quimera" y de "secuencia repetida" (Yang y col., 2008; Salatino y col., 2008) (Fig. 5). Las Gals 
"prototipo" (Gal-1, -2, -5, -7, -10, -13, -14 y -15) poseen un único DRC y pueden formar homodímeros, generando de este modo lectinas funcionalmente bivalentes. Gal-3 es la única descripta del tipo "quimera” y posee un DRC en el extremo C-terminal y un dominio $\mathrm{N}$-terminal no relacionado, hecho que facilita su oligomerización (Rabinovich y col., 2007). Las Gals del tipo “secuencia repetida" (Gal-4, -6, -8, -9 y -12) poseen dos DRC en una misma cadena polipeptídica, por lo cual son naturalmente bivalentes, aunque cada DRC pueda reconocer estructuras glucídicas sutilmente diferentes (Cooper, 2002).

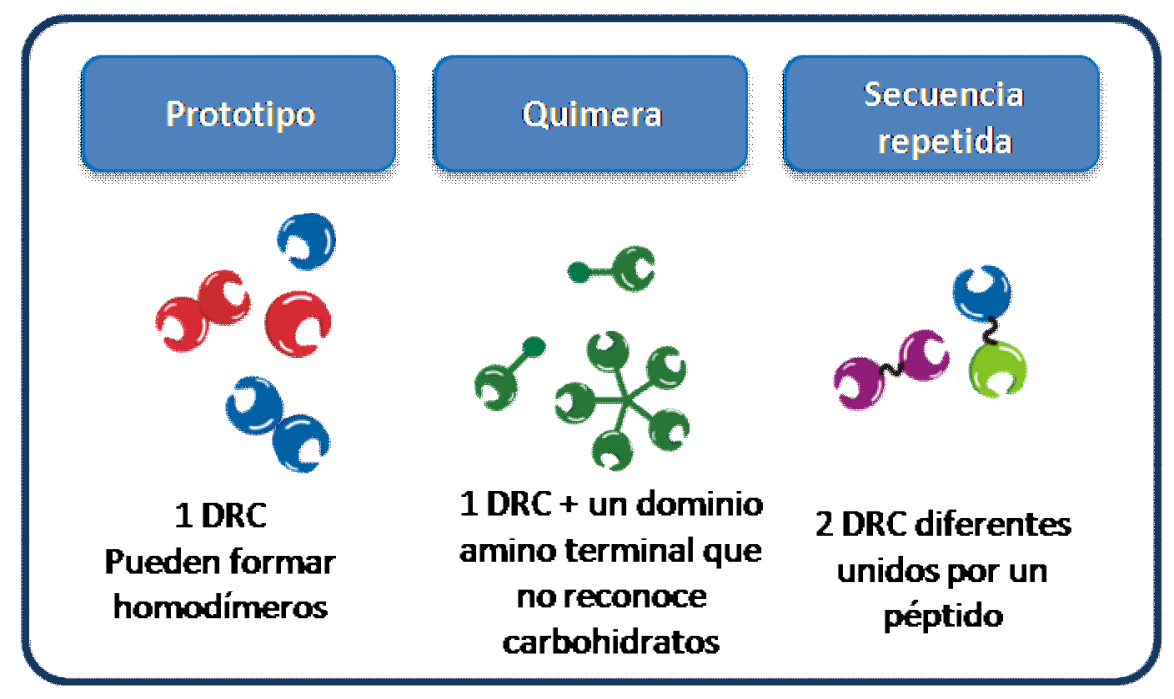

Fig. 5: Clasificación y esquema estructural de las Gals.

Modificado a partir de Salatino y col., 2008.

Las Gals pueden localizarse en diferentes compartimentos y se han descripto diversas funciones intra y extracelulares para las mismas (Liu y col., 2002; Rabinovich y col., 2007). Si bien estas proteínas se encuentran principalmente en el medio extracelular, no poseen un péptido líder en su secuencia primaria, lo cual impide su secreción por la vía clásica dependiente del retículo endoplasmático y del aparato de Golgi. En cambio, estas proteínas son liberadas al medio extracelular por un mecanismo atípico denominado ectocitosis (Yang y col., 2008).

Por su capacidad de reconocer y unir glicoproteínas de la superficie celular, las Gals forman redes entre sus diversos ligandos. Por lo tanto, según 
las glicoproteínas a las que se unan será la función que ejerzan sobre la célula. Este fenómeno, que se esquematiza en la figura 6, evita la endocitosis de las glicoproteínas y regula su distribución en la membrana (Rabinovich y col., 2007). Es por esta característica que una misma Gal puede actuar en diferentes tipos celulares y cumplir variadas funciones (como modular su interacción célula-célula o célula-matriz o regular su crecimiento, diferenciación, sobrevida, etc.) (Daniels y col., 2002; Liu \& Rabinovich, 2010; Rabinovich y col., 2007; Rubinstein y col., 2004).

Modula la interacción célula-célula
y célula-matrix

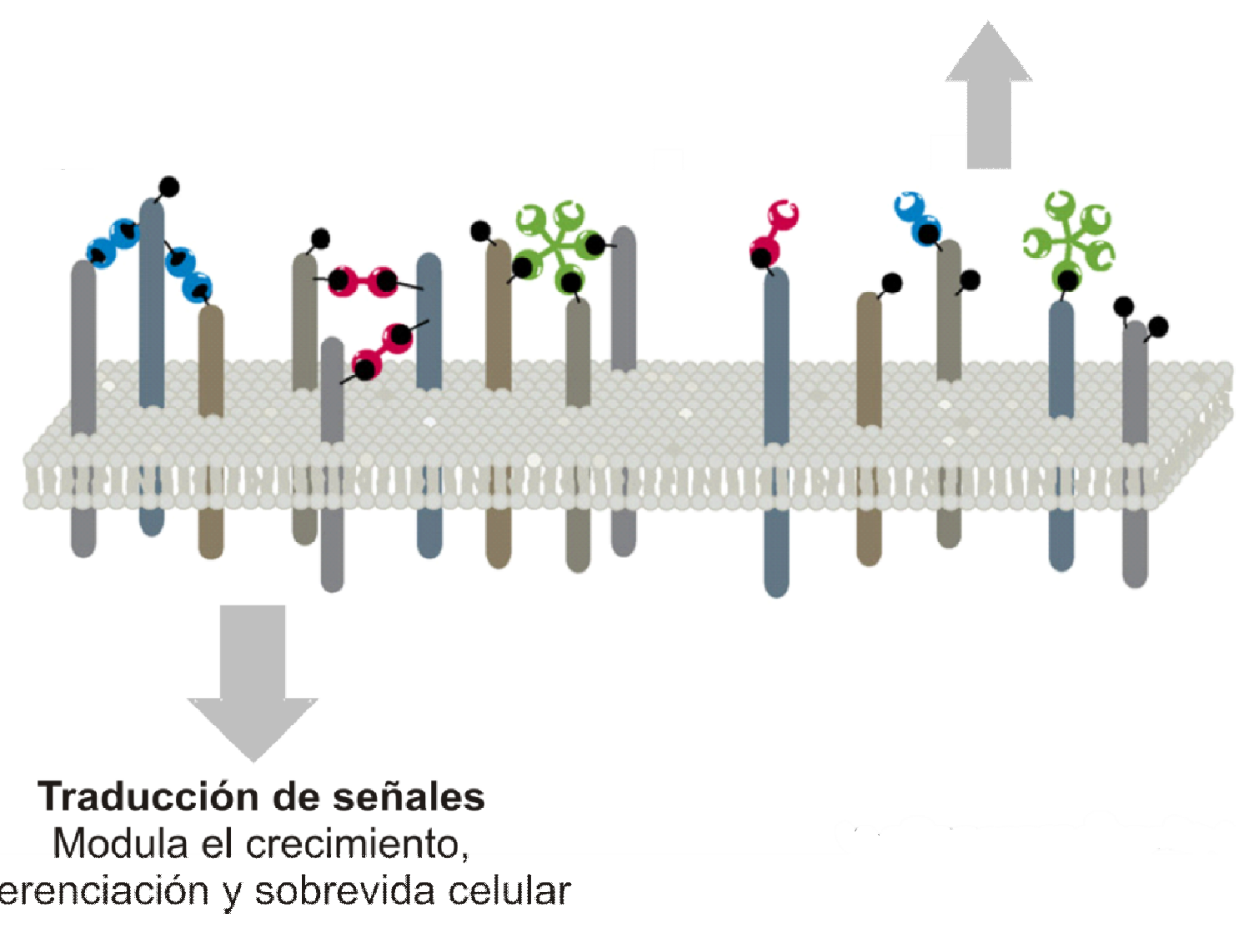

Fig. 6: Formación de redes entre las Gals y sus ligandos.

La unión de las Gals a sus ligandos específicos en la membrana celular genera un entramado de glicoproteínas que evita tanto su endocitosis como su libre movimiento. De esta manera se generan microdominios que modulan procesos celulares (diferenciación, crecimiento y sobrevida, entre otros) y la interacción con otras células o con la matriz extracelular. Modificado a partir de Rabinovich y col., 2007.

En el contexto del sistema inmune la expresión de Gals es baja en células vírgenes y en reposo, pero aumenta considerablemente luego de un 
estímulo de activación y/o diferenciación, como en el caso de LT, linfocitos B y macrófagos activados (Rabinovich y col., 1998; Rabinovich y col., 2004). En los últimos años un creciente número de evidencias a puesto en manifiesto que las Gals cumplen un rol central en el inicio y amplificación/resolución de la inflamación (Rabinovich y col., 2007). De hecho, estas proteínas han sido relacionadas con procesos como la artritis, la encefalomielitis, la uveítis, el rechazo al trasplante alogénico de células madres, la diabetes autoinmune, el cáncer y la alergia (Rabinovich y col., 2007).

En relación a las Ell, numerosos estudios en modelos animales (Nishida y col., 2012; Paclik y col., 2008; Santucci y col., 2003) indican que las Gals afectan el desarrollo de la colitis experimental (Hokama, 2008). En trabajos realizados en muestras de pacientes se ha demostrado que en las zonas inflamadas del intestino existe una desregulación en la expresión de Gal-3 (Lippert y col., 2007). Asimismo, se ha demostrado que esta lectina actúa como un factor activador de fibroblastos (Lippert y col., 2008) e inhibe la proliferación de LT (Müller y col., 2006). Por lo tanto, la disminución en la expresión de Gal-3 en las zonas inflamadas formaría parte de la respuesta fisiológica de la mucosa frente al proceso inflamatorio (Müller y col., 2006). Por otro lado, se conoce que Gal-2 y Gal-4 tienen efectos pro-apoptóticos sobre los LT de la mucosa intestinal (Paclik y col., 2008; Paclik y col., 2008) y promueven la regeneración epitelial (Paclik y col., 2008). Además, TIM-3, uno de los ligandos de Gal-9 con capacidad inhibitoria sobre linfocitos Th1, se encuentra sub-expresado en las células T de pacientes con EC (Morimoto y col., 2011). Finalmente, Gal-1 ha probado tener un rol protector e inmunomodulador en un modelo murino de colitis inducido por TNBS (Santucci y col., 2003).

De todas las Gals conocidas hasta la fecha sólo Gal-1, $-2,-3,-4$ y -9 han probado estar relacionadas con la fisiopatología de las Ell (Fig. 7). Considerando el efecto protector que Gal-1 probó tener en modelos in vivo de colitis y su ampliamente documentada capacidad inmunomoduladora en trastornos del tipo Th1 (Rabinovich y col. 1999; Toscano y col. 2011; Santucci y col., 2003; 
Toscano y col., 2007), nos propusimos estudiar su rol en la fisiopatologías de las EII.

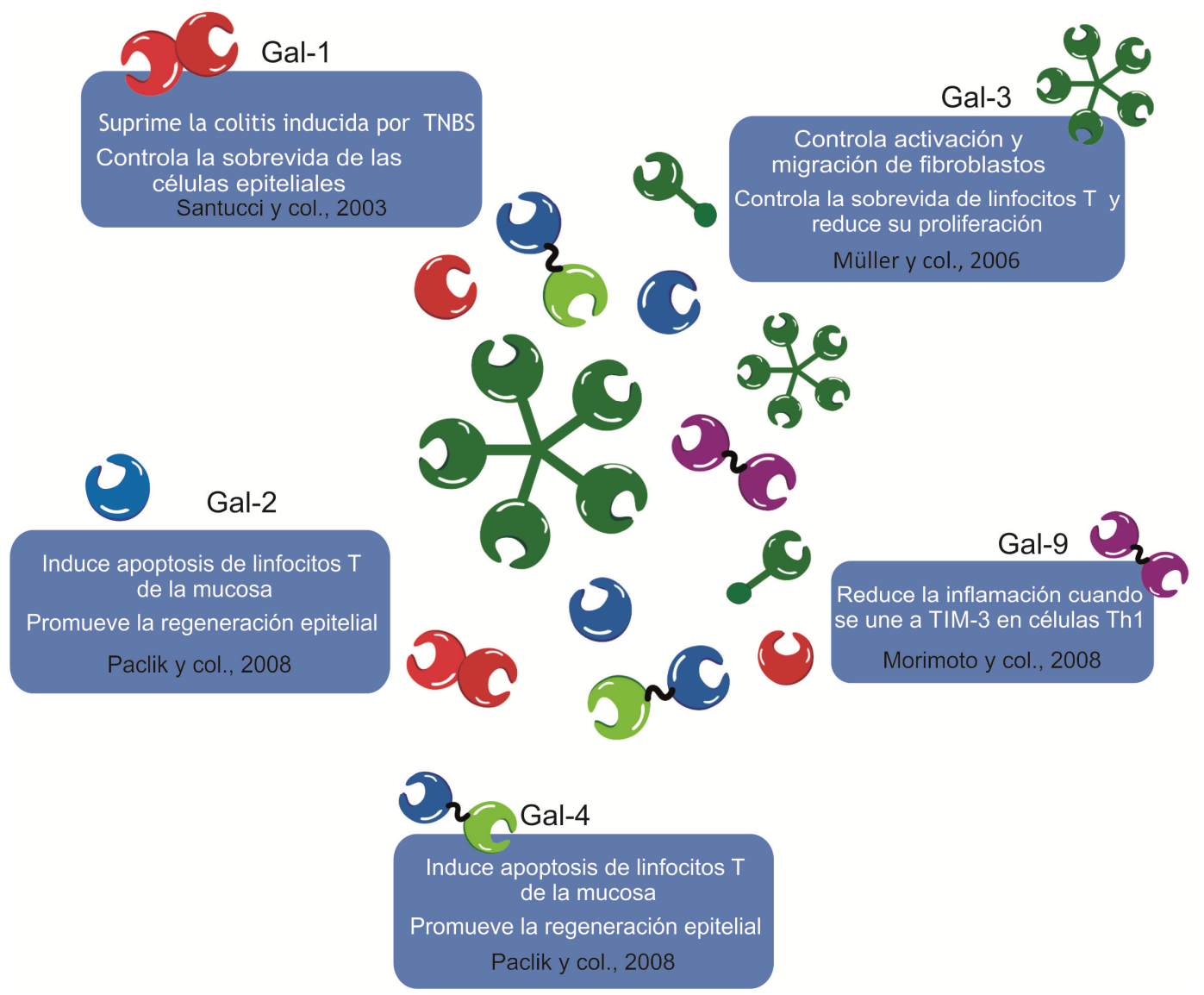

Fig. 7: Rol de las Gals en las Ell. 


\section{HIPÓTESIS DE TRABAJO Y OBJETIVOS GENERALES}

\section{HIPOTESIS DE TRABAJO}

Gal-1 tiene un rol inmunomodulador en la mucosa intestinal. Sin embargo, el entorno inflamatorio crónico de las Ell altera el patrón de expresión de esta lectina, así como el de sus ligandos específicos. Estos cambios afectan la sobrevida de diferentes tipos celulares presentes en la mucosa y contribuyen a la persistencia del foco inflamatorio.

\section{OBJETIVOS GENERALES}

En base a lo antedicho proponemos estudiar la expresión de Gal-1 en la mucosa colónica humana y murina en situaciones fisiológicas y patológicas, analizar su correlación con la actividad inflamatoria del tejido y su capacidad de modular la sobrevida de los LT y de las células epiteliales en dichos entornos. A su vez, proponemos analizar los cambios que el ambiente inflamatorio crónico de las Ell induce sobre el glicofenotipo de estas poblaciones celulares. 

MATERIALES Y MÉTODOS 



\section{MUESTRAS BIOLÓGICAS}

\subsection{Provenientes de pacientes}

Se utilizaron biopsias y piezas quirúrgicas de colon provenientes de 60 pacientes con CU (26 mujeres y 34 hombres, edad media $43 \pm 14$ ), 38 pacientes con EC ( 20 mujeres y 18 hombres, edad media 40 años \pm 18 ) y 68 controles $\sin$ EII (30 mujeres y 38 hombres, edad media 47 años \pm 17 ). Los pacientes con CU y EC se diagnosticaron en base a los hallazgos clínicos, endoscópicos e histopatológicos que se utilizan habitualmente (Lennard-Jones \& Shivananda, 1997).

La actividad de la enfermedad se evaluó siguiendo los criterios establecidos por Frøslie y colaboradores (Frøslie y col., 2007). Este índice es recomendado por el Consenso Europeo de Ell (Annese y col., 2013) y, a diferencia del Índice de Actividad de la Colitis Ulcerosa (UCAI) y el Índice de Actividad de la Enfermedad de Crohn (CDAI), es utilizado tanto para CU como para EC. Por lo tanto, la clasificación de Frøslie nos permitió establecer 
paralelismos entre pacientes con diferente patología, pero igual grado de severidad. Brevemente, el estado de la mucosa se clasificó por medio de la evaluación endoscópica con puntuaciones de 0 a 2 por dos gastroenterólogos especializados en Ell: Mucosa normal: 0 - mucosa plana y con patrón vascular conservado; mucosa levemente inflamada: 1 - ligero eritema, patrón vascular distorsionado y granularidad fina; inflamación severa: 2 - aumento de eritema, ausencia de patrón vascular, friabilidad y sangrado espontáneo (con o sin úlceras).

Las muestras de pacientes con CU y EC en remisión fueron tomadas de áreas previamente documentados como inflamadas pero sin signos de actividad (mucosa sin alteraciones macroscópicas) al momento de la colonoscopia. En estos pacientes la remisión se alcanzó a través de distintos tratamientos: mezalazina (2), mezalazina y antibioticos (1), sulfazalazina (3), 6mercaptopurina (7), 6-mercaptopurina y talidomina (1), Infliximab (1), Infliximab y 6-mercaptopurina (1).

Las muestras de mucosa no inflamada se obtuvieron de pacientes con EII, pero fueron tomadas de zonas sin inflamación macroscópica evidente y sin antecedentes previos de actividad en dicho segmento. El grado histológico de la inflamación fue evaluado por un patólogo experto a ciegas con respecto a la clasificación de los endoscopistas (Villanacci y col., 2013).

Como pacientes control se seleccionaron individuos sin antecedentes de Ell y que consultaron por alguno de los siguientes motivos: dolor abdominal inespecífico, estreñimiento, sospecha de divertículos, antecedentes de cáncer de colon o resección de pólipos. En cualquier caso, las muestras recogidas no mostraron signos de inflamación macroscópica o histológica.

Muestras provenientes de pacientes que se sometieron a trasplante de intestino (y posteriormente sufrieron rechazo del órgano por un proceso infeccioso) y pacientes adultos con enfermedad celíaca activa fueron incluidas como control de proceso inflamatorio.

Los pacientes con rechazo al trasplante de intestino ( $n=9,10-47$ años) recibieron el órgano debido al síndrome de intestino corto secundario. El 
mismo fue producto de múltiples resecciones quirúrgicas por vólvulos intestinales o por lesiones traumáticas sin patología intestinal crónica. En todos los casos se detectaron complicaciones post-operatorias sobre el trasplante intestinal y los pacientes fueron sometidos al seguimiento endoscópico de rutina hasta llegar al diagnóstico de rechazo celular agudo, el cual fue establecido siguiendo criterios internacionales (Nishida y col., 2004). Como tratamiento inmunosupresor los pacientes recibieron terapia doble: corticoides (Solumedrol o deltisona) y tacrolimus (4), o triple: corticoides (Solumedrol o deltisona), tacrolimus y rapamicina o micofenolato (5).

Las biopsias duodenales de pacientes celíacos adultos en actividad se obtuvieron durante los procedimientos de rutina (endoscopía alta) para el diagnóstico de la enfermedad ( $n=8,20-47$ años). Los mismos tuvieron confirmación del diagnóstico por el examen histológico y serológico y la evaluación de la presentación clínica. También se analizaron pacientes control no celíacos ( $n=10,30-60$ años), los cuales presentaban otras condiciones gastrointestinales, principalmente dispepsia, con serología negativa para la enfermedad celíaca y análisis histológico sin alteraciones.

\subsection{Provenientes de ratones}

Con el objetivo de estudiar la respuesta de la mucosa en un modelo experimental de colitis se utilizaron ratones BALB/C. Los mismos provinieron del bioterio de la Facultad de Ciencias Veterinarias (Universidad Nacional de La Plata). Se trató de machos de entre 6-8 semanas de edad con un peso de entre $18-25 \mathrm{~g}$.

\subsection{Línea celular}

Se empleó la línea celular Jurkat (células T de sangre periférica) como control positivo para los ensayos de unión de Gal-1 y como modelo in vitro de inflamación. Las células fueron cultivadas en RPMI completo: RPMI1640 (Gibco, Grand Island, NY, EE.UU), suplementado con suero fetal bovino (SFB; PAA 
Laboratories, Pasching, Austria) al 10\% y antibióticos (100 U/mL de penicilina y $100 \mu \mathrm{g} / \mathrm{mL}$ de estreptomicina). Durante todo el ensayo la temperatura se mantuvo a $37^{\circ} \mathrm{C}$, con humedad controlada y con una concentración de $\mathrm{CO}_{2}$ del $5 \%$.

\section{PROCESAMIENTO DE MUESTRAS}

\subsection{Conservación y transporte}

Inmediatamente después de la colonoscopia o cirugía las muestras de tejido fueron colocadas en RPMI completo, en formol al $4 \%$ o en ARN-later (Ambion, EE.UU.), según correspondiese, y almacenadas a $4^{\circ} \mathrm{C}$ para su conservación. En los casos en que las muestras iban a ser utilizadas para cultivos, y para minimizar la posibilidad de contaminación, antes de comenzar el procesamiento el tejido fue colocado en solución salina de Hank sin $\mathrm{Ca}^{2+} \mathrm{y}$ $\mathrm{Mg}^{2+}$ (HBSS; Gibco, Grand Island, NY, EE.UU.) suplementada con: $10 \%$ de SFB, anti-anti (antibiótico-antimicótico, Gibco, Grand Island, NY, EE.UU: penicilina $(100 \mathrm{U} / \mathrm{mL})$, estreptomicina $(100 \mu \mathrm{g} / \mathrm{mL})$ y anfotericina $B(0,25 \mu \mathrm{g} / \mathrm{mL}))$ y gentamicina $(750 \mu \mathrm{g} / \mathrm{mL})$ durante $30 \mathrm{~min}$ a $4^{\circ} \mathrm{C}$ y con agitación suave. En los casos en que las muestras fueron utilizadas para extracción de ARN, luego del traslado las mismas fueron almacenadas a $-80^{\circ} \mathrm{C}$ hasta su procesamiento.

\subsection{Aislamiento de células epiteliales y de células de la lámina propia}

Para el aislamiento de células de la lámina propia (LP), la mucosa de las piezas quirúrgicas fue separada mecánicamente de la submucosa y de la muscular y cortada en segmentos de $1 \mathrm{~mm}$. Las biopsias y muestras de intestino de ratón también fueron seccionadas en pequeños trozos.

Las células epiteliales fueron separadas del resto del tejido mediante agitación vigorosa en HBSS con ácido etilendiaminotetraacético (EDTA) 0,5 mM y ditiotreitol (DTT) 0,1 mM durante $15 \mathrm{~min}$. Luego de este tiempo el sobrenadante enriquecido en células epiteliales intestinales (CEI) en suspensión 
fue retirado por aspiración y centrifugado a 500g. Se descartó el sobrenadante y las células del pellet fueron lavadas y resuspendidas en medio de cultivo RPMI completo. El tejido remanente de las muestras se digirió durante $30 \mathrm{~min}$ a $37^{\circ}$ C con $1 \mathrm{mg} / \mathrm{mL}$ de colagenasa tipo I (Roche, Indianápolis, EE.UU.) y $10 \mathrm{U} / \mathrm{mL}$ de DNasa recombinante de páncreas bovino tipo I (Roche, Indianapolis, EE.UU.) en RPMI completo. La suspensión enriquecida en células de la LP fue centrifugada a $500 \mathrm{~g}$ y el pellet resuspendido en RPMI completo o AIM-V, según el procedimiento a aplicar.

\subsection{Aislamiento de células $\mathrm{CD}^{+}$de la lámina propia}

La suspensión de células obtenida de la LP fue centrifugada a 500g, luego el pellet fue lavado con buffer $\mathrm{IMag}^{\mathrm{TM}}$ (Becton Dikinson) y procesado según las instrucciones del fabricante. Brevemente, las células fueron nuevamente centrifugadas a $500 \mathrm{~g}$ y resuspendidas en una solución que contenía las perlas magnéticas conjugadas con anti-CD3 (Becton Dikinson) (50 $\mu \mathrm{L}$ cada $10^{7}$ células). La suspensión fue incubada a temperatura ambiente durante $30 \mathrm{~min}$, luego de lo cual se les agregó $1 \mathrm{~mL}$ de buffer $\mathrm{IMag}^{\mathrm{TM}}$ y se las colocó en el IMagnet ${ }^{\mathrm{TM}}$ (Becton Dikinson) durante $10 \mathrm{~min}$. Una vez finalizada la incubación se retiró el sobrenadante y las células fueron nuevamente resuspendidas en buffer $\mathrm{IMag}^{\mathrm{TM}}$ y colocadas en el IMagnet ${ }^{\mathrm{TM}}$ por 4 min. Finalizado este tiempo el sobrenadante fue extraído y las células resuspendidas en solución RA1 (GE) y $\beta$-mercaptoentanol. Por último las muestras fueron almacenadas a $-80^{\circ} \mathrm{C}$ hasta el momento de la extracción del ARN.

\section{CULTIVO DE ÓRGANO Y MODELOS IN VITRO E IN VIVO}

\subsection{Cultivo de órgano}

Con el objetivo de estudiar los cambios que un ambiente inflamatorio puede inducir en la expresión génica de la mucosa colónica, se incubaron biopsias provenientes de pacientes control con diferentes concentraciones de 
TNF- $\alpha$ humano recombinante (rhTNF- $\alpha$, RyD del sistema). Brevemente, las muestras de tejido fueron tratadas durante 30 minutos con HBSS $y$ gentamicina, según lo desarrollado previamente. Luego, las mismas fueron cultivadas durante 16 hs en RPMI completo y 1,5 ó $10 \mathrm{ng} / \mathrm{mL}$ de $\mathrm{rhTNF}-\alpha$ o RPMI completo sin rhTNF- $\alpha$. Una vez finalizado el periodo de incubación se procedió al aislamiento de ARN y su posterior análisis por PCR cuantitativa.

\subsection{Cultivo de líneas celulares}

La línea celular T Jurkat fue utilizada como modelo para determinar los cambios que un ambiente inflamatorio puede inducir sobre el glicofenotipo de los LT. Las células fueron cultivadas durante 24 hs en RPMI completo o RPMI suplementado con $\mathrm{rhTNF}-\alpha(10 \mathrm{ng} / \mathrm{mL})$. Una vez finalizado el periodo de incubación las células fueron cosechadas y analizadas por citometría de flujo (FACScalibur, BectonDickinson, Mountain View, CA, USA).

\subsection{Modelo de colitis}

Para este modelo se emplearon ratones BALB/c a los cuales se les indujo una colitis experimental por instilación rectal con ácido sulfónico 2, 4, 6trinitrobenceno (TNBS). Brevemente, los ratones recibieron una solución (Sigma-Aldrich, Alemania) de $5 \mathrm{mg}$ de TNBS 0,1 mL de etanol al 50\% con un catéter plástico de 2,5 cm de largo. Para asegurar la distribución del TNBS en todo el colon, los ratones fueron colocados en posición vertical durante 2 minutos luego de la administración del TNBS. Los animales del grupo de control recibieron $0,1 \mathrm{~mL}$ de etanol al $50 \%$. En todos los casos lo ratones fueron ayunados durante $12 \mathrm{hs}$ antes de instilación con TNBS o etanol (día cero) y sacrificados por dislocación cervical al día 7. Para estudiar los efectos del TNBS se evaluó el peso corporal, los scores clínicos e histológicos y la relación peso/longitud del colon.

El Índice de actividad de la enfermedad (IAE) es un índice que se calcula teniendo en cuenta parámetros que, de alguna manera, son análogos a la 
presentación de la enfermedad en humanos. A cada categoría se le adjudica una puntuación según la severidad: pérdida de peso (sin pérdida de peso: 0 puntos, disminución de peso entre 1-5\%: 1 punto, pérdida de peso de entre 510\%: 2 puntos, pérdida de peso de entre 10-15\%: 3, pérdida de peso de más del 15\%: 4), consistencia de las heces (normales: 0 puntos, deposiciones sueltas: 2 puntos, diarrea líquida: 4 puntos) sangrado en la heces (sin sangrado: 0 puntos, sangrado leve: 2 puntos, sangrado severo: 4 puntos). El puntaje final es la suma de cada uno de los parámetros analizados, siendo 0 para un animal que no sufrió afección y 12 para un animal con colitis severa. Este índice lo calcularon dos investigadores de manera independiente.

El grado de daño microscópico del colon fue evaluado a través del índice de actividad histológico (IAH). Este índice analiza el grado de infiltrado celular (0: sin infiltrado; 1 : aumento del número de células inflamatorias en la base de las criptas; 2: infiltrado en la submucosa; 3: infiltrado mononuclear en la capa muscular; 4: infiltrado inflamatorio transmural y edema; 4:) y el daño tisular (0: sin daño de la mucosa; 1: mínima perdida de células caliciformes; 2: pérdida importante de células caliciformes; 3: pérdida mínima de la estructura de las criptas y extensa de células caliciformes; 4: perdida extensa de la arquitectura de las criptas). El puntaje final es la suma de cada uno de los parámetros analizados, siendo 0 para un colon normal y 6 para un colon con daño severo en su arquitectura y extenso infiltrado inflamatorio.

\section{EXPRESIÓN DE GENES, PROTEÍNAS Y MARCADORES DE SUPERFICIE}

\subsection{Aislamiento de ARN y RT-PCR en tiempo real}

La extracción de ARN se realizó empleando un kit comercial para el aislamiento de ARN total (MachereyNagel, Düren, Alemania), siguiendo las instrucciones del fabricante. EI ARN aislado fue retro-transcripto utilizando la transcriptasa reversa MMLV (Invitrogen, Carlsbad, CA, USA) y luego amplificado usando como cebadores (primers) una mezcla de hexámeros generados al azar. 
Las reacciones se llevaron a cabo en un termociclador Mastercycler gradient (Eppendorf AG, Hamburgo, Alemania) con el siguiente programa: $10 \mathrm{~min}$ a $25^{\circ} \mathrm{C}, 50 \mathrm{~min}$ a $37^{\circ} \mathrm{C}$ y $15 \mathrm{~min}$ a $70^{\circ} \mathrm{C}$.

La PCR cuantitativa ( $\mathrm{PPCR}$ ) para cada uno de los genes de interés (GDI) se realizó mediante el sistema SYBR Green PCR Master Mix (BioRad, Hercules, CA, EE.UU.) utilizando un termociclador iCycler (Bio-Rad, Hercules, CA, EE.UU.). Las secuencias de los primers empleados se detallan en las tablas 1 y 2 . El programa de amplificación utilizado fue: $2 \mathrm{~min}$ a $50^{\circ} \mathrm{C}, 10 \mathrm{~min}$ a $95^{\circ} \mathrm{C}, 50$ ciclos de 15 seg a $95^{\circ} \mathrm{C}$ y 60 seg a $60^{\circ} \mathrm{C}$, con una curva final de desnaturalización de $55^{\circ} \mathrm{C}$ a $95^{\circ} \mathrm{C}$ (en pasos de $0,5^{\circ} \mathrm{C} / 10 \mathrm{seg}$ ). Cada medida fue realizada por duplicado y se utilizó el valor promedio de ciclo al punto de intersección (Ct, cyclethreshold). El nivel de expresión relativa de los GDI se calculó utilizando $\beta$ actina como gen normalizador y se muestra en unidades arbitrarias (u.a). La ecuación utilizada para calcular la expresión génica relativa fue la siguiente:

\section{Expresión relativa $\mathrm{GDI}=2^{-\Delta C t}=2^{-(\mathrm{Ct} G D I-C t \beta \text {-actina })}$}

Tabla 1: Primers empleados para la amplificación de genes murinos.

\begin{tabular}{c|c|cc} 
Gen & Nomencltura & Forward & Reverse \\
\hline Lgals1 & Gal-1 & TGAACCTGGGAAAAGACAGC & TCAGCCTGGTCAAAGGTGAT \\
Tnf- $\alpha$ & TNF- $\alpha$ & CATCTTCTCAAAATTCGAGTGACAA & CCTCCACTTGGTGGTTTGCT \\
Ifn- - -3') & IFN- - & TGGCATAGACGTGGAAGAAAAGAG & TGCAGGATTTCATGTCACCAT \\
T-bet & T-bet & TGTCCAGTCAGTAACTTTCA & CAGTCACCTGAGTCTTCTCT \\
Actb & $\beta$-actina & CGTCATCCATGGCGAACTG & GCTTCTTTGCAGCTCCTTCGT
\end{tabular}

Tabla 2: Primers empleados para la amplificación de genes humanos.

\begin{tabular}{c|c|cc} 
Gen & Nomenclatura & Forward & Secuencia $\mathbf{( 5}^{\prime} \mathbf{-} \mathbf{3}^{\prime} \mathbf{)}$ \\
& & Reverse \\
\hline LGALS1 & Gal-1 & TGAACCTGGGCAAAGACAGC & TTGGCCTGGTCGAAGGTGAT \\
LGALS3 & Gal-3 & GAAGGGAAGAAAGACAGTCG & CAAGTGAGCATCATTCACTG \\
LGALS4 & Gal-4 & CGAGGAGAAGAAGATCACCC & CTCTGGAAGGCCGAGAGG \\
LGALS9 & Gal-9 & CTTTCATCACCACCATTCTG & ATGTGGAACCTCTGAGCACTG \\
STAT-4 & stat-4 & GATCTGCAAGACGAATTTGAC & TGTCACTCTGATCCATTGTC
\end{tabular}




\begin{tabular}{c|c|cc} 
TBX21 & T-bet & GCTTCACAATATTAACAGACCC & GTTAAACGAGCTGTTCTTGG \\
GATA-3 & gata-3 & AGAATGCCGAGATTACTCAG & TACATGGACTCAAAGTTCTCC \\
GCNT1 & C2GnT-1 & CTACCCGCCCTGCGATG & CATCCAGTTCAAGTCACCAGCTC \\
MGAT5 & GnT-5 & TGCCCCTGCCGGGACTTCAT & CAGCAGCATGGTGCAGGGCT \\
TNF- $\alpha$ & TNF- $\alpha$ & GGAGAAGGGTGACCGACTCA & TGCCCAGACTCGGCAAAG \\
IFN- - & IFN- - & CCAACGCAAAGCAATACATGA & TTTTCGCTTCCCTGTTTAGC \\
ACTB & $\beta$-actina & CCTGGCACCCAGCACAAT & GCCGATCCACACGGAGTACT
\end{tabular}

\subsection{Histología e inmunohistoquímica}

Las biopsias y piezas quirúrgicas fueron fijadas en formol 5\%/PBS durante 24 hs y posteriormente deshidratadas empleando la siguiente secuencia de soluciones: etanol 30\%, 50\%, 70\%, 100\% y xileno. Una vez sustituida el agua del tejido por xileno, las muestras fueron incluidas en parafina. Se cortaron secciones de $5 \mu \mathrm{m}$ y se montaron en portaobjetos de vidrio cargados positivamente (Genex), luego se calentaron a $60^{\circ} \mathrm{C}$ durante 15 min. La muestra fue re-hidratada por inmersión en xileno y un tren de alcoholes de graduación descendente. A partir de este paso las muestras utilizadas para la tinción con hematoxilina-eosina fueron tratadas según los procedimientos de rutina. Brevemente, los cortes fueron sumergidos en hematoxilina de Mayer durante $5 \mathrm{~min}$, lavados y luego incluidos en eosina por $2 \mathrm{~min}$. Por último, las muestras fueron nuevamente deshidratadas (usando la misma secuencia de soluciones que se especificó previamente) y montadas con bálsamo sintético.

Por otra parte, las muestras utilizadas para inmunohistoquímica se trataron con $\mathrm{H}_{2} \mathrm{O}_{2}$ 10\%/PBS para bloquear la peroxidasa endógena. La recuperación antigénica se realizó con buffer citrato $10 \mathrm{mM}(\mathrm{pH} 6,0)$ y calentamiento con microondas. Por último se bloquearon los sitios inespecíficos con $10 \%$ de suero humano/PBS. Para la detección de Gal-1 se incubaron los cortes con un anticuerpo monoclonal anti-Gal-1 (cortesía del Dr. Rabinovich) (dilución 1:3000) durante la noche a $4^{\circ} \mathrm{C}$. El tejido fue luego tratado con un IgG anti-ratón conjugado a HRP (Dako) durante 1 hora a $37^{\circ} \mathrm{C}$ (dilución 1:3000). Finalmente, las muestras se incubaron con el kit de detección de DAB 
(Dako) siguiendo las instrucciones del fabricante para la obtención final del color.

\subsection{SDS PAGE y Western Blot}

Las muestras de tejido fueron homogeneizadas en solución de lisis (10 $\mathrm{mM}$ de HEPES de $\mathrm{pH}=7,9$, EDTA $1 \mathrm{mM}, 60 \mathrm{mM}$ de $\mathrm{KCl}$, Nonidet P40 (0,2 \% $(\mathrm{v} / \mathrm{v}), 1 \mathrm{mM}$ de DTT, PMSF $1 \mu \mathrm{M}$, aproteinina $0,1 \mu \mathrm{g} / \mathrm{mL}$, leupeptina $0,1 \mu \mathrm{g} / \mathrm{mL}$, $\mathrm{NaVO}_{3} 1 \mu \mathrm{M}$ y NaF $5 \mu \mathrm{M}$, Sigma, St Louis, MO, EE.UU.). El contenido total de proteínas se determinó mediante el ensayo de ácido bicinconínico (Pierce Laboratories, Rockford, IL) utilizando BSA como estándar. Luego, las muestras se estandarizaron en función de su concentración de proteínas y resolvieron en geles de poliacrilamida preparados con una concentración de monómero de $12,5 \%$ en condiciones reductoras. La electroforesis se realizó en cubas Tetra Cell (BioRad, Hercules, CA, EE.UU.), con una fuente Power Pac Basic (BioRad, Hercules, CA, EE.UU.), utilizando $25 \mathrm{~mA}$ y $50 \mathrm{~mA}$ para las fases de apilamiento y separación, respectivamente. Las electrotransferencias se realizaron en cubas MiniProtean II (BioRad, Hercules, CA, EE.UU.) a $300 \mathrm{~mA}$ durante $1 \mathrm{~h}$ sobre membranas nitrocelulosa (Osmonics, Westboro, MA, EE.UU.). La efectividad de la transferencia se verificó por tinción reversible con una solución de rojo Ponceau/ácido tricloroacético.

La presencia de Gal-1 se detectó utilizando un antisuero de conejo específico (cortesía del Dr. Rabinovich) (1:6000), mientras que para $\beta$-actina se empleó un anticuerpo monoclonal específico (Santa Cruz Biotechnology, Santa Cruz, CA, EE.UU). Para ambos casos las membranas fueron incubadas durante 1 $\mathrm{h}$ a $37^{\circ} \mathrm{C}$ con un anticuerpo secundario anti- $\gamma$ globulina de conejo conjugado a HRP (BioRad, Hercules, CA, EE.UU.). El revelado se realizó por quimioluminiscencia utilizando placas radiográficas Amrsham HyperFilm MP (GE Healthcare, Buckinhamshire, UK). El reactivo empleado tenía la siguiente composición: luminol 1,25 mM (Fluka, St Louis, MO, EE.UU), ácido p-cumárico 0,2 mM (Fluka, St Louis, MO, EE.UU), $\mathrm{H}_{2} \mathrm{O}_{2} 2,9 \mathrm{mM}$, Tris $10 \mathrm{mM}, \mathrm{pH}=8,8$. Las placas radiográficas se revelaron y fijaron de manera manual utilizando 
reactivos fotográficos Romek (Gamaxa SRL, Avellaneda, Argentina), según las instrucciones del fabricante.

\subsection{Análisis del glicofenotipo celular y capacidad de unión a Gal-1}

La suspensión de células obtenidas de la LP y la línea celular Jurkat fueron incubadas con las siguientes lectinas biotiniladas: aglutinina de Sambucus nigra (SNA, Vector Laboratories), aglutinina de maní (PNA, Vector Laboratories) o rhGal-1 biotinilada $(3 \mathrm{ng} / \mathrm{ml})$, durante $15 \mathrm{~min}$ a $4^{\circ} \mathrm{C}$. Las células fueron luego lavadas con PBS e incubadas con $20 \mu \mathrm{L}$ de suero humano durante $5 \mathrm{~min}$ a $4^{\circ} \mathrm{C}$. Por último, la expresión de marcadores de superficie fue evaluada por la adición de anti-CD25 FITC, anti-CD4 PE y anti-CD3 o anti-CD8 PE-Cy5 (Becton Dikinson Pharmingen), mientras que la detección de componentes glicosilados de realizó empleando estreptavidina-APC (Becton Dikinson Pharmingen). Las muestras fueron analizadas por citometría de flujo. La población de linfocitos de la LP fue ubicada de acuerdo a criterios de tamaño y complejidad (dispersión frontal/dispersión lateral de luz - FSC/SSC).

Las CEI de intestino grueso de ratón fueron tratadas durante $16 \mathrm{hs}$ con IL-1 $\beta$, IL-5, IL-13, TNF- $\alpha$ o IFN- $\gamma$ ( $50 \mathrm{ng} / \mathrm{mL}$ ) en RPMI completo (a $37^{\circ} \mathrm{C}$ y $5 \%$ de $\left.\mathrm{CO}_{2}\right)$, luego lavadas e incubadas en PBS con rhGal-1 biotinilada (10 ng/mL) durante $20 \mathrm{~min}$ a $4^{\circ} \mathrm{C}$. Luego de un segundo lavado, las células fueron incubadas con estreptavidina-APC y analizadas por citometría de flujo. La población de CEI fue ubicada según sus características de FSC/SSC. Ensayos similares se realizaron con células epiteliales humanas provenientes de pacientes con Ell y pacientes control.

Tanto para las células de la LP como para las CEI, las muestras control fueron tratadas con la lectina biotinilada y lactosa (100 mM) como inhibidor de las mismas.

La adquisición de datos se realizó empleando el software CellQuest (Becton Dikinson, Mountain View, CA, EE.UU.). Los análisis posteriores se llevaron a cabo utilizando el programa FlowJo (TreeStar, Asland, OR, EE.UU). 


\section{ENSAYOS DE MUERTE CELULAR}

\subsection{Tinción con Anexina V/ioduro de propidio}

Células de la LP $\left(1 \times 10^{6}\right.$ células $\left./ \mathrm{mL}\right)$ fueron incubadas durante toda la noche en medio AIM-V/ $\beta$-mercaptoetanol $1 \mathrm{mM}$ (a $37{ }^{\circ} \mathrm{C}$ y $5 \%$ de $\mathrm{CO}_{2}$ ) en presencia o ausencia de rhGal-1 $(5,10,35,70 \circ 140 \mu \mathrm{g} / \mathrm{mL})$. Luego de lavadas las células fueron centrifugadas a 500g y resuspendidas en $300 \mu \mathrm{L}$ de buffer de unión para anexina $\mathrm{V}$ (HEPES $10 \mathrm{mM}, \mathrm{NaCl} 140 \mathrm{mM}, \mathrm{CaCl} 2$ 2,5 mM, pH = 7,40), $2 \mu \mathrm{L}$ de anexina V-FITC (Becton Dickinson, Mountain View, CA, EE.UU.), $1 \mu \mathrm{L}$ de ioduro de propidio (IP) (Sigma,St Louis, MO, EE.UU.) y $1 \mu \mathrm{L}$ de anti-CD3 APC (eBioscience). Luego de $30 \mathrm{~min}$ de incubación a $4^{\circ} \mathrm{C}$ en la oscuridad, las muestras fueron analizadas por citometría de flujo. La población de LLP fue ubicada de acuerdo a sus criterios de FSC/SSC y luego se determinó el porcentaje de células $\mathrm{CD}^{+} /$Anexina $\mathrm{V}^{+} / \mathrm{IP}^{-}$(las cuales fueron consideradas como LT en apoptosis).

Las CEI de ratón fueron incubadas durante $16 \mathrm{hs}$ con de IL-1 $\beta$, IL-5, IL-13, TNF- $\alpha$ o IFN- $\gamma\left(50 \mathrm{ng} / \mathrm{mL}\right.$ ) en RPMI completo $\left(a 37^{\circ} \mathrm{C}\right.$ y $5 \%$ de $\mathrm{CO}_{2}$ ). Una vez finalizado el estímulo con las diferentes citoquinas, las células fueron lavadas e incubadas durante 6 hs en RPMI completo (a $37^{\circ} \mathrm{C}$ y $5 \%$ de $\mathrm{CO}_{2}$ ) en presencia o ausencia de rhGal-1 (100 $\mu \mathrm{g} / \mathrm{mL})$. La apoptosis se evaluó por citometría de flujo utilizando anexina V-FITC /PI según lo explicitado previamente. Las células anexina $\mathrm{V}^{+} / \mathrm{PI}^{-}$fueron consideradas en la etapa temprana de apoptosis.

Tanto para los experimentos con células de la LP como con CEI, la adquisición de datos se realizó utilizando el software CellQuest (Becton Dikinson, Mountain View, CA, EE.UU.). Los porcentajes de células apoptóticas se calcularon utilizando el programa FlowJo (TreeStar, Asland, OR, EE.UU).

\subsection{Ensayo de TUNEL por microscopía confocal}

Para evaluar la capacidad de Gal-1 de inducir apoptosis en LLP y CEI humanas en condiciones de homeostasis e inflamación se utilizaron biopsias de 
colon de pacientes control y zonas no inflamadas e inflamadas de pacientes con EII. Las mismas fueron incubadas en presencia o ausencia de rhGal-1 $(70 \mu \mathrm{g} / \mathrm{mL})$ durante $16 \mathrm{hs}$. La presencia de células apoptóticas fue evaluada por microscopia de fluorescencia confocal (Microscopio Confocal Leica SP5) utilizando el kit de TUNEL (Promega, EE.UU) según las instrucciones del fabricante. Brevemente, luego de tratar las biopsias con rhGal-1 las mismas fueron deshidratadas e incluidas en parafina, según los procedimientos histológicos de rutina. Cortes de $5 \mu \mathrm{m}$ fueron desparafinados y permeabilizados utilizando proteinasa K. Por último, las muestras fueron incubadas con la enzima TdT, desoxinucleótidos y fluoresceína-12-dUTP durante $1 \mathrm{~h}$ a $37^{\circ} \mathrm{C}$ en cámara húmeda y los núcleos fueron teñidos con DAPI $(0,5 \mathrm{ug} / \mathrm{mL})$ o IP $(1 \mathrm{mg} / \mathrm{mL})$. Finalmente se comparó la presencia de núcleos apoptóticos en campos de igual área.

\subsection{Análisis fluorométrico de la actividad caspasas-3, -8 y -9}

Las CEl fueron tratadas con buffer de lisis (EDTA 10 mM, Tris- $\mathrm{HCl} 50$ mM, $\mathrm{CINa} 50 \mathrm{mM}$, Triton X100 1\%, fluoruro de fenilmetilsulfonilo $2 \mathrm{mM}$, ortovanadato de sodio $2 \mathrm{mM}$, leupeptina $10 \mathrm{mg} / \mathrm{mL}$ y aprotinina $2 \mathrm{mg} / \mathrm{mL}, \mathrm{pH}$ $7,4)$ y el contenido de proteínas se cuantificó empleando el kit de ácido bicinconínico, utilizando BSA como estándar. Los lisados celulares se incubaron con sustratos específicos de las caspasas-3, -8 y -9: Ac-DEVD-AFC ( $\mathrm{N}$-acetil-AspGlu-Val-Asp-7-amino-4-trifluorometil coumarina), Ac-IETD-AFC ( $\mathrm{N}$-acetil-Ile-GluThr-Asp-7-amino-4-trifluorometil coumarina) y Ac-LEHD-AFC ( $\mathrm{N}$-acetil-Leu-GluHis-Asp-7-amino-4-trifluorometil coumarina) (Biomol International, Plymouth Meeting, PA, EE.UU.), respectivamente. Brevemente, el fluoróforo AFC es liberado del sustrato por la acción de la caspasa y detectado espectrofluorométricamente a $505 \mathrm{~nm}$ después de la excitación (400 nm).

Los datos de fluorescencia se normalizaron en base al contenido total de proteínas de la muestra. Con el fin de evaluar la especificidad de la reacción, se incluyeron controles usando inhibidores específicos de las caspasas: Ac-DEVDCHO, Ac-IETD-CHO y Ac-LEHD-CHO para las caspasas-3, -8 y -9 , respectivamente (CHO: aldehído) (Biomol Internacional). 


\subsection{Análisis del potencial de membrana mitocondrial}

Los cambios en el potencial de membrana mitocondrial se analizaron empleando el Kit de Permeabilidad Mitocondrial (MTt-E- $\phi$, Biomol Internacional) siguiendo las instrucciones del fabricante. El 5,50,6,60-tetracloro1,10,3,30-tetraetilo-benzamidazolocarbocyanin de ioduro (JC-1) es un fluorocromo que forma agregados. Estos agregados producen cambios en el espectro de absorción del compuesto a altas concentraciones. El JC-1 se acumula en las mitocondrias y gracias su alta concentración en la organela emite una señal fluorescente de color rojo cuando ésta se encuentra sana. Sin embargo, cuando el potencial de membrana mitocondrial disminuye como consecuencia de la inducción de apoptosis, el JC-1 difunde por el citoplasma, emitiendo fluorescencia de color verde.

Las CEI previamente tratadas con rhGal-1 se incubaron con JC-1 durante $15 \mathrm{~min}$ a $37^{\circ} \mathrm{C}$, luego se lavaron, resuspendieron en PBS y analizaron por citometría de flujo. Las CEI fueron ubicadas en base a sus criterios de FSC/SSC usando el software CellQuest (Becton Dikinson, Mountain View, CA, EE.UU.). La despolarización de la membrana mitocondrial se evaluó calculando el cociente entre fluorescencia media verde y fluorescencia media roja mediante el software FlowJo (TreeStar, Asland, OR, EE.UU). De esta manera se calculó el porcentaje de células en las cuales se indujo la vía endógena de la apoptosis dependiente de las mitocondrias.

\subsection{Expresión de Bad, Bax y Bcl-2}

Para caracterizar más detalladamente la vía endógena de apoptosis y confirmar la inducción de la misma luego de incubar a las CEI con rhGal-1, se analizaron los niveles de expresión de las proteínas pro-apoptóticas Bad y Bax, así como la anti-apoptótica Bcl-2, por citometría de flujo. Las células fueron obtenidas a partir de ensayos de asa ligada según lo descripto previamente. Las mismas fueron fijadas y permeabilizadas utilizando el buffer de fijado $y$ 
permeabilización intracelular de eBioscience (San Diego, CA, USA). Las CEI fueron incubadas con una dilución 1:50 de los anticuerpos anti-Bad-FITC (Becton Dikinson Biosciences, San José, CA, USA), anti-Bax y anti-Bcl-2 (Santa Cruz Biotechnology Inc., Dallas, Texas, USA), luego lavadas con buffer FACS e incubadas con anti- - -globulina de conejo conjugado a FITC (Becton Dikinson Biosciences San José, Ca, USA) en una dilución 1:100. Las incubaciones con los anticuerpos primarios y secundarios se realizaron por $30 \mathrm{~min}$ a $4^{\circ} \mathrm{C}$.

En todos los casos se utilizaron los correspondientes controles de isotipo (Becton Dikinson Biosciences San José, Ca, USA). Las CEl fueron ubicadas según sus criterios de $\mathrm{FSC} / \mathrm{SSC}$ usando el software CellQuest (Becton Dikinson, Mountain View, CA, EE.UU.). El porcentaje de células $\mathrm{Bad}^{+}, \mathrm{Bax}^{+}$, y Bcl-2 ${ }^{+}$se determinó mediante el software FlowJo (TreeStar, Asland, OR, EE.UU).

\section{ANÁLISIS ESTADÍSTICOS}

La comparación entre grupos se realizó mediante un análisis de la varianza (ANOVA) seguido por la prueba de Tukey o mediante un test de Student para las comparaciones pareadas o no pareadas, según correspondiese. Un p-valor menor de 0,05 fue considerado como estadísticamente significativo. El rango normal de expresión para cada Gal se definió como los niveles de ARNm entre Q1 - 1,5 x RIQ y Q3 + 1,5 x RIQ (Q1: 1er cuartil, Q3: 3er cuartil; IQR: rango inter cuartil), de la población de control.

Para los análisis multivariados de la expresión génica se empleó un análisis discriminante (AD). Esta técnica tiene la finalidad de determinar si existen diferencias significativas respecto a un conjunto de variables medidas sobre grupos previamente establecidos. En el caso de que existan tales diferencias, este análisis trata de explicar en qué sentido se dan y facilitar los procedimientos de clasificación sistemática de nuevas observaciones de origen desconocido (Silvestre y col., 2013).

En este trabajo el $A D$ se utilizó para analizar de manera conjunta los niveles de ARNm de Gal-1, -3, -4, -9, STAT4, T-bet y GATA3 en pacientes control, 
pacientes con Ell y pacientes con otras patologías inflamatorias del intestino. Los datos se representaron en gráficos de componentes principales y en gráficos de centroides. En estos gráficos los objetos similares se encuentran uno cerca del otro y los ejes son una combinación lineal de las variables incluidas en el análisis.

El análisis de validación cruzada (VC), por el método de "leave-one-out" (dejar uno afuera), se utilizó para confirmar la segregación de grupos observada en los gráficos de componentes principales. En este método se toma aleatoriamente una de las muestras de la base de datos (dato de prueba) y se realiza en análisis estadístico en función a los datos remanentes. De esta manera se genera algoritmo que, por un lado separa los grupos previamente establecidos, pero además, se utiliza para predecir a cuál de ellos pertenece el dato de prueba. Este procedimiento se repite tantas veces como muestras haya en la base de datos, variando el dato de prueba en cada repetición. Por lo tanto, al final del análisis se obtiene un porcentaje de veces que las muestras fueron recategorizadas en el grupo asignado a priori.

Las curvas de característica operativa del receptor (ROC) representan gráficamente la sensibilidad (tasa de verdaderos positivos) vs especificidad (tasa de falsos positivos). El área bajo la curva ROC (ADC) mide la capacidad de una variable (el nivel de expresión de ARNm de las Gals, marcadores inmunológicos o una combinación de los mismos) para distinguir entre dos grupos. Un valor de ADC pueden variar entre 0,5 y 1 , donde 1 corresponde a un sistema capaz de una discriminación perfecta, mientras que un valor de 0,5 indica una total falta de poder discriminatorio. 
Rol de galectina-1 en la fisiopatología

de las Enfermedades Inflamatorias Intestinales 



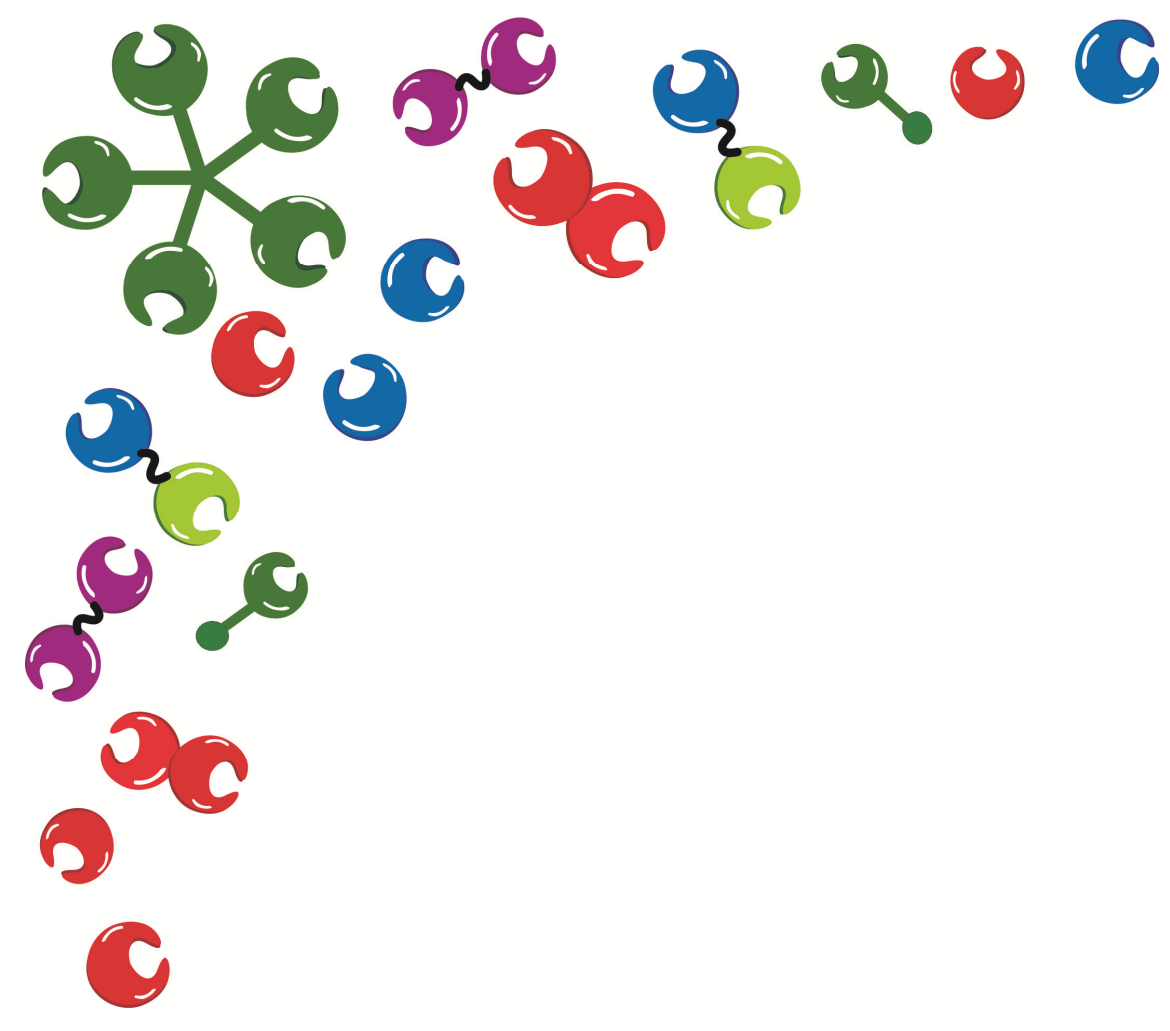

\section{CAPITULO I}

Análisis de galectinas como marcadores de actividad en las Enfermedades Inflamatorias Intestinales 



\section{INTRODUCCIÓN}

La evaluación de la inflamación intestinal constituye un reto difícil. Diferenciar pacientes con CU de aquellos con EC y, a su vez, éstas de otras patologías inflamatorias, suele ser complejo. De hecho, el cuadro clínico puede presentar una sintomatología sumamente inespecífica, por ejemplo únicamente diarrea y dolor abdominal (Abraham \& Thirumurthi, 2009; Baumgart \& Sandborn, 2007).

En la actualidad, el método de diagnóstico y seguimiento más confiable requiere de la endoscopía con toma de biopsias (Abraham \& Thirumurthi, 2009). Por tratarse de un método invasivo, por lo cual conlleva un cierto riesgo para el paciente, se está trabajando en la búsqueda de marcadores biológicos para diagnóstico y pronóstico. Sin embargo, la colonoscopía sigue siendo la prueba "gold estándar" irremplazable.

Un biomarcador ideal para las Ell debería brindar información para el diagnóstico de la patología, diferenciar entre EC y CU, determinar la actividad 
de la enfermedad, predecir los periodos de riesgo y la respuesta a la terapia. Dado que todas estas características difícilmente puedan ser cumplidas con un sólo marcador, se utilizan múltiples biomarcadores en combinación con las pruebas clínicas de rutina (Abraham \& Thirumurthi, 2009).

Los biomarcadores serológicos (proteína C reactiva, anticuerpo anticitoplasma de neutrófilo o p-ANCA, anticuerpo específico de Saccharomycescerevisiae o ASCA, etc.) pueden complementar el diagnóstico, evaluar diferentes estadios de la enfermedad, etc. No obstante, éstos suelen tener baja especificidad o sensibilidad, dependiendo de cuál se trate. A su vez, otras patologías inflamatorias intestinales también muestran alterados estos parámetros, lo cual que constituye un factor de confusión a la hora del diagnóstico (Papp y col., 2007).

Debido a su contacto directo con la mucosa intestinal, los biomarcadores fecales parecerían ser los más adecuados para determinar el estado de un paciente con Ell (Abraham \& Thirumurthi, 2009). Entre éstos, los niveles de las proteínas derivadas de neutrófilos (calprotectina y lactoferrina) suelen ser los mayormente empleados por numerosas razones. En primer lugar, su determinación analítica es muy sencilla (ELISA comercial). Además, por tratarse de proteínas muy estables las muestras son de fácil conservación, y su sensibilidad y especificidad resulta más elevada que la de los marcadores serológicos. Sin embargo, el cáncer de colon, los pólipos, las infecciones (tanto virales como bacterianas), la cirrosis hepática, la obesidad, el tratamiento con anti-inflamatorios no esteroides e inclusive la edad del paciente son factores que alteran los niveles de estos marcadores (Tibble y col. 2000).

A su vez, los índices clínicos de actividad de la enfermedad, como el CDAI, el UCAI, y el índice de actividad de Harvey-Bradshaw reflejan el estado general del paciente y su calidad de vida, lo cual no necesariamente se correlaciona con grado de inflamación de la mucosa (Biancone y col., 2002; Cellier y col., 1994; Crama-Bohbouth y col., 1989).

Como se mencionó previamente, la CU y la EC fueron en un principio clasificadas como patologías Th2 y Th1 respectivamente. Por lo tanto, 
Análisis de galectinas como marcadores de actividad en las Enfermedades Inflamatorias Intestinales

diferentes mediadores inmunológicos fueron estudiados como potenciales biomarcadores de estas enfermedades. (Christophi y col., 2012). Entre estos mediadores se encuentran gata-3, IL-5, IL-13 e IL-33, y T-bet, stat-1/4, IFN- $\gamma$, IL12 e IL-23, asociados a una respuesta Th2 y Th1 respectivamente (Christophi y col., 2012; Neurath, 2002; Baumgart \& Sandborn, 2007). Sin embargo, dado que se trata de enfermedades muy complejas, y no se conocen completamente los mecanismos inmunopatogénicos que las gobiernan (Abraham \& Thirumurthi, 2009; Kugathasan y col., 2007; Christophi y col., 2012), no se han hallado hasta el momento biomarcadores eficientes que puedan ser aplicados para diagnóstico, pronóstico o inclusive para diferenciar CU de EC (Geremia y col., 2014; Neurath, 2014).

Un sistema que permita analizar de manera conjunta y simultánea todos los marcadores puede captar pequeñas variaciones de éstos y convertir esa sutil información en datos relevantes, con lo cual el uso de herramientas bioinformáticas puede ser de gran utilidad. Dentro del conjunto de análisis multivariados, el $A D$ en conjunto con la VC, por el método "leave-one-out", y las curvas ROC permiten este tipo de aproximaciones. De hecho, el análisis conjunto de los signos clínicos y biomarcadores mediante esta metodología permite un diagnóstico precoz de la enterocolitis necrosante en neonatos, así como la distinción entre grupos de alto y bajo riesgo (Sylvester y col., 2013). Cabe destacar que la efectividad de dichas distinciones mejoró considerablemente al analizar de manera conjunta todos los indicadores, en contraposición a los análisis individuales (Sylvester y col., 2013).

Como mencionamos anteriormente, en el intestino se expresan diferentes Gals. Si bien su rol en el contexto de las Ell aún no ha sido completamente esclarecido, debido a los antecedentes que relacionan a estas proteínas con la fisiología del sistema inmune, es lógico suponer que tengan un rol compensatorio como reguladores anti-inflamatorios. Específicamente en colon, Gal-3 y -4 están expresadas en la zona basolateral de los enterocitos, mientras que Gal-1 se halla en la LP y capa muscular subyacente (Nio-Kobayashi y col., 2009), donde los leucocitos, fibroblastos y células de musculo liso son la 
principal fuente de esta lectinas (Kaltner y col., 2002; Nio-Kobayashi y col., 2009).

Empleando un modelo murino de colitis se ha demostrado claramente que Gal-1 cumple un rol protector, dado que su administración revierte completamente la inflamación intestinal. (Santucci y col., 2003). Este efecto anti-inflamatorio probablemente se deba a las propiedades pro-apoptóticas de esta lectina sobre los LT activados presentes en la mucosa intestinal. (Santucci y col., 2003; Toscano y col., 2007) y mediante la inducción de IL-10 e IL-27, citoquinas regulatorias implicadas en la inducción de tolerancia (Ilarregui y col., 2009; van der Leij y col., 2007).

Por otro lado, Gal-3 ha sido implicada en las Ell, ya que se han hallado niveles significativamente disminuidos de esta lectina en las zonas inflamadas, en comparación con las zonas no inflamadas. De hecho, Müller y colaboradores (2006) demostraron que esta lectina controla la sobrevida de los LT activados (Müller y col., 2006), mientras que Lipper y colaboradores (2007 y 2008) probaron que induce la maduración y migración de los fibroblastos de la LP (Lippert y col., 2007, 2008). Por lo tanto, la ausencia de Gal-3 en las zonas inflamadas colaboraría con la respuesta fisiológica frente a una infección (Müller y col., 2006), sin embargo, la cronicidad del la inflamación estimularía la aparición de estenosis y fístulas (Lippert y col., 2007, 2008).

A Gal-4 se le han adjudicado diversas funciones en la fisiología de la inflamación. Según Hokama y colaboradores (2004), la administración de Gal-4 retrasa la recuperación de una colitis inducida por dextran de sodio y sulfato (DSS). Este fenómeno se debe a que las células epiteliales del intestino secretan grandes cantidades de esta lectina, la cual estimula la producción de IL-6 por parte de las células T CD4 ${ }^{+}$(Hokama y col., 2004). Además, los cambios en el glicofenotipo de estos LT del intestino durante dicho modelo de inflamación permiten que Gal-4 forme redes en la superficie de los mismos, potenciando la sinapsis inmunológica. Este fenómeno sobre-estimula a la quinasa PKC $\theta$ y promueve la activación de dichas células (Nishida y col., 2012). Por lo tanto, la disminución de sus niveles (al igual que los de Gal-3) parecería ser una 
respuesta fisiológica de la mucosa para controlar una inflamación aberrante. Sin embargo, a esta lectina también se le han adjudicado capacidades inmunosupresoras, ya que reduce la inflamación intestinal en la fase aguda de un modelo colitis inducido por DSS, estimula la apoptosis de células $T$ de la mucosa e inhibe la secreción de citoquinas pro-inflamatorias (Paclik y col., 2008).

Finalmente, se ha demostrado que Gal-9 ejerce funciones proapoptótica en linfocitos Th1 a través de la unión a TIM-3 (Dardalhon y col., 2010). Tanto TIM-3 como Gal-9 se encuentran sub-expresados en la mucosa intestinal de pacientes con CU y en ratones a los cuales se les indujo una colitis experimental por DSS. A su vez, la administración de un antagonista de TIM-3 exacerba la colitis, mientras que la administración de Gal-9 recombinante la atenúa (Shi y col., 2012). En resumen, estas cuatro Gals están implicadas tanto en la homeostasis como en la inflamación del intestino, por lo cual se postula que podrían contribuir a la fisiopatología de las Ell.

El desarrollo de biomarcadores novedosos que permitan un mayor conocimiento sobre la patogénesis, el pronóstico y la terapia dirigida es una importante necesidad insatisfecha en las Ell. Dado que Gal-1, $-3,-4$ y -9 han sido relacionadas con la fisiología del intestino y han mostrado un valor pronóstico en diversas patologías gastrointestinales (cáncer de colon y estómago y EC) (Demetter y col., 2008), proponemos evaluar la expresión del ARNm de estas lectinas en la mucosa del colon como biomarcador de las Ell. 



\section{OBJETIVOS ESPECÍFICOS}

\section{Evaluar:}

- Los niveles de expresión génica de Gal-1, -3, -4 y -9 en los diferentes segmentos del intestino en condiciones de homeostasis e inflamación.

- La expresión conjunta de Gal-1, -3, -4 y -9 como marcador de inflamación.

\section{Correlacionar:}

- Los niveles de expresión de las Gals con diferentes tipos de patologías inflamatorias y la actividad de las mismas. 

RESULTADOS Y CONCLUSIONES PARCIALES

La expresión de las galectinas está desregulada en las zonas inflamadas de pacientes con Ell

Con el objetivo de evaluar a Gal-1 como biomarcador en las Ell, se analizaron los niveles de ARNm que codifican para esta lectina en biopsias de colon provenientes de pacientes control y de pacientes con Ell. En primera instancia se evaluó la expresión de LGALS1 (gen que codifica para Gal-1) en las diferentes porciones del colon (ascendente, transverso, descendente, sigma y recto) en pacientes control. Se observó que el ARNm para esta proteína es expresado de manera constitutiva y homogénea en las diferentes secciones del intestino grueso (Fig. 1.1 A). Esta comparación es sumamente relevante, ya que las Ell pueden afectar diferentes porciones del intestino, y nos indica que la expresión génica de Gal-1 es independiente de la porción del colon que se muestree.

En una segunda instancia se evaluó la expresión de LGALS1 en biopsias provenientes de pacientes con Ell (zonas no inflamadas e inflamadas). Como zonas no inflamadas se consideraron aquellos segmentos que, al momento del estudio, presentaron un aspecto endoscópico normal y, además, no hayan mostrado signos de inflamación previa. A su vez, las zonas inflamadas se clasificaron en dos grupos en base a los criterios de Frøsly (2007): zonas con inflamación leve (eritema, patrón vascular levemente distorsionado y granularidad fina) y zonas con inflamación severa (aumento de eritema, ausencia de patrón vascular, friabilidad, sangrado espontáneo y presencia o ausencia de úlceras).

Como puede observarse en la figura 1.1 B, la expresión de LGALS1 en las biopsias provenientes de zonas inflamadas pacientes con Ell es significativamente mayor a la observada en los tejidos de pacientes control y zonas no inflamadas de pacientes con Ell. Dichas diferencias resultaron particularmente marcadas en las zonas con inflamación severa (Fig. 1.1 B). Si 
bien estos cambios son significativos, la utilización de Gal-1 como biomarcador requiere establecer un valor de corte que permita distinguir una mucosa sana de una inflamada. Para tal fin se delimitó una zona de confianza, cuyos límites se corresponden a la presencia de los valores extremos de la población control. Utilizando esta aproximación pudo determinarse que los niveles de expresión de LGALS1 permiten diferenciar en un $40 \%$ de los casos a las muestras de pacientes con Ell activa de los controles. Considerando que este porcentaje no sólo es bajo, sino que además no permite diferenciar áreas con inflamación leve de áreas no inflamadas o tejido proveniente de pacientes control, decidimos ampliar este análisis e incluir la expresión génica de Gal -3, -4 y -9.

\section{Gal-1}

A

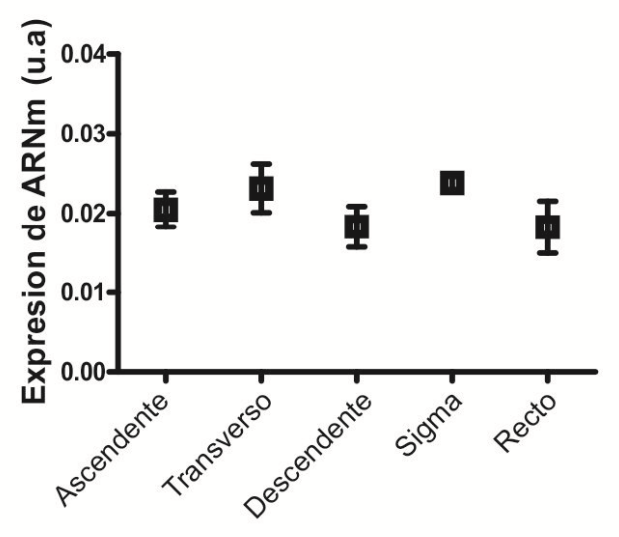

B

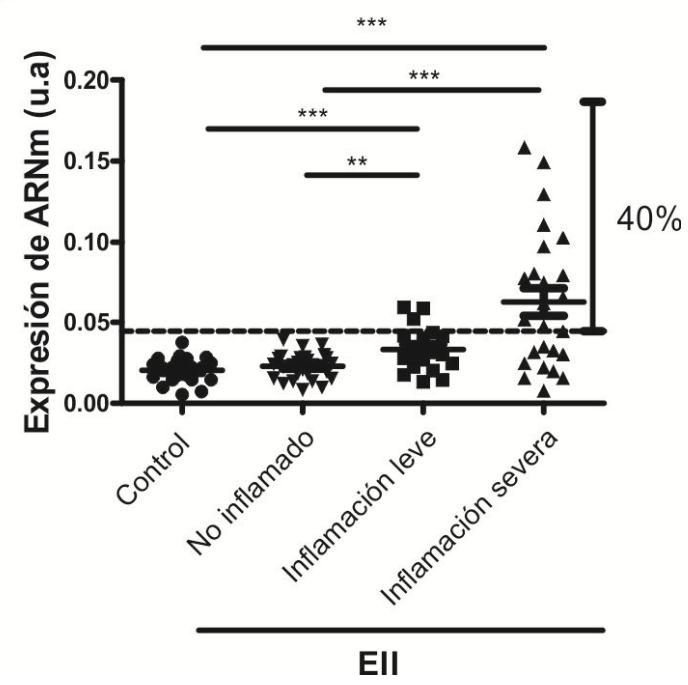

Fig. 1.1: Niveles de expresión de LGALS1 en la mucosa colónica.

A) Expresión del ARNm que codifica para Gal-1 por qPCR en las diferentes secciones del colon de pacientes control $(n=9)$. B). Expresión génica de Gal-1 en pacientes control $(n=22)$ y pacientes con Ell clasificados según el grado de inflamación de la mucosa (no inflamado, $n=26$; inflamación leve, $n=18$; e inflamación severa, $n=25$ ). Los datos se expresan como valores medios \pm ESM. La línea punteada indica el valor de corte para el rango normal esperado en muestras provenientes de pacientes control. ( ${ }^{* * *} \mathrm{P}<0,001$; ${ }^{* *} \mathrm{P}<0,01$; u.a: unidades arbitrarias). 
Al igual que para Gal-1, se analizaron los niveles de expresión de LGALS3, 4 y 9, (que codifican para Gal-3, -4 y -9 respectivamente) en biopsias de pacientes control y de pacientes con Ell (zonas no inflamadas e inflamadas). Se observó que la expresión de estas 3 lectinas también es constitutiva y homogénea en todas las regiones del colon (Fig. 1.2 A, C y E). Además, pudo determinarse que Gal-4 es (de las lectinas estudiadas) la más expresada en el colon, con niveles de ARNm comparables con los de $\beta$-actina, seguida de LGALS3, LGALS9 y LGALS1 respectivamente.

Al analizar la expresión génica de estas 3 lectinas en muestras de pacientes con Ell observamos que, contrariamente a lo hallado para Gal-1, la mucosa inflamada presenta niveles de expresión de LGALS3, LGALS4 y LGALS9 menores a los observados en la mucosa de pacientes control y zonas no inflamadas de pacientes con Ell (Fig. 1.2 B, D y F). En los casos de muestras provenientes de mucosa levemente inflamada, dichos cambios resultaron significativos sólo para Gal-4 (Fig 1.2 D). Sin embargo, los niveles de expresión de LGALS-4 sólo permitieron distinguir un $42 \%$ de los pacientes con Ell activa, y los mismos pertenecieron casi exclusivamente al grupo de pacientes con Ell severa. Por otra parte, la expresión de LGALS-9 permitió distinguir a un 58\% de los pacientes con Ell activa (Fig. 1.2 F). Pero, al igual que para LGALS-4, su capacidad de discernir entre una mucosa inflamada y una control está restringida casi exclusivamente a aquellos pacientes con inflamación severa. 
A
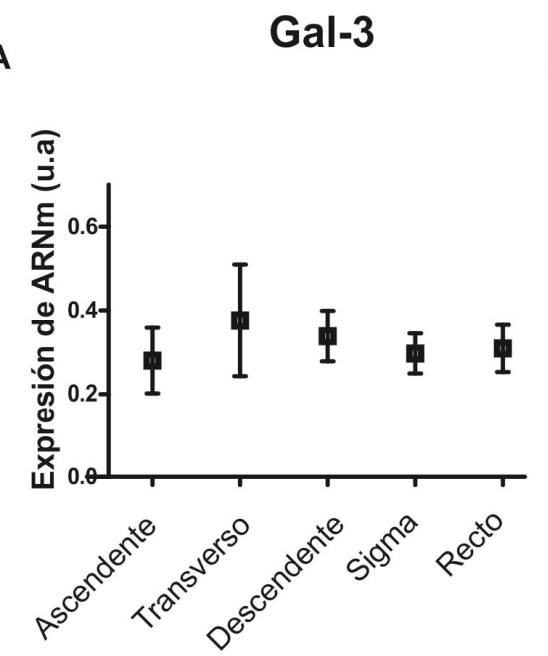

C

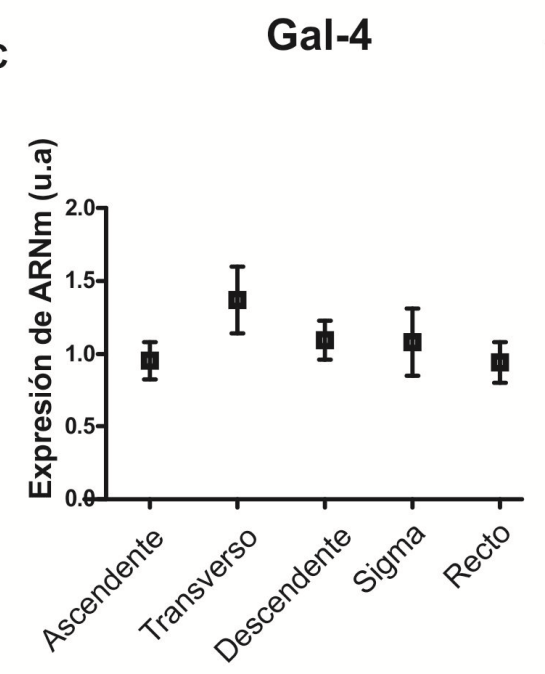

E

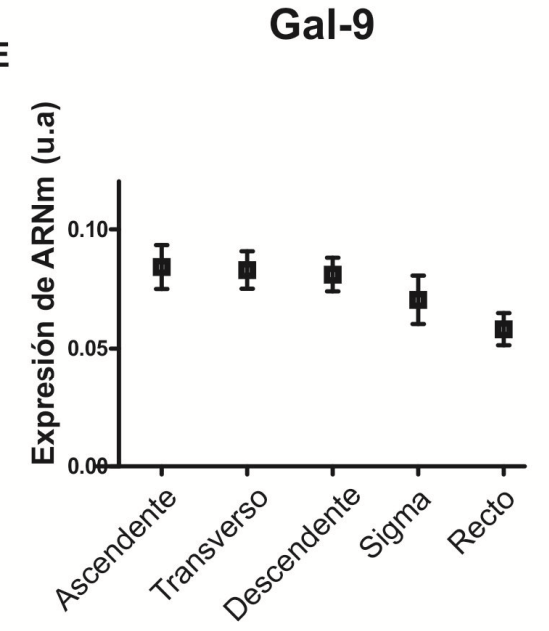

B
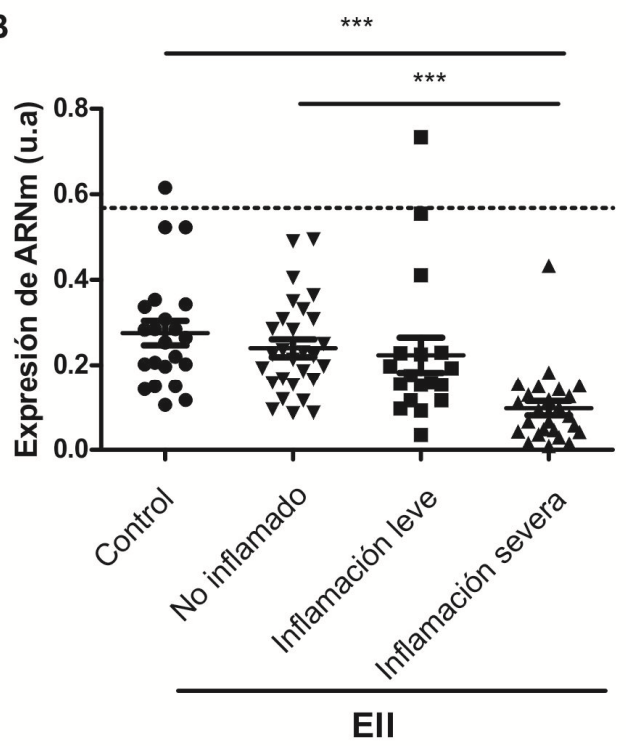

D
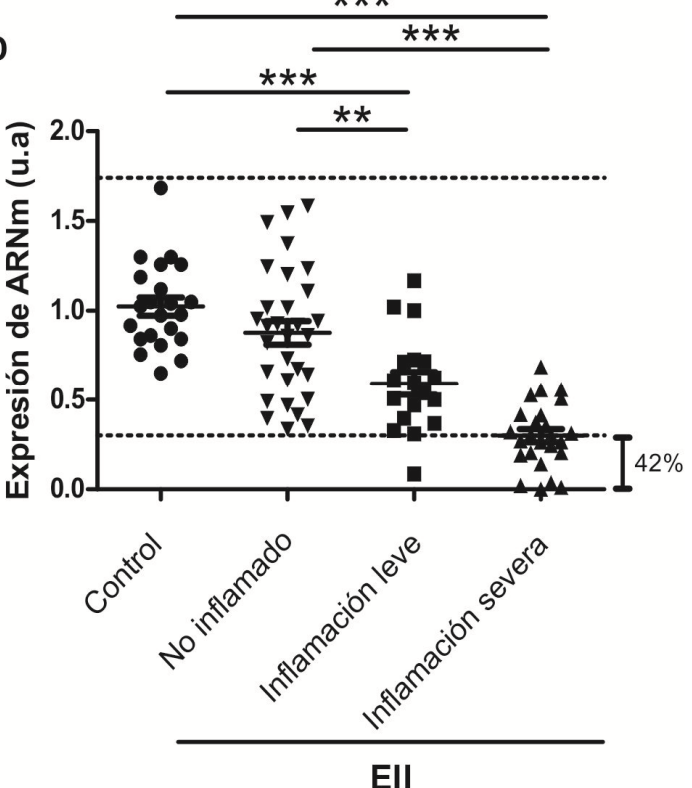

EII

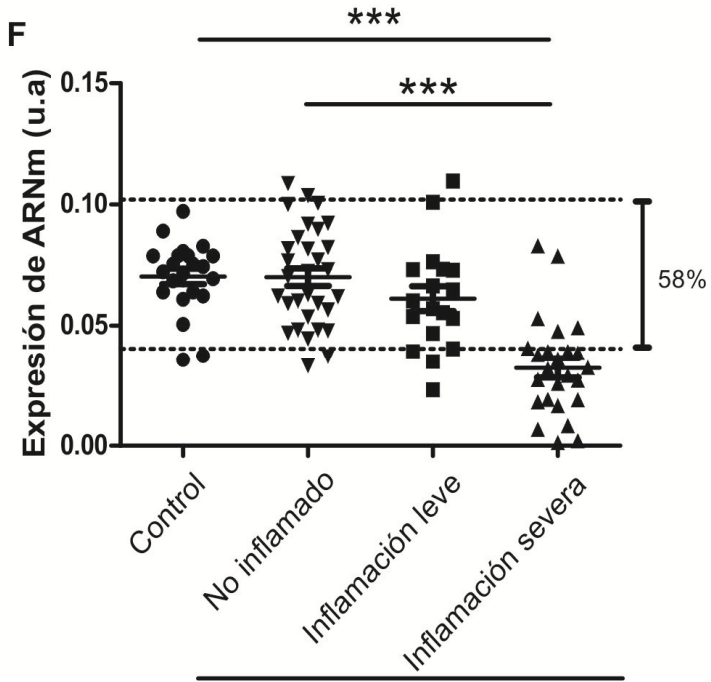

EII 
Fig. 1.2: Niveles de expresión de LGALS3, 4, y 9 en la mucosa colónica.

A) Expresión de LGALS3 en las diferentes secciones del colon de pacientes control ( $n=9)$. B) Niveles de ARNm que codifican para Gal-3 en la mucosa de pacientes control y de pacientes con EII. C) Expresión de LGALS4 en las diferentes secciones del colon de pacientes control ( $n=9)$. D) Niveles de ARNm que codifican para Gal-4 en la mucosa de pacientes control y de pacientes con EII. E) Expresión de LGALS9 en las diferentes secciones del colon de pacientes control $(n=9)$. F) Niveles de ARNm que codifican para Gal-9 en la mucosa de pacientes control y de pacientes con EII. Pacientes control, $n=22$. Los pacientes con Ell fueron clasificados según el grado de inflamación de la mucosa colónica (no inflamada, $n=26$; inflamación leve, $n=18$; e inflamación severa, $n=25)$. Los datos se expresan como valores medios $\pm E S M$. Las líneas punteadas indican los valores de corte para el rango normal esperado en muestras provenientes de pacientes control (*** $\mathrm{P}<0,001 ; * * \mathrm{P}<0,01)$.

Para estudiar la sensibilidad (fracción de verdaderos positivos) y especificidad (fracción de falsos positivos) de las Gals como marcadores de inflamación se analizó el área debajo de la curva ROC para cada lectina según el grado de inflamación (Fig. 1.3). Los valores de ADC son independientes del valor de corte utilizado y pueden variar entre 0,5 y 1 , siendo 0,5 el resultado de una prueba sin capacidad diagnóstica y 1 un valor diagnóstico perfecto. En concordancia con lo observado en las figuras 1.1 y 1.2 , se obtuvieron bajos valores de $A D C$ al comparar la expresión de estas Gals entre las zonas con inflamación leve y mucosa control (excepto en el caso de Gal-4, cuyo ADC resulto de 0,84) (Fig. 1.3 A). Este hecho indica que, a excepción de Gal-4, el análisis individual de estas Gals no tiene una buena capacidad diagnóstica para diferenciar mucosa levemente inflamada de aquella proveniente de pacientes control. Por el contrario, todas las Gals mostraron una alta sensibilidad y especificidad para distinguir entre las áreas con inflamación severa y muestras control $(A D C>0,8)$, especialmente Gal-4 $(A \cup C=0,95)$ (Fig. $1.3 B)$. 
Gal-1

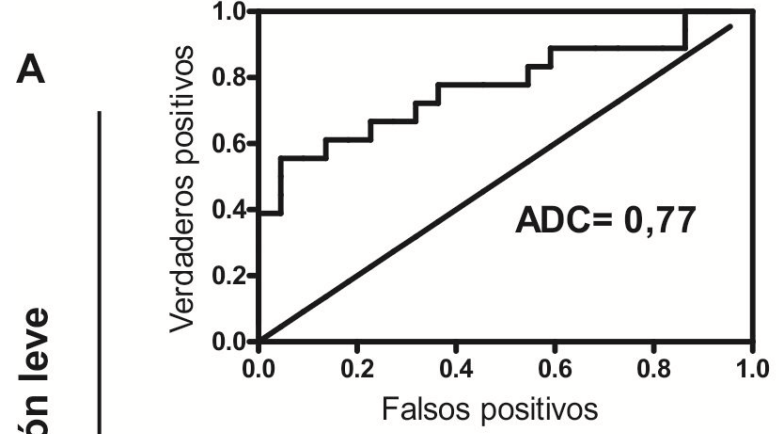

Gal-4

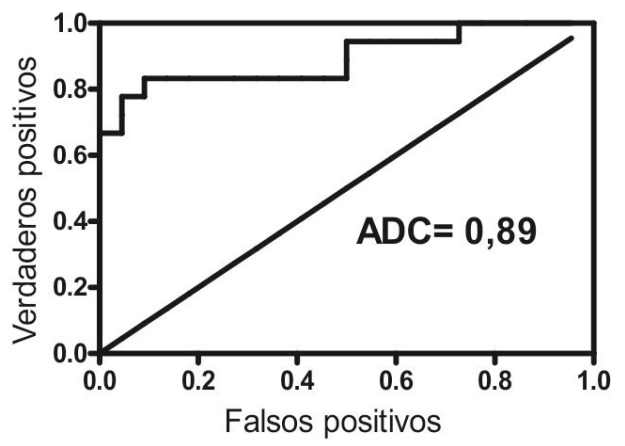

Gal-1

B

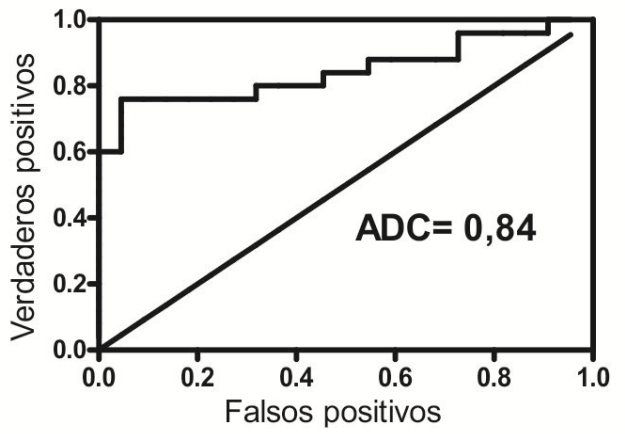

Gal-4

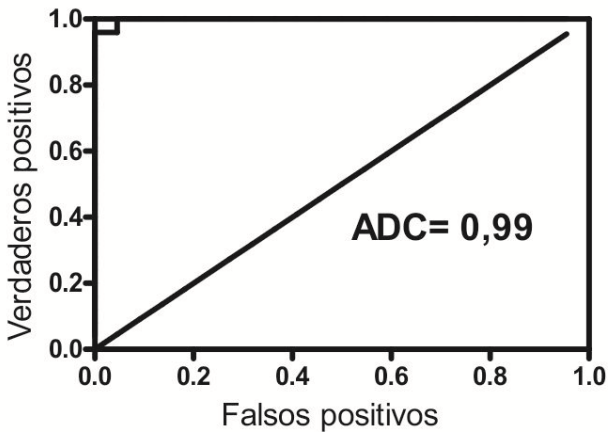

Gal-3

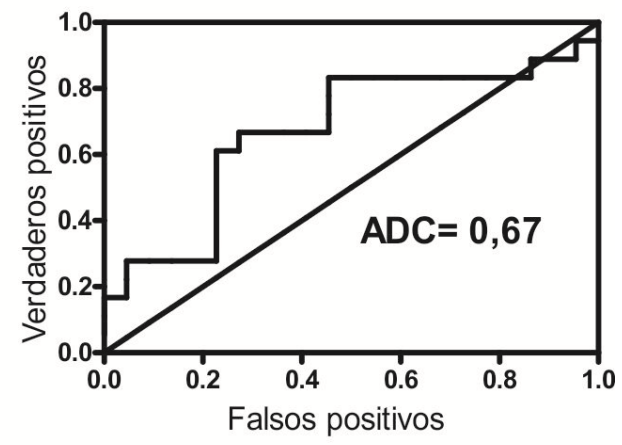

Gal-9

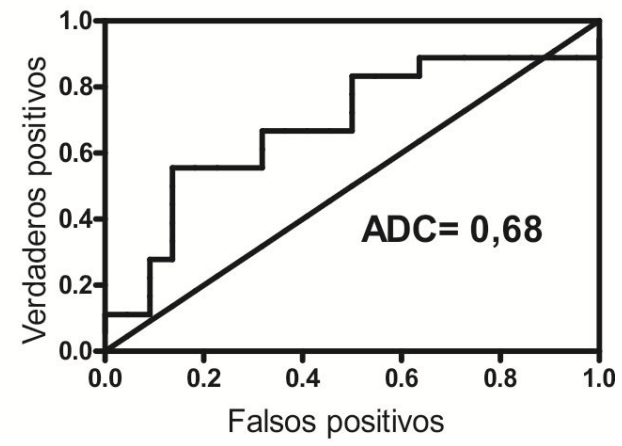

Gal-3

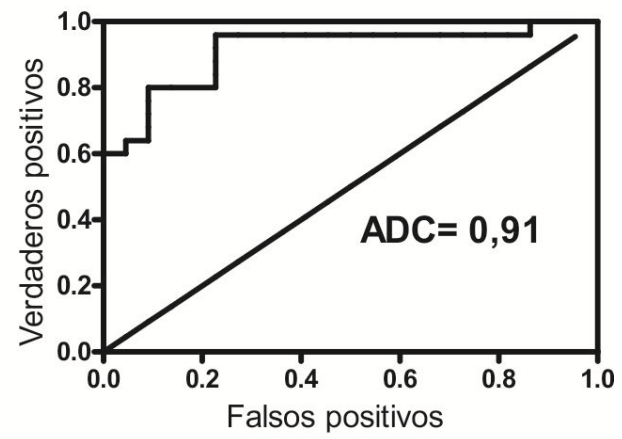

Gal-9

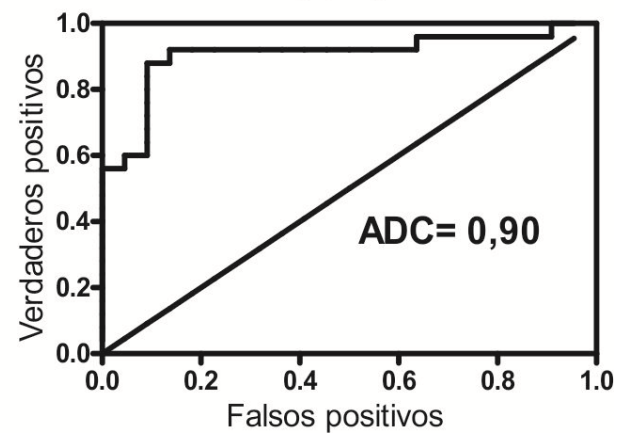

Fig. 1.3: Análisis de sensibilidad y especificidad de las Gals como indicadores de inflamación.

A) Curvas ROC y valores de ADC para la expresión de Gal-1, -3, -4 y -9 en muestras provenientes de zonas con inflamación leve. B) Curvas ROC y valores de ADC para la expresión de Gal-1, -3, -4 
y -9 en muestras provenientes de zonas con inflamación severa. Pacientes control, $n=22$, pacientes con Ell leve, $n=18$ y pacientes con Ell severa, $n=25$. ROC: característica operativa del receptor. ADC: Área debajo de la curva. Verdaderos positivos: sensibilidad. Falsos positivos: especificidad.

Por lo tanto, a pesar de las diferencias observadas en la expresión de estas Gals, el análisis individual de las mismas no permite diferenciar las muestras provenientes de pacientes con Ell activa de aquellas provenientes de pacientes control, ni las muestras con inflamación leve de las que presentan inflamación severa (Fig. 1.1 y 1.2 A). De hecho, si bien en algunos casos el estudio de las curvas ROC (Fig. 1.3) mostró que estas Gals tienen capacidad diagnóstica, el análisis individual de las mismas sólo puede discriminar en un bajo porcentaje de casos entre las muestras provenientes de mucosa inflamada (leve y severa) y mucosa control (Gal-1 $=40 \%$; Gal-3 $=0 \%$; Gal-4 $=42 \%$ y Gal- $9=$ $58 \%)$. En vista de estos resultados decidimos realizar un análisis multivariado, teniendo en cuenta la expresión conjunta de estas 4 Gals.

\section{La expresión conjunta de Gal-1, $-3,-4$ y -9 refleja el grado de actividad de la mucosa}

A través del análisis discriminante se pudieron agrupar las muestras en base a los niveles de expresión de Gal-1, $-3,-4$ y -9 , mientras que el método de validación cruzada nos permitió evaluar el desempeño del sistema. Los resultados del $A D$ se muestran en gráficos de componentes principales y en gráficos de centroides. El gráfico de componentes principales se utiliza para reducir la dimensionalidad de un conjunto de datos. En este caso lo utilizamos para visualizar la expresión conjunta de estas 4 Gals en un sistema de 2 ejes (los cuales son una combinación lineal de las variables originales). Debido que el gráfico de componentes principales muestra a todos individuos incluidos en el análisis, también utilizamos el gráfico de centroides, el cual nos aporta una visión simplificada de los resultados. 
Como puede observarse en la figura 1.4, el AD no mostró diferencias significativas entre las muestras de pacientes control y las zonas no inflamadas o en remisión de pacientes con Ell. Por otra parte, las muestras provenientes de zonas inflamadas de pacientes con Ell fueron discriminadas claramente. De hecho, al comparar la mucosa inflamada, no inflamada y en remisión de pacientes con Ell y la de pacientes control, el análisis de VC predijo la identidad de las muestras con el siguiente porcentaje de éxito: Ell-inflamado=81,40\% ( $n=$ 43); Ell-no inflamado $=23,08 \%(n=26)$; Ell-remisión $=25 \%(n=16)$ y controles= $31,82 \%(n=22)$. Esto significa que las muestras de mucosa inflamada constituyen una población particular, diferente de las otras 3 incluidas en este análisis. A su vez, implica que las muestras de zonas no inflamadas y en remisión de pacientes con Ell y las muestras control conforman un grupo homogéneo, donde es imposible distinguir entre ellas (por eso los bajos porcentajes obtenidos de la VC). Por lo tanto, estos resultados indican que los cambios en la expresión del ARNm de las Gals están relacionados con la actividad del proceso inflamatorio. Pero más importante aún, que una vez superada la inflamación con el tratamiento (zonas en remisión), se restablece un patrón de expresión de Gals que es igual al de los pacientes control. 


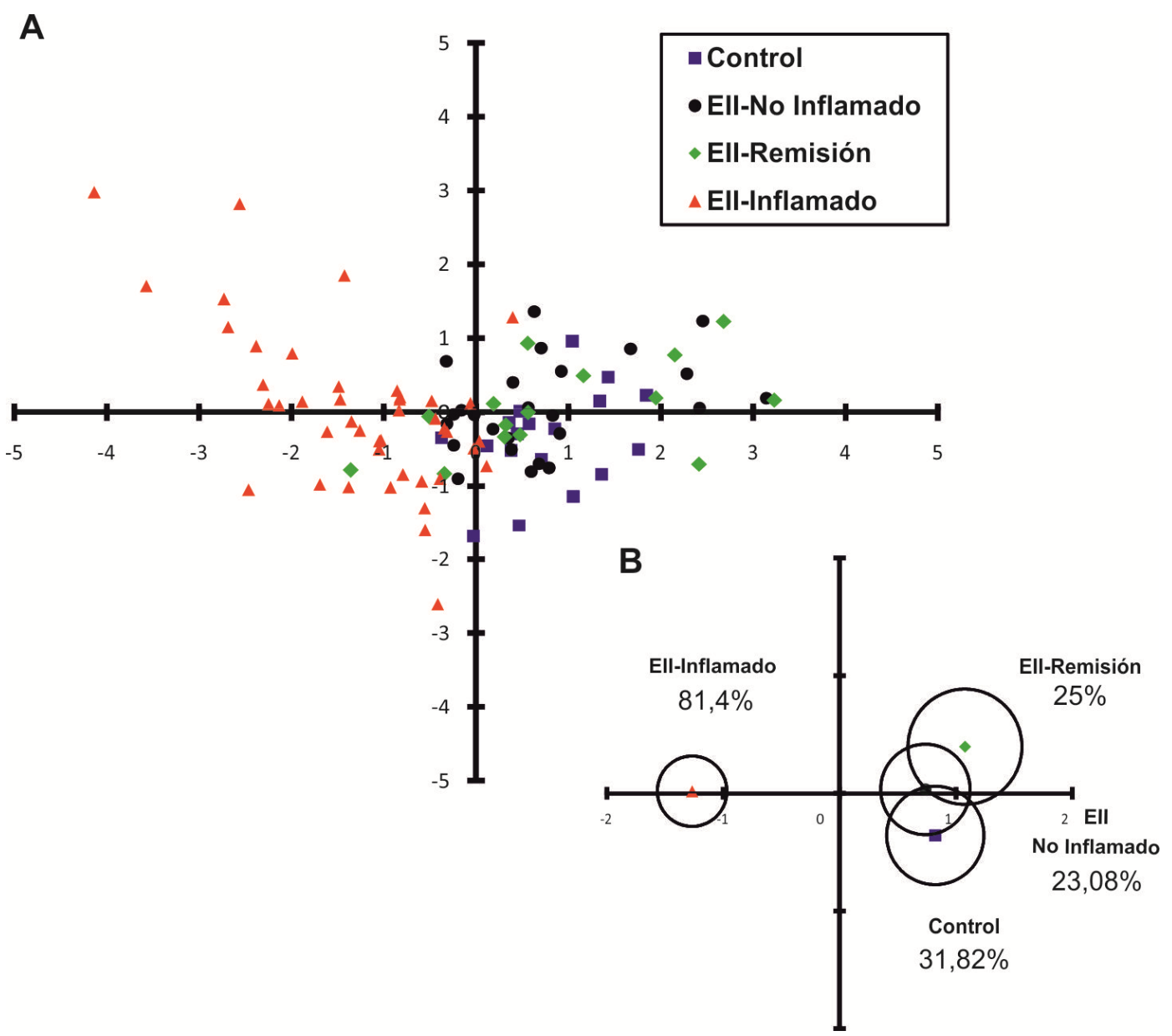

Fig. 1.4: Análisis discriminante de la expresión de las diferentes Gals en muestras de colon en pacientes control y pacientes con Ell.

A) Gráfico de componentes principales para la expresión de ARNm de Gal-1, -3, -4 y -9 en biopsias de pacientes con Ell (inflamado, $n=43$; no inflamado, $n=26$ y remisión, $n=16$ ) y pacientes control, $n=22$. B) Gráfico de centroides correspondiente a las poblaciones de pacientes con Ell-inflamado, Ell-no inflamado, Ell-remisión y pacientes control.

Dado que encontramos una clara discriminación en muestras provenientes de áreas inflamadas, decidimos estudiar si existía una correlación entre los niveles de expresión génica de las Gals y el grado de actividad de la enfermedad. Encontramos que es posible diferenciar la inflamación leve de la severa (Fig. 1.5), por lo cual el AD permite caracterizar la actividad del foco inflamatorio. De hecho, a través de la VC se encontró que las muestras provenientes de pacientes con Ell y actividad leve eran reconocidas como tales un $66,67 \%$ de las veces $(n=18)$, mientras que aquellas con inflamación severa 
eran recategorizadas como tales en un $72 \%$ de los casos $(n=25)$. Las muestras provenientes de zonas marcadamente inflamadas fueron "confundidas" sólo con muestras provenientes de zonas levemente inflamadas, nunca con muestras control (Fig. 1.5 A). Los pacientes control fueron reconocidos como tales en un $82,82 \%$ de los casos. Estos resultados confirman que la expresión de ARNm de estas Gals se correlaciona con el grado de inflamación del colon.

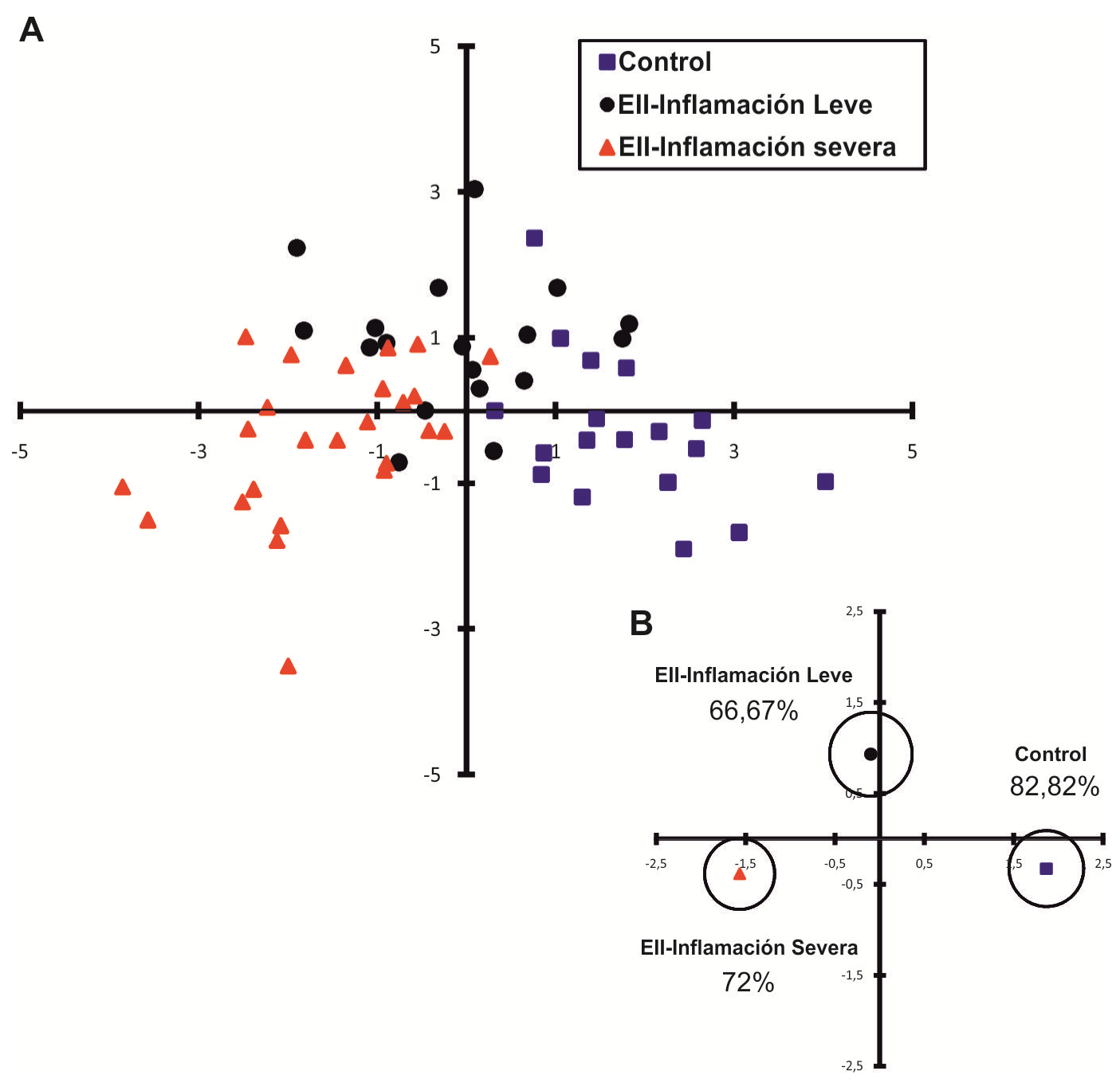

Fig. 1.5: Análisis discriminante de la expresión de las diferentes Gals según el grado de inflamación.

A) Gráfico de componentes principales para la expresión de ARNm de Gal-1, -3, -4 y -9 en biopsias de pacientes con Ell activa (inflamación leve y severa) y biopsias de pacientes control. B). Gráfico de centroides correspondientes a las poblaciones de pacientes con Ell (con 
inflamación severa y leve) y pacientes control. Pacientes control, $n=22$; pacientes con Ell leve, $n=18$ y pacientes con Ell severa, $n=25$.

\section{La expresión de ARNm de las galectinas no permite discriminar entre inflamación en EC y CU}

Aunque el $A D$ mostró un buen rendimiento para discernir entre muestras de pacientes con Ell activa y muestras de pacientes control (Fig. 1.6 A, $\left.\mathrm{VC}_{\text {Ell-activa }}=92 \%, \mathrm{VC}_{\text {CONTROL }}=82 \%, \mathrm{AUC}=0,97\right)$, la expresión de estas Gals no resulto útil para discernir entre CU y EC (Fig. 1.6 C). De hecho, los porcentajes de efectividad de la $\mathrm{VC}$ resultaron: $\mathrm{VC}_{\mathrm{EC}}=44,44 \%(\mathrm{n}=18), \mathrm{VC}_{\mathrm{CU}}=44,00 \%$ ( $\mathrm{n}=$ 25) y $V_{\text {CONTROL }}=81,82 \%(n=22)$. Este resultado implica que el patrón de expresión de esta 4 Gals está igualmente desregulado en CU y en EC. Por lo tanto, decidimos agregar al $A D$ los niveles de expresión de marcadores inmunológicos que previamente fueron documentados como diferencialmente expresados entre estas 2 patologías. En primer lugar encontramos que el análisis combinado de la expresión de stat-4, gata-3 y T-bet (Fig. 1.6 B) no permite discernir entre Ell activa y controles $\left(\mathrm{VC}_{\text {Ell-Inflamado }}=58 \%\right.$; $\mathrm{VC}_{\mathrm{CONTROL}}=$ $77 \%$; $A \cup C=0,72$ ). Por lo tanto, al comparar los resultados mostrados en las figuras $1.6 \mathrm{~A}$ y $1.6 \mathrm{~B}$, podemos observar que el análisis que mejor discrimina entre muestras de pacientes con Ell y pacientes control es el que considera la expresión conjunta de las 4 Gals.

Por último, se llevó a cabo el AD utilizando los valores de expresión de ARNm de las Gals junto a los marcadores inmunológicos y se observó que tampoco era posible discriminar entre CU y EC de manera adecuada (Fig. 1.6 D). Sin embargo, este análisis permitió diferenciar claramente las muestras provenientes de pacientes control y las muestras de pacientes con EII $\left(\mathrm{VC}_{\mathrm{EC}}=\right.$ $31,25 \% ; V_{C U}=40,91 \%$ y VC $\left.C_{\text {CONTROL }}=86,36 \%\right)$. 
A

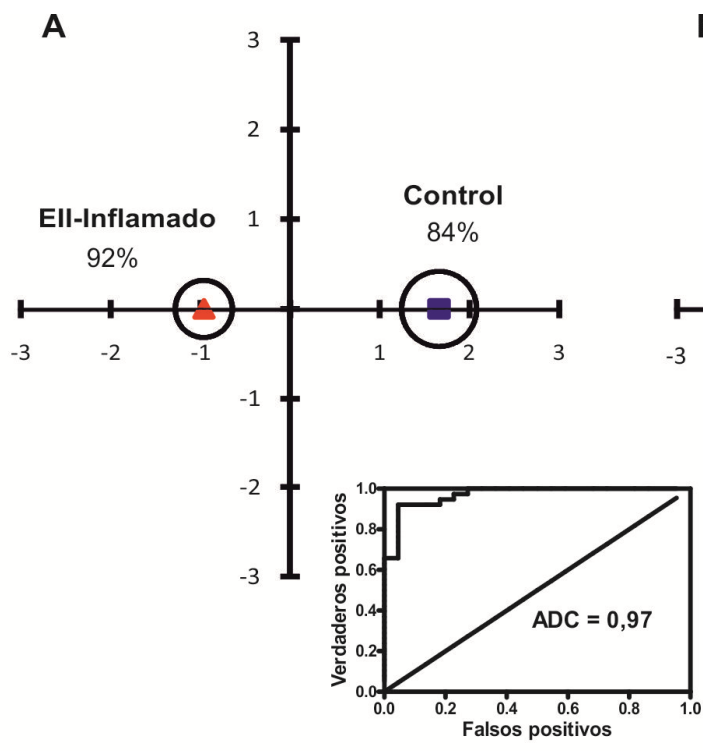

B

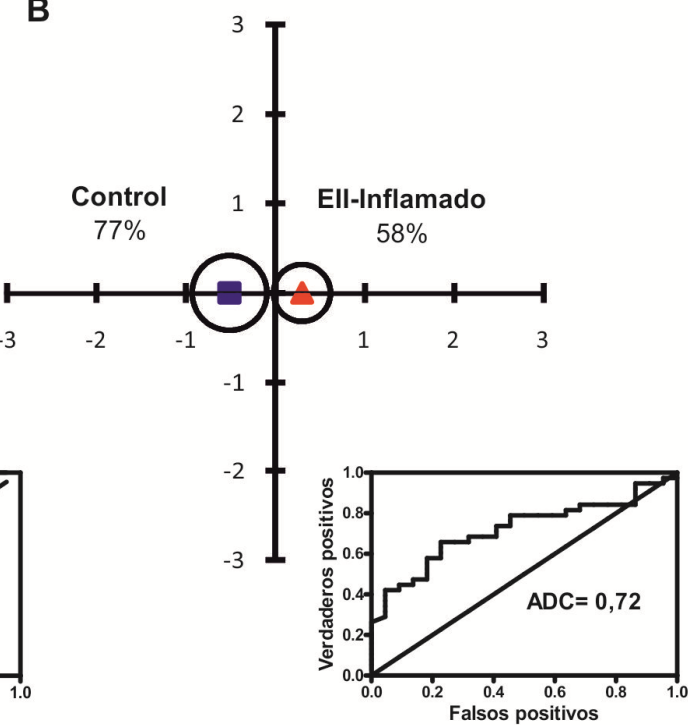

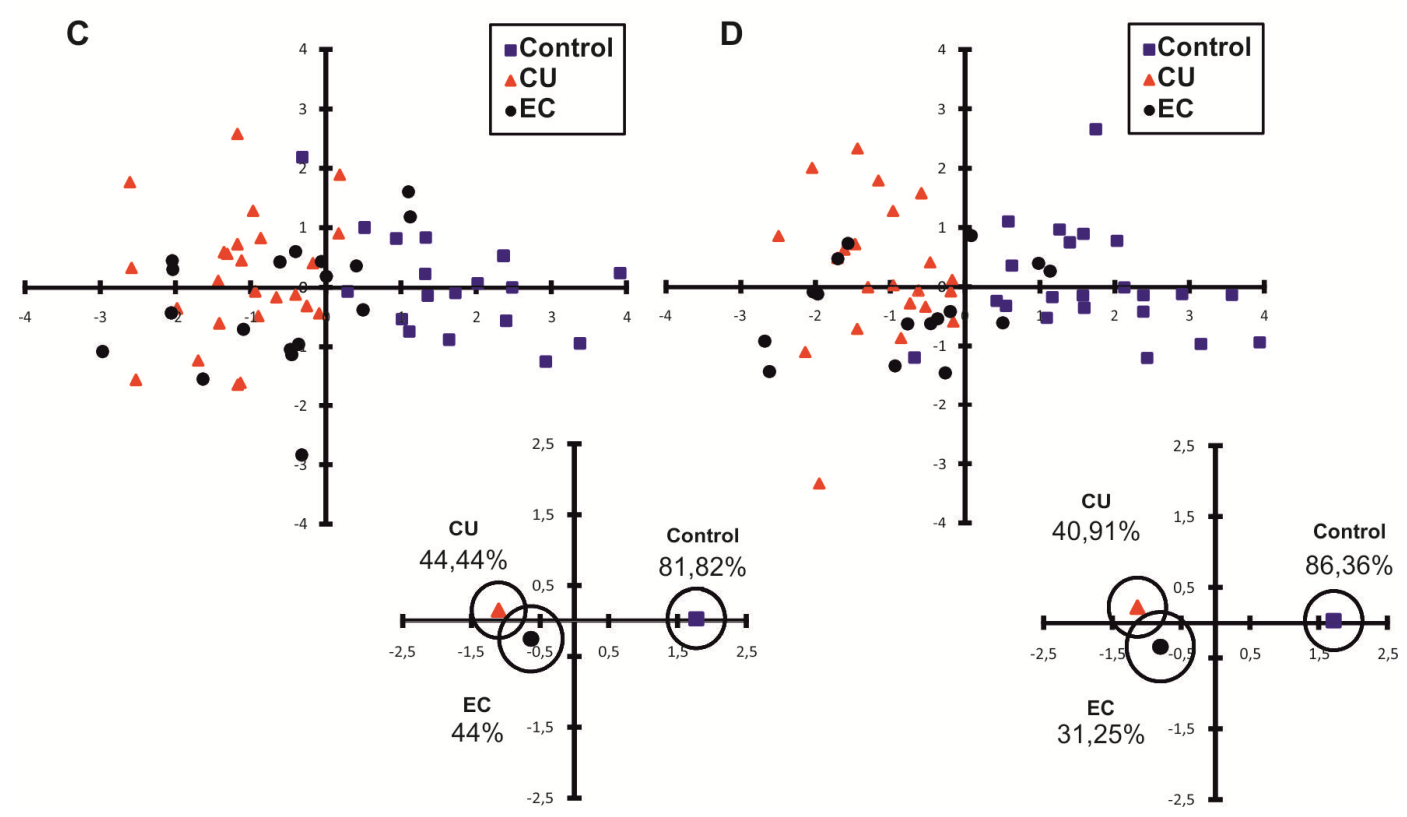

Fig. 1.6: Análisis discriminante de la expresión de las Gals y marcadores inmunológicos asociados a células $\mathrm{T}$.

A) Gráfico de centroides de las poblaciones de pacientes con Ell activa y pacientes control al analizar la expresión del ARNm de Gal-1,-3,-4 y -9 en biopsias de mucosa colónica. Curvas ROC y valores de ADC para la discriminación entre pacientes con Ell activa y pacientes control. B) Gráfico de centroides de las poblaciones de pacientes con Ell activa y pacientes control al analizar la expresión de gata-3, stat-4 y T-bet en biopsias de mucosa colónica. Curvas ROC y valores de ADC para la discriminación entre pacientes con Ell activa y pacientes control. C) Gráfico de componentes principales y gráfico de centroides para la expresión de LGALS1, 3, 4 y 9 en biopsias de pacientes con EC y CU activa y biopsias de pacientes control. D) Gráfico de 
componentes principales y gráfico de centroides para la expresión de LGALS1, 3, 4 y 9, gata-3, stat-4 y T-bet en biopsias de pacientes con EC y CU activa y biopsias de pacientes control. Pacientes control, $n=22$; pacientes con $\mathrm{CU}, \mathrm{n}=25$ y pacientes con $\mathrm{EC}, \mathrm{n}=18$.

En conjunto, estos resultados indican que, de los marcadores estudiados, la expresión de las Gals es la que mayormente contribuye a distinguir entre los pacientes con Ell activa y los controles, pero además, que el patrón de expresión de estos genes está igualmente desregulado en las zonas inflamadas de pacientes con CU o EC.

\section{Las galectinas se expresan diferencialmente dependiendo del tipo de inflamación intestinal}

Con el objetivo de determinar si los cambios en el patrón de expresión de Gals observados en CU y EC eran específicos de las Ell, analizamos los niveles de ARNm de estas lectinas en biopsias de pacientes con otras patologías inflamatorias del intestino. Se estudiaron muestras de pacientes con enfermedad celíaca en actividad y pacientes que recibieron trasplante de intestino y posteriormente sufrieron una inflamación del mismo asociada a rechazo agudo.

Inicialmente analizamos la expresión génica de las 4 Gals en muestras de duodeno y de colon provenientes de pacientes control. Como muestra la figura 1.7 A, los niveles de expresión de las 4 lectinas son significativamente menores en el intestino delgado que en el colon. La principal diferencia se observó para la Gal-9, con niveles de ARNm 3,3 veces mayores en el colon que en el intestino delgado (Fig. 1.7 A). A su vez, estas diferencias fueron claramente evidenciadas por el $A D\left(V C_{D E L G A D O}=90 \%, V C_{C O L O N}=90,91 \%\right)$ (Fig. 1.7 B). En base a estos resultados, las muestras provenientes de pacientes celíacos o pacientes con rechazo fueron comparados con biopsias de intestino delgado tomadas de pacientes control. Como se observa en la figura $1.7 \mathrm{C}$, los pacientes celíacos no pudieron ser diferenciados de los pacientes control. 
Por otra parte, las muestras que provenían de pacientes con rechazo mostraron un perfil particular de expresión de Gals, diferente del observado tanto para pacientes celíacos como para pacientes control $\left(\mathrm{VC}_{\mathrm{CEL}} \mathbf{i ́}_{\mathrm{ACOS}}=50 \%\right.$, $\mathrm{VC}_{\text {RECHAZO }}=77,78 \%$ y VC CONTROL $=70 \%$ ) (Fig. $1.7 \mathrm{C}$ ). La principal diferencia se observó para los niveles de LGALS1, los cuales resultaron 4 veces mayores en los pacientes con rechazo al injerto trasplantado que en los pacientes control. Asimismo, también se observaron diferencias significativas en los niveles de LGALS3. En conjunto, estos resultados reflejan que la expresión de estas 4 lectinas depende del ambiente inflamatorio del intestino. 
A
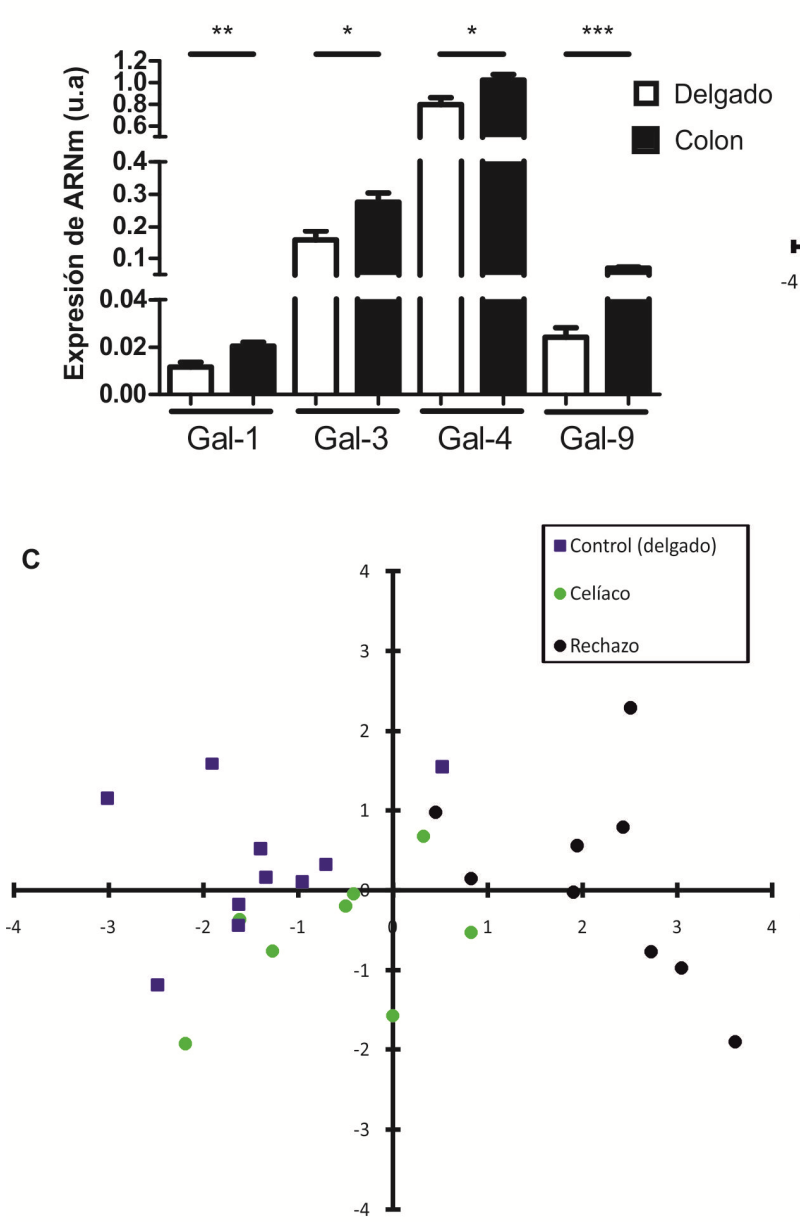

B

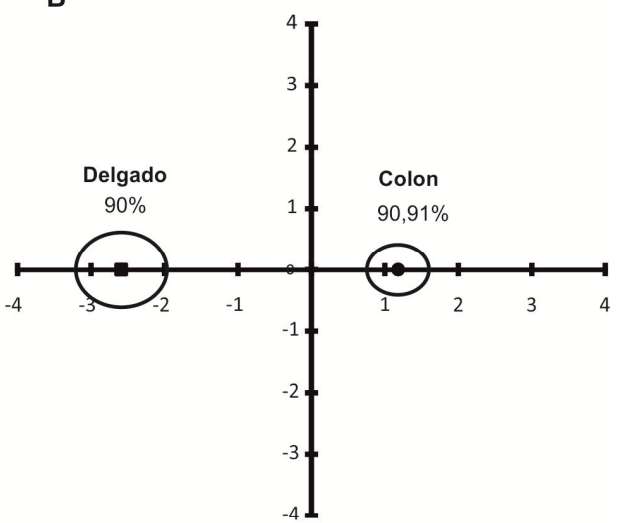

D

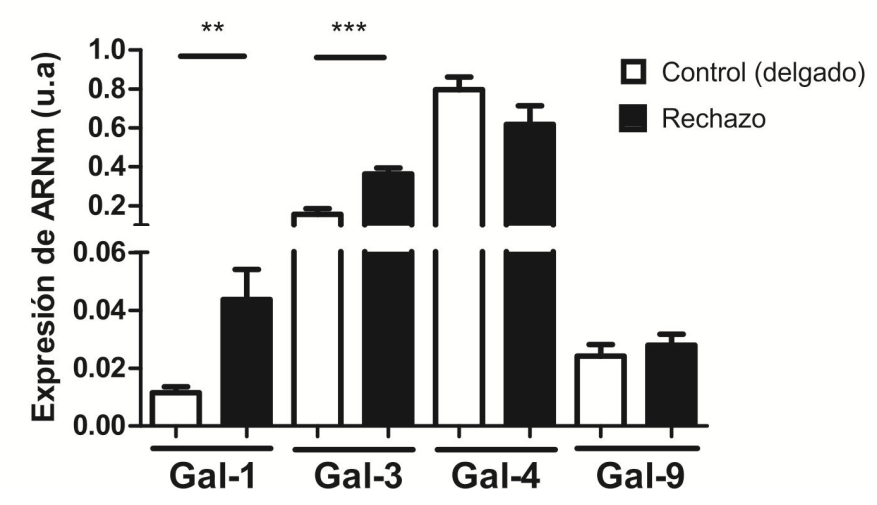

Fig. 1.7: Análisis discriminante de la expresión de Gals en pacientes con diferentes patologías inflamatorias intestinales.

A) Niveles de expresión de LGALS1, $-3,-4$ y -9 en biopsias de colon ( $n=22$ ) e intestino delgado $(n=10)$ de pacientes control. Los datos se expresan como valores medios \pm ESM. B) Gráfico de centroides para la expresión de las diferentes Gals en muestras de intestino delgado y colon en pacientes control. C) Gráfico de componentes principales y gráfico de centroides de pacientes 
control $(n=10)$, pacientes con enfermedad celíaca activa $(n=8)$ y pacientes con rechazo al trasplante de intestino ( $n=10)$. D) Niveles de expresión de LGALS1, $-3,-4$ y -9 en biopsias de pacientes control (intestino delgado) y pacientes con rechazo al trasplante de intestino. Los datos se expresan como valores medios \pm ESM. ${ }^{*} p<0,05 ; * * p<0,01 ; * * * p<0,001$.

Por otra parte, considerando que las Ell y el rechazo al trasplante generan cambios en el patrón de expresión de Gals (en relación a sus respectivos controles), decidimos comparar estas dos patologías y determinar sí el perfil de expresión de Gal-1, -3, -4 y -9 era particular de cada tipo de inflamación. Como se muestra en la figura 1.8, el AD reveló que la inflamación crónica en las Ell tiene un comportamiento diferencial en cuanto a la modulación de la expresión de estas lectinas respecto a la inflamación en un rechazo del intestino trasplantado $\left(\mathrm{VC}_{\text {CONTROL }}\right.$ (DELGADO) $=80 \% \%, \mathrm{VC}_{\mathrm{RECHAZO}}=$ $66,67 \%$ y VC CONTROL (COLON) $_{1}=86,36 \%, \mathrm{VC}_{\text {EIII }}=73,68 \%$ ).

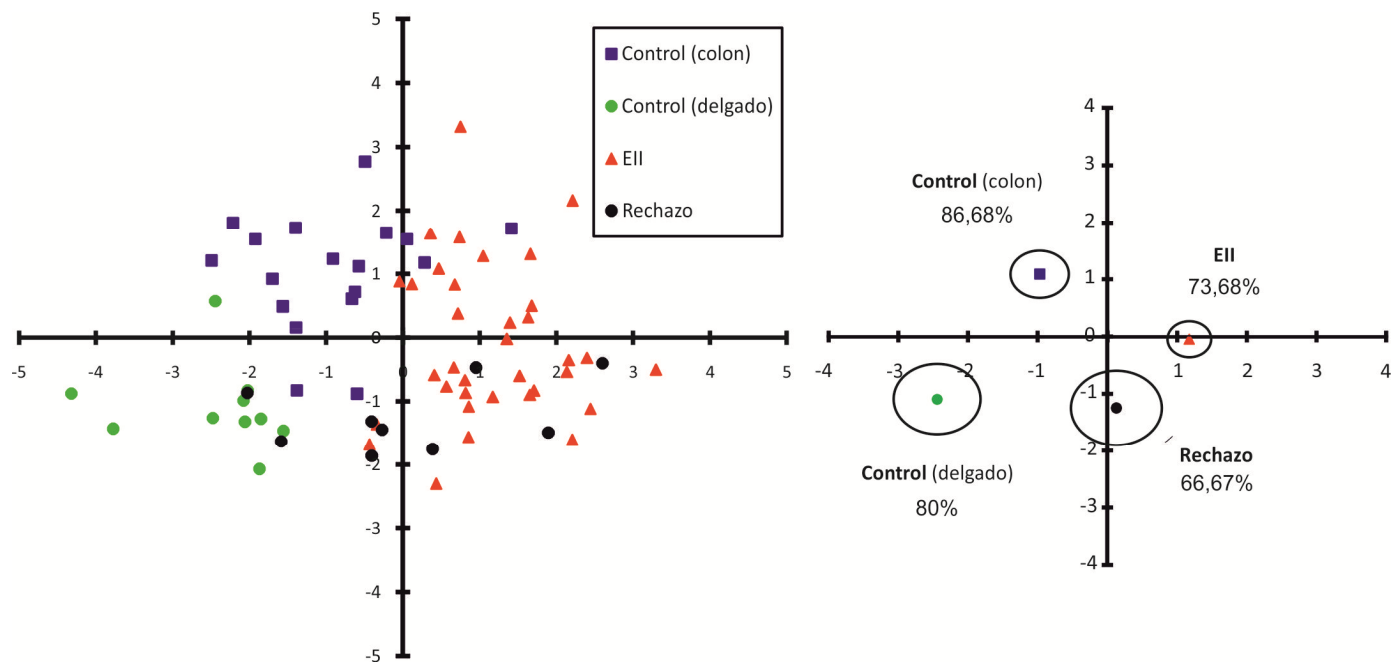

Fig. 1.8: Análisis discriminante de la expresión de Gals en pacientes control, pacientes con Ell y pacientes con rechazo al trasplante de intestino.

Gráfico de componentes principales y gráfico de centroides para pacientes control (colon, $\mathrm{n}=22$; delgado, $n=10)$, pacientes con Ell activa $(n=43)$ y pacientes con rechazo al injerto trasplantado $(n=10)$.

En conjunto, estos resultados muestran que los cambios observados en el patrón de expresión de estas Gals son específicos de cada patología 
inflamatoria. Por lo tanto, inferimos que la expresión de estas lectinas se encuentra modulada en función del proceso inmunopatogénico subyacente.

Además, hemos observado que la expresión génica de Gal-1 se encuentra incrementada en diferentes patologías inflamatorias del intestino. Este hecho puede ser interpretado como una respuesta compensatoria del la mucosa, tendiente a revertir el proceso inflamatorio. 



\section{DISCUSIÓN}

En los últimos años los modelos murinos han revelado que diferentes Gals están relacionadas con la resolución de los procesos inflamatorios intestinales (Nishida y col., 2012; Santucci y col., 2003) y como aquí postulamos, probablemente estén implicadas en las Ell (Lippert y col., 2008; Müller y col., 2006; Paclik y col., 2008). En este estudio describimos por primera vez que la expresión génica de las Gals puede ser utilizada como un marcador que refleje diferentes situaciones inflamatorias del intestino. Analizamos la expresión de Gal-1, -3, -4, y -9 por medio de qPCR en biopsias de colon de 22 pacientes control y 57 pacientes con Ell y observamos que la expresión de estas lectinas puede discernir entre la mucosa inflamada y la mucosa no inflamada, en remisión o control. Asimismo, encontramos que los niveles de ARNm de estas Gals también reflejan el grado de actividad de la enfermedad, y permiten diferenciar entre Ell y otros tipos de inflamación intestinal crónica (enfermedad celíaca) o aguda (rechazo al trasplante de intestino).

Las Gals analizadas en este estudio están ampliamente distribuidas a lo largo de todo el tracto gastrointestinal (Nio-Kobayash y col., 2009) y han sido involucradas en la regulación de la homeostasis intestinal. De hecho, los cambios en la expresión de Gal-1, Gal-3 y Gal-4 serían mecanismos puestos en juego para controlar la inflamación. En relación a Gal-1, dada su capacidad inmunoreguladora, el incremento de sus niveles en el intestino influiría en la sobrevida de las células T de la mucosa (Santucci y col., 2003; Toscano y col., 2007) y en la secreción de IL-10 e IL-27 (Ilarregui y col., 2009; van der Leij y col., 2007). A su vez, Gal-3 controla tanto la sobrevida de los LT activados como la maduración y migración de fibroblastos en la mucosa, mientras que Gal-4 potencia la sinapsis inmunológica, con la consecuente sobre-activación de estas células (Nishida y col., 2012). Por lo tanto, un cambio en sus niveles de expresión podría interpretarse como un mecanismo que la mucosa induce para evitar o controlar una respuesta inmunológica aberrante 
En la primera parte de este trabajo analizamos la expresión génica de Gal$1,-3,-4$ y -9 por qPCR en la mucosa colónica de pacientes control y pacientes con Ell. Pudimos determinar que, en homeostasis, las mismas se expresan de forma homogénea en las diferentes secciones del colon, pero dichos niveles están alterados en las zonas inflamadas de los pacientes con Ell. Sin embargo, el análisis individual de estas Gals no posee suficiente valor predictivo como indicador biológico que pueda ser utilizado para complementar la clínica de los pacientes. De hecho, el análisis individual de estas Gals no permite distinguir el grado de inflamación de la mucosa, y sólo en muy pocos casos logra discernir entre una muestra proveniente de una zona inflamada y una proveniente de un paciente control. Por lo tanto, se realizó un análisis multivariado de la expresión de estas cuatro Gals. Encontramos que el AD puede predecir en el $82 \%$ de los casos la identidad de las muestras con inflamación activa (EIl leve y severa) cuando se las compara con muestras provenientes de mucosa sin alteraciones macroscópicas (pacientes control, Ell no inflamada e Ell en remisión).

Por otra parte, las zonas no inflamadas o en remisión de pacientes con CU o EC no pudieron distinguirse de la mucosa control, lo cual indica que no existen anormalidades intrínsecas en la regulación de estas Gals en este tipo de muestras. Además, observamos que este análisis no pudo discriminar EC activa de CU activa, lo cual significa que la expresión de estas lectinas está igualmente desregulada en ambas condiciones inflamatorias. Por el contrario, cuando se analizaron los niveles de expresión de estas Gals en los tejidos inflamados de pacientes que fueron sometidos a trasplante de intestino y luego sufrieron un rechazo agudo del mismo, se encontró que la expresión génica de estas cuatro lectinas podía distinguir la inflamación crónica de una mucosa por Ell de una inflamación aguda por rechazo del injerto. Otra patología inflamatoria intestinal que fue analizada es la enfermedad celíaca. El $A D$ reveló que el comportamiento de la mucosa en cuanto a la expresión diferencial de estas 4 lectinas es totalmente distinto al de las otras 2 patologías inflamatorias intestinales. De hecho, el empleo de estas 4 Gals no nos permitió diferenciar una mucosa normal de una mucosa con inflamación crónica y activa en un 
paciente celíaco. Sin embargo, ambos grupos resultaron claramente distinguibles de los pacientes con rechazo al trasplante de intestino. Estos hallazgos sugieren que el patrón de expresión de estas Gals es característico de cada patología y podrían estar reflejando los diferentes mecanismos que las gobiernan.

Aunque esta prueba podría utilizarse de manera eficiente para evaluar pacientes con diagnóstico de Ell, como mencionamos anteriormente, la EC no pudo distinguirse de la CU. Por lo tanto, incluimos en este análisis los niveles de expresión de mediadores inflamatorios que han sido descriptos como diferencialmente expresados en ambas patologías (Christophi y col, 2012; Neurath, 2002). Sin embargo, con dicha aproximación tampoco fue posible distinguir entre muestras provenientes de pacientes con $\mathrm{CU}$ y pacientes con EC. Mediante el uso de la curva ROC hemos demostrado que, para diferenciar muestras de Ell de controles, la expresión de estas Gals tiene mayor sensibilidad y especificidad que los marcadores inmunológicos. Con la metodología empleada, el aporte de gata-3, T-bet y stat-4 posiblemente quede enmascarado entre el resto de los tipos celulares que no necesariamente expresan estos mediadores. Probablemente un resultado más claro podría obtenerse si en lugar de aislar el ARNm de la mucosa completa lo hiciéramos de LT activados de la LP. Sin embargo, debido a su complejidad operativa, este procedimiento no sería práctico como una estrategia diagnóstica.

Para remarcar, el $A D$ reveló que las muestras de pacientes control y pacientes con Ell en remisión o zonas sin actividad se comportan de manera similar, y diferente a lo observado en las zonas inflamadas de pacientes con Ell. Este hallazgo sugiere que la inflamación es la condición que provoca la desregulación de las Gals, probablemente para controlar o limitar la condición inflamatoria.

Actualmente se encuentran disponibles marcadores biológicos sanguíneos (VSG, PCR, auto-anticuerpos) y de materia fecal (calprotectina, lactoferrina) que proporcionan herramientas que pueden complementar la evaluación clínica y ayudar en el diagnóstico de las Ell (Abraham \& Thirumurthi, 
2009). Estos marcadores ayudan a diferenciar entre EC y CU, enfermedad activa y en reposo, mucosa en recuperación y recaída de la enfermedad, por lo cual pueden aportar información importante para evaluar la historia de la enfermedad en cada paciente. Sin embargo, la toma de muestras durante la colonoscopia, a pesar de ser una prueba invasiva, sigue siendo el único procedimiento insustituible para evaluar la inflamación de la mucosa (Abraham \& Thirumurthi, 2009).

Teniendo en cuenta que la expresión de las Gals tiene potencial aplicación como marcador pronóstico en diversas patologías intestinales (Demetter y col., 2008; Frol’ová y col., 2009), y que los cambios en la producción de ARNm son eventos rápidos, la expresión de Gals en la mucosa permitiría evaluar el curso de la enfermedad, y de esta manera predecir una posible recaída cuando se sospeche. Asimismo, esta metodología podría emplearse para monitorear el estado de la inflamación de la mucosa una vez que el tratamiento farmacológico se ha iniciado. De hecho, el AD mostró una alta correlación entre los niveles de expresión de estas Gals y el grado de actividad de la inflamación intestinal. Este resultado está en correlación con lo postulado por Kugathasan y col. (2007), donde los autores muestran que la producción de IL-10, IL-12, IL-4 e IFN- $\gamma$ no es uniforme en las EII, sino que cambia conforme evoluciona el curso de la enfermedad (Kugathasan y col., 2007). De manera similar a lo obtenido por Sylvester y colaboradores (2013), estos resultados demuestras la utilidad de los análisis multivariados, en contraposición de los análisis individuales de múltiples marcadores, al momento de evaluar el diagnóstico de una patología y la distinción de grupos dentro de la misma (Sylvester y col., 2013).

Por último, teniendo en cuenta que Gal-1 ha sido ampliamente descripto como una proteína anti-inflamatoria (Rabinovich y col. 1999; Toscano y col. 2011; Santucci y col., 2003; Toscano y col., 2007), y que sus niveles se encuentran significativamente incrementados en la mucosa inflamada de pacientes con diversas patologías inflamatorias intestinales, postulamos que esta lectina podría desempeñar una función compensatoria para controlar la 
inflamación en las Ell. Probablemente el control de la sobrevida de las células Th1 y Th17 (Toscano y col., 2007) que median estas enfermedades y la inducción de los circuitos regulatorios que involucran a las células dendríticas tolerogénicas (Ilarregui y col., 2009) sean los mecanismos inducidos.

En conclusión, hemos mostrado que el análisis conjunto de los niveles de ARNm de Gal-1, -3, -4 y -9 constituye una herramienta útil tanto para distinguir entre pacientes con Ell activa y pacientes control o con Ell inactiva/en remisión como para diferenciar el grado de inflamación de una mucosa o distintas patologías inflamatorias intestinales agudas y crónicas. 



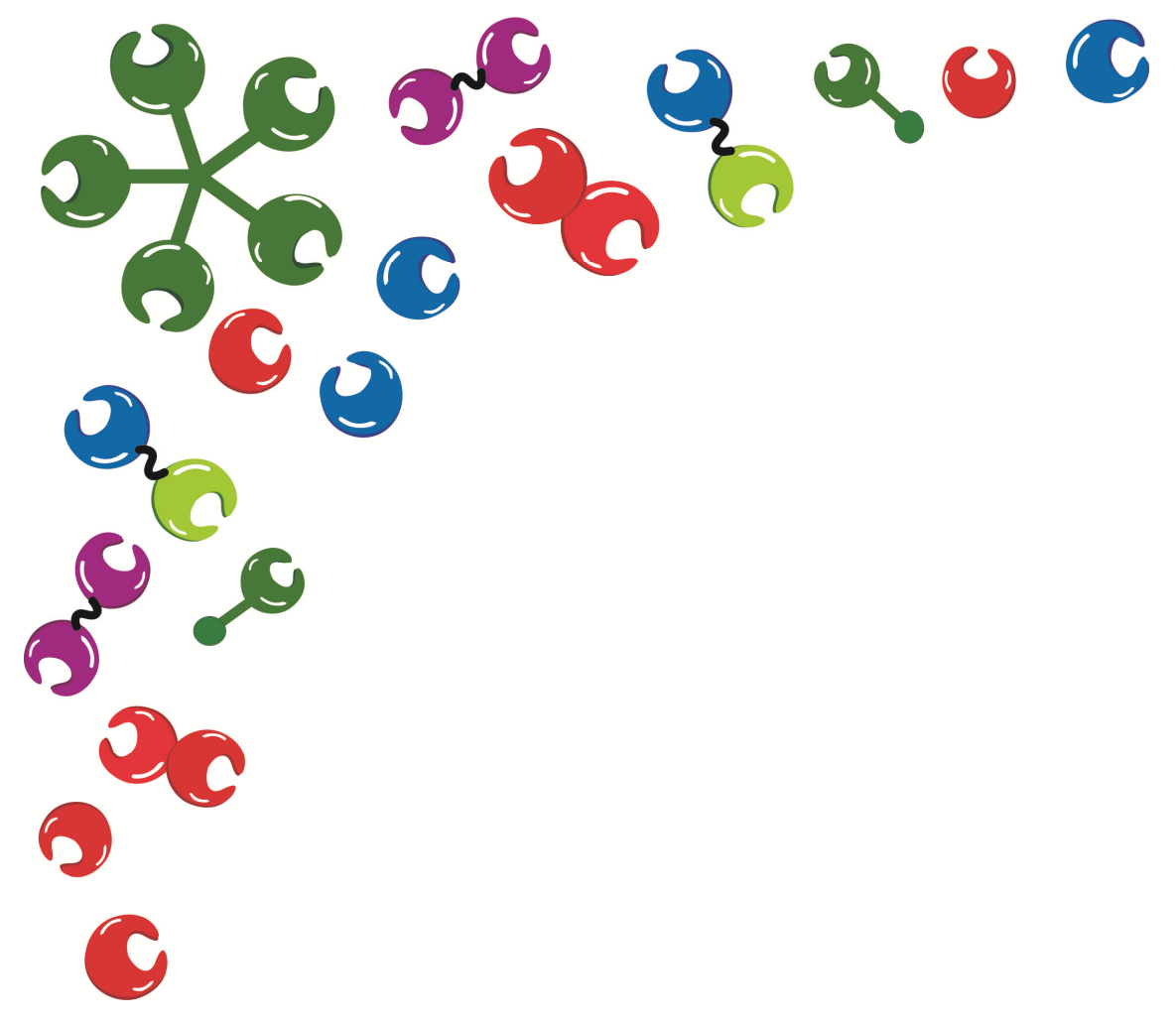

\section{CAPITULO II}

Expresión de galectina-1 en la inflamación intestinal 



\section{INTRODUCCIÓN}

Durante los últimos años se ha asignado a las Gals un papel fundamental en la regulación de la respuesta inmune (Rabinovich y col., 2007). En particular, Gal-1 ha sido implicada en la maduración, migración, activación y sobrevida de los LT tanto a nivel central como periférico (Toscano y col., 2007; Chung y col., 2000; Rabinovich y col., 1997; Ilarregui y col., 2009; van der Leij y col., 2007). Se ha demostrado que esta proteína inhibe la proliferación y expansión clonal de LT activados, mediante mecanismos que involucran el bloqueo de la activación celular (Chung y col., 2000), arresto del ciclo celular (Blaser y col., 1998; Rabinovich y col., 1997) e inducción de apoptosis (Rabinovich y col., 2002; Toscano y col., 2007). A su vez, se ha demostrado que esta proteína, a bajas concentraciones, posee propiedades inmunosupresoras independientemente de su efecto pro-apoptótico. De hecho, Gal-1 es capaz de inhibir la adhesión de LT activados a diferentes proteínas de la matriz extracelular (laminina y fibronectina), la secreción de citoquinas pro-inflamatorias (TNF- $\alpha$ e IFN- - ) y la activación de NF-kB (Rabinovich y col. 1999; Toscano y col. 2011). 
Las propiedades inmunoreguladoras de Gal-1 han sido ampliamente demostradas en diferentes modelos de inflamación crónica y autoinmunidad. Particularmente, se ha demostrado que el aporte terapéutico de Gal-1 (terapia génica o proteica) disminuye la respuesta inflamatoria y las manifestaciones clínicas de la artritis inducida por colágeno en un modelo experimental de artritis reumatoide en ratón (Rabinovich y col., 1999). En dicho modelo el tratamiento provoca un aumento en la susceptibilidad a la apoptosis de los LT auto-reactivos y un desvío de la respuesta inmune hacia un perfil Th2, caracterizado por una disminución en la producción de IFN- $\gamma$ y un incremento de la expresión de IL-5. Estos resultados han sido reproducidos en numerosos modelos de autoinmunidad órgano-específica como la hepatitis inducida por concanavalina $A$, diabetes autoinmune y uveítis autoinmune experimental, entre otros (Baum y col., 2003; Perone y col., 2006; Toscano y col., 2006). Asimismo, en un modelo experimental de rechazo fetal inducido por estrés, se describió que la administración de Gal-1 restaura la tolerancia mediante el desvío de la respuesta inmune hacia un perfil Th2 y la expansión de células T regulatorias (Treg), mecanismos que permiten preservar el desarrollo fetal (Blois y col., 2007).

Asimismo, se ha demostrado que Gal-1 se expresa en numerosos tipos celulares, en situaciones fisiológicas y patológicas (EII, enfermedades tumorales, etc). En particular, diferentes células del sistema inmune son capaces de secretar Gal-1 (LT estimulados con antígenos, células B activadas y células T aloreactivas) (Blaser y col., 1998; Rabinovich y col., 2002; Zúñiga y col., 2001). A su vez, se ha descripto que las Treg expresan niveles superiores de esta proteína respecto a LT efectores, mientras que en ensayos in vitro se demostró que Gal-1 actúa como un mediador clave para la función inmunosupresora de estas células (Garín y col., 2007).

En periferia, la expresión de Gal-1 se halla regulada por el factor de transcripción Blimp-1 y contribuye a la diferenciación de linfocitos $B$ a células plasmáticas (Rabinovich \& Toscano, 2009). Notablemente, Clark y colaboradores, demostraron que los linfocitos $B$ anérgicos expresan mayores 
niveles de ARNm de Gal-1 que las células B convencionales (Clark y col., 2007). A su vez, en modelos experimentales de melanoma, linfoma y carcinoma de pulmón, se demostró que Gal-1 es sintetizada y secretada por células tumorales. Este hecho inhibe el desarrollo de una respuesta inmune Th1 anti tumoral y, por lo tanto, favorece la progresión y escape tumoral (Banh y col., 2011; Rubinstein y col., 2004; Salatino y col, 2013; Soldati y col., 2012).

También se ha demostrado que Gal-1 es importante para el desarrollo de la inmunidad innata y la resolución de la inflamación aguda. En este sentido, Gal-1 inhibe el reclutamiento y degranulación de mastocitos y eosinófilos (Vasta \& Ahmed, 2009), mientras que en neutrófilos bloquea el reclutamiento al sitio de la inflamación y promueve la exposición de fosfatidilserina y posterior muerte celular por apoptosis (La y col., 2003; Rabinovich y col., 2000; Stowell y col., 2007). Asimismo, macrófagos activados producen niveles considerables de Gal-1 (Rabinovich y col., 1996), lo cual regula el balance entre el estado de activación clásico (pro-inflamatorio) o alternativo (anti-inflamatorio) en estas células (Correa y col., 2003). Además, en este tipo de células, Gal-1 inhibe la síntesis de óxido nítrico, ácido araquidónico y prostaglandina $E_{2}$, incrementa la actividad de arginasa e interfiere en la capacidad estimulatoria de células T (Correa y col., 2003; Rabinovich y col., 2000; Rabinovich \& Toscano, 2009).

Considerando el rol clave que Gal-1 ejerce sobre la fisiología de la respuesta inmune (Fig. 2.1), proponemos que existe una desregulación en la expresión o funcionalidad de esta lectina en las Ell. Llamativamente, los ratones Lgal1 $^{-1}$ no muestran marcadas alteraciones a nivel inmunológico (Daniels y col., 2002). Esto se debe probablemente a la variedad de Gals y a la similitud de sus sitios de unión, por lo cual podrían tener una función redundante (Daniels y col., 2002). Sin embargo, la alteraciones de alguna de ellas podría predisponer al desarrollo de una patología (Blois y col., 2007; Toscano y col., 2007). Tal es el caso de la sialoadenitis, patología que aparece espontáneamente en los ratones Lgals $1^{-1}$ de más de 20 meses de edad (Toscano, comunicación personal). En este sentido, los ratones Lgal1 $^{\text {\%- }}$ no desarrollan espontáneamente inflamación intestinal (Muglia y col., 2011), pero sí tardan más tiempo en recuperarse de la 
colitis inducida por TNBS que los ratones salvajes (Morosi y col., 2014). Probablemente estos efectos estén relacionados con la acción profiláctica y terapéutica que la administración de Gal-1 tiene sobre la colitis inducida por TNBS. De hecho, esta lectina induce una reducción tanto en el número de células T de bazo activadas por el hapteno como en la producción de citoquinas inflamatorias (especialmente de IFN- $\gamma$ ) (Santucci y col., 2003). Dichos cambios se traducen en una mejora notable en los aspectos clínicos e histopatológicos de la colitis (Santucci y col., 2003).

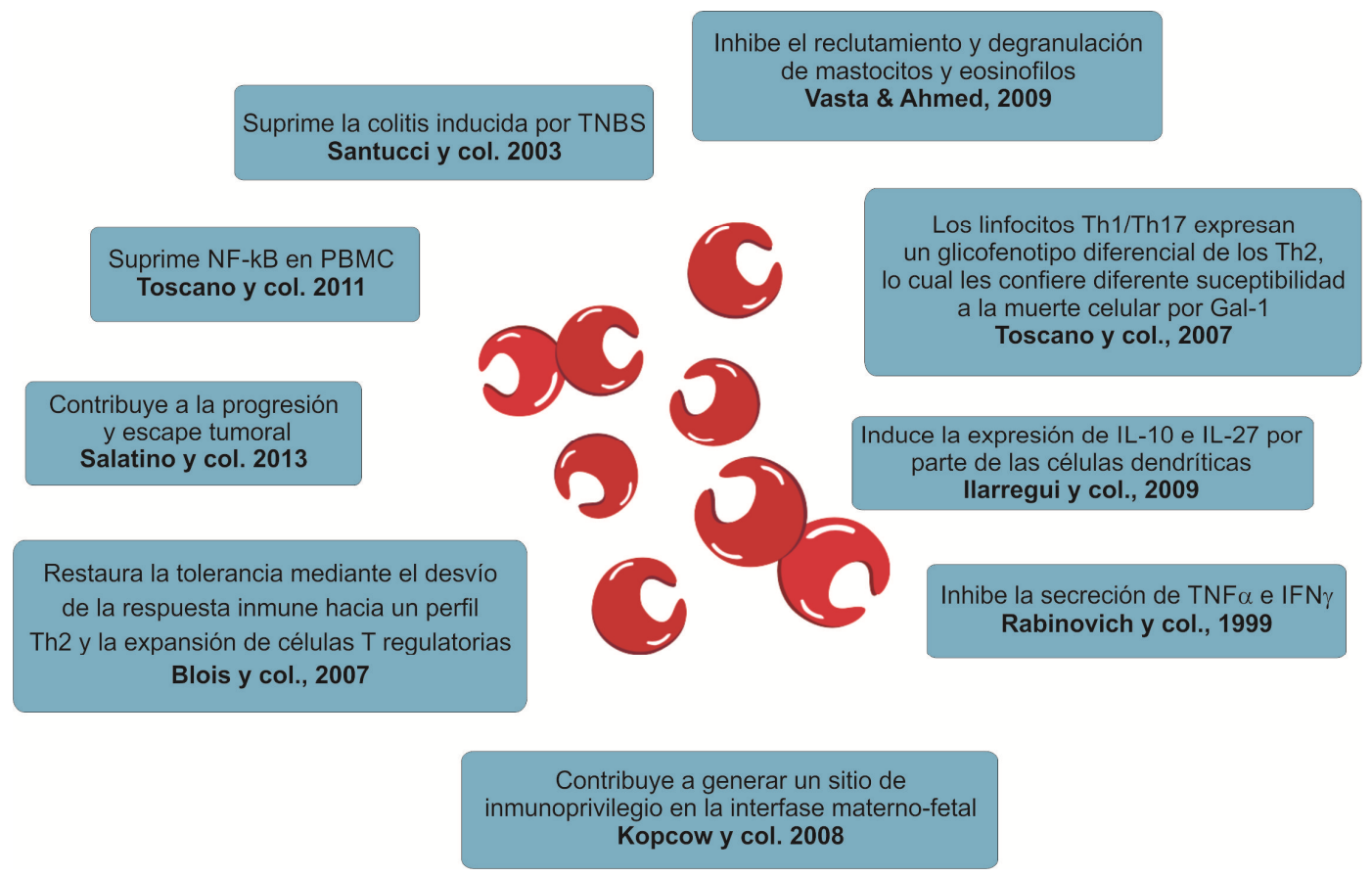

Fig. 2.1: Rol de Gal-1 en la regulación de la respuesta inmune.

Considerando que las Ell son patologías con un fuerte componente Th1/Th17, y que Gal-1 ha sido postulada como una proteína inmunoreguladora con capacidad de inhibir ese tipo de respuestas, proponemos estudiar la expresión de esta lectina tanto en condiciones de homeostasis, como en la respuesta a la inflamación intestinal en muestras de intestino humano y en un modelo murino de colitis. 


\section{OBJETIVOS ESPECÍFICOS}

\section{Evaluar:}

- La expresión de Gal-1 en las diferentes secciones del intestino humano.

- La localización de Gal-1 en la mucosa colónica humana en condiciones de homeostasis

- La expresión de Gal-1 en situaciones de inflamación intestinal crónica en pacientes con Ell y en un modelo murino de colitis aguda. 



\section{RESULTADOS Y CONCLUSIONES PARCIALES}

\section{Gal-1 está diferencialmente expresada en las zonas inflamadas de la mucosa colónica de los pacientes con Ell}

En el capítulo 1 se mostró que la expresión transcripcional de Gal-1 es constitutiva y homogénea en todos los segmentos del colon, y que los niveles de ARNm están incrementados en las zonas inflamadas de pacientes con Ell (Fig. 1.1). Utilizando biopsias de pacientes control se estudió por inmunoblotting la producción de esta proteína en distintas regiones del colon (Fig. 2.2 A). Se encontró que, a nivel de proteína, Gal-1 es producida de manera constitutiva en todos los segmentos del intestino grueso (Fig. 2.2 A). Mediante ensayos de inmunohistoquímica y $\mathrm{qPCR}$ se observó que esta proteína se expresa fundamentalmente en LP de la mucosa colónica (Fig. 2.2 B y C).

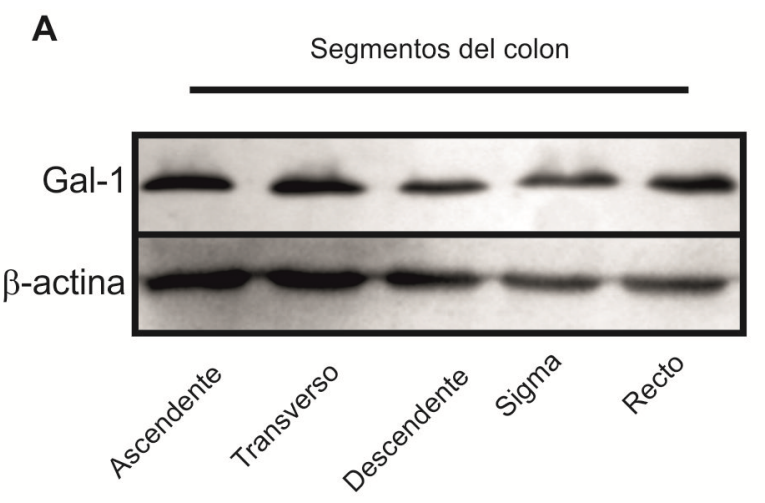

B

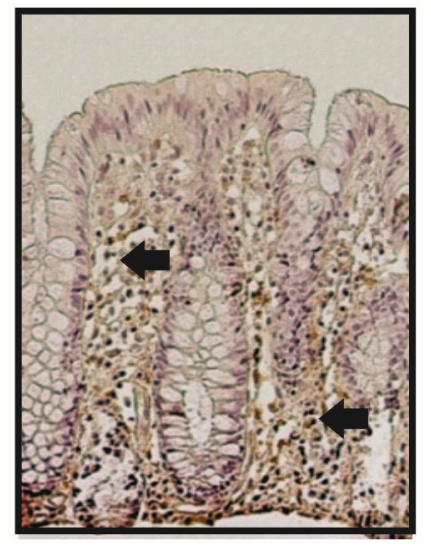

C

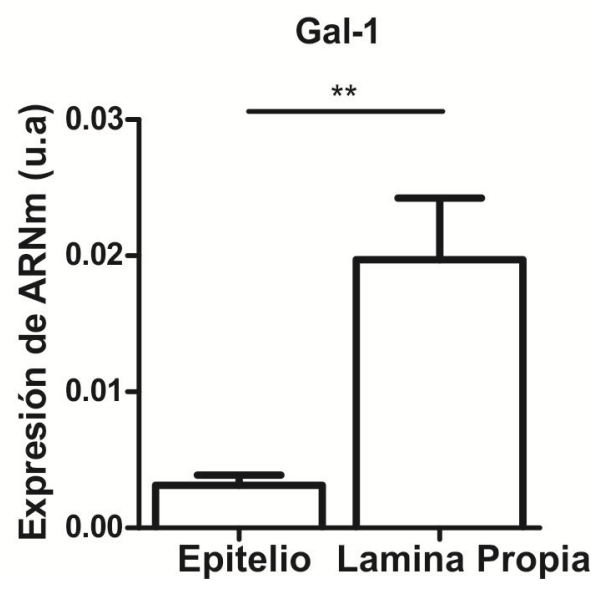


Fig. 2.2: Expresión de Gal-1 en la mucosa colónica de pacientes control.

A) Niveles de Gal-1 por inmunoblotting en las diferentes regiones del colon. $\beta$-actina se utilizó como control de carga. B) Gal-1 por inmunohistoquímica en la mucosa colónica de pacientes control. Las flechas negras indican los lugares con mayor expresión de la proteína. C) Expresión de LGALS1 en el compartimiento epitelial y en la lámina propia en pacientes control ( $n=5)$. Los resultados de la $\mathrm{RT}-\mathrm{qPCR}$ se muestran como la media \pm ESM. ${ }^{* *} \mathrm{p}<0.01$.

Una vez dilucidada la expresión y localización de Gal-1 en el colon de pacientes control procedimos a estudiar los niveles de expresión de ARNm de Gal-1 en biopsias de pacientes con Ell. Encontramos que la mucosa inflamada de pacientes con CU y EC muestra niveles significativamente aumentados de LGALS1 en comparación con la mucosa no inflamada y la mucosa de los pacientes control (Fig. 2.3. A). Sin embargo, al analizar los niveles de producción de Gal-1 encontramos que la mucosa inflamada de pacientes con CU y EC presenta menores niveles de esta proteína en comparación con la mucosa no inflamada (Fig. 2.3 B y C). Estos resultados, en principio contradictorios, sugieren la participación de diferentes mecanismos en la regulación de la expresión génica y la producción o persistencia de Gal-1 en la mucosa colónica de pacientes con Ell. Teniendo en cuenta que Gal-1 ha sido descripta como un inductor de apoptosis en LT (Toscano y col., 2007), el incremento en los niveles de ARNm de esta lectina podría ser un mecanismo fisiológico tendiente a controlar la inflamación. Pero, por otro lado, también sugiere la existencia de otros mecanismos que regulan los niveles de esta proteína. 


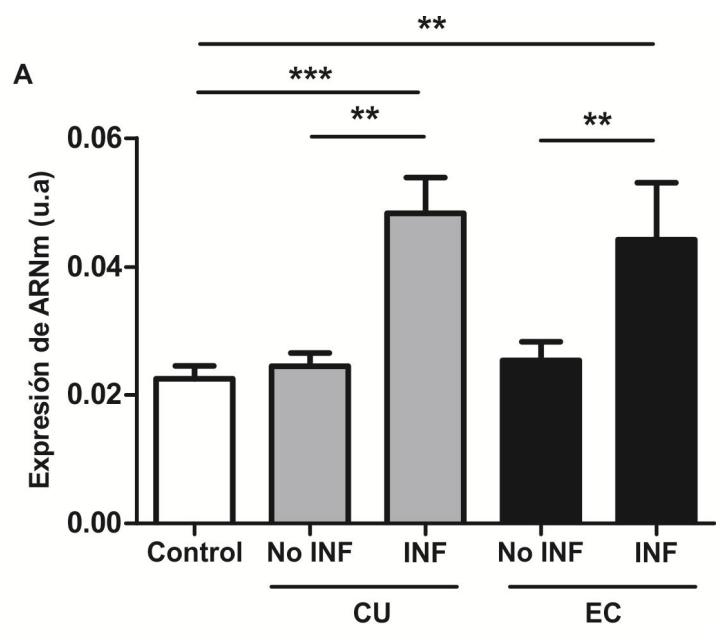

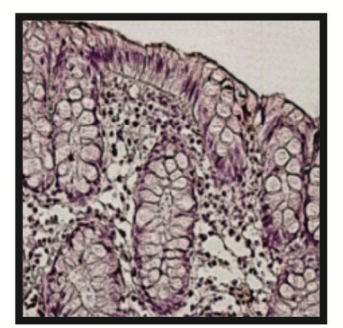

No Inflamado
CU

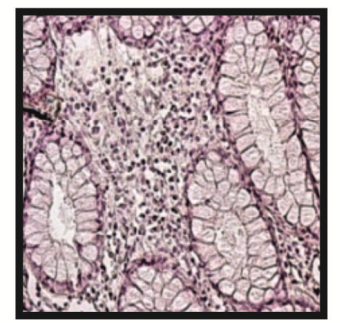

Inflamado

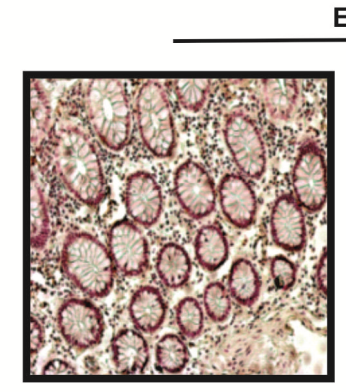

No Inflamado

EC

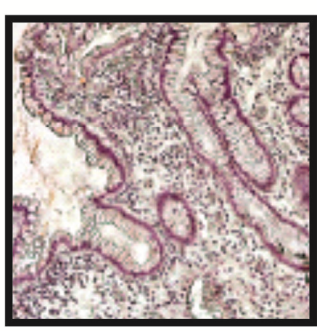

Inflamado
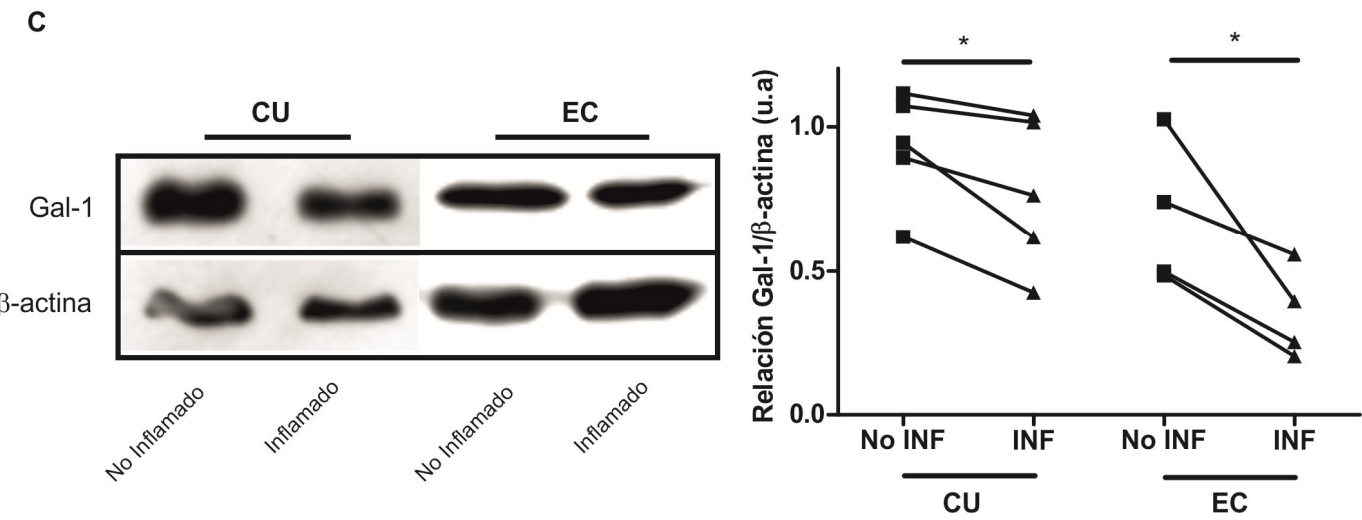

Fig. 2.3: Expresión de Gal-1 en biopsias de pacientes con Ell.

A) Niveles de expresión de LGALS1 en biopsias de pacientes control ( $n=22)$ y de pacientes con CU $(n=25)$ y EC $(n=18)$ (zonas inflamadas y no inflamadas). Los resultados de la RT-qPCR se muestran como la media \pm ESM. B) Inmunohistoquímicas para Gal-1 en mucosa de pacientes representativos con CU y EC (zonas no infamadas e inflamadas). C) Inmunoblotting para Gal-1 y $\beta$-actina en pacientes con CU y EC (zonas no infamadas e inflamadas). Se muestran 2 casos representativos de los 5 pacientes con CU y los 4 con EC analizados. Relación Gal-1/ $\beta$-actina entre las zonas no inflamadas e inflamadas de pacientes con CU ( $n=5$ ) y EC $(n=4)$, obtenidos a partir del inmunoblotting. NO INF: no inflamado; INF: inflamado. *p<0.05, $* * \mathrm{p}<0.01, * * * \mathrm{p}<0.001$. 
A fin de profundizar estos estudios y comprender la complejidad del sistema, recurrimos al empleo de dos modelos: un modelo murino de colitis aguda y un cultivo de órgano empleando biopsias de pacientes control.

\section{Los niveles de Gal-1 aumentan en un modelo de colitis inducida por TNBS}

Con el objetivo de analizar si un ambiente inflamatorio in vivo induce un incremento en los niveles de Gal-1 en la mucosa intestinal se utilizó un modelo murino de colitis experimental. Ratones BALB/c fueron tratados por vía rectal con etanol 50\% y $5 \mathrm{mg}$ de TNBS (grupo colitis) o con etanol 50\% (grupo control). Observamos que los ratones tratados con TNBS desarrollaron rápidamente una colitis con marcada pérdida de peso (Fig. 2.4 A), diarrea, sangrado y un significativo incremento en el índice de actividad de la enfermedad (IAE) (Fig. 2.4 B). El examen morfológico del intestino mostró que, en comparación con los ratones control, los ratones tratados con TNBS presentan un significativo incremento en la relación peso/longitud del colon (Fig. 2.4 C). A nivel histológico, encontramos que el TNBS produjo edema del colon, criptas hiperproliferativas e infiltrado mononuclear en la LP, y un marcado aumento en el índice de actividad histológico (IAH) (Fig. $2.5 \mathrm{D}$ y E). Todos estos hallazgos indican la presencia de un proceso inflamatorio en la mucosa colónica. Con el fin de cuantificar este proceso inflamatorio se analizó la expresión génica de marcadores inmunológicos por qPCR. Como puede observarse en la figura $2.4 \mathrm{~F}$, encontramos que los ratones tratados con TNBS presentaron incrementos significativos en los niveles de ARNm de Tnf- $\alpha$, T-bet e Inf- $\gamma$. 
A

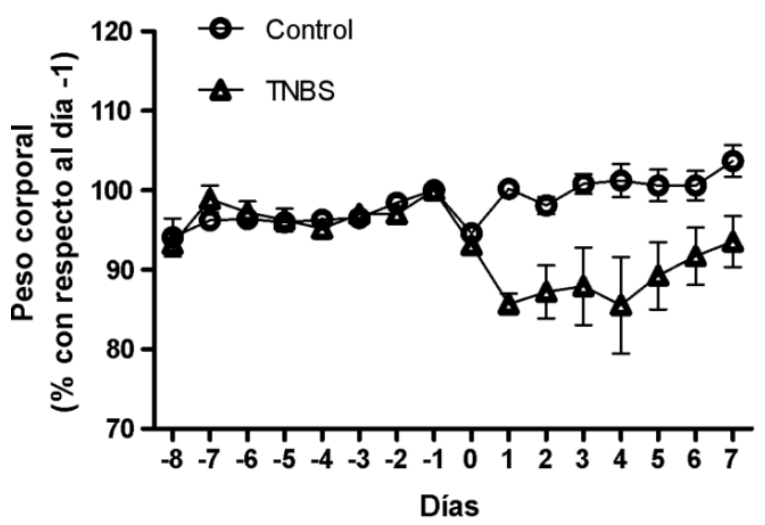

B

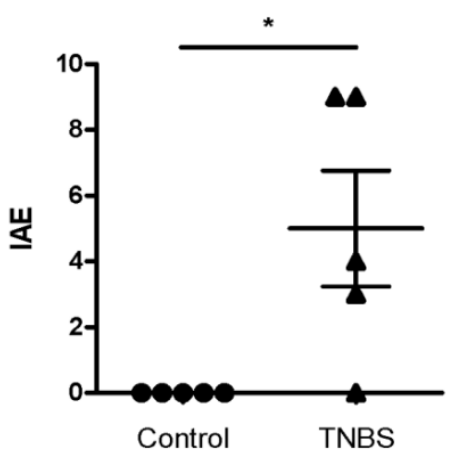

C

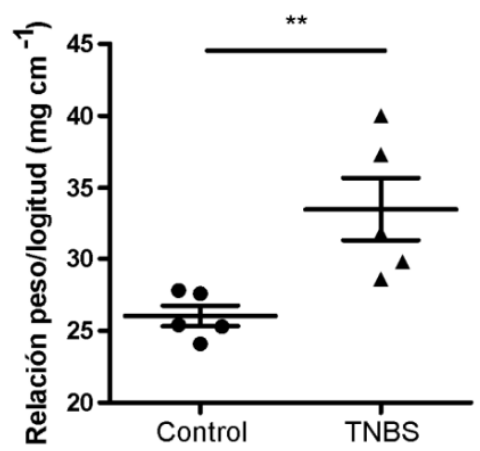

E

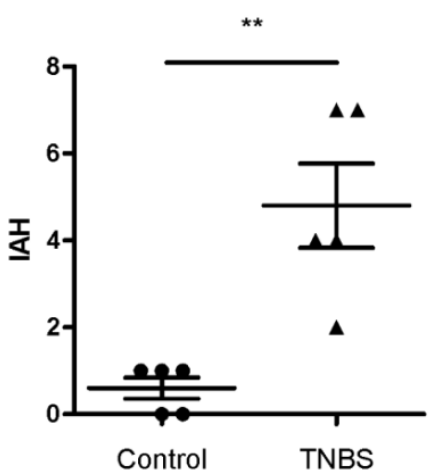

D
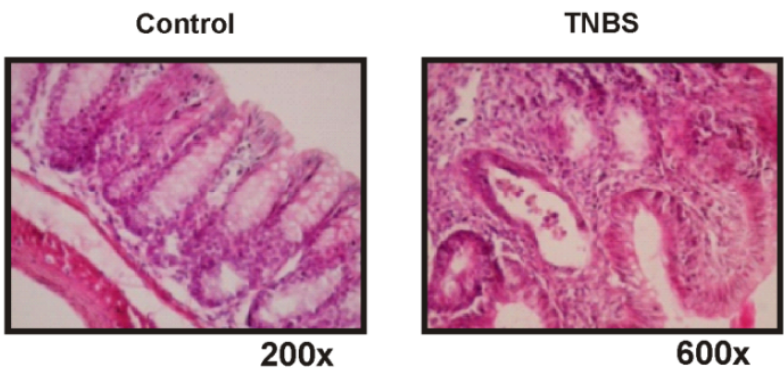

*

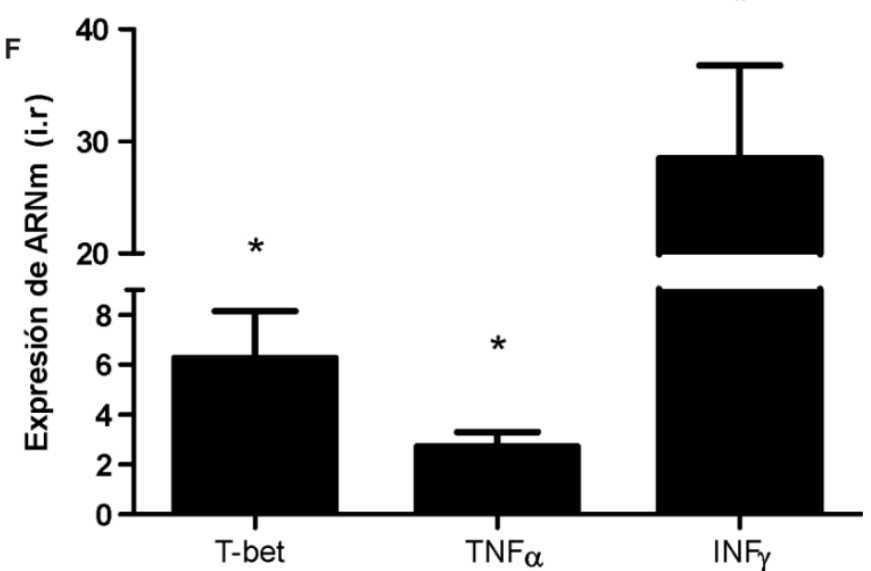

Fig. 2.4: Modelo murino de colitis inducido por TNBS.

Ratones BALB/c $(n=5)$ fueron tratados con etanol $50 \%$ y $5 \mathrm{mg}$ de TNBS (grupo colitis) o etanol 50\% (grupo control). A) Monitoreo del peso corporal diario durante el estudio. B) Índice de actividad de la enfermedad al día 7. C) Relación longitud/peso del intestino. D) Análisis histopatológico del colon por medio de la tinción con hematoxilina-eosina. E) Índice de actividad histológico. F) Expresión relativa de Tnf- $\alpha$, T-bet e Ifn- $\nu$ por qPCR. Los niveles de ARNm se muestran como el incremento relativo en función a la media del grupo control. En todos los casos los resultados se muestran como la media \pm ESM. IAE: índice de actividad de la enfermedad. IAH: índice de actividad histológico. $\left.{ }^{*} \mathrm{p}<0,05 ;{ }^{*} \mathrm{p}<0,01\right)$ 
Al analizar este modelo de colitis aguda la expresión de Gal-1 en el colon, observamos que, al inducir la inflamación intestinal, se produce un incremento en los niveles de Gal-1, tanto a nivel transcripcional como de proteína (Fig. 2.5 A, B y C).

A
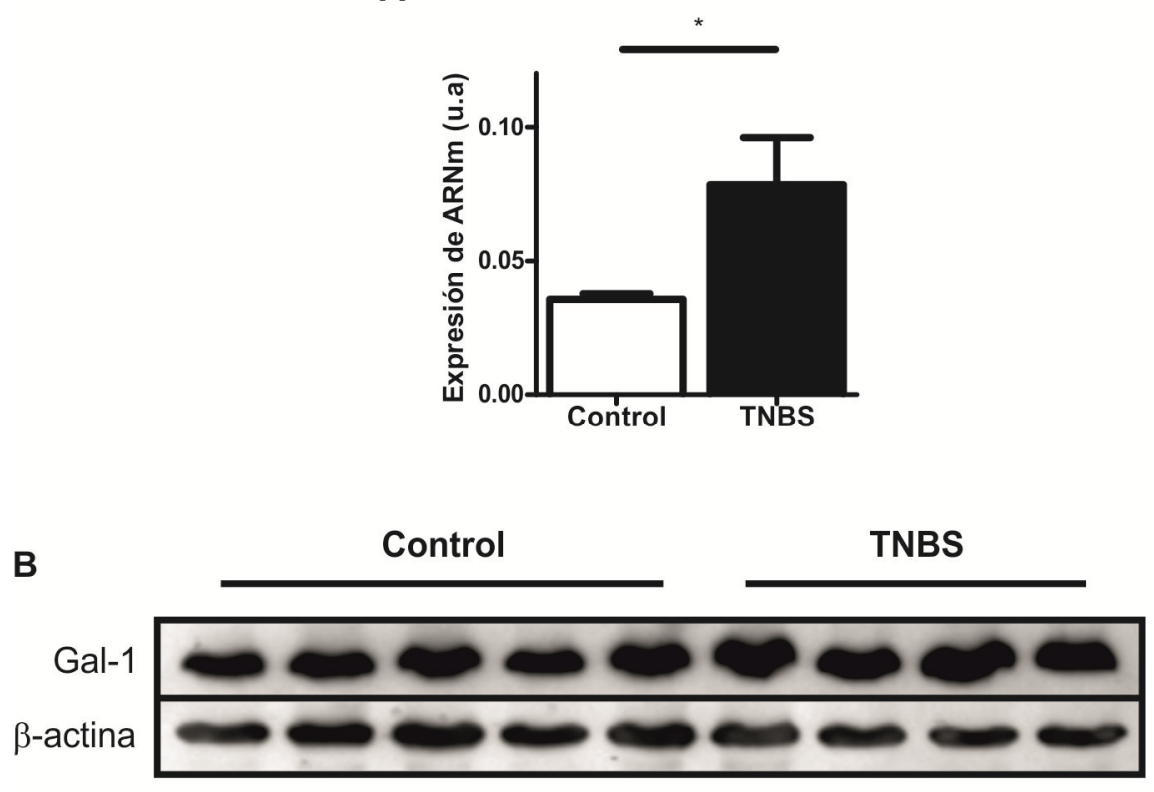

C

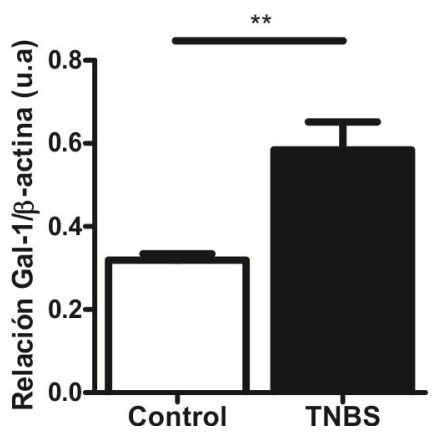

Fig. 2.5: Expresión de Gal-1 en el colon de ratones del modelos de colitis inducido por TNBS.

Se analizaron muestras de colon de ratones BALB/C por PCR cuantitativa y SDS PAGE y western blot (grupo control, $n=5$, grupo colitis, $n=4$ ). Los niveles de Gal-1 (ARNm y proteína) se normalizaron según los de $\beta$-actina. A) Niveles de expresión de Lgals1 por qPCR. B) Inmunoblotting para Gal-1 en animales control y animales tratados con TNBS. C) Relación Gal$1 / \beta$-actina de la intensidad de las bandas (en unidades arbitrarias) en los ratones control y los ratones tratados con TNBS. Los resultados se expresan como la media \pm ESM $\left({ }^{*} p<0.05 ;{ }^{* *}\right.$ $p<0,01)$. 
Por lo tanto, utilizando un modelo in vivo de inflamación aguda pudimos determinar que la respuesta fisiológica de la mucosa intestinal frente a una inflamación aguda es incrementar los niveles de Gal-1.

TNF- $\alpha$ induce la expresión de Gal-1 en la mucosa colónica humana, pero las proteasas secretadas por los miofibroblastos ejercen una acción proteolítica sobre esta lectina

Con el fin de determinar los efectos que un medio ambiente proinflamatorio tiene sobre la mucosa intestinal, biopsias de pacientes control fueron incubadas durante 16 hs en presencia de rhTNF- $\alpha$. Observamos que el sólo hecho de incubar las biopsias con medio de cultivo como control durante estos periodos de tiempo, induce una reducción del 50\% en los niveles de ARNm de Gal-1 (Fig. 2.6 A). Sin embargo, el agregado de las diferentes concentraciones de rhTNF- $\alpha(1,5$ y $10 \mathrm{ng} / \mathrm{mL})$ indujo un incremento significativo de los niveles de LGALS1 en comparación a las muestras incubadas sólo con medio (incremento en la expresión de LGAL-1 respecto al control= $38 \% ; 56 \%$ y $42 \%$ respectivamente). Este resultado está en concordancia con lo observado en la patología (Fig. $2.3 \mathrm{~A}$ ), donde las zonas inflamadas presentan un incremento significativo en los niveles de expresión de ARNm de Gal-1. Sin embargo, al estudiar mediante inmunoblotting los niveles de proteína de Gal-1, se encontró que éstos fueron menores en la mucosa inflamada en comparación con la mucosa no inflamada (Fig. 2.3 B y C).

Considerando que una de las posibles explicaciones a este fenómeno sería que la Gal-1 fuese degradada in situ en las zonas inflamadas de pacientes con Ell, decidimos estudiar si el sobrenadante de fibroblastos aislados de muestras colónicas de pacientes con CU y EC contiene proteasas capaces de alterar la integridad de esta lectina. Esta hipótesis se apoya en trabajos previos en donde se encontró que en la mucosa inflamada de pacientes con Ell se expresan mayores cantidades de proteasas, en especial metaloproteasas (MMPs) 1, 3, 9, 12 y 14, que en la mucosa colónica de pacientes control (Kirkegaard y col., 2004; Sengupta \& MacDonald, 2007). Además, se ha 
demostrado que la MMP7 tiene la capacidad de degradar Gal-3 (Puthenedam y col., 2011).

Para comprobar esta hipótesis, y sobre la base que los fibroblastos son una fuente conocida de proteasas, incubamos rhGal-1 con el sobrenadante de cultivos de fibroblastos provenientes de zonas inflamadas de pacientes con Ell y pacientes control durante 2 y 24 hs. La degradación proteica fue evaluada por SDS PAGE/ western blot. Como puede observarse en la figura 2.6 B, los sobrenadantes de cultivo obtenidos a partir de zonas inflamadas de pacientes con Ell tienen componentes con capacidad de degradar la rhGal-1. Contrariamente, los sobrenadantes de cultivos de fibroblastos obtenidos a partir de pacientes control no muestran capacidad de clivar esta lectina. 
A

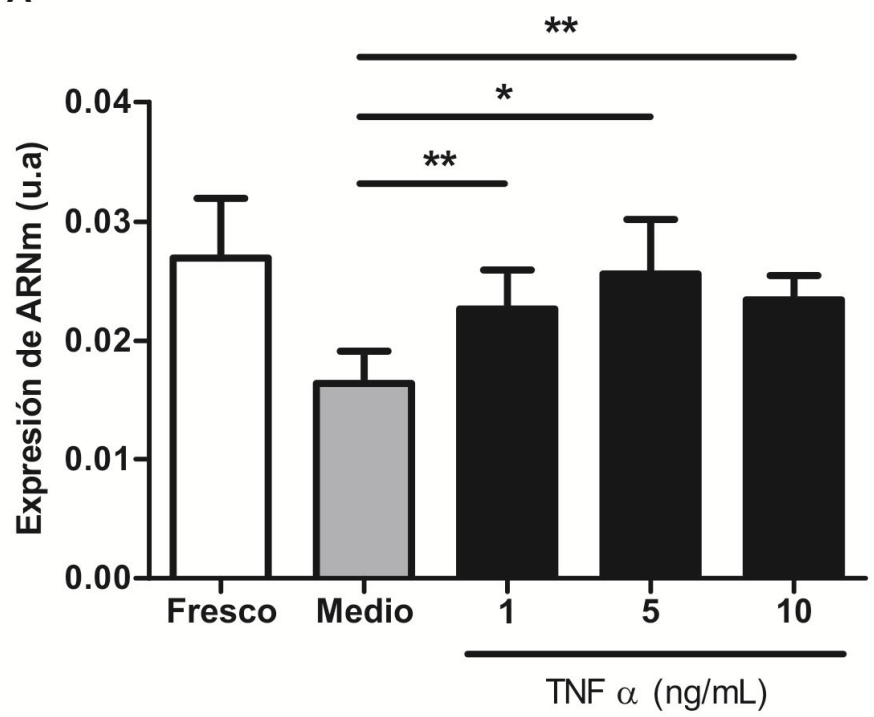

B

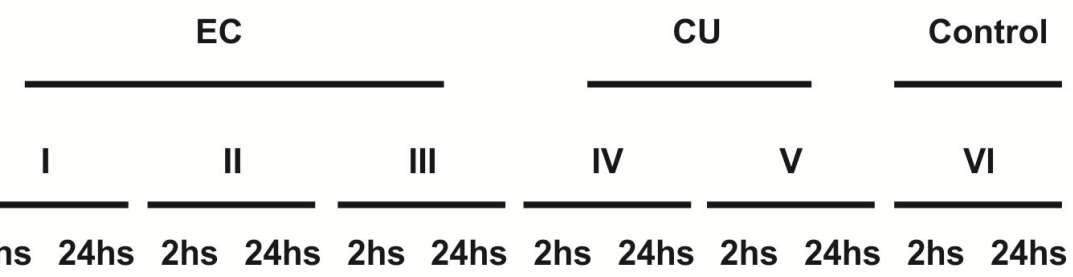

C
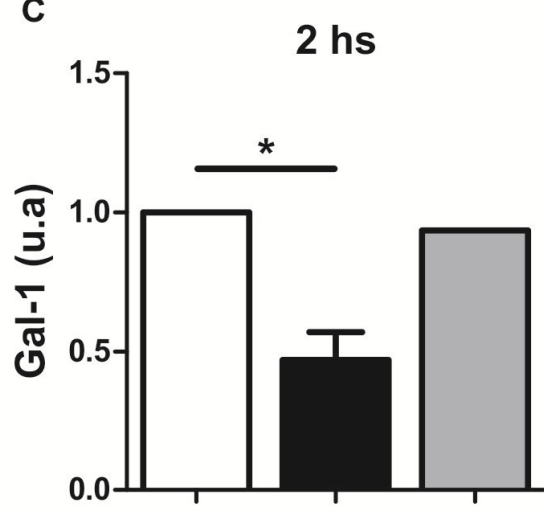

Medio

$(+)$

$(-)$

$(-)$

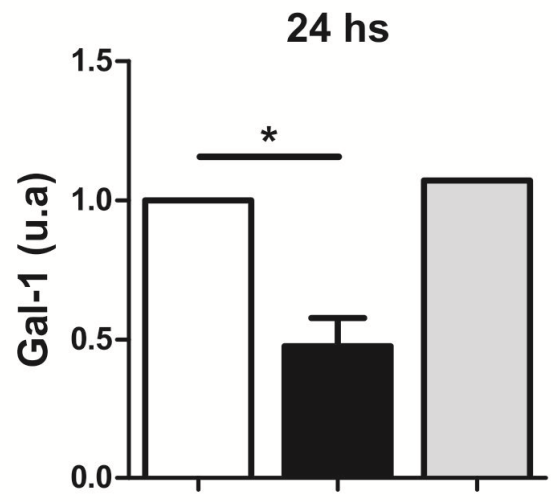

Sobrenadante de fibroblastos (EII)

Sobrenadante de fibroblastos (control)

$(-) \quad(+) \quad(-)$

$(-) \quad(-) \quad(+)$
(+)

$(-)$

$(-)$
$(+)$

$(-)$

$(-) \quad(-)$

(+)

Fig. 2.6: TNF- $\alpha$ induce la expresión de Gal-1 mientras que las proteasas presentes en sobrenadantes de fibroblastos la degradan.

A) Niveles de expresión de LGALS1 en biopsias de pacientes control incubadas con TNF- $\alpha(n=9)$. Las muestras de tejido fueron incubadas durante 16hs con RPMI completo (control) o con RPMI 
completo y TNF- $\alpha$ (1, 5 o $10 \mathrm{ng} / \mathrm{mL}$ de TNF- $\alpha$ ). Los niveles de ARNm de Gal-1 se expresan como la media \pm ESM. B) Inmunoblotting de Gal-1 incubada con diferentes sobrenadantes provenientes de cultivos de fibroblastos aislados a partir de pacientes con CU, EC y de pacientes control. En cada calle se sembró $10 \mu \mathrm{L}$ de rhGal-1 $(1 \mathrm{mg} / \mathrm{mL})$ y se reveló con un anti-Gal-1 policlonal. C) Cuantificación de la intensidad de las bandas (en unidades arbitrarias). Los resultados se muestran como el cociente entre las muestras incubadas con sobrenadante del cultivo de fibroblastos (obtenidos a partir de zonas inflamadas de pacientes con Ell y pacientes control) y las incubadas con medio de cultivo. ${ }^{*} p<0.05 ; * *<<0.01$.

Por lo tanto, sobre la base de estos resultados, proponemos que el entorno inflamatorio del colon en pacientes con Ell sería el responsable de la degradación local de Gal-1. Este hallazgo permite comprender la disociación encontrada entre los niveles de ARNm de Gal-1 y de proteína en el tejido inflamado de pacientes con Ell. 


\section{DISCUSIÓN}

La respuesta inmune se caracteriza por la permanente activación celular y acción coordinada de mediadores pro- y anti-inflamatorios (Vallabhapurapu \& Karin, 2009). En la mucosa intestinal numerosos y complejo mecanismos inmunológicos son continuamente estimulados, provocando un estado constante de inflamación controlada (Wullaert, 2010). En este escenario intervienen mecanismos compensatorios que constantemente controlan la inflamación, evitando así el daño tisular (Garrett y col., 2010; Xavier \& Podolsky, 2007).

Gal-1 es una lectina endógena con un predominante rol inmunosupresor (Perone y col., 2006; Rabinovich y col., 1999; Toscano y col., 2006). De hecho, ratones Lgals1\% desarrollan espontáneamente patologías autoinmunes con mayor severidad y demoran más tiempo en recuperarse de una colitis inducida por TNBS (Blois y col., 2007; Toscano y col., 2007; Morisi y col., 2014). Además se ha demostrado que en el contexto de la inflamación intestinal, la administración profiláctica y terapéutica de rhGal-1 logra prevenir, e incluso revertir la colitis inducida por TNBS (Santucci y col., 2003). Teniendo en cuenta estos antecedentes nos propusimos estudiar el rol de Gal-1 en la mucosa intestinal humana.

En este trabajo hemos demostrado que Gal-1 se expresa constitutivamente en la LP del colon en condiciones de homeostasis. Como se mostró previamente, los niveles de expresión de ARNm para esta lectina se encuentran significativamente incrementados en las zonas inflamadas de pacientes con Ell. Sin embargo, los niveles de proteína para Gal-1 se encuentran disminuidos en dichos tejidos. En base a nuestra hipótesis inicial sobre el posible rol de las proteasas presentes en el tejido inflamado en pacientes con ElI, decidimos investigar la disociación entre niveles de ARNm y proteína. Al igual que en el resto de los tejidos, el intestino responde frente a la inflamación crónica tratando de restaurar la integridad y arquitectura dañada a través del 
proceso de cicatrización. La migración de fibroblastos hacia la zona inflamada resulta esencial durante la etapa inicial de cicatrización (Biancheri y col., 2014).

Sin embargo, cuando la severidad o extensión del daño supera la capacidad regenerativa del órgano, la persistencia de los fibroblastos provoca la acumulación de tejido cicatrizal, dando origen al proceso denominado fibrosis (Rieder \& Fiocchi, 2009). A su vez, las citoquinas presentes en el tejido (principalmente TGF- $\beta$ ) inducen la transformación de fibroblastos en miofibroblastos (Sengupta \& MacDonald 2007). Los miofibroblastos son células claves para la fibrosis, ya que durante la remodelación tisular secretan MMPs y peptidasas que degradan la matriz extracelular. Dada su capacidad de generar daño tisular, la actividad de las MMPs está bajo un estricto control por parte de sus inhibidores, los TIMPs (Nagase \& Woessner, 1999).

En condiciones patológicas, como en las Ell, los miofibroblastos de la mucosa pierden su capacidad de migración y son continuamente estimulados por la exposición a numerosos mediadores inflamatorios (Biancheri y col., 2014). El desbalance en el eje MMPs/TIMPs ocasiona la consecuente lesión de la mucosa con la aparición de úlceras y fístulas (Biancheri y col., 2014). Trabajos previos han demostrado que la MMP7 tiene la capacidad de degradar a Gal-3, y que dicho clivaje inhibe su acción regeneradora sobre la línea epitelial T84 (Puthenedam y col., 2011).

En conjunto, estos antecedentes nos llevaron a pensar que, al igual que con Gal-3, en el tejido inflamado podrían existir proteasas que degraden a Gal1 , hecho que permitiría explicar la disociación entre los elevados niveles de ARNm para Gal-1 y los bajos niveles de proteína. Encontramos que en el sobrenadante de fibroblastos aislados del colon de pacientes con CU y EC existen proteasas que serían las responsables de la degradación de Gal-1. Por otra parte, el sobrenadante de cultivo de fibroblastos de colon proveniente de pacientes control no muestra capacidad de clivar esta lectina. Estos resultados son coherentes con Kikegaard y colaboradores (2004), en donde dichos autores muestran que los fibroblastos presentes en la mucosa inflamada de pacientes con Ell expresan mayores cantidades de proteasas (en especial MMPs) que los 
fibroblastos presentes en la mucosa colónica de pacientes control (Kirkegaard y col., 2004).

En este estudio mostramos que, en condiciones de homeostasis, Gal-1 es expresada y secretada a la matriz extracelular de la LP. Si bien trabajos previos han descripto la localización de esta lectina en la mucosa intestinal (Nio-Kobayashi y col., 2009), ésta es la primera vez que se evalúa en humanos.

Considerando que Gal-1 es expresada normalmente en sitios de inmunoprivilegio (Kopcow y col., 2008; Rabinovich y col., 2002; Uehara y col., 2001), es razonable suponer que esta lectina está intrínsecamente relacionada con la mantención de la homeostasis intestinal. De hecho, esta lectina podría estar contribuyendo a generar un ambiente tolerogénico tendiente a controlar el continuo desafío antigénico por parte de la microbiota (Garrett y col., 2010; Xavier \& Podolsky, 2007). Por lo tanto, sugerimos que el aumento en la transcripción de esta proteína en las zonas inflamadas de pacientes con Ell podría formar parte de un mecanismo compensatorio que tienda a controlar la inflamación. De hecho, cuando la inflamación fue inducida experimentalmente, ya sea en el modelo de colitis o cultivando las biopsias de pacientes control ex vivo con TNF- $\alpha$, encontramos que los niveles de Gal-1 aumentan.

Estos resultados confirman que la respuesta normal de la mucosa frente a un estímulo inflamatorio es incrementar los niveles de esta lectina como un posible mecanismo fisiológico para controlar la sobrevida de la población T. Dicho incremento podría estar asociado con la activación de NF-kB, una de las vías más descriptas como disparadores de la inflamación en trastornos inflamatorios intestinales (Schreiber y col., 1998; Wullaert, 2010).

La asociación entre Gal-1 y NF-kB fue puesta de manifiesto por Toscano y colaboradores (2011). Dichos autores demostraron que en células mononucleares de sangre periférica (PBMC) la activación NF-kB por TNF $\alpha$ induce la transcripción de Gal-1. A su vez, la secreción de esta lectina inhibe de manera autocrina a NF-kB (Toscano y col., 2011).

De manera coherente con estos hallazgos, nosotros hemos encontrado que en enfermedad celíaca, en la cual los niveles de TNF- $\alpha$ están disminuidos 
(Bondar \& Chirdo, resultados no publicados), no se observan incrementos en los niveles de Gal-1 en la mucosa en relación con los controles. Sin embargo, la expresión de esta lectina se encuentra incrementada (a nivel de ARNm) en las zonas inflamadas de pacientes con Ell y en las biopsias provenientes de pacientes con rechazos al trasplantes de intestino (Fig. 1.7 D). Por lo tanto, nuestros resultados estarían sugiriendo un rol inmunoregulador para Gal-1 en la fisiología del intestino y confirmarían que esta lectina tiene relevancia en la fisiopatología de las Ell, como lo postularon Santucci y colaboradores (2003).

En conclusión, utilizando un modelo murino de colitis y el cultivo ex vivo de biopsias demostramos que la respuesta de la mucosa frente a un entorno inflamatorio agudo es incrementar los niveles de Gal-1. Sin embargo, esta lectina se encuentra disminuida en los tejidos inflamados de pacientes con Ell, lo cual puede explicarse por la acción de las proteasas secretadas por fibroblastos. Posiblemente la degradación de Gal-1 afecte su rol en la resolución de los procesos inflamatorios y contribuya a la cronicidad de la enfermedad 


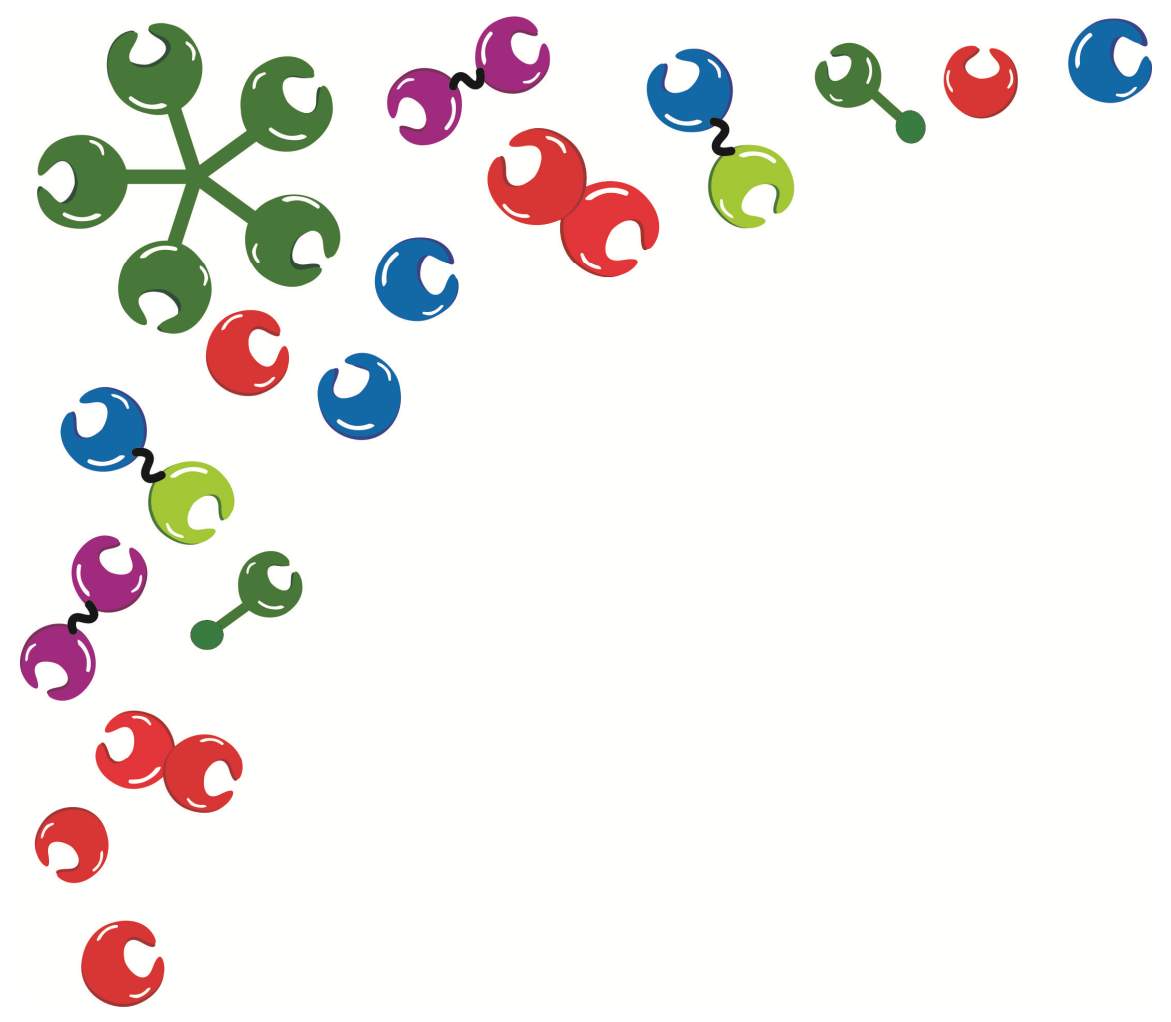

CAPITULO III

Modulación del efecto pro-apoptótico de galectina-1 sobre los linfocitos $T$ en el entorno inflamatorio de las EII 



\section{INTRODUCCIÓN}

Como se mencionó en secciones anteriores, existe un consenso sobre los mecanismos aberrantes del sistema inmune que participan en el desarrollo de las Ell. Si bien se ha descripto la contribución de numerosos factores en el establecimiento y permanencia del foco inflamatorio (Baumgart \& Carding, 2007b; Neurath, 2014), es sabido que los LT cumplen un rol central en la fisiopatología de la enfermedad (Neuman, 2007).

Es ampliamente conocido que en una mucosa en homeostasis los LT se activan en forma antígeno-específica. El control y erradicación del estímulo determinan que se inicien los mecanismos tendientes a suprimir la población de LT activados a fin de atenuar la respuesta inmune y restituir la fisiología del órgano (Mowat y col., 2004; Strober y col., 2003). Este proceso constituye uno de los mecanismos centrales para controlar la sobrevida de las células activadas, y si bien suele ser sumamente eficiente y altamente regulado, fallas 
en el mismo han sido registradas no sólo en las Ell, sino también en la diabetes, el asma y la artritis reumatoide, entre otras inmunopatologías (Neuman, 2007).

Como se muestra en la figura 3.1, en las Ell la imposibilidad de regular la sobrevida y actividad de las células $T$ de la mucosa intestinal genera una respuesta inmune sostenida e inadecuada (Baumgart \& Carding, 2007a; Geremia y col., 2014; Neurath, 2014). Por su capacidad de inducir apoptosis en las células epiteliales, estimular la activación de fibroblastos y de la inmunidad innata, se ha atribuido un rol preponderante a las células T CD4 ${ }^{+}$(Th1, Th2 y Th17) en la fisiopatología de las Ell (Geremia y col., 2014; Neurath, 2014; Westendorf y col., 2010). Sin embargo, algunos estudios también han identificado a los $\mathrm{LT} \mathrm{CD8}^{+}$como una célula inflamatoria importante en estas patologías. De hecho, los LT CD8 ${ }^{+}$son una de las principales fuentes de TNF- $\alpha$ e IFN- $\gamma$ en la mucosa colónica de los pacientes con Ell (Neuman, 2007; Westendorf y col., 2010). Además, estas células han mostrado tener la capacidad de mediar recidivas en un modelo de colitis por TNBS. Dicho efecto es atribuido a la capacidad de los $\mathrm{LT} C D 8^{+}$de destruir la barrera epitelial tras reconocer antígenos presentes en los enterocitos (Nancey y col., 2006).

Por otra parte, la constante producción de mediadores inflamatorios como TNF- $\alpha$, IL-21, IL-22 o IL-6 por parte de LT CD4 $4^{+}$y $\mathrm{CD}^{+}$(o por otros tipos celulares que son activados por éstos) estimulan el desarrollo de tumores (Fig. 3.2), una de las complicaciones habituales en las Ell (Goretsky y col., 2012; Neurath, 2014; Ullman \& Itzkowitz, 2011). Teniendo en cuenta estos antecedentes, cualquier mecanismo dirigido a controlar la sobrevida de las células T sería de crucial importancia en la terapéutica de las Ell. Diversos estudios que centraron su atención en este punto e identificaron alteraciones a nivel de la familia de Bcl-2/Bax (Ina y col., 1999; Itoh y col., 2001), NF-kB (Klein y col., 2004) y del sistema Fas/FasL (Suzuki y col., 2000), mecanismos centrales para regular el balance de sobrevida vs apoptosis de los LT. 


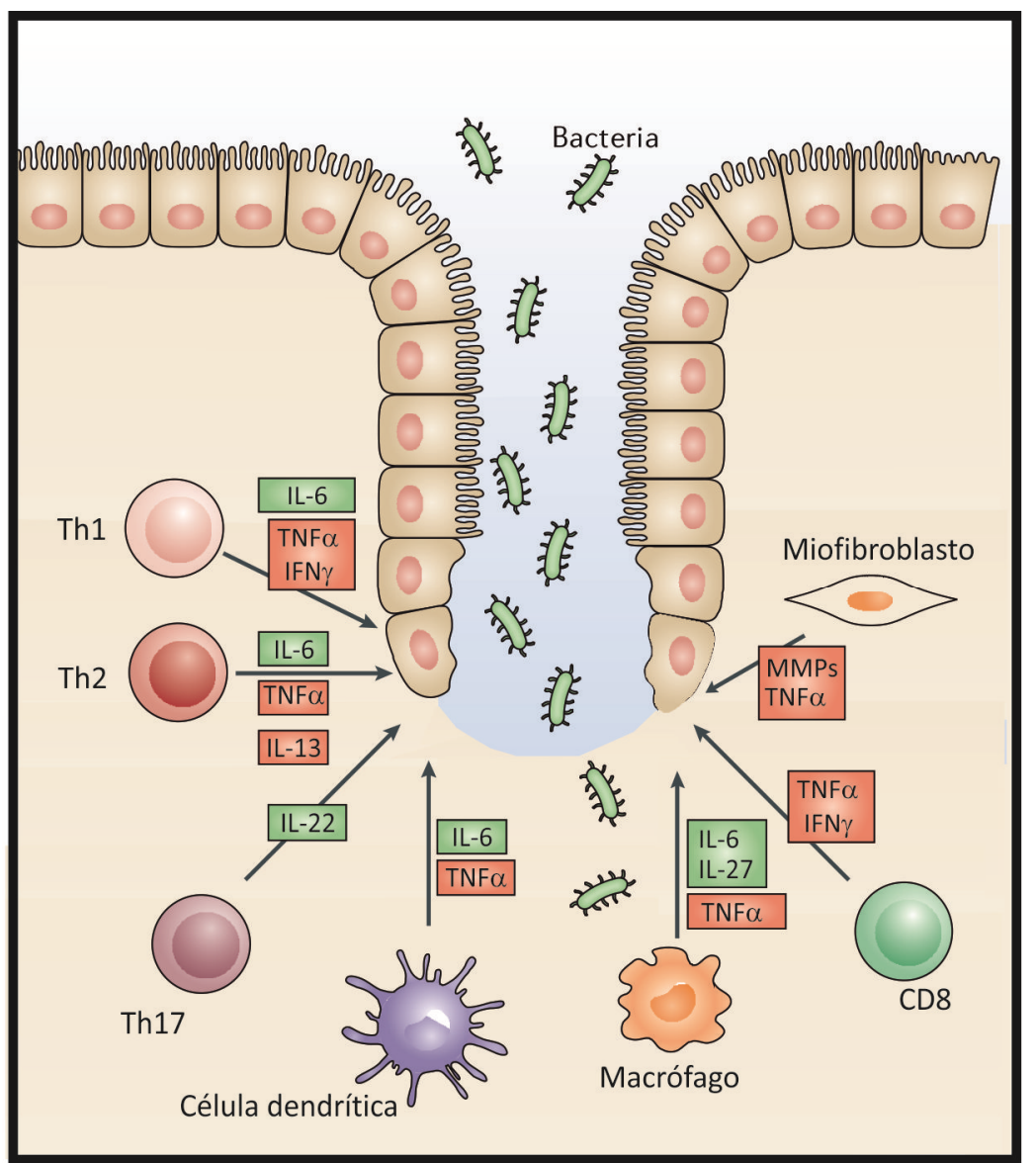

Fig. 3.1: Las células epiteliales intestinales están expuestas a numerosos estímulos pro y antiinflamatorios durante los procesos crónicos de las Ell.

Las citoquinas mostradas tienen un rol central en el daño/cicatrización de la mucosa, ya que controlan la sobrevida de las células epiteliales. Los recuadros verdes indican las citoquinas con efectos beneficiosos para la regeneración de la mucosa, los rojos indican aquellas con efectos patogénicos. Modificado a partir de Neurath, 2014.

La familia de $\mathrm{Bcl}-2$ y proteínas asociadas consisten en un conjunto de moléculas intrínsecamente relacionadas con los procesos de muerte celular. Si bien sus diversos miembros poseen roles antagónicos (ya que $\mathrm{Bcl}-2$ protege de la apoptosis, mientras que Bax la promueve) es el balance entre éstos lo que determina la sobrevida de la célula (Neuman, 2007). Se ha reportado que en las zonas inflamadas de pacientes con EC existe una relación Bcl-2/Bax elevada, sugiriendo un desbalance que favorece la sobrevida de los LT de la mucosa (Ina 
y col., 1999). Asimismo, se ha observado que en pacientes con CU hay niveles disminuidos de Bax en las zonas inflamadas (Itoh y col., 2001).

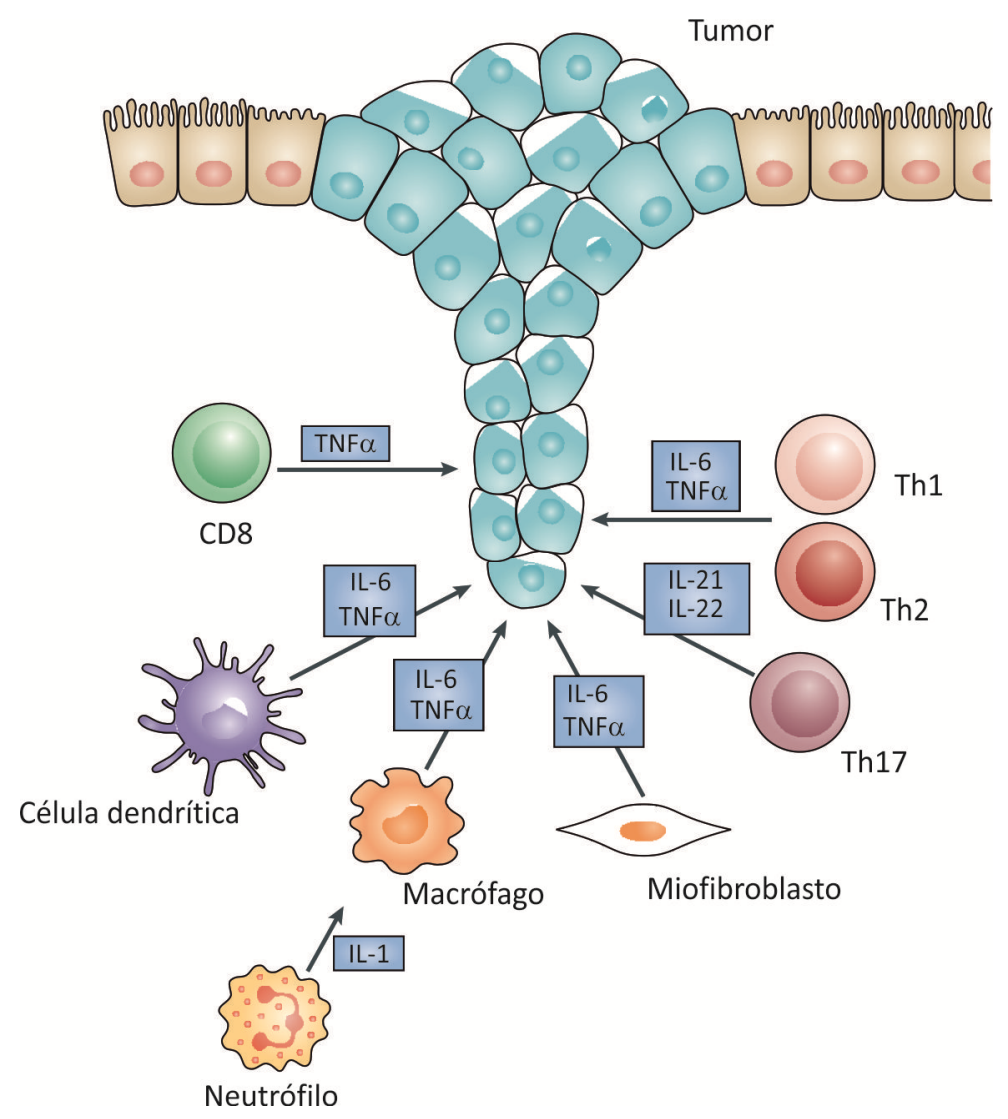

Fig. 3.2: La sobre-exposición a citoquinas pro-inflamatorias estimula el desarrollo de cáncer en pacientes con Ell.

La exposición crónica de la mucosa a citoquinas pro-inflamatorias propicia el desarrollo de tumores asociado a colitis. Modificado a partir de Neurath, 2014.

NF-kB es una proteína citoplasmática capaz de regular la expresión de genes relacionados con mediadores de inflamación y con la sobrevida de los linfocitos (Neuman, 2007). Como se mencionó anteriormente, los niveles de NF-kB se encuentran incrementados en los pacientes con Ell, por lo tanto, este mecanismo estaría contribuyendo con la persistencia de las células inflamatorias en la mucosa intestinal (Klein y col., 2004).

Asimismo, el sistema Fas/FasL es uno de los principales ejes que controlan la sobrevida de los linfocitos. Las células $T$ expresan en forma 
constitutiva Fas y al activarse inducen la expresión en membrana de FasL para limitar su sobrevida y controlar la respuesta inmune (Neuman, 2007). Se ha demostrado que $\mathrm{LT} \mathrm{CD}^{+}$y $\mathrm{CD}^{+}$provenientes de zonas inflamadas de pacientes con CU expresan FasL. Por lo tanto, se postula que existen fallas en los mecanismos intracelulares que regulan la muerte inducida por activación (Suzuki y col., 2000).

Estos defectos asociados a la sobrevida de los LT se combinan con fallas descriptas en los mecanismos regulatorios mediados por citoquinas. Es sabido que TGF- $\beta$ es una citoquina supresora a nivel de células de la inmunidad innata y adaptativa. Esta citoquina controla la expresión génica en diferentes tipos celulares a través del receptor de TGF- $\beta$ (RTGF- $\beta$ ) y la participación de Smad2, Smad3 y Smad4. En este mecanismo Smad7 actúa como un inhibidor para controlar la activación de la vía (Biancheri y col., 2014). Se ha observado que en las zonas inflamadas de pacientes con Ell los niveles de Smad7 se encuentran significativamente incrementados, hecho que estaría inhibiendo la función inmunosupresora de TGF- $\beta$. Este fenómeno explica el incremento observado en los niveles de esta citoquina en el tejido y contribuye con la persistencia del foco inflamatorio (Monteleone y col., 2008). En conjunto, estos estudios demuestran la existencia de fallas en distintos mecanismos regulatorios tendientes a controlar la sobrevida de los LT en la mucosa colónica. Además, explican, por lo menos en parte, la marcada resistencia de estas células a la apoptosis (Di Sabatino y col., 2004).

Como se mencionó en el capítulo II, uno de los mecanismos por el cual Gal-1 regula la respuesta inmune es mediante el control de la sobrevida de los LT. Se ha demostrado que esta lectina controla en forma diferencial la apoptosis de células Th1 y Th17, como así también de células inmaduras (por ejemplo timocitos $\mathrm{CD}^{-} \mathrm{CD} 8^{-}$o $\mathrm{CD}^{+} \mathrm{CD}^{+}$). Este hecho sugiere una posible implicancia de Gal-1 en la tolerancia central (Bi y col., 2008; Stillman y col., 2006) y periférica (Toscano y col., 2007) y está relacionado con el glicofenotipo de estas células. El grupo del Dr. Rabinovich ha demostrado que los LT diferenciados a un perfil Th1 o Th17 presentan de manera disponible a los 
ligandos específicos para Gal-1. Contrariamente, las células Th2 tienen ácido siálico enmascarando a dichos azúcares, lo cual impide la unión de Gal-1 (Toscano y col., 2007). Sobre la base de estos hallazgos se planteó que la administración de esta lectina tiene un efecto anti-inflamatorio en aquellos procesos mediados por células Th1/Th17, tal como ocurre en modelos experimentales de autoinmunidad (Salatino y col., 2008) y de colitis (Santucci y col., 2003).

Cuando la Gal-1 es secretada por las células permanece asociada a la superficie de éstas o bien a componentes específicos de la matriz extracelular circundante (Cho \& Cummings, 1995; He \& Baum, 2004). Esta lectina ha demostrado tener especificidad por los $\mathrm{N}$ - y O-glicanos de determinadas glicoproteínas del sistema inmune, tales como CD2, CD3, CD7, CD43 y CD45 (Pace y col., 1999; Walzel y col., 2000).

Con respecto a la transducción de señales, se ha descripto que la unión de Gal-1 a sus ligandos induce una redistribución de microdominios o clusters en la membrana plasmática (Fig.6 de la introducción) (Daniels y col., 2002; Liu \& Rabinovich, 2010; Rabinovich y col., 2007; Rubinstein y col., 2004). Por ejemplo, la molécula CD45 posee dos dominios fosfatasa en su extremo citoplasmático y se considera que las señales de muerte se desencadenan por una inhibición de la actividad fosfatasa a causa de la proximidad espacial de estas moléculas en los clusters (Majeti y col., 1998). A su vez, durante esta redistribución se induce la exclusión de la proteína quinasa exclusiva de linfocitos (LCK) del sitio de sinapsis inmunológica. Este evento modifica las vías de señalización activadas en las células T, inhibiendo aquellas relacionadas con las funciones efectoras de la respuesta inmune. Al mismo tiempo, que se promueve la externalización de fosfatidilserina y la activación de la caspasa 3 , iniciando los procesos de muerte celular (Novák y col., 2014) .

Como se mencionó anteriormente, el mecanismo que dispare una Gal determinada va a estar dado por los residuos glicosídicos que se encuentren unidos a una determinada molécula. Por ejemplo, las células $\mathrm{HH}$, una línea $\mathrm{T}$ derivada de un paciente con linfoma cutáneo, son $\mathrm{CD}^{+}$, pero resultan 
resistentes a la muerte celular inducida por Gal-1 (Roberts y col., 2003). Una de las particularidades de estas células $T$ es que carecen de O-glicanos que decoren sus proteínas de membrana (Galvan y col., 2000; Nguyen y col., 2001).

Como se muestra en la figura 3.3, el núcleo 1 de los O-glicanos (que es reconocido por la lectina aglutinina del maní, PNA) es el sustrato aceptor para las 1,6-N-acetilglucosaminiltransferasa (C2GnT), una familia de enzimas que añaden lactosamina a los O-glicanos inmaduros (Daniels y col., 2002). La acción de esta enzima es lo que permite la maduración de los O-glicanos, proceso esencial para que Gal-1 pueda unirse a los mismos.

Por lo tanto, inhibir la actividad o expresión de la C2GnT modularía la unión de lectinas a la membrana celular. De hecho, cuando se restituye la expresión de esta enzima en células $\mathrm{HH}$, éstas se vuelven sensibles a la apoptosis inducida por Gal-1 (Cabrera y col., 2006). Esto constituye un mecanismo alternativo al descripto por Toscano y colaboradores (2007), donde la acción de las sialiltransferasas enmascara los azúcares con ácido siálico (Toscano y col., 2007). En cuanto a su relación con la fisiología intestinal, la disminución de los niveles del C2GnT ha sido postulada como una de las causas que contribuyen a la inflamación en un modelo de colitis inducido por TNBS (Nishida y col., 2012).. 


\section{O-Glicanos}

\section{SNA}

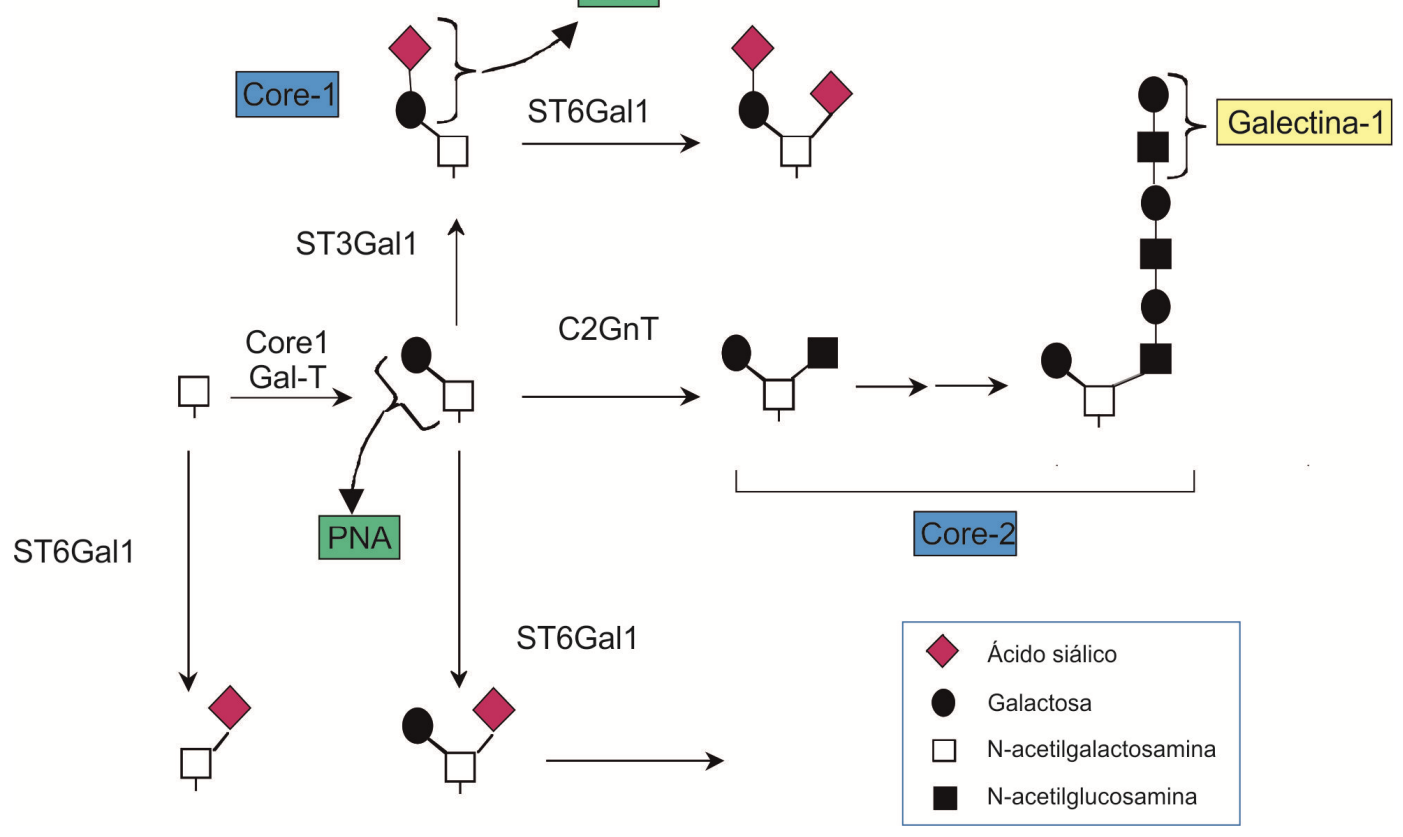

Fig. 3.3: Biosíntesis de O-glicanos y sitios de unión de las diferentes lectinas.

PNA: aglutinina del maní, SNA: aglutinina de Sambucus nigra: C2GnT: 1,6-Nacetilglucosaminiltransferasa. $\quad$ ST3-Gal-1: $\quad \alpha 2-3 \quad$ sialiltransferasa. $\quad$ ST6GalNAc: $\quad \alpha 2-6$ sialiltransferasa. Modificado a partir de Danieles y col., 2002.

Considerando que tanto la CU como la EC poseen un fuerte componente Th1 (Geremia y col., 2014; Neurath, 2014), donde la población T cumple un rol central en el desarrollo y en la cronicidad de la enfermedad (Baumgart \& Sandborn, 2007; Neuman, 2007), y que Gal-1 tiene una probada capacidad inmunomoduladora en desordenes de este tipo (Salatino y col., 2008; Santucci y col., 2003), decidimos estudiar el rol de esta lectina en la fisiología de los LT de la mucosa colónica humana en condiciones de homeostasis e inflamación. 


\section{OBJETIVOS ESPECÍFICOS}

\section{Evaluar:}

- El rol que Gal-1 ejerce en la sobrevida de los LT de la mucosa colónica en situaciones fisiológicas y en Ell:

- Los cambios que un ambiente inflamatorio crónico induce en el glicofenotipo de las células T de la mucosa colónica humana. 



\section{RESULTADOS Y CONCLUSIONES PARCIALES}

\section{Gal-1 controla la sobrevida de los linfocitos $\mathbf{T}$ de la lámina propia en homeostasis}

Considerando que estudios previos han atribuido a Gal-1 la capacidad de inducir apoptosis en LT activados y LT diferenciados a un perfil Th1 y Th17 (Cabrera y col., 2006; Toscano y col., 2007), decidimos estudiar el rol de esta lectina en la sobrevida de células T presentes en la LP del colon humano. A partir de biopsias provenientes de pacientes control se aislaron células de la LP e incubaron durante $16 \mathrm{hs}$ con diferentes concentraciones de rhGal-1 $(5,10,35$, 70 y $140 \mu \mathrm{g} / \mathrm{mL}$ ) o medio de cultivo. El porcentaje de células en apoptosis temprana (anexina $\mathrm{V}^{+} / \mathrm{IP}^{-}$) se analizó por citometría de flujo. La población $\mathrm{T}$ fue seleccionada por sus características morfológicas (FSC/SSC) y el empleo de un anticuerpo anti-CD3 conjugado a FITC.

Como puede observarse en la figura 3.4, Gal-1 indujo en forma dosisdependiente la apoptosis de los LT de la LP (LTLP). Este incremento en las células anexina $\mathrm{V}^{+} / \mathrm{IP}^{-}$resultó estadísticamente significativo a partir de 10 $\mu \mathrm{g} / \mathrm{mL}$ (Fig. 3.4 A-B). Por lo tanto, en condiciones de homeostasis la producción de Gal-1 por parte de las células de la LP podría contribuir a controlar la sobrevida de los LT, protegiendo a la mucosa de una acumulación linfocitaria y probablemente de un proceso inflamatorio. A fin de comparar el efecto proapoptótico de Gal-1 sobre los LTLP en situaciones de homeostasis e inflamación, realizamos el mismo análisis, pero con células provenientes de zonas inflamadas y no inflamadas de pacientes con Ell. Luego de incubar las células durante 16 hs con medio o con rhGal-1 (10 $\mu \mathrm{g} / \mathrm{mL})$ observamos que los LT aislados de zonas inflamadas son refractarios a la muerte celular inducida por esta lectina (Fig. 3.4 C y D). Sin embargo, los LTLP aislados de un tejido no inflamado muestran el mismo comportamiento que el observado en los pacientes control. 
A rGal-1

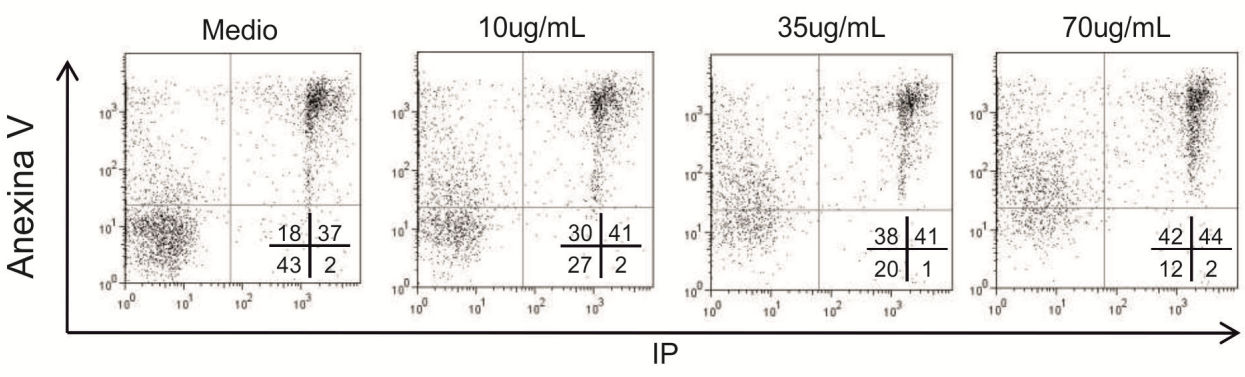

B

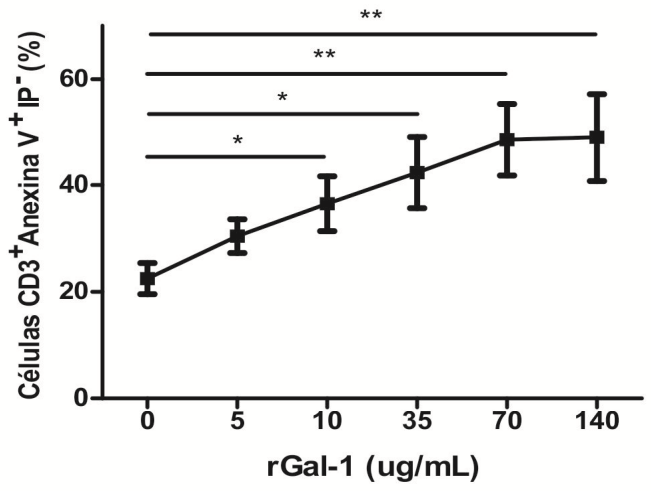

C

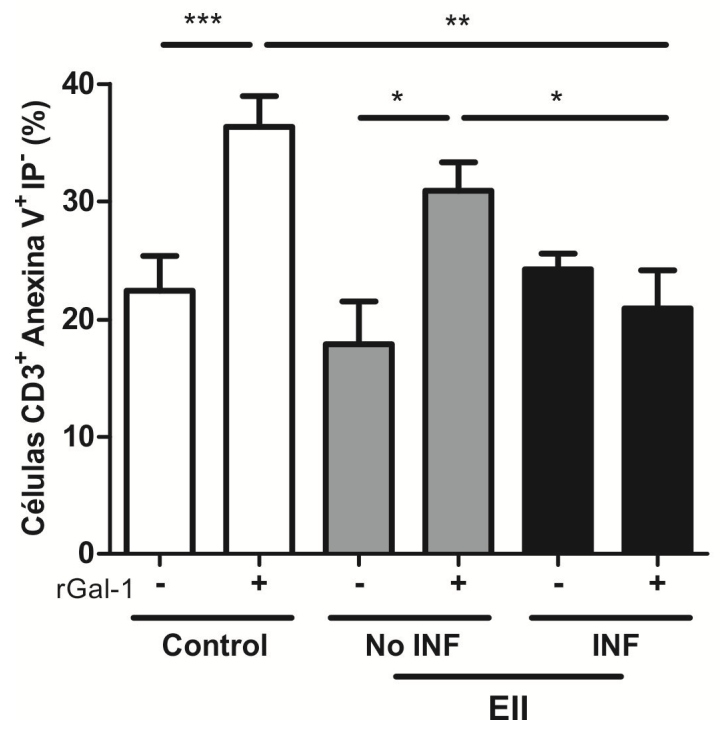

D
No Inflamado

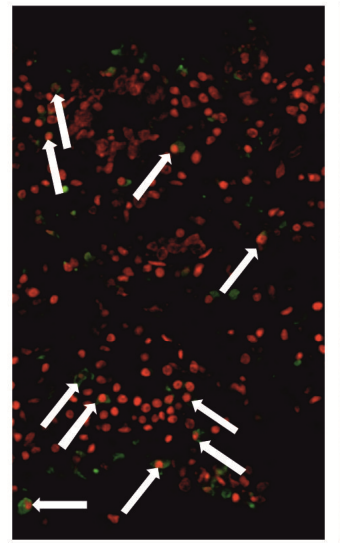

70ug/mL rGal-1
$\mathrm{CU}$

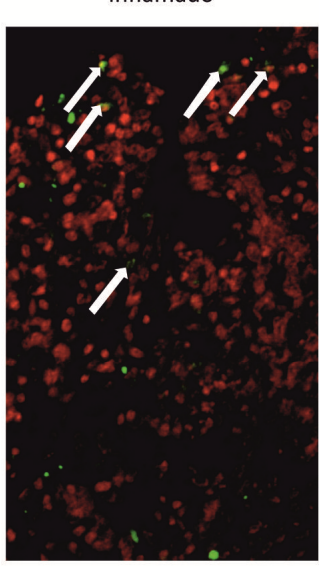

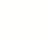

Fig. 3.4: Análisis del efecto pro-apoptótico de Gal-1 sobre los LTLP del colon humano.

A) Células aisladas de la LP de pacientes control fueron incubadas con diferentes concentraciones de rhGal-1 durante 16hs. La inducción de apoptosis se analizó por citometría de flujo mediante la tinción con anexina V, IP y un anticuerpo anti-CD3. B) Porcentaje de células $\mathrm{CD}^{+} /$Anexina $^{+} / \mathrm{IP}^{-}$provenientes de pacientes control luego de ser incubadas con diferentes concentraciones de $\mathrm{rGal}-1(\mathrm{n}=3)$. C) Porcentaje de células $\mathrm{CD}^{+} /$anexina $\mathrm{V}^{+} / \mathrm{IP}^{-}$de pacientes 
control $(n=6)$ y pacientes con Ell (zonas no inflamadas e inflamadas, $n=5$ ) luego de ser incubadas con rhGal-1 (10 $\mathrm{gg} / \mathrm{mL})$ o medio durante 16hs. D) Ensayo de TUNEL por microscopia confocal donde se observan las células TUNEL $^{+}$(núcleos verdes) en la lámina propia luego de incubar biopsias completas (zonas no inflamadas e inflamadas de pacientes con CU) con 70 $\mu \mathrm{g} / \mathrm{mL}$ de rhGal-1 o medio durante 16hs. Las flechas blancas indican las zonas con células TUNEL $^{+}$.Los resultados se muestran como la media \pm el ESM. NO INF: no inflamado; INF: inflamado. ${ }^{*} p<0.05 ;{ }^{* *} p<0.01 ; * * p<0.001$.

Estos resultados estaría indicando que la exposición de los LTLP a un foco inflamatorio persistente (como es el caso de las Ell) modifica la susceptibilidad de estas células al efecto pro-apoptótico de Gal-1, volviéndolas resistentes a estímulos que, en condiciones fisiológicas, modulan su sobrevida.

\section{Las células T de la lámina propia muestran una capacidad diferencial de unir} Gal-1

Con el fin de analizar los mecanismos que determinan la pérdida de susceptibilidad a Gal-1 por parte de los LTLP en las aéreas inflamadas del intestino, se estudió la presencia de los ligandos específicos para esta lectina por citometría de flujo. La población $\mathrm{T}$ fue ubicada por sus características morfológicas (FSC/SSC) y caracterizada mediante el empleo de anticuerpos antiCD3, anti-CD4, anti-CD8 y anti CD25 (Fig. 3.5 A, B y C). La capacidad de unir Gal1 se determinó mediante el uso de rhGal-1 biotinilada y streptavidina-APC. Como control negativo se utilizaron PBMC de pacientes control. De manera coherente con los resultados de apoptosis previos, se observó que en la mucosa colónica de pacientes control tanto la población $\mathrm{T} \mathrm{CD}^{+}$, como la $\mathrm{CD} 8^{+}$, unen Gal-1 (Fig. 3.5 D). Esta unión es especifica de glúcidos, ya que al realizar este ensayo en presencia de lactosa $(100 \mathrm{mM})$ la capacidad unir Gal-1 fue completamente inhibida (Fig. 3.5 D). Trabajos previos determinaron que los LT $\mathrm{CD}^{+}$de periferia sólo tienen capacidad de unir Gal-1 cuando están activados (Toscano y col., 2007). Nosotros pudimos observar que en la mucosa colónica de los pacientes control tanto los $\mathrm{LT}$ activados $\left(\mathrm{CD}^{+} \mathrm{CD} 25^{+}\right)$, como los no 
activados ( $\mathrm{CD}^{+} \mathrm{CD}^{-} 5^{-}$), expresan los ligandos específicos para esta lectina (Fig. 3.5 D). De hecho, en los pacientes control el $17 \pm 3 \%$ de los $L T C D 4^{+}$y el $50 \pm 7 \%$ de los $\mathrm{CD}^{+}$tienen capacidad de unir Gal-1 (Fig. 3.5 B).

A

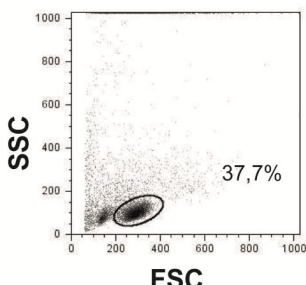

FSC
B

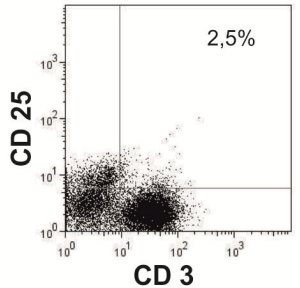

C

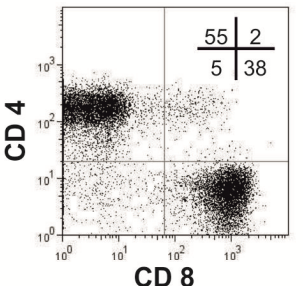

Gal-1 (LTLP)

- Gal-1 + lactosa (LTLP)

--- Gal-1 (PBMC)

D

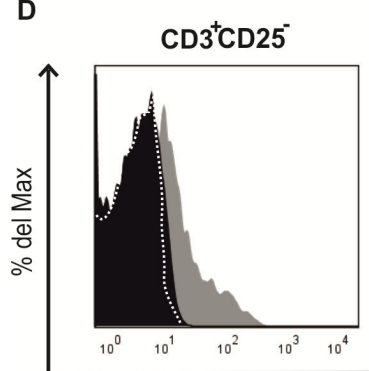
$\mathrm{CD}^{+} \mathrm{CD} 25^{-}$ $\mathrm{CD}^{+} \mathrm{CD} 25^{+}$

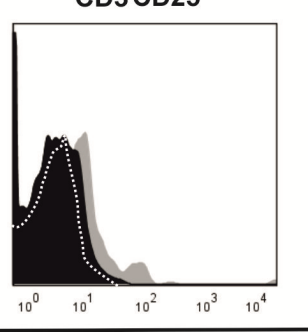

$\mathrm{CD}^{+}$
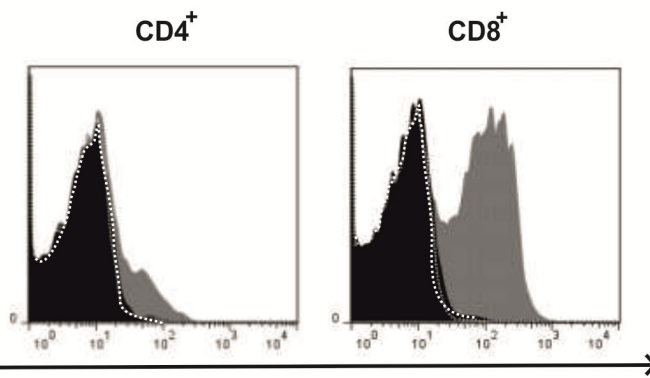

Unión a Gal-1

Fig. 3.5: Unión de Gal-1 a células T provenientes de la mucosa colónica de pacientes control.

A) Características de la dispersión frontal/dispersión lateral de luz (FSC/SSC) de la población de linfocitos T aislados de la LP. B) Análisis de la expresión de CD3 y CD25 en linfocitos aislados de la LP. C) Análisis de los linfocitos $\mathrm{T} \mathrm{CD}^{+}$y $\mathrm{CD}^{+}$en la LP. El recuadro superior indica el porcentaje de células $\mathrm{CD}^{+}$y $\mathrm{CD}^{+}$. D) Histograma representativo de la capacidad de unión de Gal-1 de los LTLP de un paciente control. Con negro se indican las muestras incubadas con rhGal-1 biotinilada, estreptavidina-APC y lactosa, mientras que con gris las muestras las células incubadas solamente con rhGal-1 biotinilada y estreptavidina-APC. La línea blanca punteada corresponde a PMBC (paciente control) incubadas con rhGal-1 biotinilada y estreptavidina-APC (control negativo).

Posteriormente analizamos la capacidad de unión de Gal-1 en células aisladas de la mucosa colónica de pacientes con CU y EC (zonas inflamadas y no inflamadas en ambas patologías). Pudimos determinar que, cuando los LTLP provienen de un área inflamada tienen una significativa disminución en su 
capacidad de unir Gal-1 (Fig. 3.6 A y B). Estos resultados fueron observados tanto para los $\mathrm{LT} \mathrm{CD4}{ }^{+}$(células Gal- ${ }^{+}=\mathrm{CU}: 4,7 \pm 1,7 \%$; EC: $9,4 \pm 3 \%$ ) como los $\mathrm{CD}^{+}$(células Gal-1 ${ }^{+}=\mathrm{CU}: 20 \pm 3,8 \%$; EC: $14,5 \pm 5,3 \%$ ) (Figs. $3.6 \mathrm{C}$ y D, respectivamente). Notablemente, los LT activados provenientes de zonas inflamadas de pacientes con CU o EC tampoco mostraron capacidad de unir esta lectina (Fig. 3.6 A y B). No se observaron diferencias en el porcentaje de LTLP-Gal- $1^{+}\left(\mathrm{CD}^{+}\right.$o $\left.\mathrm{CD}^{+}\right)$entre pacientes control y zonas no inflamadas de pacientes con Ell (Fig. 3.6 C). 


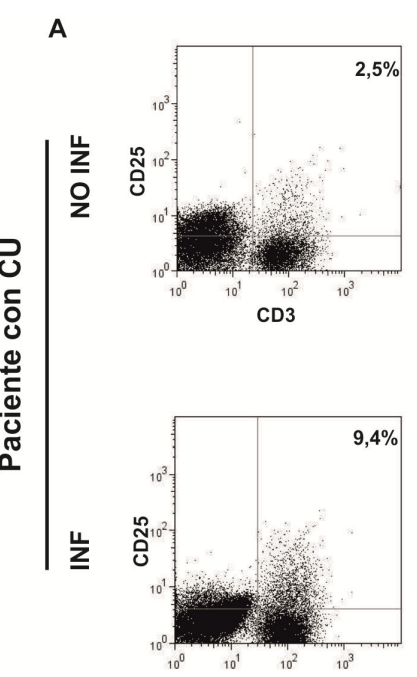

$\mathrm{CD} 3$
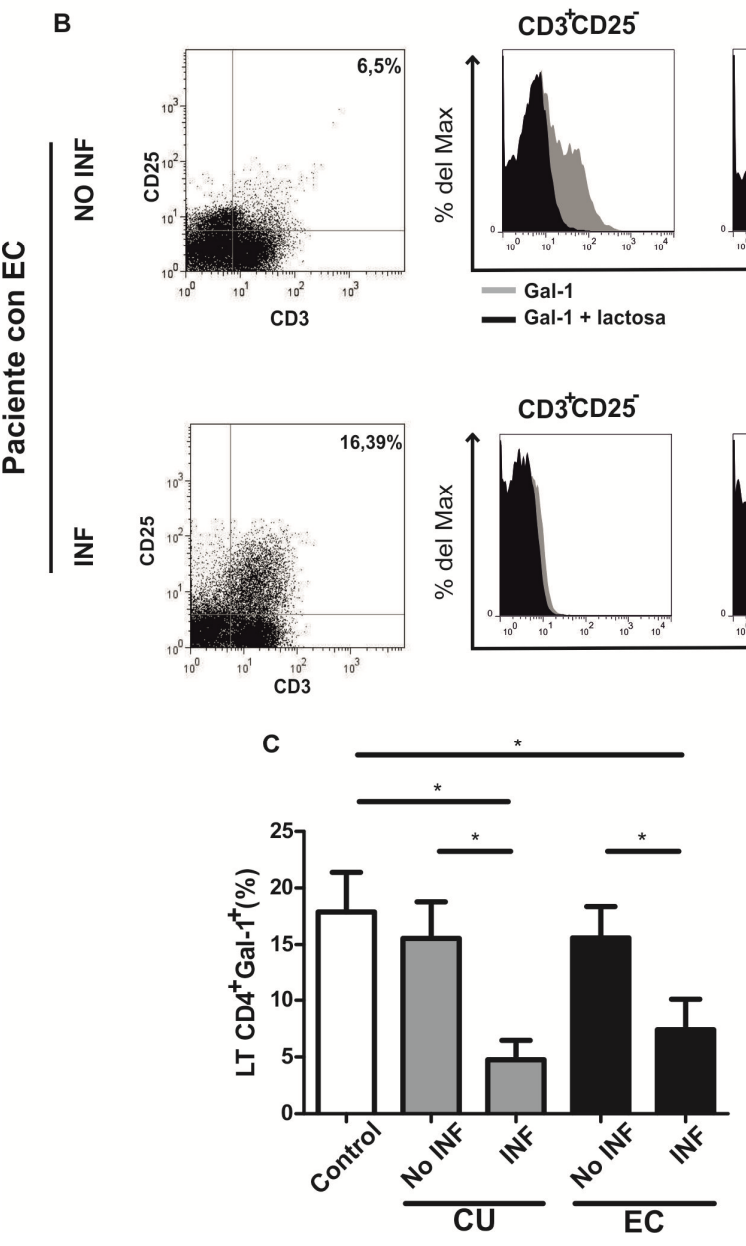

$\mathrm{CD}^{+}{ }^{+} \mathrm{CD} 25^{+} \quad \mathrm{CD}^{+}$
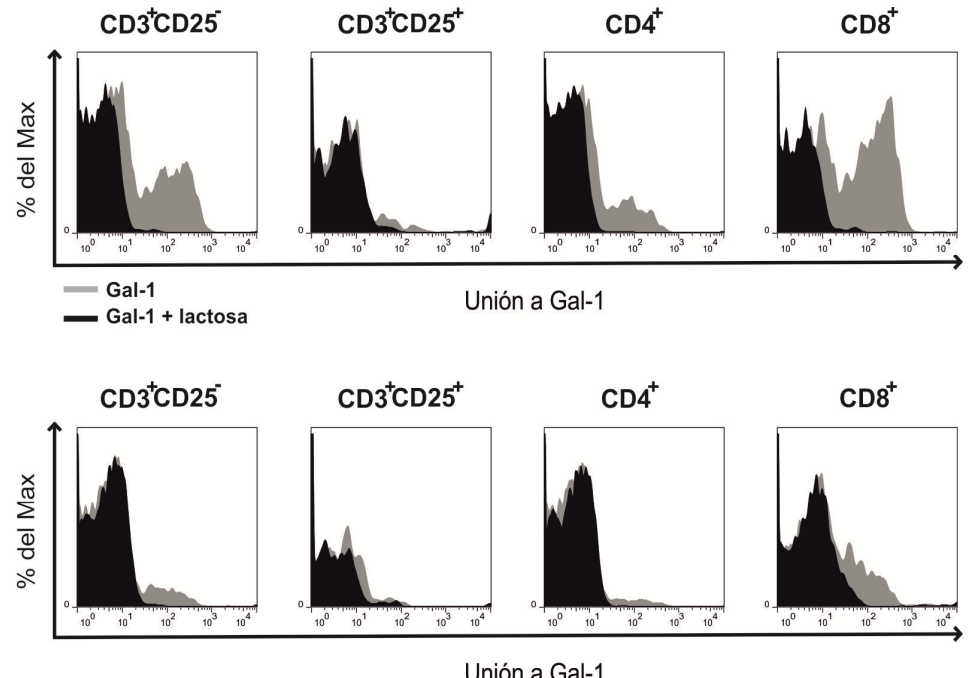

Unión a Gal-1
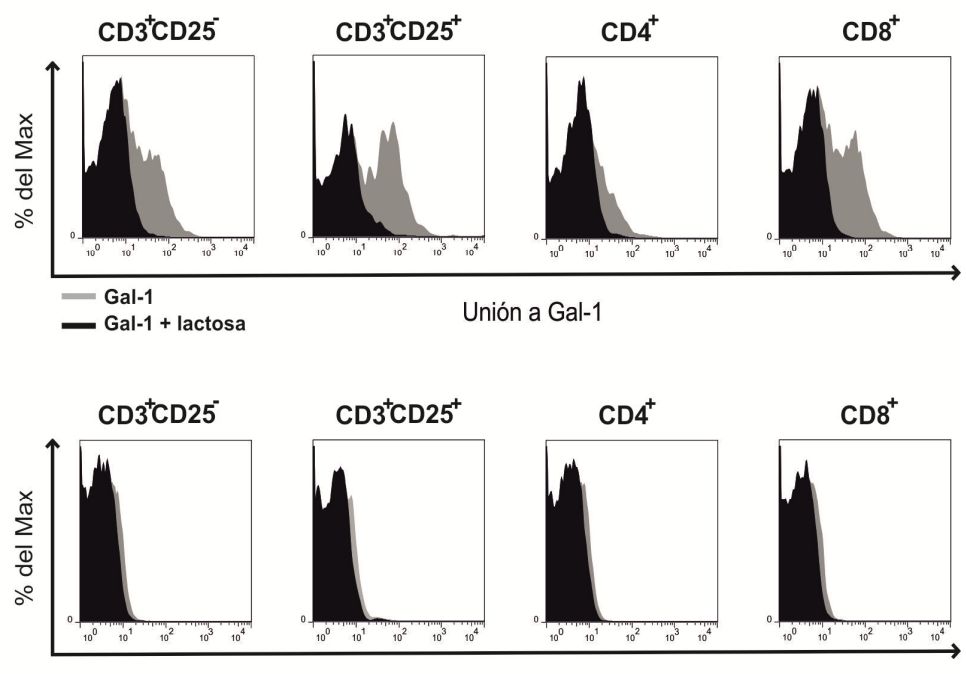

Unión a Gal-1

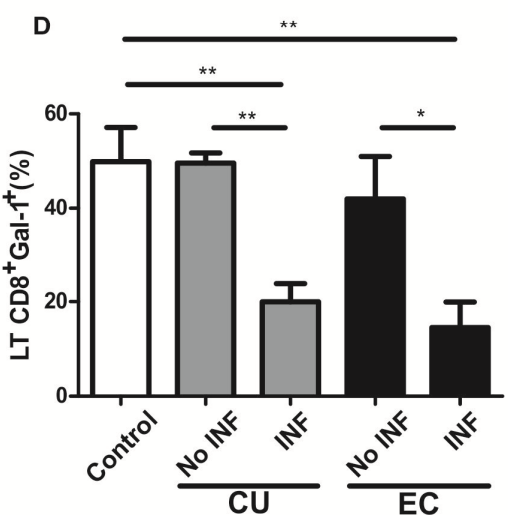

Fig. 3.6: Análisis de la capacidad de unión de Gal-1 por los LTLP de pacientes con Ell.

Se analizaron las poblaciones de linfocitos $\mathrm{CD}^{+} / \mathrm{CD}^{2} 5^{+}$(activados) y $\mathrm{CD}^{+} / \mathrm{CD}^{2} 5^{-}$(no activados), $\mathrm{CD}^{+}$y $\mathrm{CD}^{+}$en pacientes con Ell (zonas no inflamadas e infamadas). Las poblaciones $\mathrm{TCD}^{+}$y $\mathrm{CD} 8^{+}$analizadas incluyen tanto a las células $\mathrm{CD}_{25} 5^{+}$como a las $\mathrm{CD} 25^{-}$. A y B) Capacidad de unir Gal-1 por parte de linfocitos de la LP en un pacientes con CU y EC respectivamente. En los 
histogramas se marcan con negro las muestras incubadas con rhGal-1 biotinilada, estreptavidina-APC y lactosa (100 mM), mientras que con gris se muestran las incubadas con rhGal-1 biotinilada y estreptavidina-APC. C) Capacidad de unir Gal-1 por parte de los linfocitos T $\mathrm{CD}^{+}$. D) Capacidad de unir Gal-1 por parte de los linfocitos T CD8 ${ }^{+}$. Pacientes control, $n=10$; pacientes con $\mathrm{CU}, \mathrm{n}=7$; pacientes con $\mathrm{EC}, \mathrm{n}=6$. Los resultados muestran la media del porcentaje de células Gal-1 ${ }^{+} \pm$el ESM. * ${ }^{*}<0.05 ; * * p<0.01$.

Por lo tanto, los LTLP provenientes de pacientes control y zonas no inflamadas de pacientes con Ell expresan los ligandos específicos para Gal-1 de manera intrínseca y disponible. Notablemente, dicha capacidad de unir la lectina es independiente de su estado de activación. De hecho, tanto las células $\mathrm{CD}^{+} \mathrm{CD} 25^{+}$como las $\mathrm{CD}^{+} \mathrm{CD}_{25}{ }^{-}$resultaron $\mathrm{Gal}-1^{+}$cuando se las incubó con la Gal-1 biotinilada. Sin embargo, la inflamación crónica del colon en pacientes con Ell disminuye significativamente la capacidad de unir esta lectina en todas las poblaciones $T$ analizadas.

\section{Las células $\mathbf{T}$ de la lámina propia expresan un glicofenotipo diferencial en pacientes con Ell}

Con el fin de determinar si la imposibilidad de unir Gal-1 se debe a cambios en el glicofenotipo de estas células se analizó la capacidad de unión de 2 lectinas vegetales biotiniladas: aglutinina de Sambucus nigra (SNA) y de maní (PNA). SNA se utilizó para determinar la presencia de ácido siálico en los extremos de los azucares de superficie, mientras que PNA indica presencia de O-glicanos (ligando específico de Gal-1). El análisis de muestras provenientes de pacientes control y pacientes con Ell arrojó el siguiente resultado: en los pacientes control el glicofenotipo se correlaciona con un ambiente permisivo para la unión de Gal-1, ya que tanto las células $\mathrm{T} C D 4^{+}$como las $\mathrm{CD}^{+}$resultaron negativas para SNA y positivas para PNA (Fig. 3.7 A). Asimismo, y de manera coherente con lo observado en cuanto a la capacidad de unión a Gal-1, en los pacientes control el porcentaje de $\mathrm{LT}^{\mathrm{CD}} 8^{+}$que unen PNA resultó 
significativamente superior al observado para los $\operatorname{LT~CD4}^{+}(22,8 \pm 3,1 \%$ y $18,9 \pm$ 2,5\% respectivamente) (Fig. $3.7 \mathrm{~B}$ ).

A

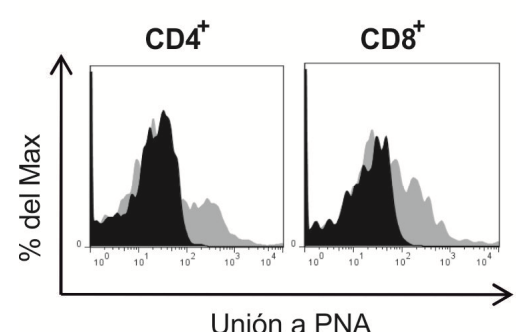

PNA
PNA + lactosa

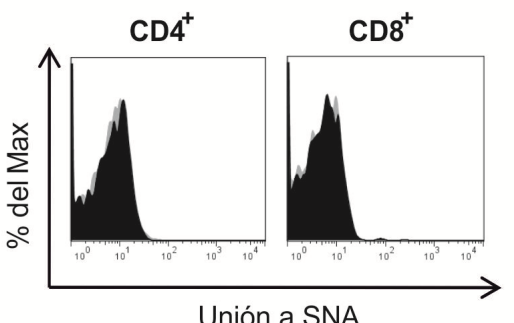

Unión a SNA
B

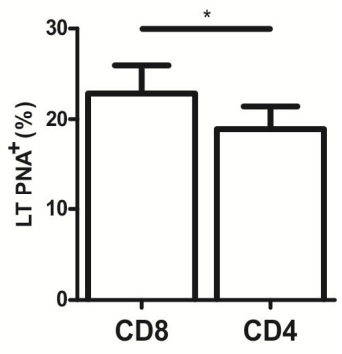

Fig. 3.7: Glicofenotipo de los linfocitos $T$ de la lámina propia en pacientes control.

A) Unión de PNA y SNA a LT $C D 4^{+}$y $C D 8^{+}$de la LP. Con gris se marcan las muestras incubadas con las respectivas lectinas biotiniladas y estreptavidina-APC, mientras que con negro se indican las células incubadas con la lectina biotinilada, estreptavidina-APC y lactosa (100 mM). B) Análisis estadístico del porcentaje de células $\mathrm{CD}^{+} \mathrm{PNA}^{+}$y $\mathrm{CD}^{+} \mathrm{PNA}^{+}(n=10)$. Los resultados se muestran como la media del porcentaje de células $\mathrm{PNA}^{+} \pm$ESM. ${ }^{*} \mathrm{p}<0.05$.

De la misma manera, analizamos la capacidad de unir PNA y SNA en LTLP de pacientes con Ell. Pudimos determinar que el glicofenotipo de los LT aislados de zonas no inflamadas de pacientes con CU y EC es similar al observado en los pacientes control. De hecho, tanto los LT CD4 ${ }^{+}$como los CD8 ${ }^{+}$ reconocen PNA, pero no SNA (Fig. 3.8 A y B). Sin embargo, en condiciones de inflamación, los LTLP presentan un glicofenotipo diferente (Fig. 3.8 A y B). No se observó incremento en la capacidad de unión a SNA, con lo cual podemos descartar que los ligandos para Gal-1 hayan sido enmascarados por residuos de ácido siálico. Por otra parte, pudimos determinar que existe una significativa disminución en la capacidad de unión a PNA, tanto para los LT CD4 ${ }^{+}$(NO INF: 25 $\pm 5,5 \%$; INF: $18 \pm 3,4 \%$ ) como los CD8 ${ }^{+}$(NO INF: $22,8 \pm 4,1 \%$; INF: $16 \pm 4,6 \%$ ) (Fig. $3.8 \mathrm{C})$.

Por lo tanto, los $\mathrm{LTLP}_{\mathrm{CD}} 4^{+}$y $\mathrm{CD} 8^{+}$de pacientes control o de áreas no inflamadas de pacientes con Ell presentan la misma capacidad de reconocimiento de PNA y Gal-1. Sin embargo, dicha capacidad de 
reconocimiento disminuye significativamente cuando estas células se encuentra en un entorno inflamatorio crónico. En ninguno de los casos se observó unión a SNA. Considerando que PNA reconoce O-glicanos, que son uno de los sitios de unión de Gal-1, la disminución en la expresión de estas moléculas constituiría un mecanismo de pérdida de sensibilidad a la muerte celular inducida por Gal-1. 
A $\quad \mathrm{CD4}^{+} \quad$ Paciente con CU $\mathrm{CD}^{+}$
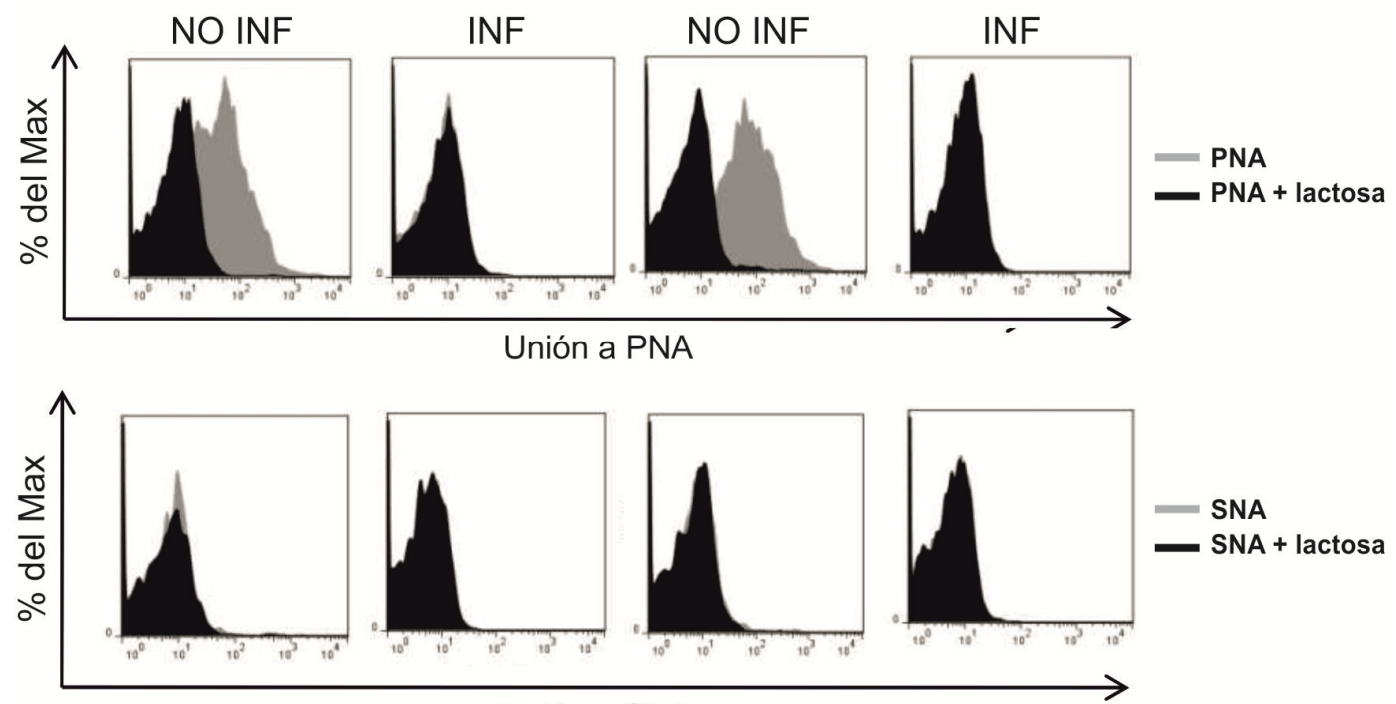

- SNA

- SNA + lactosa

Unión a SNA

B $\mathrm{CD}^{+} \quad$ Paciente con EC $\mathrm{CD}^{+}$

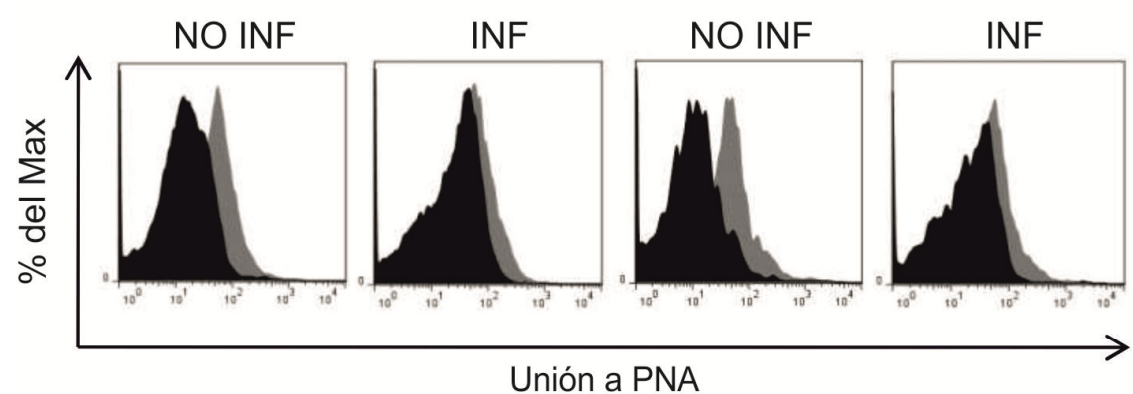

- PNA

- PNA + lactosa

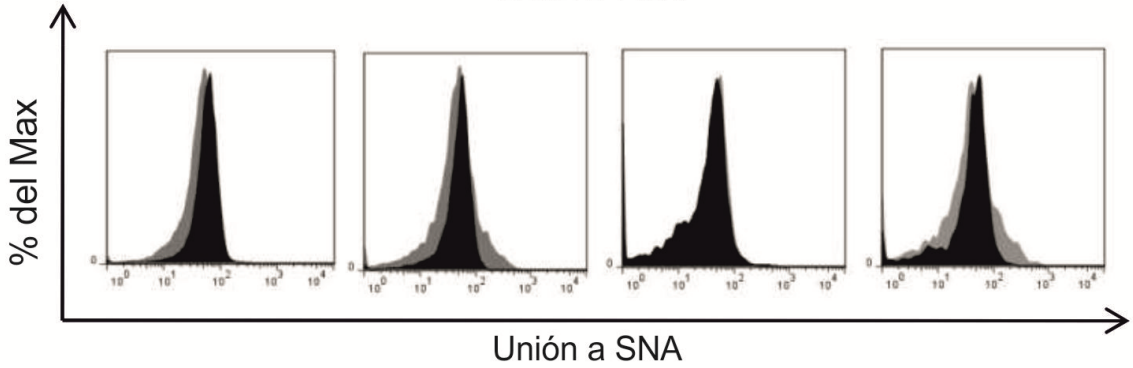

SNA

SNA + lactosa

C
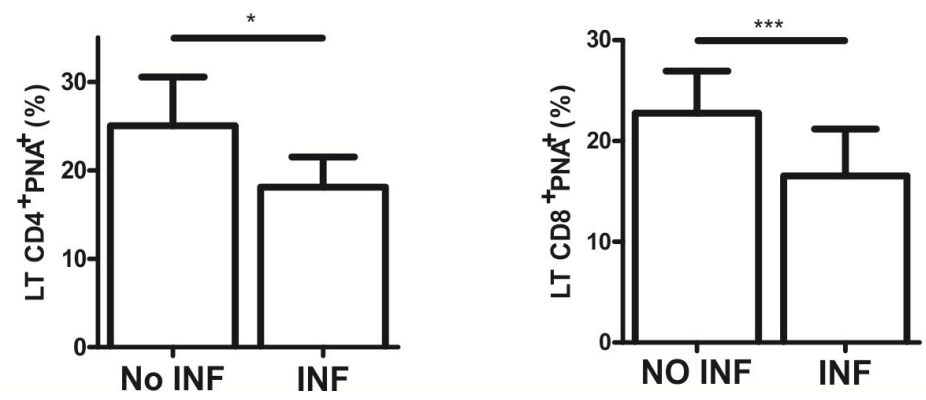
Fig. 3.8: Unión de PNA y SNA en LTLP provenientes de pacientes con Ell.

La capacidad de unir PNA y SNA en linfocitos $\mathrm{T} \mathrm{CD4}^{+}$y $\mathrm{CD} 8^{+}$aislados del colon de pacientes con Ell se analizó por citometría de flujo. Los histogramas muestran un caso representativo de cada grupo de pacientes. Con gris se marcan las muestras incubadas con las respectivas lectinas biotiniladas y estreptavidina-APC, mientras que con negro se indican las células incubadas con la lectina biotinilada, estreptavidina-APC y lactosa (100 mM). A) Capacidad de los LTLP de unir PNA y SNA en zonas no inflamadas e inflamadas de un paciente con CU. B) Capacidad de los LTLP de unir PNA y SNA en zonas no inflamadas e inflamadas de un paciente con EC. C) Análisis estadístico del porcentaje de células $\mathrm{CD}^{+} \mathrm{PNA}^{+}$y $\mathrm{CD}^{+} \mathrm{PNA}^{+}$en zonas no inflamadas e inflamadas de pacientes con EII $(n=7)$. Los resultados se muestran como la media del porcentaje de células $\mathrm{PNA}^{+} \pm$el ESM. NO INF: no inflamado; INF: inflamado. ${ }^{*} \mathrm{p}<0.05 ;{ }^{* * *} \mathrm{p}<0,001$.

Para profundizar este análisis y demostrar nuestra hipótesis decidimos estudiar la vía de síntesis de los O-glicanos. C2GnT-1 cataliza la adición de Nacetilglucosamina a O-glicanos, con lo cual es una enzima central en la maduración de estos azúcares. Trabajos previos relacionan a esta enzima con la inflamación intestinal (Nishida y col., 2012) y con la disminución en la sensibilidad a Gal -1 (Cabrera y col., 2006). Por lo tanto decidimos comparar los niveles de expresión de esta enzima en las áreas no inflamadas e inflamadas de los pacientes con Ell.

Utilizando biopsias de la mucosa colónica pudimos determinar que la expresión de C2GnT-1 se encuentra disminuida en las zonas inflamadas del colon, en comparación a la mucosa de pacientes control y aquellas provenientes de zonas no inflamadas de pacientes con Ell. Notablemente, encontramos que en las zonas en remisión la expresión de esta enzima retornan a niveles comparables con los observados en la mucosa no inflamada o mucosa control (Fig. 3.9 A). A fin de corroborar que la expresión de esta enzima se encuentra disminuida en las células $\mathrm{CD}^{+}$de la mucosa colónica analizamos sus niveles de expresión en LTLP aislados mediante el empleo de perlas magnéticas conjugadas a anti-CD3.

Como se muestra en la figura $3.9 \mathrm{~B}, \mathrm{C} 2 \mathrm{GnT}-1$ se expresa de manera constitutiva en los LTLP de pacientes control y sus niveles disminuyen significativamente cuando estas células se encuentran en un foco inflamatorio 
crónico (Fig. 3.9 C). Considerando que tanto la capacidad de unión a PNA como los niveles de expresión de C2GnT-1 están relacionados con la biosíntesis de Oglicanos, decidimos analizar los niveles de expresión de la enzima GnT-5 en los LT aislados de la LP. GnT-5 es una enzima que ramifica N-glicanos, ligando adicional de Gal-1. Pudimos observar que esta enzima también se expresa de manera constitutiva en las células $\mathrm{T} \mathrm{CD}^{+}$de pacientes control, aunque sus niveles de ARNm son significativamente menores a los de C2GnT-1 (Fig. 3.9 B). A su vez, los niveles de expresión de esta enzima también son significativamente menores en los LTLP aislados de zonas inflamadas en relación a las zonas no inflamadas (Fig. 3.9 D). De manera concomitante con la disminución en la expresión de C2Gn-1 y GnT-5, la población T proveniente de zonas inflamadas mostró un significativo incremento en la expresión de TNF- $\alpha$ (Fig. 3.9 E) e IFN- $\gamma$ (Fig. 3.9 F), confirmando que se trata de LT Th1.

Estos resultados estarían indicando que en situaciones de homeostasis, los LTLP expresan la maquinaria celular para generar los ligandos específicos para Gal-1. Por otra parte, cuando estos LT se encuentran en un entorno inflamatorio, la expresión de estas enzimas está disminuída. Es importante resaltar que en las áreas sin actividad (no inflamadas o en remisión) los niveles de ARNm para C2GnT1 son similares a los de la mucosa control, suponiendo una normal glicosilación de los componentes de membrana que pueden ser reconocidos por Gal-1. Consecuentemente, cuando los LT se encuentran en áreas no inflamadas tienen capacidad de unir Gal-1 y son susceptibles a la muerte celular por esta lectina. 
A

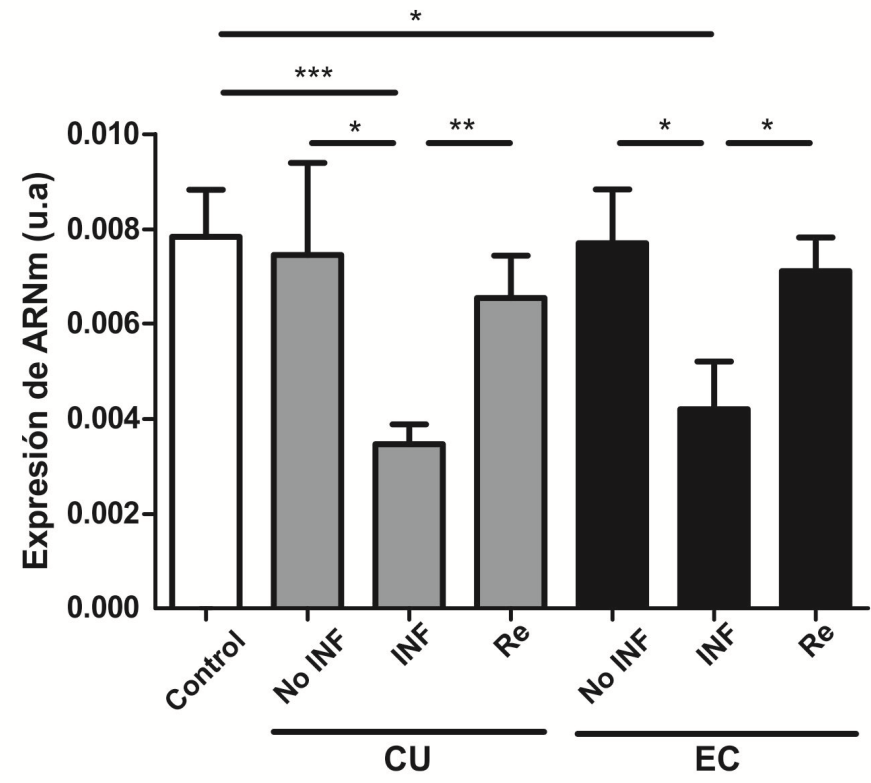

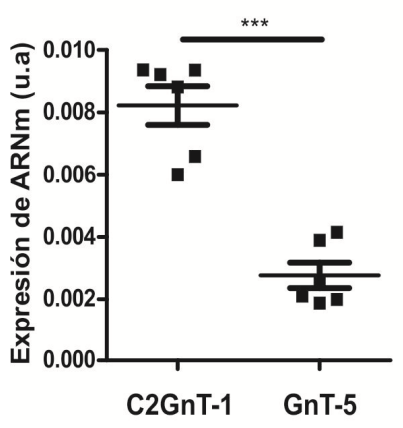

C

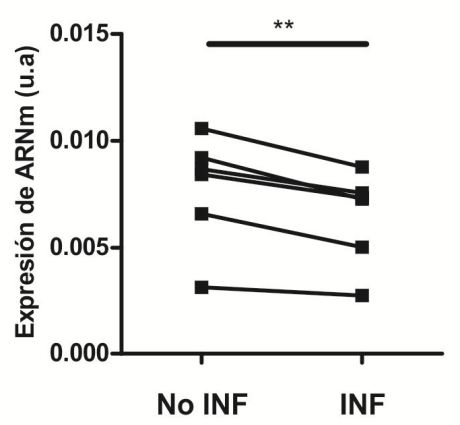

D

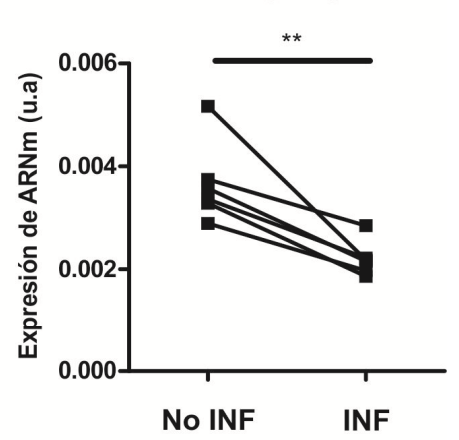

E

TNF- $\alpha$

$\mathbf{F}$

IFN- $\gamma$
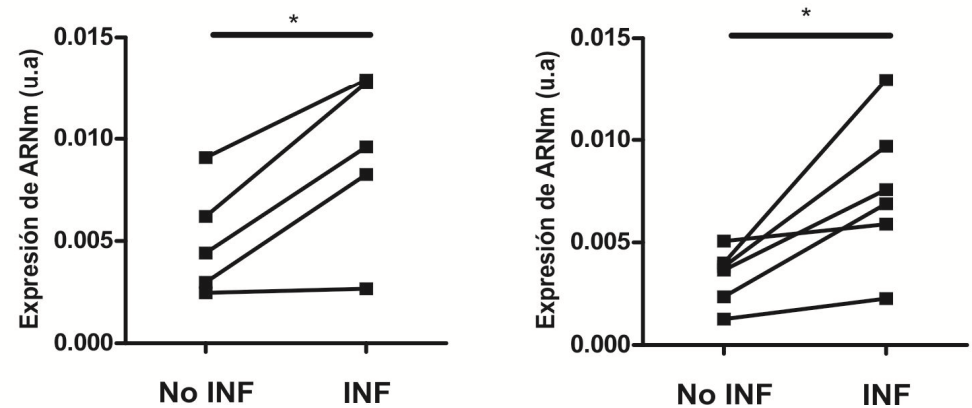

Fig. 3.9: El ambiente inflamatorio de las Ell modula la expresión de las enzimas que ramifican los ligandos de Gal-1.

A) Expresión de C2GnT-1 en biopsias de mucosa colónica. B) Expresión de C2GnT-1 y GnT-5 en linfocitos CD3 aislados de la lámina propia de pacientes control. C) Expresión de C2GnT-1 en linfocitos CD3 aislados de zonas no inflamadas e inflamadas de un mismo paciente con Ell 
$(n=6)$. D) Expresión de GnT-5 en linfocitos CD3 aislados de zonas no inflamadas e inflamadas de un mismo paciente con EII ( $n=6)$. E) Expresión de TNF- $\alpha$ en linfocitos CD3 aislados de zonas no inflamadas e inflamadas de un mismo paciente con EII ( $n=5)$. F) Expresión de IFN- $\gamma$ en linfocitos CD3 aislados de zonas no inflamadas e inflamadas de un mismo paciente con Ell ( $n=6)$. Los resultados se muestran como la media \pm el ESM. NO INF: no inflamado; INF: inflamado. $* p<0.05 ; * * p<0,01 ; * * * p<0,001$.

Por último, se analizó si un ambiente inflamatorio in vitro es capaz de inducir las mismas alteraciones del glicofenotipo observado en la patología. Se incubaron biopsias de pacientes control en presencia o ausencia de rhTNF- $\alpha$ (10 $\eta \mathrm{g} / \mathrm{mL}$ ) durante 16 hs y luego se analizaron los niveles de expresión de la enzima C2GnT-1 por qPCR (Fig. 3.10 A). Se observó que el sólo hecho de incubar las biopsias con medio de cultivo durante este periodo de tiempo induce una marcada reducción en los niveles de ARNm de esta enzima. No obstante, el estímulo con TNF- $\alpha$ indujo un incremento significativo de la expresión C2GnT-1 en comparación a las muestras incubadas con medio.

Con el fin de dilucidar si dichos cambios afectan el glicofenotipo de los LT y su capacidad de unir Gal-1, se incubaron células de la línea celular Jurkat en presencia o ausencia de TNF- $\alpha$. Se utilizó este modelo ya que dicha línea celular presenta un glicofenotipo similar al observado en las células $\mathrm{T}$ de la mucosa de pacientes control (Fig. 3.10 B). Contrariamente a lo observado en las zonas inflamadas de pacientes con EII, los LT incubados con TNF- $\alpha$ mostraron mayor capacidad de unir tanto PNA como Gal-1 (Fig. 3.10 C y D). 
A

\section{C2GnT-1}

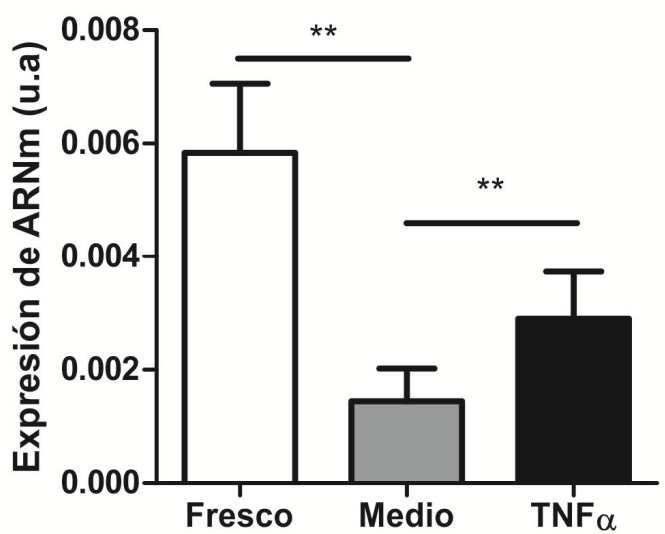

B

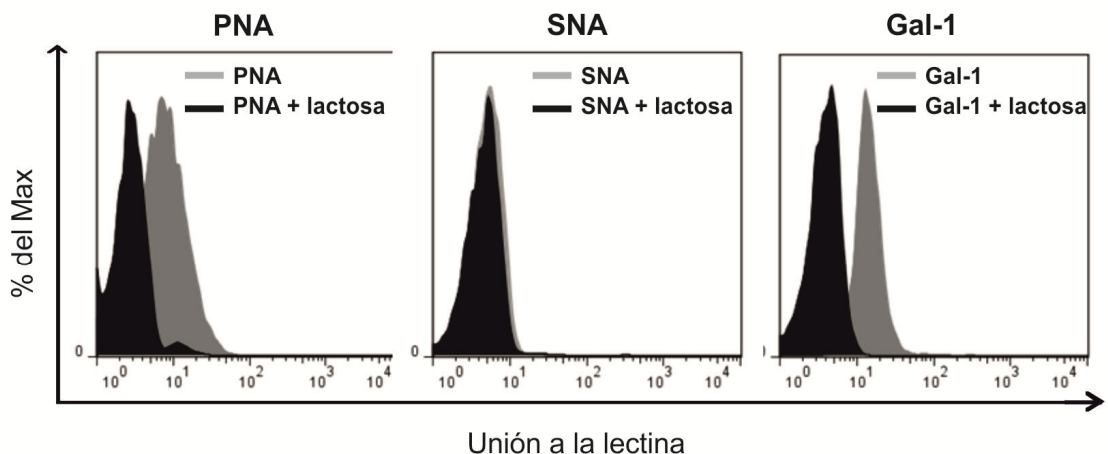

C
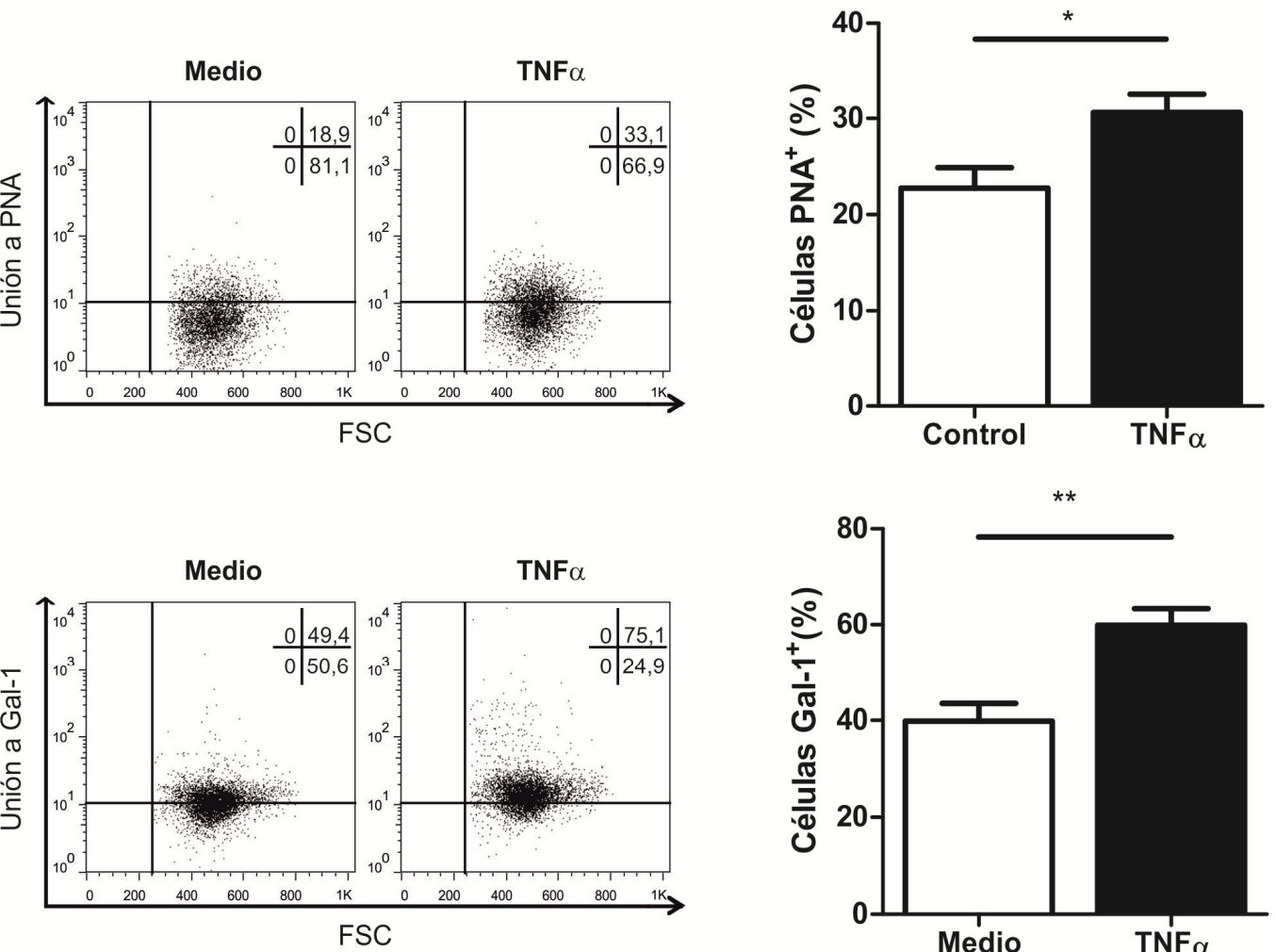

Fig. 3.10: Expresión de C2GnT-1 y capacidad de los LT de unir Gal-1 en ensayos in vitro. 
A) Expresión de C2GnT-1 en biopsias enteras de colon de pacientes control luego de ser incubadas durante $16 \mathrm{hs}$ con TNF- $\alpha(10 \mathrm{ng} / \mathrm{mL})$ o medio de cultivo $(\mathrm{n}=8)$. La barra con relleno blanco muestra los niveles de expresión de C2GnT-1 previos a la incubación. B) Glicofenotipo de la línea celular Jurkat analizado por citometría de flujo. Histogramas correspondientes a la unión de PNA, SNA y Gal-1. En cada histograma las líneas con relleno negro corresponden a células incubadas con la respectiva lectina biotinilada, estreptavidina-APC y lactosa (100 mM), mientras que con gris se indican las muestras incubadas con lectina biotiniladas $y$ estreptavidina-APC. C) Análisis de la capacidad de las células Jurkat de unir PNA y Gal-1 luego de ser incubadas con TNF- $\alpha$ (10 ng/mL) o medio de cultivo durante $24 \mathrm{hs}$. Se muestran Dot blots representativos y el análisis estadístico de cada ensayo. Los resultados corresponden a tres experimentos independientes. En todos los casos se utilizaron controles con lactosa (100 mM) para determinar el porcentaje de células positivas para cada lectina. Los resultados se muestran como la media \pm el ESM. ${ }^{*} p<0.05 ; * * p<0,01$.

Estos resultados nos indican que durante una inflamación aguda, como en la fase II de las Ell (Fig. 2 de la introducción general), la respuesta fisiológica de la mucosa sería generar un glicofenotipo permisivo para que Gal-1 pueda ejercer su efecto pro-apoptótico sobre los LTLP. Sin embargo, cuando estas células se encuentran en un entorno inflamatorio crónico (como en la mucosa inflamad de pacientes con ElI), la capacidad pro-apoptóica de esta lectina se encuentra inhibida por la disminución de la expresión de C2GnT-1. Este hecho contribuiría a la permanencia de los LTLP en las zonas inflamadas, con la consecuente liberación de mediadores pro-inflamatorios que propician la cronicidad de la enfermedad. 


\section{DISCUSION}

Trabajos previos han demostrado que Gal-1 podría tener un rol en la fisiopatología de las Ell, de hecho, Santucci y colaboradores (2003) claramente demostraron que la administración exógena de Gal-1 revierte la inflamación en un modelo murino de colitis (Santucci y col., 2003). Probablemente dicha capacidad inmunomoduladora se deba, entre otros efectos, a su capacidad de inducir apoptosis sobre las células $T$ activadas en un proceso inflamatorio agudo (Santucci y col., 2003; Toscano y col., 2007). Sin embargo, en este trabajo probamos que en los entornos inflamatorios de pacientes con Ell se induce una glicosilación diferencial de los LT de la mucosa, mecanismo por el cual dichas células se vuelven resistentes a la muerte celular inducida por Gal-1. Al igual que las demás fallas en el control de la sobrevida de las células T (Neuman, 2007), estos cambios contribuirían a la persistencia de las mismas en la mucosa, con la consecuente liberación de mediadores pro-inflamatorios. Dichos efectos repercuten directamente en la integridad de la barrera epitelial y la activación de la inmunidad innata y adaptativa, perpetuando el proceso inflamatorio (Neurath, 2014; Geremia y col., 2014).

Gal-1, probablemente el miembro más estudiado de la familia de las Gals, está altamente relacionada con el control de la sobrevida de las células T (Toscano y col., 2007; Cabrera y col., 2006; Kopcow y col., 2008; Novák y col., 2014). Esta lectina es ampliamente expresada en los sitios inmunoprivilegio, tales como placenta, testículos y retina (Kopcow y col., 2008; Rabinovich y col., 2002; Uehara y col., 2001), hecho que refleja su preponderante rol regulatorio. Nuestros resultados muestran que bajo condiciones homeostáticas esta proteína es expresada principalmente por las células de la LP y ejerce un efecto pro-apoptótico sobre las células T de ese compartimento. Si bien los LT de periferia deben ser activados in vitro para expresar los ligandos de Gal-1 (Toscano y col., 2007), los provenientes de la mucosa intestinal mostraron ser capaces de unir esta lectina de manera constitutiva. Resultados similares 
fueron obtenidos en placenta, donde las células $T$ de la decidua mostraron un glicofenotipo permisivo para Gal-1 y diferente al de los LT de periferia (Kopcow y col., 2008). Según dichos autores, este sería un mecanismo fisiológico para proteger al feto de células T aloreactivas (Kopcow y col., 2008).

Teniendo en cuenta que el lumen gastrointestinal aloja un gran número de microorganismos comensales, patógenos y antígenos dietarios y medioambientales, los mecanismos para controlar la respuesta inmune local son esenciales a la hora de mantener la integridad del tejido y la homeostasis intestinal (Pasparakis, 2009). En este contexto, Gal-1 estaría ejerciendo una acción regulatoria sobre diferentes tipos celulares.

Siendo que las células $\mathrm{T}$ son uno de los componentes críticos de la respuesta inmune de la mucosa, es de crucial importancia mantener una estrecha vigilancia sobre las mismas (Baumgart \& Carding, 2007b; Geremia y col., 2014; Neurath, 2014). En el capítulo I se mostró que las zonas inflamadas de pacientes con Ell expresan mayores niveles de ARNm para Gal-1 que las zonas en homeostasis. Dado que esta lectina induce apoptosis en los LT provenientes de la mucosa colónica de pacientes control y zonas no inflamadas de pacientes con Ell, dicha respuesta en el tejido inflamado podría formar parte de un mecanismo compensatorio de la mucosa para evitar una respuesta inmune exacerbada. Estos resultados están en concordancia con Toscano y colaboradores (2012), quienes mostraron que en las células T de sangre periférica la expresión de Gal-1 está relacionada con estímulos inflamatorios. Los autores mostraron que la exposición a TNF- $\alpha$ promueve la expresión de Gal1 mediante la activación de NF-kB. En forma similar a lo que se observa en el sistema Fas/FasL, Gal-1 genera un efecto inhibidor sobre dicha vía de señalización (Toscano y col., 2011).

Por lo tanto, este mecanismo constituiría una respuesta fisiológica compensatoria para limitar la actividad de los LTLP. Sin embargo, la persistencia de los LT en las zonas inflamadas de pacientes con Ell induce una desregulación de la glicosilación de estas células. Dichos cambios repercuten en el glicofenotipo celular, impidiendo la unión de Gal-1 por un mecanismo 
independiente de la sialilación (Toscano y col., 2007). Del mismo modo, cambios en el glicofenotipo originados por estímulos ambientales también fueron observados por Croci y colaboradores (2014). Estos autores probaron que la exposición a citoquinas inmunosupresores (IL-10 y TGF- $\beta$ ) favorecen un glicofenotipo permisivo para Gal-1 en células del endotelio vascular, mientras que las señales pro-inflamatorias (IL-17 e INFY) reducen la expresión de los ligandos para esta lectina (Croci y col., 2014). Por lo tanto, es probable que en el caso de la mucosa intestinal de pacientes con Ell, los cambios en el balance entre citoquinas pro- y anti-inflamatorias durante un período de recaída pudiera influir en la capacidad de los LTLP de unir Gal-1.

Nuestro hallazgo confirma que en el tejido inflamado hay una menor frecuencia de LT PNA ${ }^{+}$, en comparación con muestras provenientes de zonas no inflamados o de pacientes control. Por otra parte, no se detectó unión de SNA en los tejidos inflamados o no inflamados. Este hecho indica que, a diferencia de lo observado en las células T de sangre periférica, la sialilación no está implicada en el control de la unión a Gal-1 (Toscano y col., 2007). Por lo tanto, la pérdida de la capacidad de unir esta lectina sería debido a una reducción de los sitios glicosilados específicos, en lugar de un enmascarado de los mismos con ácido siálico.

Para alcanzar una mejor comprensión de este mecanismo se estudió la expresión de las enzimas implicadas en la glicosilación de las proteínas de membrana. C2GnT-1 es una enzima que modifica dichas proteínas en el aparato de Golgi para su posterior exportación a la membrana celular (Wopereis y col., 2006). Esta enzima es responsable de la ramificación de los O-glicanos en los leucocitos a través de la adición de $\mathrm{N}$-acetilglucosamina al núcleo-1, permitiendo la configuración de un sitio apto para la unión de Gal-1 (Daniels y col., 2002).

Nuestros resultados demuestran que la inflamación crónica de la Ell regula de manera negativa la expresión de C2GnT-1. Teniendo en cuenta que una sola glicosiltransferasa puede modificar numerosas y diferentes glicoproteínas (Varki y col., 2000; Wu y col., 1996), cambios modestos en la 
actividad de estas enzimas, o en su localización, pueden alterar profundamente el glicofenotipo celular. De hecho, se ha demostrado que una reducción del $30 \%$ en la actividad sialiltransferasa en las células $\mathrm{T} \mathrm{CD}^{+}$activadas es suficiente para suprimir la adición de ácido siálico terminal a CD45 (Amado y col., 2004). Teniendo en cuenta que en células T la pérdida de expresión de C2GnT-1 ha sido relacionada con la pérdida de sensibilidad a Gal-1 (Cabrera y col., 2006), se decidió estudiar si esta enzima estaba diferencialmente expresada en las zonas inflamadas de pacientes con Ell. Pudimos determinar que en los tejidos inflamados de pacientes con CU y EC se expresan niveles más bajos de C2GnT-1 en comparación con los tejidos no inflamados o en muestras provenientes de pacientes control. Es importante destacar que la expresión de esta enzima se incrementó en las zonas en remisión de Ell, reflejando la actividad del tejido. Además, las células $\mathrm{CD}^{+}$asiladas de la LP de pacientes con Ell (tanto zonas no inflamadas como zonas inflamadas) mostraron este mismo comportamiento.

Con el fin de determinar si el comportamiento observado en los LTLP aislados de un proceso inflamatorio crónico es similar al de un proceso agudo, decidimos cultivar biopsias de pacientes control en presencia de TNF- $\alpha$. En este caso pudimos observar que esta citoquina estimula la expresión de C2GnT-1. Este resultado, sumado al incremento en la capacidad de unir tanto PNA como Gal-1 por parte de células Jurkat tratadas con TNF- $\alpha$, sugiere que la respuesta normal de la mucosa frente a un estímulo inflamatorio agudo es incrementar los ligandos específicos para Gal-1. Sin embargo, la mucosa se comporta de manera diferencial cuando el foco inflamatorio es crónico, y la población $T$ desarrolla un glicofenotipo no permisivo para esta lectina. Estos cambios contribuyen a la persistencia de los LT en la mucosa inflamada de pacientes con Ell, fenómeno que no había sido descripto hasta el momento.

En conclusión, los LTLP poseen un glicofenotipo particular que les permite unir Gal-1 en situaciones de homeostasis y en un proceso inflamatorio agudo frente a un estímulo antigénico. Este mecanismo actuaría como control fisiológico en la sobrevida de las células $T$ una vez que el estímulo fue controlado o eliminado. Sin embargo, el ambiente inflamatorio crónico de las 
Ell inhibe la maquinaria de glicosilación, impidiendo la unión de esta lectina.

Dichos cambios hacen que la población T sea refractaria a la muerte celular inducida por Gal-1, contribuyendo a la persistencia de los mismos en el foco inflamatorio. 



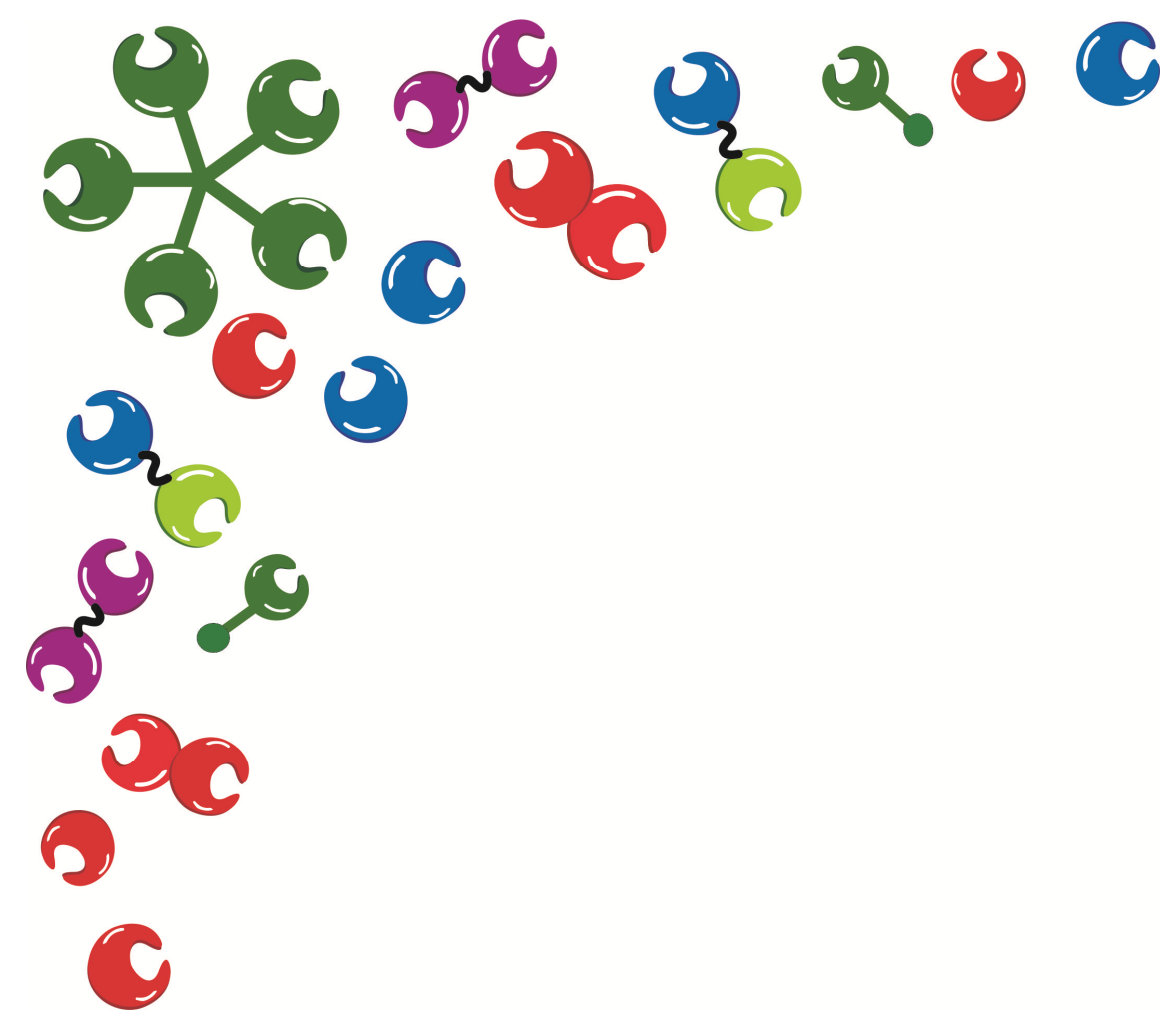

CAPITULO IV

Galectina-1 controla la sobrevida de las células epiteliales en el intestino 



\section{INTRODUCCIÓN}

La mucosa intestinal es continuamente desafiada por una gran variedad de antígenos dietarios y de microorganismos tanto comensales como patógenos. Estos deben ser cuidadosamente discriminados para estimular una respuesta inmune o la inducción de tolerancia, según corresponda (Puthenedam y col., 2011).

El epitelio intestinal es una parte esencial de la mucosa, ya que cada uno de los tipos celulares que la componen (células $M$, de Paneth, caliciformes, enteroendocrinas y enterocitos) contribuyen a formar una barrera semipermeable que separa la LP del lumen. Además de su función de interface, las CEI participan en la absorción de nutrientes y defensa contra microorganismos, permitiendo la mantención de un delicado equilibrio entre homeostasis e inflamación (Garrett y col., 2010). Uno de los mecanismos por los cuales el epitelio mantiene la funcionalidad de la barrera es mediante un constante recambio de las células que lo componen. De hecho, este tejido es 
tan dinámico que logra una completa renovación cada 3-5 días (Edelblum y col., 2006). Esto es posible gracias al balance entre proliferación, diferenciación y apoptosis de sus células. Durante dicho proceso las células epiteliales se diferencian a partir de células madre ubicadas en las criptas y migran hacia la punta de la vellosidad. A medida que se produce este desplazamiento las células van experimentando un controlado programa de maduración, el cual culmina con su pérdida luego de morir por apoptosis (Gassler y col., 2007; Gordon \& Hermiston, 1994).

Mantener la integridad del epitelio es crítico para la homeostasis del intestino, ya que en el lumen se encuentra el mayor y más diverso conjunto de microorganismos procariotas y eucariotas con el cual el organismo está en contacto (Hooper \& Gordon, 2001). Si bien existen mecanismos fisiológicos para evitar el ingreso de microorganismos desde el lumen durante la regeneración del epitelio, ciertos estímulos pueden inducir una tasa de apoptosis que compromete la integridad y permeabilidad de la barrera epitelial $y$, por lo tanto, incrementa la susceptibilidad a infecciones (Hooper \& Gordon, 2001). En modelos animales se ha probado que el aumento de la permeabilidad intestinal es un factor que predispone a desarrollar inflamación intestinal (Garrett y col, 2010).

En el caso de las Ell, la activación aberrante de la inmunidad, tanto innata como adaptativa, estimula una descontrolada apoptosis de las células de la cripta (Di Sabatino y col., 2003; Goretsky y col., 2012). Dicho incremento en la apoptosis es atribuido a la exposición a estímulos pro-inflamatorios como IL-13, TNF- $\alpha$ e IFN- $\gamma$ (Di Sabatino y col., 2003; Goretsky y col., 2012; Edelblum y col., 2006; Geremia y col., 2014). Si bien en los últimos años se ha comenzado a comprender alguno de los mecanismos subyacentes, poco es lo que se sabe sobre cómo estos mediadores inflamatorios pueden ocasionar la disrupción de la barrera epitelial. En relación a esto, Goretsky y colaboradores (2012) descubrieron que TNF- $\alpha$ induce la producción de especies reactivas de nitrógeno, a través de la activación de la oxido nítrico sintasa. Este proceso induce la muerte celular por un mecanismo dependiente de p53 (Biancheri y 
col., 2014). La importancia de estos mecanismos se pone en manifiesto con el uso de los anticuerpos bloqueantes de TNF- $\alpha$. Si bien las vías de señalización que son afectadas por este fármaco aún no han sido completamente descriptas, lo pacientes que utilizan este tratamiento obtienen una significativa mejoría en sus signos clínicos y una reducción en la tasa de apoptosis epitelial de las zonas afectadas (Goretsky y col., 2012). Por lo tanto, regular la sobrevida de estas células es clave para evitar el ingreso de microorganismo y antígenos de la dieta al interior de la mucosa (Garrett y col., 2010).

Varios miembros de la familia de las Gals se expresan a lo largo del tracto digestivo en condiciones fisiológicas y patológicas (Müller y col., 2006; Nio-Kobayashi y col., 2009; Paclik y col., 2008; Paclik y col., 2008) y, como hemos mencionado en diferentes pasajes de este trabajo, han sido relacionadas con diversos aspectos de las Ell (Demetter y col., 2008; Hokama y col., 2008). Gal-2, -3 y -4 son producidas por el epitelio intestinal y tienen capacidad de regular la sobrevida de las células T (Müller y col., 2006; Paclik y col., 2008; Paclik y col.,, 2008) y estimular la regeneración de la mucosa (Paclik y col., 2008; Puthenedam y col., 2011). En cuanto a Gal-1, Santucci y colaboradores (2003) obtuvieron importantes resultados en cuanto a la capacidad de esta lectina de modular la colitis inducida por TNBS (Santucci y col., 2003). Trabajos previos de nuestro grupo demostraron que esta Gal-1 es uno de los factores que regulan la sobrevida de los enterocitos mientras estos migran por el eje cripta-vellosidad, y que dicho control se ejerce por medio de mecanismos que involucran capasas y la vía mitocondrial (Muglia y col., 2011). En función de estos resultados previos decidimos analizar el rol de Gal-1 en la sobrevida de las células epiteliales de ratón y humanas en un contexto de homeostasis e inflamación. 



\section{OBJETIVOS ESPECÍFICOS}

\section{Evaluar:}

- Los cambios que un ambiente inflamatorio in vitro inducen en la capacidad de unir Gal-1 por parte de los enterocitos.

- El rol de Gal 1 en la sobrevida de los enterocitos luego de la exposición in vitro a citoquinas pro-inflamatorias.

- El mecanismo por el cual Gal-1 induce apoptosis en enterocitos.

- Los cambios que un ambiente inflamatorio in vivo inducen en la capacidad de unir Gal-1 por parte de los enterocitos y su susceptibilidad a la muerte celular inducida por esta lectina. 



\section{RESULTADOS Y CONCLUSIONES PARCIALES}

El entorno inflamatorio modula la capacidad de los enterocitos de unir Gal-1, así como su susceptibilidad a la muerte celular

A fin de profundizar sobre el rol de Gal-1 en la mucosa intestinal, decidimos estudiar la relación entre esta lectina y el compartimento epitelial en situaciones de homeostasis e inflamación. Para tal fin aislamos enterocitos de ratón y los incubamos en presencia de diferentes citoquinas pro-inflamatorias de la inmunidad innata y adaptativa (IL-1 $\beta$, IFN- $\gamma$, TNF- $\alpha$, IL-5 e IL-13). Posteriormente evaluamos su capacidad de unir Gal-1 y la susceptibilidad a la muerte celular.

Como se muestra en la figura 4.1 A, la exposición a IL-1 $\beta$, TNF- $\alpha$ e IL-13 incrementa la capacidad de las CEI de unir Gal-1. Este hallazgo indica que la expresión de los ligandos específicos para esta lectina pueden ser inducidos por diferentes ambientes pro-inflamatorios. Considerando que en trabajos previos de nuestro grupo se determinó que Gal-1 regula la sobrevida de este tipo de células (Muglia y col., 2011), decidimos estudiar si un entorno inflamatorio in vitro potenciaba dicho efecto. Observamos que la exposición de las CEI a las citoquinas que incrementan su capacidad de unir Gal-1 también aumentan su susceptibilidad a la muerte celular por esta lectina (Fig. 4.1 B). De hecho, sólo un $7 \%$ de los enterocitos incubados con medio de cultivo y Gal-1 resultaron positivos para la tinción con Anexina $V$, mientras que más del $20 \%$ de las células tratadas con IL-1 $\beta$, TNF- $\alpha$ o IL-13, y luego con Gal-1 durante $6 \mathrm{hs}$, mostraron ser Anexina $\mathrm{V}^{+}$. Por lo tanto, la exposición a determinados mediadores proinflamatorios estimula la muerte celular inducida por Gal-1. 

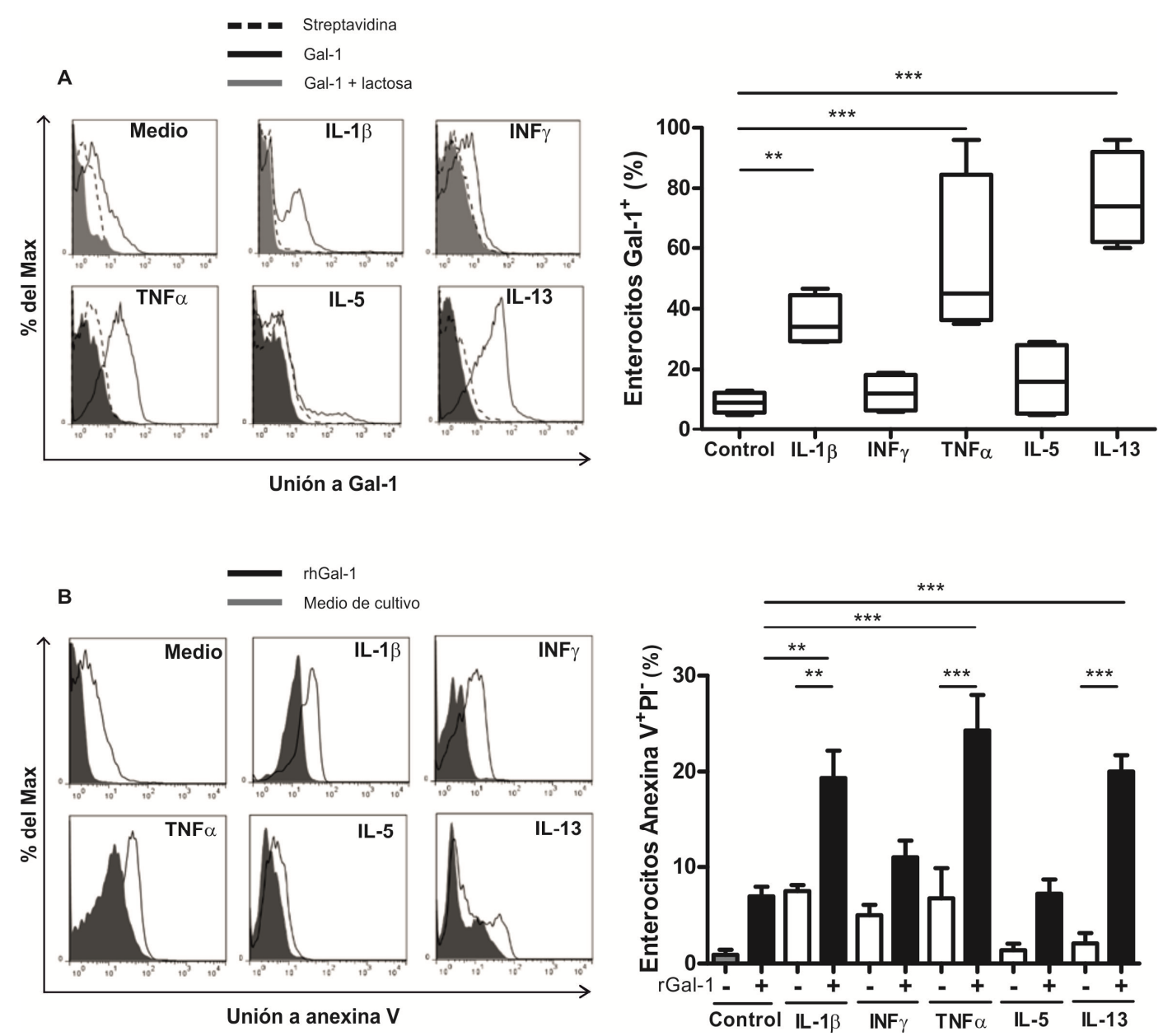

Fig. 4.1: Análisis de la capacidad de unión de Gal-1 e inducción de apoptosis en enterocitos frente a estímulos pro-inflamatorios.

La capacidad de unir Gal-1 biotinilada y la inducción de apoptosis (tinción con anexina V y IP) fueron analizadas por citometría de flujo. A) Capacidad de unir Gal-1 por parte de enterocitos previamente incubados con diferentes estímulos inflamatorios. Se muestran histogramas representativos de cada uno de los estímulos ensayados y el análisis estadístico correspondiente $(n=12)$. La línea con relleno gris pertenece a enterocitos incubados con streptavidina-APC, la línea punteada a enterocitos incubados con Gal-1 y lactosa (100mM) y la línea continua sin relleno pertenece a enterocitos incubados con Gal-1. B) Tinción con anexina $V$ y IP en células epiteliales incubadas con IL-1 $\beta$, IL-5, IL-13, TNF- $\alpha$ o IFN- $\gamma(50 \mathrm{ng} / \mathrm{mL})$ y luego con rhGal-1 (100 ug/mL). Sólo se analizaron las células en apoptosis temprana (anexina $\left.V^{+} I P^{-}\right)$. Se muestran histogramas representativos para cada una de las condiciones ensayadas y el análisis estadístico correspondiente $(n=6)$. Los resultados están expresados como la media \pm ESM $* * p<0,01 ; * * * p<0,001$ 
Con el objetivo de ahondar sobre los mecanismos de muerte celular inducidos por esta lectina, decidimos analizar el potencial de membrana mitocondrial en enterocitos aislados de ratón. Los cambios en la permeabilidad mitocondrial fueron evidenciados por medio de la tinción con JC1 y posterior análisis de las células por citometría de flujo. Pudimos determinar que la vía mitocondrial de apoptosis era inducida si luego de incubar las CEI con IL-1B, TNF- $\alpha$ o IL-13, las mismas eran tratadas con Gal-1 (4.2 A). Además, por medio del análisis fluorométricos con sustratos específicos de las diferentes caspasas y sus inhibidores pudimos determinar que Gal-1 induce la activación de la caspasa 9 (Fig. 4.2 B). De la misma manera, al analizar por citometría de flujo la inducción de diferentes factores pro- y anti-apoptoticos, observamos que Gal-1 incrementa los niveles de Bad y Bax y disminuye los de Bcl-2 (Fig. 4.2 C-E). 


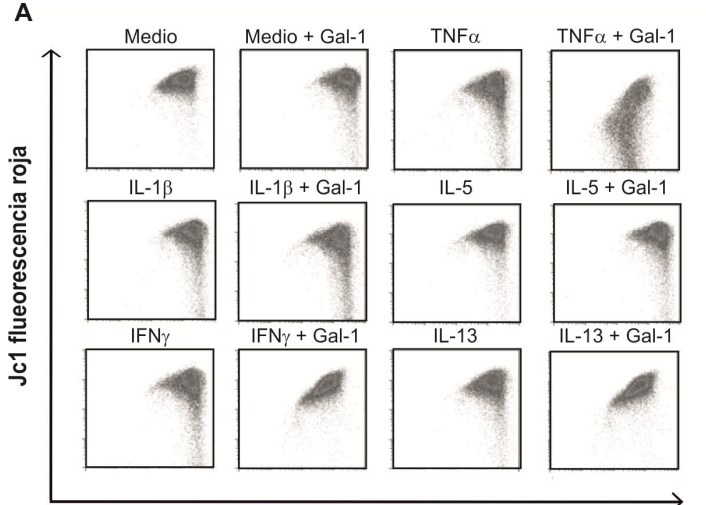

Jc1 fluorescencia verde
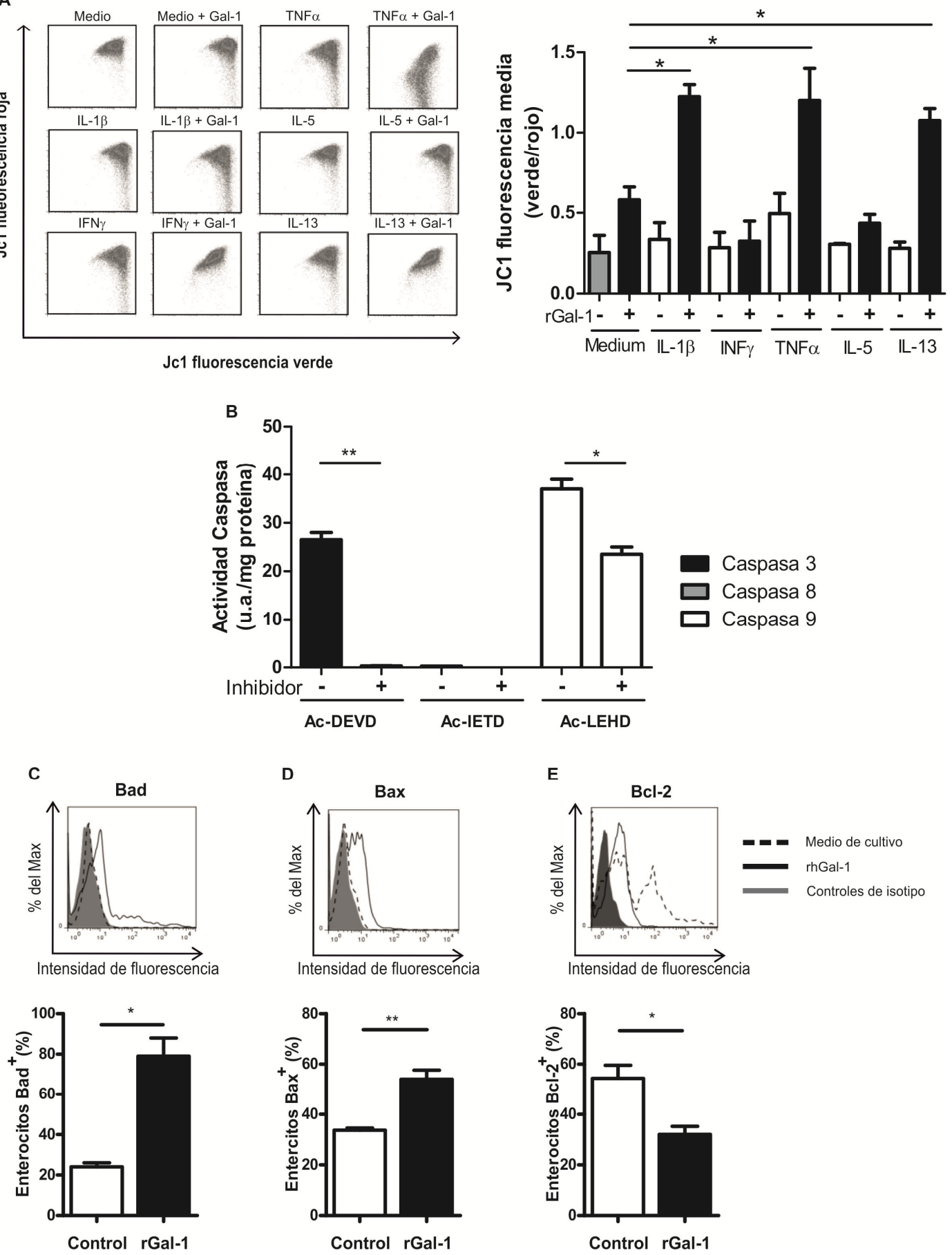

Fig. 4.2: Análisis de los mecanismos de apoptosis inducidos por Gal-1 en enterocitos murinos.

A) Análisis por citometría de flujo del potencial de membrana mitocondrial (tinción con JC1) de enterocitos incubados primero con diferentes estímulos pro-inflamatorios y posteriormente con rhGal-1 (100 $\mathrm{\mu g} / \mathrm{mL})$. Se muestran dot-blot representativos de la fluorescencia roja y verde para cada uno de los estímulos ensayados y el análisis estadístico correspondiente $(n=6)$. Los valores corresponden al cociente de fluorescencia verde/fluorescencia roja. B) Análisis de la actividad de las caspasa 3, 8 y 9 en enterocitos incubados con rGal-1 $(100 \mu \mathrm{g} / \mathrm{mL})$. La actividad 
de las caspasas fue evaluada por fluorometría empleando sustratos e inhibidores específicos. C) Análisis de la expresión de Bad, Bax y Bcl-2 por citometría de flujo en enterocitos incubados con rhGal-1 (100 $\mu \mathrm{g} / \mathrm{mL})$. Luego de ser incubadas con rhGal-1 las células fueron permeabilizadas y teñidas con anticuerpos específicos. Se muestran histogramas representativos para cada una de estas proteínas pro-apoptoticas (la línea con relleno gris corresponde a los controles de isotipo, la línea punteada a células tratadas sólo con medio de cultivo y la línea continua sin relleno a enterocitos incubados con rhGal-1) y el análisis estadístico correspondiente $(n=6)$. Los resultados están expresados como la media $\pm \mathrm{ESM} * \mathrm{p}<0,5 ;{ }^{*} \mathrm{p}<0,01$.

Por lo tanto, encontramos que al incubar enterocitos murinos con citoquinas pro-inflamatorias se potencia el efecto pro-apoptótico de Gal-1, promoviendo la inducción de la vía endógena dependiente de la mitocondria, la activación de la caspasa 9 y alteraciones en la relación entre factores pro- y anti-apoptóticos.

\section{El entorno inflamatorio promueve in vivo un glicofenotipo permisivo para el reconocimiento de Gal-1 en los enterocitos y favorece la inducción de apoptosis}

Con el objetivo de determinar si un ambiente inflamatorio in vivo podía modular la capacidad de los enterocitos de unir Gal-1, así como su susceptibilidad a la muerte celular, se analizaron células epiteliales de colon provenientes de un modelo murino de colitis inducido por TNBS y ratones control. Las características de los ratones tratados con TNBS y los ratones control se muestra en la figura 2.4. Brevemente, en los ratones tratados con TNBS se observó una significativa pérdida de peso, diarrea, sangrado, alteraciones a nivel macroscópico e histológico y un significativo incremento en los niveles de ARNm para Tnf- $\alpha$, Ifn- $\gamma$ y T-bet. Como hemos demostrado en trabajos previos (Muglia y col., 2011), los enterocitos tienen una capacidad innata de unir esta lectina. Sin embargo, como se muestra en figura $4.3 \mathrm{~A}$, el porcentaje de $\mathrm{CEI}-\mathrm{Gal}-1^{+}$se ve significativamente incrementado en los ratones tratados con TNBS (CEI-Gal-1': 15,8 \pm 4,2 \% vs. $50 \pm$ 7,9 \%, grupo control y grupo colitis respectivamente). Estos resultados son consistentes con los 
obtenidos in vitro, donde observamos que IL-1 $\beta$, TNF- $\alpha$ e IL-13 estimulan la expresión de los ligandos específicos para esta lectina.

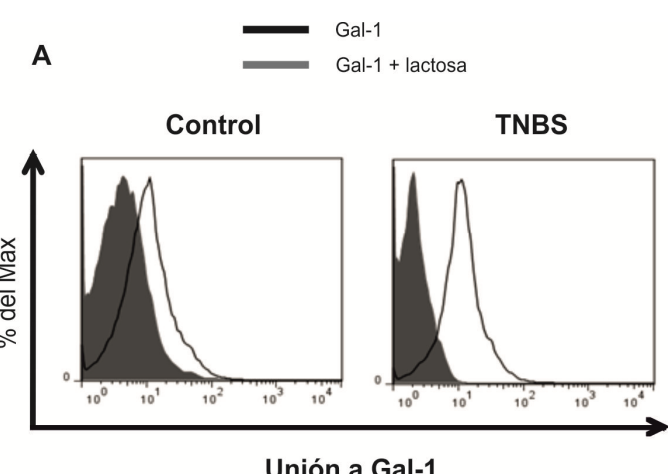

Unión a Gal-1

B

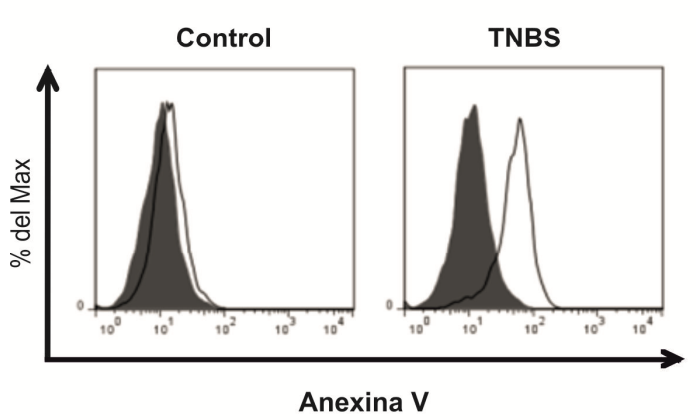

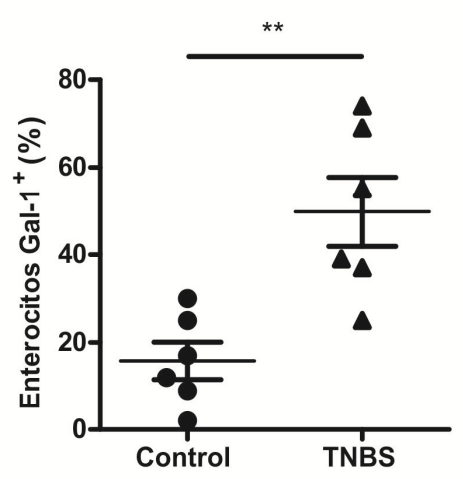

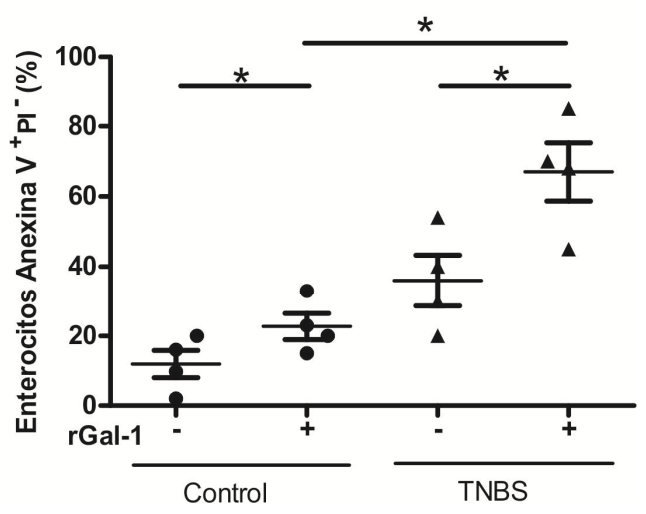

Fig. 4.3: Análisis del reconocimiento de Gal-1 e inducción de apoptosis en enterocitos aislados de ratones con colitis.

La capacidad de unir Gal-1 y la tinción con anexina V y IP fueron analizadas por citometría de flujo. A) Capacidad de unir Gal-1 por parte de los enterocitos provenientes de ratones tratados con TNBS y ratones control. Se muestran los histogramas representativos de cada uno de los grupos y el análisis estadístico correspondiente ( $n=6$ por grupo). Como control se incubaron enterocitos con Gal-1 y lactosa (100mM). B) Tinción con anexina V y IP en células epiteliales provenientes de ratones tratados con TNBS y ratones control luego de ser incubadas con medio de cultivo o rGal-1 $(70 \mu \mathrm{g} / \mathrm{mL})$ durante $18 \mathrm{hs}$. Sólo se analizaron las células en apoptosis temprana (anexina $\mathrm{V}^{+} \mathrm{IP} \mathrm{P}^{-}$). Se muestran los histogramas representativos de cada uno de los grupos (las líneas con relleno gris corresponden a enterocitos incubados con medio de cultivo, mientras que las líneas sin relleno corresponden a células tratadas con rhGal-1) y el análisis estadístico correspondiente ( $n=4$ por grupo). Los resultados están expresados como la media \pm $\operatorname{ESM} * p<0,05 ; * * p<0,01$. 
Posteriormente estudiamos el efecto pro-apoptótico de Gal-1 sobre esta población y observamos que las células provenientes de ratones tratados con TNBS son más sensibles a la apoptosis por Gal-1 que aquellas obtenidas a partir de ratones control (Fig. 4.3 B). Si bien en ambos grupos ocurre muerte celular espontánea (11 \pm 3,9 \% vs. $36 \pm 7,2 \%$, grupo control y tratado con TNBS respectivamente), el porcentaje de células sensibles a esta lectina resultó significativamente mayor en los ratones a los que se les indujo la colitis. De hecho, la frecuencia de células anexina $\mathrm{V}^{+} / \mathrm{IP}^{-}$fue del $22 \pm 3,8 \%$ para los enterocitos de ratones controles tratados con Gal-1, mientras que en células de ratones con colitis la misma resultó del $67 \pm 8,2 \%$.

\section{La capacidad de unir Gal-1 y la susceptibilidad a la muerte celular inducida por esta lectina está incrementada en pacientes con enfermedad inflamatoria intestinal}

Teniendo en cuenta estos resultados, decidimos estudiar si el foco inflamatorio crónico presente en pacientes con Ell también podría modificar la sensibilidad de los enterocitos a Gal-1. Para tal fin aislamos CEI del colon de pacientes con CU, EC (zonas no inflamadas e inflamadas) y pacientes control. Comparamos de manera pareada la capacidad de unir Gal-1 de las células provenientes de zonas no inflamadas e inflamadas de un mismo paciente con Ell y, a su vez, con muestras de pacientes control.

Como se muestra en la figura $4.4 \mathrm{~A}$, el porcentaje de enterocitos que unen Gal-1 resultó significativamente mayor en las zonas inflamadas que en las zonas no inflamadas, y que en las de pacientes control. De hecho, el $25 \pm 4 \%$ de las células epiteliales provenientes de zonas inflamadas resultaron Gal-1 ${ }^{+}$, mientras que en las zonas no inflamadas y en muestras provenientes de pacientes control sólo el $11 \pm 1,95 \%$ y 6,33 $\pm 1,43 \%$ de las CEI mostró capacidad de unir esta lectina, respectivamente. Estos resultados demuestran que en los enterocitos la susceptibilidad a la muerte celular inducida por Gal-1 se ve alterada cuando se pierde la homeostasis del tejido. 
Para corroborar y confirmar este hallazgo incubamos biopsias provenientes de pacientes control y pacientes con Ell (zonas no inflamadas e inflamadas) con rhGal-1 $(70 \mu \mathrm{g} / \mathrm{mL})$ y estudiamos la presencia de células apoptóticas (técnica de TUNEL) por microscopia confocal de fluorescencia. Como muestra la figura $4.4 \mathrm{~B}$, pudimos observar que en pacientes con Ell el compartimento epitelial de las zonas inflamadas presenta un mayor número de células $\mathrm{TUNEL}^{+}$luego de ser incubadas con Gal-1, en relación a las zonas no inflamadas o provenientes de pacientes control (en la figura se muestran resultados representativos, obtenidos de muestras de colon de un paciente control y un paciente con $\mathrm{CU}$ ). 


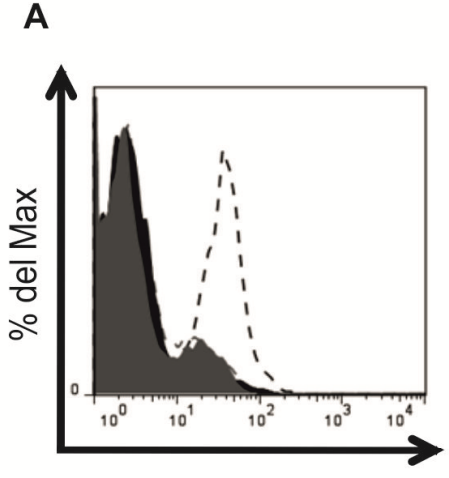

Unión a Gal-1

- - Enterocitos zona inflamada Gal-1

- Enterocitos zona no inflamada Gal-1

Enterocitos zona inflamada Gal-1 + lactosa

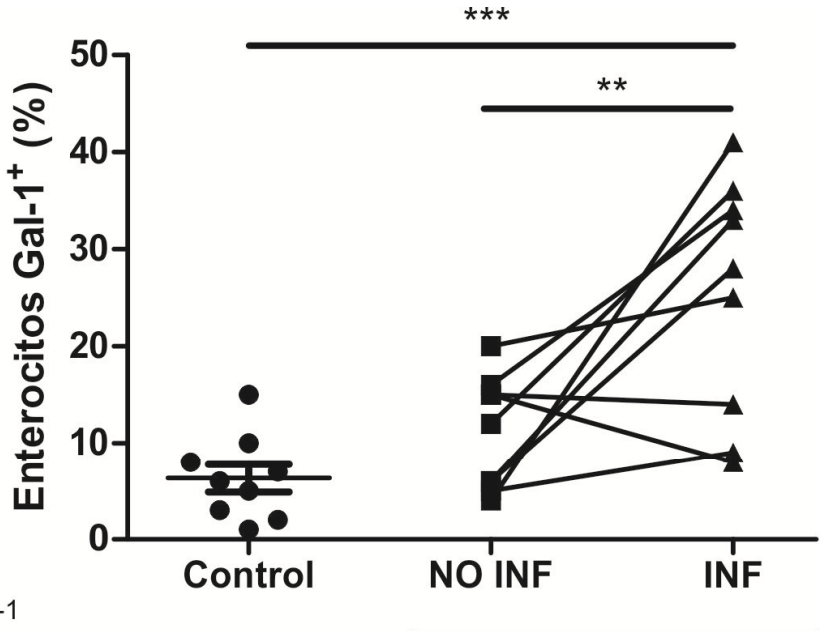

EII

Enterocitos zona no inflamada Gal-1 + lactosa

B

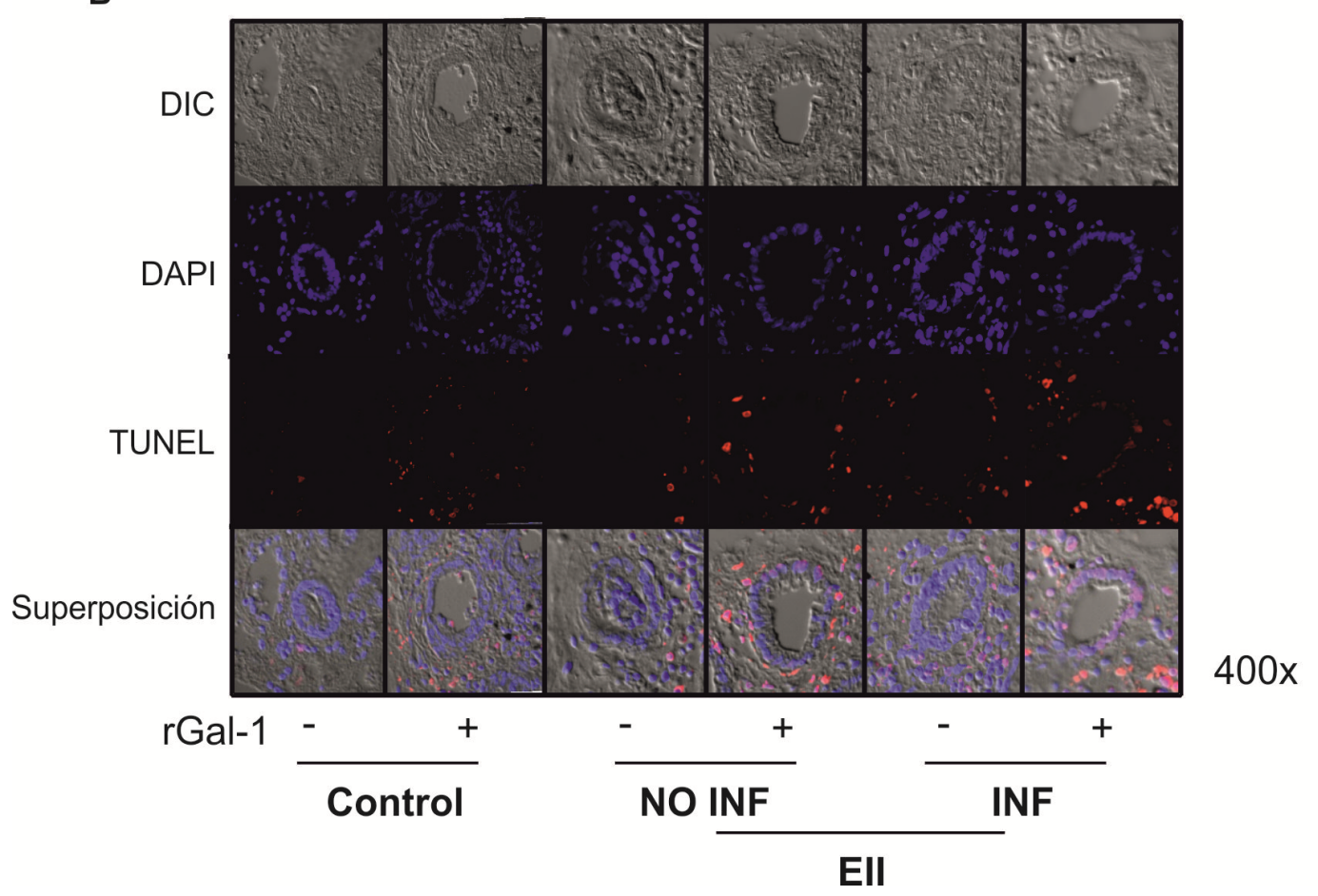

Fig. 4.4: Análisis de la capacidad de unión de Gal-1 de enterocitos aislados de pacientes control y pacientes con Ell, y de la presencia de células apoptóticas en la mucosa colónica luego de la incubación con Gal-1.

A) Capacidad de unir Gal-1 por parte de los enterocitos provenientes de pacientes control, zonas no inflamadas e inflamadas de pacientes con Ell. Se muestra un histograma representativo de la capacidad de unir Gal-1 en zonas no inflamadas e inflamadas en un paciente con EC y el análisis estadístico correspondiente (pacientes control, n=9; pacientes con 
EII, $n=9)$. En el histograma las líneas con relleno negro y gris perteneces a enterocitos provenientes de zonas infamadas y no inflamadas (respectivamente) incubados con Gal-1 y lactosa $(100 \mathrm{mM})$, la línea punteada negra y la gris corresponde a enterocitos provenientes de zonas infamadas y no inflamadas (respectivamente) incubados con Gal-1. Los resultados están expresados como la media $\pm \operatorname{ESM}\left({ }^{* *} p<0,01 ;{ }^{* *} p<0,001\right)$. B) Apoptosis en biopsias de colon proveniente de pacientes control $(n=4)$ y pacientes con Ell $(n=4)$ incubadas con rhGal-1.La inducción de apoptosis fue analizada por la técnica de TUNEL a través de microscopia confocal de fluorescencia. Las biopsias fueron incubadas durante 18 hs en presencia o ausencia de rhGal$1(70 \mu \mathrm{g} / \mathrm{mL})$. Los núcleos se muestran en azul (DAPI) o rojo (TUNEL). Los resultados mostrados corresponden a un paciente control y un paciente con CU representativos. DIC: differential contrast microscopy.

En conjunto, estos resultados indican que el ambiente inflamatorio del intestino de pacientes con Ell promueve la expresión de un glicofenotipo permisivo para Gal-1 en el compartimento epitelial. Estos cambios modulan la sobrevida de las CEI y, probablemente, la integridad y permeabilidad de la barrera epitelial, con la consecuente traslocación de antígenos microbianos desde el lumen intestinal. Por lo tanto sostenemos que estos fenómenos estarían propiciando la persistencia del foco inflamatorio. 


\section{DISCUSIÓN}

Para hacer frente a los antígenos y microorganismos a los cuales está expuesto el intestino, la mucosa está equipa con una compleja red de células y mediadores solubles que mantienen un dinámico balance entre homeostasis e inflamación (Baumgart \& Carding, 2007b; Geremia y col., 2014; Neurath, 2014). En este complejo escenario el compartimento epitelial cumple funciones básicas tales como la producción de moco, péptidos antimicrobianos (defensinas $\alpha$ y $\beta$ ) y citoquinas (TGF- $\beta$ ). Además, dependiendo del antígeno al que se esté expuesto, la interacción de las células epiteliales con otras células del sistema inmune delinean el tipo de mecanismo inmunológico que se inducirá (Geremia y col., 2014; Neurath, 2014).

En trabajos previos se ha documentado que las Gals son expresadas en forma ubicua en todo el tracto intestinal, tanto en situaciones fisiológicas como patológicas (Demetter y col., 2008; Nio-Kobayashi y col., 2009). Si bien varias son las lectinas que han sido implicadas en la fisiopatología de las Ell (Hokama, 2008), Gal-1 es de particular importancia, ya que ha demostrado un rol protector en un modelo murino de colitis inducido por TNBS. Dicho rol protector parece estar relacionado con la inducción de apoptosis en células T activadas de la mucosa (Santucci y col., 2003). Sin embargo, también es posible que el mecanismo implicado se relacione con la inducción de un perfil tolerogénico (mediado por IL-10 e IL-27 ) por parte de las células dendríticas (Ilarregui y col., 2009).

En las Ell se ha documentado la secreción exacerbada de mediadores pro-inflamatorios, así como la desregulación de la respuesta inmune y la pérdida de la integridad de la barrera epitelial (Di Sabatino y col., 2003; Goretsky y col., 2012). A pesar del mencionado efecto inmunoregulador de Gal1, no hay estudios sobre su rol en las Ell. Considerando el papel central que el epitelio juega en la regulación de la homeostasis intestinal, hemos investigado si esta lectina ejerce algún efecto sobre las CEI. 
Existen numerosos trabajos que relacionan la apoptosis de las CEI con la patogénesis de la inflamación de la mucosa. Di sabatino y colaboradores (2003) demostraron que el incremento en la apoptosis de enterocitos está asociada con la EC, donde la tasa de células apoptóticas es significativamente mayor en las zonas inflamadas en comparación a las zonas no inflamadas. De manera consistente con esos trabajos Helller y colaboradores (2005) demostraron que, en pacientes con CU, IL-13 afecta la funcionalidad de la barrera epitelial al inducir apoptosis de los enterocitos (Heller y col.., 2005). Además, esta citoquina afecta la expresión de moléculas que forman parte de las uniones estrechas de las CEI, con lo cual su expresión en la mucosa repercute en la permeabilidad intestinal (Pender y col., 2005). A su vez, la exposición a TNF- $\alpha$ e IFN- $\gamma$ también probó ser un factor clave en la sobrevida de las células del epitelio intetinal (Heller y col., 2005; Goretesky y col., 2012). De la misma manera, existen antecedentes en los cuales Gal-1 induce apoptosis en la línea celular Caco-2 (línea celular de colonocitos tumorales humanos) a través de un mecanismo dependiente de calpaína e independiente de caspasas (Wells y col., 1999). En trabajos previos de nuestro grupo hemos demostrado que esta lectina induce apoptosis en enterocitos de ratón y humanos a través de la vía mitocondrial y con activación de la caspasa 3 (Muglia y col., 2011).

En el presente trabajo probamos que el mecanismo de muerte celular de las CEI no sólo es a través de la vía intrínseca, sino que involucra otros mecanismos. De hecho, pudimos determinar que en las $\mathrm{CEl}$; la muerte celular inducida por Gal-1 es dependiente de caspasa-9 y de la relación entre mediadores pro- y anti-apoptóticos, dado que hallamos incremento en los niveles de Bax y Bad y disminución de Bcl-2. Además, demostramos que un ambiente inflamatorio con características Th1, como es el inducido por TNBS y el que se instaura en los pacientes con Ell, modula la maquinaria de glicosilacion del epitelio intestinal, incrementando el porcentaje de células con ligandos específicos para Gal-1. Este fenómeno afecta la susceptibilidad de las CEI a la inducción de apoptosis por Gal-1. 
Existen antecedentes de alteraciones en la glicosilacion del epitelio durante procesos patogénicos del intestino (inflamación y neoplasia), principalmente afectando los O-glicanos (An y col., 2007; Fu y col., 2011; Goto y col., 2014). Recientemente Croci y colaboradores (2014) demostraron que, en células del epitelio endotelial, las citoquinas inmunosupresoras (IL-10 y TGF- $\beta 1$ ) inducen la expresión de un glicofenotipo más permisivo para Gal-1. A su vez, la exposición a mediadores inflamatorios, como IFN- $\gamma$ e IL-17, disminuye los ligandos para esta lectina (Croci y col., 2014). Considerando que la presencia de citoquinas pro-inflamatorias modifica la expresión de glicosidasas y glicosiltransferasas (responsables de sintetizar los glicanos de superficie) y, por lo tanto, del glicofenotipo celular, es necesario profundizar los estudios sobre los mecanismos que generan estos cambios en contextos donde hay una disrupción de la homeostasis intestinal.

En conclusión, estos resultados demuestran que la exposición a estímulos pro-inflamatorios incrementa la sensibilidad de las CEI a la muerte celular inducida por Gal-1. Este proceso es mediado por la vía mitocondrial y caspasa dependiente y puede contribuir a la pérdida de la integridad epitelial. Este fenómeno estaría incrementando la permeabilidad intestinal, lo cual indefectiblemente modifica los diferentes y complejos circuitos regulatorios que operan en esta mucosa. 

DISCUSIÓN Y CONCLUSIONES FINALES 



\section{DISCUSIÓN FINAL}

En el presente trabajo de tesis estudiamos distintos aspectos de la vinculación entre las Gals y la fisiología de las Ell. En primera instancia nos centramos en el estudio de la expresión génica de Gals como biomarcadores de inflamación. Como hemos mencionado previamente, el desarrollo de biomarcadores que permitan un mayor conocimiento sobre la patogénesis, el pronóstico y la terapia dirigida es una importante necesidad insatisfecha en el campo de las Ell. Por lo tanto, hallar nuevos marcadores que aporten información sobre la historia de la enfermedad en un paciente con Ell es un objetivo importante de la comunidad médica y científica.

En este sentido, nos dedicamos a analizar los niveles de expresión de 4 Gals que previamente habían sido asociadas con diferentes situaciones de las EII (Lippert y col., 2008; Müller y col., 2006; Paclik y col., 2008; Santucci y col., 2003), así como en otras enfermedades inflamatorias del intestino (Demetter y col. 2008). Utilizando una aproximación multivariada pudimos determinar que en pacientes con CU y EC, la expresión de LGALS1, 3, 4 y 9 puede discernir entre 
la mucosa inflamada y la mucosa no inflamada, en remisión y control. A su vez, los niveles de ARNm de estas Gals también reflejan la actividad del proceso inflamatorio, y permiten diferenciar entre Ell y otros tipos de inflamación intestinal crónica (enfermedad celíaca) y aguda (rechazo al trasplante de intestino). Probablemente, la capacidad de discernir entre las diferentes patologías inflamatorias intestinales esté relacionada con los mecanismos fisiopatológicos que las gobiernan.

$\mathrm{Si}$ bien actualmente se encuentran disponibles diversos marcadores biológicos de sangre y fecales para complementar la evaluación clínica y ayudar en el diagnóstico de las Ell (Abraham \& Thirumurthi, 2009), la toma de muestras durante la colonoscopia, sigue siendo un procedimiento insustituible a la hora de realizar el diagnostico y evaluar la actividad de la enfermedad (Abraham \& Thirumurthi, 2009). Considerando que los cambios en la producción de ARNm son eventos rápidos, el $A D$ de la expresión de estas Gals en la mucosa permitiría evaluar el curso de la enfermedad y predecir una posible recaída. Asimismo, considerando la alta correlación entre los niveles de expresión de estas Gals y el grado de actividad de la inflamación intestinal, esta metodología podría utilizarse para monitorear el estado de la inflamación de la mucosa una vez que el tratamiento farmacológico se ha iniciado.

Es ampliamente conocido que en una mucosa en homeostasis los LT se activan continuamente en forma antígeno-específica. Este hecho provoca que el intestino se encuentre en un estado basal de inflamación, fundamental para la correcta fisiología del órgano (Wullaert, 2010). A fin de controlar y erradicar el estímulo antigénico, constantemente se inician mecanismos tendientes a suprimir a los LT activados una vez que estos han cumplido su función efectora, y así restituir la homeostasis intestinal (Mowat y col., 2004; Strober y col., 2003). Uno de los mecanismos centrales para este proceso involucra el control de la sobrevida de las células T activadas. Si bien dicho circuito es sumamente eficiente y altamente regulado, fallas en el mismo han sido descriptas en diversas inmunopatologías, entre ellas CU y EC. Dichas fallas determinan que en las zonas inflamadas de pacientes con Ell los LTLP muestren una marcada resistencia a la apoptosis. (Di Sabatino y col., 2004). Como consecuencia se 
establece una respuesta aberrante de la inmunidad innata y adaptativa (Th1 y Th17), con la concomitante expresión continua y exacerbada de citoquinas proinflamatorias. Con el tiempo, este proceso se transforma en crónico y progresivo, donde la acción directa o indirecta de estos mediadores inflamatorios induce daños en el tejido y la persistencia de la enfermedad. Por lo tanto, cualquier tratamiento que logre limitar la sobrevida de estas células tendría potenciales aplicaciones terapéuticas en las Ell.

Una vez dilucidado que el análisis de la expresión de las Gals brinda información importante sobre la actividad de la mucosa colónica en un paciente con Ell, y considerando que Gal-1 es una lectina endógena con un predominante efecto anti-inflamatorio en inmunopatologías Th1 (Perone y col., 2006; Rabinovich y col., 1999; Toscano y col., 2006), en una segunda etapa decidimos estudiar el rol fisiológico de esta lectina a nivel de los LTLP y las CEI.

En este estudio mostramos por primera vez que, cuando la mucosa colónica humana se encuentra en condiciones de homeostasis, Gal-1 es expresada y secretada en la matriz extracelular de la LP. Pero, además, hemos observado que los niveles de ARNm codificantes para esta lectina se encuentran significativamente incrementados tanto en la mucosa de pacientes que fueron sometidos a trasplante de intestino y sufrieron rechazo del mismo, como en las zonas inflamadas de pacientes con Ell.

Por lo tanto, postulamos que incrementar los niveles mucosales de Gal-1 sería un mecanismo compensatorio para limitar la inflamación intestinal. De hecho, cuando la misma fue inducida experimentalmente, ya sea en el modelo de colitis o cultivando las biopsias de pacientes control ex vivo con TNF- $\alpha$, encontramos que la expresión de Gal-1 aumenta. Este incremento podría estar asociado con la activación de NF-kB, ya que la estimulación de esta vía por TNF$\alpha$ induce la expresión de Gal-1 (Tosacano y col., 2011). Sin embargo, al estudiar los niveles proteicos de Gal-1 en el tejido encontramos que éstos se encuentran disminuidos en las áreas inflamadas. Estos resultados, en principio contradictorios, sugieren la participación de diferentes mecanismos en la 
regulación de la expresión génica y la producción y persistencia de esta lectina en la mucosa colónica de pacientes con Ell.

Por lo tanto, decidimos investigar si la disociación entre niveles de ARNm y proteína se debía a la acción de las proteasas secretadas durante la remodelación tisular que se da en las Ell. De hecho, la migración de fibroblastos hacia la zona inflamada resulta esencial durante la etapa inicial de cicatrización (Biancheri y col. 2014). Sin embargo, cuando la severidad o extensión del daño supera la capacidad regenerativa del órgano, se induce la transformación de fibroblastos en miofibroblastos (Sengupta \& MacDonald 2007). Estas células secretan MMPs y peptidasas que degradan la matriz extracelular, al punto de originar las lesiones tardías más severas de las Ell (estenosis, perforaciones, fístulas) (Biancheri y col., 2014). Además, trabajos previos han demostrado que la MMP7 tiene la capacidad de degradar a Gal-3, y que dicho clivaje inhibe su acción regeneradora sobre la línea epitelial T84 (Puthenedam y col., 2011).

Sobre la base de esta información decidimos incorporar un nuevo "actor" en nuestro sistema, los fibroblastos, por lo cual analizamos la capacidad del sobrenadante de cultivo de estas células de degradar rhGal-1. Encontramos que los fibroblastos aislados del colon de pacientes con CU y EC secretan al medio de cultivo proteasas con capacidad de clivar rhGal-1. Por otra parte, el sobrenadante de cultivo de fibroblastos de colon proveniente de pacientes control no muestra capacidad degradativa sobre esta lectina.

En conjunto, estos resultados confirman que el incremento en la expresión de Gal-1 sería un mecanismo fisiológico para restablecer la homeostasis intestinal luego de un proceso inflamatorio. Los mismos están en concordancia con los obtenidos por Morosi y colaboradores (2014), en donde descubrieron que los ratones Lgals $1^{-/-}$tardan más tiempo que los salvajes en recuperarse de una colitis experimental aguda inducida por TNBS (Morosi y col., 2014). Pero, además, indican que durante un proceso inflamatorio crónico los fibroblastos ejercen un efecto pro-inflamatorio al degradar Gal-1. Por lo tanto, el mecanismo homeostático que contribuye a regular la inflamación intestinal por medio de Gal-1 se vería interrumpido por la acción local de las proteasas secretadas en la mucosa. 
El rol inmunoregulador de Gal-1 en una colitis experimental aguda inducida por TNBS fue demostrado por Santucci y colaboradores (2003), donde la administración exógena de esta lectina revierte completamente el cuadro inflamatorio. En dicho trabajo los autores proponen que el mecanismo protector de esta lectina en la fisiología del intestino está relacionado con el control de la sobrevida de las células T activadas.

Para probar esta hipótesis decidimos evaluar la capacidad pro-apoptótica de Gal-1 en LTLP de muestras provenientes de pacientes control y pacientes con Ell. En este trabajo pudimos confirmar que, bajo condiciones de homeostasis, esta proteína induce la muerte celular de los LTLP. Llamativamente, los LT provenientes de la mucosa intestinal mostraron ser capaces de unir esta lectina de manera constitutiva, aún estando no activados. Si bien resultados similares fueron obtenidos en placenta (Kopcow y col., 2008), esto constituye una diferencia sustancial con respecto a los LT de sangre periférica, los cuales sólo unen Gal-1 cuando se encuentran activados (Toscano y col., 2007). Asimismo, los LTLP aislados de zonas inflamadas de pacientes con Ell resultaron refractarios a la apoptosis inducida por Gal-1. Este hecho es concordante con la menor frecuencia de LT con capacidad de unir esta lectina en zonas inflamadas, en comparación con muestras provenientes de zonas no inflamados o de pacientes control.

En base a nuestros resultados sobre el reconocimiento de lectinas vegetales y la expresión de enzimas relacionadas con la síntesis de los ligandos de Gal-1, estamos en condiciones de afirmar que las áreas inflamadas y las no inflamadas muestran un glicofenotipo diferencial. Además, podemos aseverar que la falta de reconocimiento de Gal-1 por parte de los LTLP provenientes de zonas inflamadas es independiente de la sialilación (Toscano y col., 2007), pero está relacionado con la reducción de los sitios glicosilados específicos para esta lectina. De hecho, en las células $\mathrm{HH}$, una línea $\mathrm{T}$ derivada de un paciente con linfoma cutáneo, la pérdida de expresión de C2GnT-1 inhibe la síntesis de estos ligandos, fenómeno que conlleva a la pérdida de sensibilidad a la muerte celular inducida por Gal-1 (Cabrera y col., 2006). 
En este trabajo pudimos determinar que, tanto en los tejidos inflamados de pacientes con CU y EC, como en los LT de dichas áreas, se expresan menores niveles de C2GnT-1 en comparación con los tejidos no inflamados y las muestras provenientes de pacientes control. Sin embargo, mediante el cultivo ex vivo de biopsias y líneas celulares $T$ pudimos determinar que la respuesta normal de la mucosa frente a un estímulo inflamatorio agudo sería incrementar los ligandos específicos para Gal-1. Este mecanismo, igual que el incremento de los niveles de esta lectina, serían parte de la respuesta fisiológica de la mucosa para controlar una inflamación aguda. Dicho mecanismo se ve alterado en los focos inflamatorios crónicos, ocasionando que los LT activados presenten un glicofenotipo no permisivo para la unión de Gal-1.

En resumen, a pesar de ser degradada in situ, se observan niveles detectables de Gal-1 en las zonas inflamadas de pacientes con CU y EC, sin embargo, los cambios en el patrón de glicosilaciones en los LT los torna refractarios a la muerte celular inducida por esta lectina. Estos cambios contribuyen a la persistencia de los LTLP en la mucosa inflamada de pacientes con Ell, con la consecuente liberación sostenida de mediadores inflamatorios. Este fenómeno, no descripto en la bibliografía, estaría contribuyendo a la cronicidad del foco inflamatorio.

Finalmete, considerando que existen numerosos trabajos que relacionan la apoptosis de las CEI con la patogénesis de la inflamación de la mucosa (Di sabatino y col., 2003), decidimos estudiar el rol de Gal-1 en este tipo celular. Al igual que los LTLP, las CEI también mostraron ser sensibles a la apoptosis inducida por Gal-1 en condiciones fisiológicas. Dicho mecanismo activa la vía mitocondrial y es dependiente de las caspasas 3 y 9 y de la relación entre mediadores pro- $\mathrm{y}$ anti-apoptóticos (incremento en los niveles de Bax y Bad y disminución de Bcl-2). Además, demostramos que un ambiente inflamatorio con características Th1 modula la expresión de los ligandos específicos para Gal-1 en el epitelio intestinal. Sin embargo, a diferencia de lo observado para los LTLP, dicho cambio indujo un incremento en el porcentaje CEI con capacidad de unir esta lectina. Como pudo observarse en el modelo murino in vivo e in vitro, y en el cultivo ex vivo de biopsias de pacientes control 
y pacientes con Ell, el entorno inflamatorio incrementa la susceptibilidad del epitelio a la inducción de muerte celular por Gal-1. Dicho fenómeno podría incrementar la permeabilidad intestinal $y$, por lo tanto, contribuir a la cronicidad de la enfermedad.

De nuestros resultados se desprende que en el contexto de las Ell la administración terapéutica de Gal-1 no induciría una reducción en el número de células $\mathrm{T}$ activadas en las zonas inflamadas del intestino. Probablemente este hecho esté relacionado con los diferentes mecanismos que se activan en una inflamación aguda o crónica. Sin embargo, considerando que una vez controlada la inflamación los niveles de expresión de C2GnT-1 retornan a los valores fisiológicos, y los linfocitos T recuperan su capacidad de reconocimiento de Gal-1, es factible que la administración de esta lectina permita mantener el control de la población T a través de su efecto pro-apoptótico. Asimismo, no descartamos que durante el proceso inflamatorio Gal-1 tenga un rol inmunoregulador sobre otras poblaciones celulares (células dendríticas, macrófagos, Treg, etc), como fue descrito por Ilarregui (2009) y Blois (2007) (Ilarregui y col., 2009; Blois y col., 2007).

Considerando que el ambiente inflamatorio de las Ell altera la síntesis de los ligandos específicos para Gal-1, comprender los mecanismos que gobiernan la expresión de glicosidasas y glicosiltransferasas en condiciones patológicas permitirá desarrollar nuevas estrategias terapéuticas para restaurar el glicofenotipo celular típico de los LTLP y las CEI y, por lo tanto, controlar la inflamación intestinal. 



\section{CONCLUSIONES FINALES}

- El análisis conjunto de los niveles de ARNm de Gal-1, -3, -4 y -9 constituye una herramienta útil tanto para distinguir entre pacientes con Ell activa y pacientes control o con Ell inactiva/en remisión. Además, permite diferenciar el grado de inflamación de la mucosa en pacientes con Ell y distinguirla de otras patologías inflamatorias intestinales agudas y crónicas. Estos resultados están incluidos en el manuscrito: CONTEXT-DEPENDENT REGULATION OF THE HUMAN GALECTINSIGNATURE IN DIFFERENT INTESTINAL INFLAMMATORY SETTINGS. Papa Gobbi, R.; De Francesco, N.; Bondar C., Muglia, C.; Chirdo F., Rumbo M., Toscano, M.; Rocca, A.; Sambuelli, A.; Rabinovich, G. \& Docena, G.

- La respuesta fisiológica de la mucosa frente al entorno inflamatorio es incrementar la expresión de Gal-1, tanto a nivel génico como proteico. Sin embargo, esta lectina constituye un sustrato para las proteasas secretadas por lo fibroblastos o miofibroblastos inducidos en el tejido inflamado. Posiblemente la degradación de Gal-1 afecte su rol en la resolución de los procesos inflamatorios y contribuya a la cronicidad de la enfermedad. Estos resultados están incluidos en el manuscrito: INTESTINAL INFLAMMATION LICENCES LAMINA PROPRIA T CELLS FOR GALECTIN-1 UNRESPONSIVENESS AND PROLONGED SURVIVAL IN IBD. Papa Gobbi, R.; Muglia, C.; Rocca, A.; Sambuelli, A., Yantorno, M., Curciarello, R., Orsini Delgado, L., Biancheri, P., Di Sabatino, A., MacDonald T., Toscano, M.; Rabinovich, G. \& Docena, G.

- Los LTLP poseen un glicofenotipo particular que les permite unir Gal-1 en situaciones de homeostasis y en un proceso inflamatorio agudo. Este mecanismo actuaría como control fisiológico de la sobrevida de las células T. Sin embargo, el ambiente inflamatorio crónico de las Ell modifica la maquinaria celular de glicosilación, impidiendo la unión de esta lectina. Dichos cambios determinan que los LT activados sean refractarios a la muerte celular inducida por Gal-1, 
contribuyendo a la persistencia de los mismos en el foco inflamatorio. Estos resultados están incluidos en el manuscrito: INTESTINAL INFLAMMATION LICENCES LAMINA PROPRIA T CELLS FOR GALECTIN-1 UNRESPONSIVENESS AND PROLONGED SURVIVAL IN IBD. Papa Gobbi, R.; Muglia, C.; Rocca, A.; Sambuelli, A., Yantorno, M., Curciarello, R., Orsini Delgado, L., Biancheri, P., Di Sabatino, A., MacDonald T., Toscano, M.; Rabinovich, G. \& Docena, G.

- La exposición a estímulos pro-inflamatorios incrementa la sensibilidad de las CEI a la muerte celular inducida por Gal-1. Este proceso, mediado por la vía mitocondrial y dependiente de caspasas, induciría un incremento en la permeabilidad intestinal, contribuyendo de esta manera a la persistencia del foco inflamatorio. Estos resultados están incluidos en el manuscrito: INFLAMMATORY CONDITIONS REGULATE SUSCEPTIBILITY OF INTESTINAL EPITHELIAL CELLS TO GALECTIN-1 INDUCED CELl DEATH. Muglia, C., Papa Gobi, R., Smaldini, P., Orsini Delgado, L., Candia, M., Zanuzzi, C.; Sambuelli, A., Rocca, A., Toscano, M., Rabinovich, G. \& Docena, $G$. 


\section{BIBLIOGRAFIA}

A. Varki, R. Cummings, J. Esko, H. Freeze, G. Hart, and J. M. (2000). Essentials of Glycobiology. Carbohydrate Research, 325(3), 233-234. doi:10.1016/S00086215(99)00334-1

Abraham, B. P., \& Thirumurthi, S. (2009). Clinical Signifi cance of Infl ammatory Markers.

Amado, M., Yan, Q., Comelli, E. M., Collins, B. E., \& Paulson, J. C. (2004). Peanut agglutinin high phenotype of activated CD8 $+\mathrm{T}$ cells results from de novo synthesis of CD45 glycans. The Journal of Biological Chemistry, 279(35), 36689-97. doi:10.1074/jbc.M405629200

An, G., Wei, B., Xia, B., McDaniel, J. M., Ju, T., Cummings, R. D., ... Xia, L. (2007). Increased susceptibility to colitis and colorectal tumors in mice lacking core 3-derived O-glycans. The Journal of Experimental Medicine, 204(6), 141729. doi:10.1084/jem.20061929

Annese, V., Daperno, M., Rutter, M. D., Amiot, A., Bossuyt, P., East, J., ... Eliakim, R. (2013). European evidence based consensus for endoscopy in inflammatory bowel disease. Journal of Crohn's \& Colitis, 7(12), 982-1018. doi:10.1016/j.crohns.2013.09.016

Bach, J.-F. (2002). The Effect of Infections on Susceptibility to Auntoimmune and Alleric Disease. The New England Journal Of Medicine, 347(12), 911-920.

Banh, A., Zhang, J., Cao, H., Bouley, D. M., Kwok, S., Kong, C., ... Le, Q.-T. (2011). Tumor galectin-1 mediates tumor growth and metastasis through regulation of T-cell apoptosis. Cancer Research, 71(13), 4423-31. doi:10.1158/0008-5472.CAN-10-4157

Baum, L. G., Blackall, D. P., Arias-Magallano, S., Nanigian, D., Uh, S. Y., Browne, J. M., ... Baldwin, G. C. (2003). Amelioration of graft versus host disease by galectin-1. Clinical Immunology (Orlando, Fla.), 109(3), 295-307. Retrieved from http://www.ncbi.nlm.nih.gov/pubmed/14697744

Baumgart, D. C., \& Carding, S. R. (2007a). Gastroenterology 1 Infl ammatory bowel disease : cause and immunobiology, 369, 1627-1640.

Baumgart, D. C., \& Carding, S. R. (2007b). Inflammatory bowel disease: cause and immunobiology. Lancet, $369(9573), \quad 1627-40 . \quad$ doi:10.1016/S01406736(07)60750-8

Baumgart, D. C., \& Sandborn, W. J. (2007). Infl ammatory bowel disease : clinical aspects and established and evolving therapies, 369, 1641-1657. 
Beck, P. L., \& Wallace, J. L. (1997). Cytokines in inflammatory bowel disease. Mediators of Inflammation, 6(2), 95-103. doi:10.1080/09629359791785

Biancheri, P., Giuffrida, P., Docena, G. H., MacDonald, T. T., Corazza, G. R., \& Di Sabatino, A. (2014). The role of transforming growth factor (TGF)- $\beta$ in modulating the immune response and fibrogenesis in the gut. Cytokine \& Growth Factor Reviews, 25(1), 45-55. doi:10.1016/j.cytogfr.2013.11.001

Biancone, L., De Nigris, F., Del Vecchio Blanco, G., Monteleone, I., Vavassori, P., Geremia, A., \& Pallone, F. (2002). Review article: monitoring the activity of Crohn's disease. Alimentary Pharmacology \& Therapeutics, 16 Suppl 4, 29-33. Retrieved from http://www.ncbi.nlm.nih.gov/pubmed/12047257

Blaser, C., Kaufmann, M., Müller, C., Zimmermann, C., Wells, V., Mallucci, L., \& Pircher, H. (1998). Beta-galactoside-binding protein secreted by activated $\mathrm{T}$ cells inhibits antigen-induced proliferation of $\mathrm{T}$ cells. European Journal of Immunology, 28(8), 2311-9. Retrieved from http://www.ncbi.nlm.nih.gov/pubmed/9710209

Blois, S. M., Ilarregui, J. M., Tometten, M., Garcia, M., Orsal, A. S., Cordo-Russo, R., ... Arck, P. C. (2007). A pivotal role for galectin-1 in fetomaternal tolerance. Nature Medicine, 13(12), 1450-7. doi:10.1038/nm1680

Cabrera, P. V, Amano, M., Mitoma, J., Chan, J., Said, J., Fukuda, M., \& Baum, L. G. (2006). Haploinsufficiency of C2GnT-I glycosyltransferase renders T lymphoma cells resistant to cell death. Blood, 108(7), 2399-406. doi:10.1182/blood-2006-04-018556

Cellier, C., Sahmoud, T., Froguel, E., Adenis, A., Belaiche, J., Bretagne, J., ... Louis, H. S. (1994). Correlations between clinical activity, endoscopic severity, and biological parameters in colonic or ileocolonic Crohn' s disease . A prospective multicentre study of 121 cases, (2), 231-235.

Cho, M., \& Cummings, R. D. (1995). Galectin-1, a beta-galactoside-binding lectin in Chinese hamster ovary cells. II. Localization and biosynthesis. The Journal of Biological Chemistry, 270(10), 5207-12. Retrieved from http://www.ncbi.nlm.nih.gov/pubmed/7890631

Christophi, G. P., Rong, R., Holtzapple, P. G., Massa, P. T., \& Landas, S. K. (2012). Immune markers and differential signaling networks in ulcerative colitis and Crohn's disease. Inflammatory Bowel Diseases, 18(12), 2342-56. doi:10.1002/ibd.22957

Chung, C. D., Patel, V. P., Moran, M., Lewis, L. A., \& Miceli, M. C. (2000). Galectin-1 induces partial TCR zeta-chain phosphorylation and antagonizes processive TCR signal transduction. Journal of Immunology (Baltimore, Md. : 1950), 165(7), 3722-9. Retrieved from http://www.ncbi.nlm.nih.gov/pubmed/11034377 
Clark, A. G., Chen, S., Zhang, H., Brady, G. F., Ungewitter, E. K., Bradley, J. K., ... Foster, M. H. (2007). Multifunctional regulators of cell growth are differentially expressed in anergic murine B cells. Molecular Immunology, 44(6), 1274-85. doi:10.1016/j.molimm.2006.06.001

Correa, S. G., Sotomayor, C. E., Aoki, M. P., Maldonado, C. A., \& Rabinovich, G. A. (2003). Opposite effects of galectin-1 on alternative metabolic pathways of L-arginine in resident, inflammatory, and activated macrophages. Glycobiology, 13(2), 119-28. doi:10.1093/glycob/cwg010

Cosnes, J., Gower-Rousseau, C., Seksik, P., \& Cortot, A. (2011). Epidemiology and natural history of inflammatory bowel diseases. Gastroenterology, 140(6), 1785-94. doi:10.1053/j.gastro.2011.01.055

Crama-Bohbouth, G., Pena, A. S., Biemond, I., Verspaget, H. W., Blok, D., Arndt, J. W., ... Lamers, C. B. (1989). Are activity indices helpful in assessing active intestinal inflammation in Crohn's disease? Gut, 30(9), 1236-40. Retrieved from

http://www.pubmedcentral.nih.gov/articlerender.fcgi?artid=1434263\&tool=pmc entrez\&rendertype $=$ abstract

Croci, D. O., Cerliani, J. P., Dalotto-Moreno, T., Méndez-Huergo, S. P., Mascanfroni, I. D., Dergan-Dylon, S., ... Rabinovich, G. a. (2014). Glycosylation-dependent lectin-receptor interactions preserve angiogenesis in anti-VEGF refractory tumors. Cell, 156(4), 744-58. doi:10.1016/j.cell.2014.01.043

Daniels, M. a, Hogquist, K. a, \& Jameson, S. C. (2002). Sweet "n" sour: the impact of differential glycosylation on T cell responses. Nature Immunology, 3(10), 903-10. doi:10.1038/ni1002-903

Dardalhon, V., Anderson, A. C., Karman, J., Apetoh, L., Chandwaskar, R., Lee, D. H., ... Kuchroo, V. K. (2010). Tim-3/galectin-9 pathway: regulation of Th1 immunity through promotion of CD11b+Ly-6G+ myeloid cells. Journal of Immunology (Baltimore, Md. : 1950), 185(3), 1383-92. doi:10.4049/jimmunol.0903275

Demetter, P., Nagy, N., Martin, B., Mathieu, A., Dumont, P., Decaestecker, C., \& Salmon, I. (2008). The galectin family and digestive disease. doi:10.1002/path

Di Sabatino, A., Ciccocioppo, R., Cinque, B., Millimaggi, D., Morera, R., Ricevuti, L., ... Corazza, G. R. (2004). Defective mucosal T cell death is sustainably reverted by infliximab in a caspase dependent pathway in Crohn's disease. Gut, 53(1), 70-7. Retrieved from http://www.pubmedcentral.nih.gov/articlerender.fcgi?artid=1773915\&tool=pmc entrez\&rendertype $=$ abstract

Di Sabatino, A., Ciccocioppo, R., Luinetti, O., Ricevuti, L., Morera, R., Cifone, M. G., ... Corazza, G. R. (2003). Increased enterocyte apoptosis in inflamed areas 
of Crohn's disease. Diseases of the Colon and Rectum, 46(11), 1498-507. doi:10.1097/01.DCR.0000089118.20964.12

Edelblum, K. L., Yan, F., Yamaoka, T., \& Polk, D. B. (2006). Regulation of apoptosis during homeostasis and disease in the intestinal epithelium. Inflammatory Bowel Diseases, 12(5), 413-24. doi:10.1097/01.MIB.0000217334.30689.3e

Frol'ová, L., Smetana, K., Borovská, D., Kitanovicová, A., Klimesová, K., Janatková, I., ... Tlaskalová-Hogenová, H. (2009). Detection of galectin-3 in patients with inflammatory bowel diseases: new serum marker of active forms of IBD? Inflammation Research: Official Journal of the European Histamine Research Society ... [et Al.], 58(8), 503-12. doi:10.1007/s00011-009-0016-8

Frøslie, K. F., Jahnsen, J., Moum, B. a, \& Vatn, M. H. (2007). Mucosal healing in inflammatory bowel disease: results from a Norwegian population-based cohort. Gastroenterology, 133(2), 412-22. doi:10.1053/j.gastro.2007.05.051

Fu, J., Wei, B., Wen, T., Johansson, M. E. V, Liu, X., Bradford, E., ... Xia, L. (2011). Loss of intestinal core 1-derived O-glycans causes spontaneous colitis in mice. The Journal of Clinical Investigation, 121(4), 1657-66. doi:10.1172/JCI45538

Galvan, M., Tsuboi, S., Fukuda, M., \& Baum, L. G. (2000). Expression of a specific glycosyltransferase enzyme regulates $\mathrm{T}$ cell death mediated by galectin- 1 . The Journal of Biological Chemistry, 275(22), 16730-7. doi:10.1074/jbc.M001117200

Garín, M. I., Chu, C.-C., Golshayan, D., Cernuda-Morollón, E., Wait, R., \& Lechler, R. I. (2007). Galectin-1: a key effector of regulation mediated by CD4+CD25+ T cells. Blood, 109(5), 2058-65. doi:10.1182/blood-2006-04-016451

Garrett, W. S., Gordon, J. I., \& Glimcher, L. H. (2010). Homeostasis and inflammation in the intestine. Cell, 140(6), 859-70. doi:10.1016/j.cell.2010.01.023

Gassler, N., Roth, W., Funke, B., Schneider, A., Herzog, F., Tischendorf, J. J. W., ... Kopitz, J. (2007). Regulation of enterocyte apoptosis by acyl-CoA synthetase 5 splicing. Gastroenterology, 133(2), 587-98. doi:10.1053/j.gastro.2007.06.005

Geremia, A., Biancheri, P., Allan, P., Corazza, G. R., \& Di Sabatino, A. (2014). Innate and adaptive immunity in inflammatory bowel disease. Autoimmunity Reviews, 13(1), 3-10. doi:10.1016/j.autrev.2013.06.004

Gordon, J. I., \& Hermiston, M. L. (1994). Differentiation and self-renewal in the mouse gastrointestinal epithelium. Current Opinion in Cell Biology, 6(6), 795803. Retrieved from http://www.ncbi.nlm.nih.gov/pubmed/7880525

Goretsky, T., Dirisina, R., Sinh, P., Mittal, N., Managlia, E., Williams, D. B., ... Barrett, T. a. (2012). p53 mediates TNF-induced epithelial cell apoptosis in 
IBD. The American Journal of Pathology, 181(4), 1306-15. doi:10.1016/j.ajpath.2012.06.016

Goto, Y., Obata, T., Kunisawa, J., Sato, S., Ivanov, I. I., Lamichhane, A., ... Kiyono, H. (2014). Innate lymphoid cells regulate intestinal epithelial cell glycosylation. Science, 345(6202), 1254009. doi:10.1126/science.1254009

He, J., \& Baum, L. G. (2004). Presentation of galectin-1 by extracellular matrix triggers $\mathrm{T}$ cell death. The Journal of Biological Chemistry, 279(6), 4705-12. doi:10.1074/jbc.M311183200

Heller, F., Florian, P., Bojarski, C., Richter, J., Christ, M., Hillenbrand, B., ... Schulzke, J. D. (2005). Interleukin-13 is the key effector Th2 cytokine in ulcerative colitis that affects epithelial tight junctions, apoptosis, and cell restitution. Gastroenterology, 129(2), 550-64. doi:10.1016/j.gastro.2005.05.002

Hokama, A. (2008). Roles of galectins in inflammatory bowel disease. World Journal of Gastroenterology, 14(33), 5133. doi:10.3748/wjg.14.5133

Hokama, A., Mizoguchi, E., \& Mizoguchi, A. (2008). Roles of galectins in inflammatory bowel disease. World Journal of Gastroenterology: WJG, 14(33), 5133-7.

Hokama, A., Mizoguchi, E., Sugimoto, K., Shimomura, Y., Tanaka, Y., Yoshida, M., ... Mizoguchi, A. (2004). Induced reactivity of intestinal CD4(+) T cells with an epithelial cell lectin, galectin-4, contributes to exacerbation of intestinal inflammation. Immunity, 20(6), 681-93. doi:10.1016/j.immuni.2004.05.009

Hooper, L. V, \& Gordon, J. I. (2001). Commensal host-bacterial relationships in the gut. Science (New York, N.Y.), 292(5519), 1115-8. Retrieved from http://www.ncbi.nlm.nih.gov/pubmed/11352068

Ilarregui, J. M., Croci, D. O., Bianco, G. a, Toscano, M. a, Salatino, M., Vermeulen, M. E., ... Rabinovich, G. a. (2009). Tolerogenic signals delivered by dendritic cells to $\mathrm{T}$ cells through a galectin-1-driven immunoregulatory circuit involving interleukin 27 and interleukin 10. Nature Immunology, 10(9), 981-91. doi:10.1038/ni.1772

Ina, K., Itoh, J., Fukushima, K., Kusugami, K., Yamaguchi, T., Kyokane, K., ... Fiocchi, C. (1999). Resistance of Crohn's disease T cells to multiple apoptotic signals is associated with a Bcl-2/Bax mucosal imbalance. Journal of Immunology (Baltimore, Md.: 1950), 163(2), 1081-90. Retrieved from http://www.ncbi.nlm.nih.gov/pubmed/10395708

Itoh, J., de La Motte, C., Strong, S. A., Levine, A. D., \& Fiocchi, C. (2001). Decreased Bax expression by mucosal $\mathrm{T}$ cells favours resistance to apoptosis in Crohn's disease. Gut, 49(1), 35-41. Retrieved from http://www.pubmedcentral.nih.gov/articlerender.fcgi?artid=1728348\&tool=pmc entrez\&rendertype $=$ abstract 
Kaltner, H., Seyrek, K., Heck, A., Sinowatz, F., \& Gabius, H.-J. (2002). Galectin-1 and galectin-3 in fetal development of bovine respiratory and digestive tracts. Comparison of cell type-specific expression profiles and subcellular localization. Cell and Tissue Research, 307(1), 35-46. doi:10.1007/s004410100457

Kirkegaard, T., Hansen, A., Bruun, E., \& Brynskov, J. (2004). Expression and localisation of matrix metalloproteinases and their natural inhibitors in fistulae of patients with Crohn's disease. Gut, 53(5), 701-9. Retrieved from http://www.pubmedcentral.nih.gov/articlerender.fcgi?artid=1774029\&tool=pmc entrez\&rendertype $=$ abstract

Klein, W., Tromm, A., Folwaczny, C., Hagedorn, M., Duerig, N., Epplen, J. T., ... Griga, T. (2004). A polymorphism of the NFKBIA gene is associated with Crohn's disease patients lacking a predisposing allele of the CARD15 gene. International Journal of Colorectal Disease, 19(2), 153-6. doi:10.1007/s00384003-0531-y

Kopcow, H. D., Rosetti, F., Leung, Y., Allan, D. S. J., Kutok, J. L., \& Strominger, J. L. (2008). T cell apoptosis at the maternal-fetal interface in early human pregnancy, involvement of galectin-1. Proceedings of the National Academy of Sciences of the United States of America, 105(47), 18472-7. doi:10.1073/pnas.0809233105

Kugathasan, S., Saubermann, L. J., Smith, L., Kou, D., Itoh, J., Binion, D. G., ... Fiocchi, C. (2007). Mucosal T-cell immunoregulation varies in early and late inflammatory bowel disease. Gut, 56(12), 1696-705. doi:10.1136/gut.2006.116467

La, M., Cao, T. V, Cerchiaro, G., Chilton, K., Hirabayashi, J., Kasai, K.-I., ... Perretti, M. (2003). A novel biological activity for galectin-1: inhibition of leukocyte-endothelial cell interactions in experimental inflammation. The American Journal of Pathology, 163(4), 1505-15. Retrieved from http://www.pubmedcentral.nih.gov/articlerender.fcgi?artid=1868297\&tool=pmc entrez\&rendertype $=$ abstract

Lennard-Jones, J. E., \& Shivananda, S. (1997). Clinical uniformity of inflammatory bowel disease a presentation and during the first year of disease in the north and south of Europe. EC-IBD Study Group. European Journal of Gastroenterology \& Hepatology, 9(4), 353-9. Retrieved from http://www.ncbi.nlm.nih.gov/pubmed/9160197

Lippert, E., Falk, W., Bataille, F., Kaehne, T., Naumann, M., Goeke, M., ... Rogler, G. (2007). Soluble galectin-3 is a strong, colonic epithelial-cell-derived, lamina propria fibroblast-stimulating factor. Gut, 56(1), 43-51. doi:10.1136/gut.2005.081646

Lippert, E., Gunckel, M., Brenmoehl, J., Bataille, F., Falk, W., Scholmerich, J., ... Rogler, G. (2008). Regulation of galectin-3 function in mucosal fibroblasts: 
potential role in mucosal inflammation. Clinical and Experimental Immunology, 152(2), 285-97. doi:10.1111/j.1365-2249.2008.03618.x

Liu, F.-T., \& Rabinovich, G. a. (2010). Galectins: regulators of acute and chronic inflammation. Annals of the New York Academy of Sciences, 1183, 158-82. doi:10.1111/j.1749-6632.2009.05131.x

Majeti, R., Bilwes, A. M., Noel, J. P., Hunter, T., \& Weiss, A. (1998). Dimerizationinduced inhibition of receptor protein tyrosine phosphatase function through an inhibitory wedge. Science (New York, N.Y.), 279(5347), 88-91. Retrieved from http://www.ncbi.nlm.nih.gov/pubmed/9417031

Monteleone, G., Boirivant, M., Pallone, F., \& MacDonald, T. T. (2008). TGF-beta1 and Smad7 in the regulation of IBD. Mucosal Immunology, 1 Suppl 1(November), S50-3. doi:10.1038/mi.2008.55

Morimoto, K., Hosomi, S., Yamagami, H., Watanabe, K., Kamata, N., Sogawa, M., ... Arakawa, T. (2011). Dysregulated upregulation of T-cell immunoglobulin and mucin domain-3 on mucosal $\mathrm{T}$ helper 1 cells in patients with Crohn's disease. Scandinavian Journal of Gastroenterology, 46(6), 701-9. doi: $10.3109 / 00365521.2011 .568518$

Morosi, L., Morales, R., Toscano, M., Rabinovich, G. \& Mariño, K. (2014). Endogenous galectin-1 plays a key role in inflammatory bowel disease. In GlycoAR (p. 21). Buenos Aires.

Mowat, A. M., Millington, O. R., \& Chirdo, F. G. (2004). Anatomical and cellular basis of immunity and tolerance in the intestine. Journal of Pediatric Gastroenterology and Nutrition, 39 Suppl 3, S723-4. Retrieved from http://www.ncbi.nlm.nih.gov/pubmed/15167360

Mowat, A. M., Parker, L. A., Beacock-Sharp, H., Millington, O. R., \& Chirdo, F. (2004). Oral tolerance: overview and historical perspectives. Annals of the New York Academy of Sciences, 1029, 1-8.

Muglia, C., Mercer, N., Toscano, M. a, Schattner, M., Pozner, R., Cerliani, J. P., ... Docena, G. H. (2011). The glycan-binding protein galectin-1 controls survival of epithelial cells along the crypt-villus axis of small intestine. Cell Death \& Disease, 2(5), e163. doi:10.1038/cddis.2011.44

Müller, S., Schaffer, T., Flogerzi, B., Fleetwood, A., Weimann, R., Schoepfer, A. M., \& Seibold, F. (2006). Galectin-3 modulates T cell activity and is reduced in the inflamed intestinal epithelium in IBD. Inflammatory Bowel Diseases, 12(7), 588-97. doi:10.1097/01.MIB.0000225341.37226.7c

Nagase, H., \& Woessner, J. F. (1999). Matrix Metalloproteinases. Journal of Biological Chemistry, 274(31), 21491-21494. doi:10.1074/jbc.274.31.21491 
Neuman, M. G. (2007). Immune dysfunction in inflammatory bowel disease. Translational Research: The Journal of Laboratory and Clinical Medicine, 149(4), 173-86. doi:10.1016/j.trs1.2006.11.009

Neurath, M. F. (2002). The Transcription Factor T-bet Regulates Mucosal T Cell Activation in Experimental Colitis and Crohn's Disease. Journal of Experimental Medicine, 195(9), 1129-1143. doi:10.1084/jem.20011956

Neurath, M. F. (2014). Cytokines in inflammatory bowel disease. Nature Reviews. Immunology, 14(5), 329-42. doi:10.1038/nri3661

Nguyen, J. T., Evans, D. P., Galvan, M., Pace, K. E., Leitenberg, D., Bui, T. N., \& Baum, L. G. (2001). CD45 modulates galectin-1-induced T cell death: regulation by expression of core 2 O-glycans. Journal of Immunology (Baltimore, Md.: 1950), 167(10), 5697-707. Retrieved from http://www.ncbi.nlm.nih.gov/pubmed/11698442

Nio-Kobayashi, J., Takahashi-Iwanaga, H., \& Iwanaga, T. (2009). Immunohistochemical localization of six galectin subtypes in the mouse digestive tract. The Journal of Histochemistry and Cytochemistry: Official Journal of the Histochemistry Society, 57(1), 41-50. doi:10.1369/jhc.2008.952317

Nishida, A., Nagahama, K., Imaeda, H., Ogawa, A., Lau, C. W., Kobayashi, T., ... Mizoguchi, A. (2012). Inducible colitis-associated glycome capable of stimulating the proliferation of memory CD4+ $\mathrm{T}$ cells. The Journal of Experimental Medicine, 209(13), 2383-94. doi:10.1084/jem.20112631

Nishida, S., Hadjis, N. S., Levi, D. M., Kato, T., Vaidya, A., Nery, J. R., ... Tzakis, A. G. (2004). Intestinal and multivisceral transplantation after abdominal trauma. The Journal of Trauma, 56(2), 323-7. doi:10.1097/01.TA.0000044627.81521.ED

Novák, J., Kriston-Pál, É., Czibula, Á., Deák, M., Kovács, L., Monostori, É., \& Fajka-Boja, R. (2014). GM1 controlled lateral segregation of tyrosine kinase Lck predispose T-cells to cell-derived galectin-1-induced apoptosis. Molecular Immunology, 57(2), 302-9. doi:10.1016/j.molimm.2013.10.010

Pace, K. E., Lee, C., Stewart, P. L., \& Baum, L. G. (1999). Restricted receptor segregation into membrane microdomains occurs on human $\mathrm{T}$ cells during apoptosis induced by galectin-1. Journal of Immunology (Baltimore, Md. : 1950), 163(7), 3801-11. Retrieved from http://www.ncbi.nlm.nih.gov/pubmed/10490978

Paclik, D., Berndt, U., Guzy, C., Dankof, A., Danese, S., Holzloehner, P., ... Sturm, A. (2008). Galectin-2 induces apoptosis of lamina propria T lymphocytes and ameliorates acute and chronic experimental colitis in mice. Journal of Molecular Medicine (Berlin, Germany), 86(12), 1395-406. doi:10.1007/s00109007-0290-2 
Paclik, D., Danese, S., Berndt, U., Wiedenmann, B., Dignass, A., \& Sturm, A. (2008). Galectin-4 controls intestinal inflammation by selective regulation of peripheral and mucosal T cell apoptosis and cell cycle. PloS One, 3(7), e2629. doi:10.1371/journal.pone.0002629

Paclik, D., Lohse, K., Wiedenmann, B., Dignass, A. U., \& Sturm, A. (2008). Galectin-2 and -4 , but not galectin-1, promote intestinal epithelial wound healing in vitro through a TGF-beta-independent mechanism. Inflammatory Bowel Diseases, 14(10), 1366-72. doi:10.1002/ibd.20499

Papp, M., Norman, G. L., Altorjay, I., \& Lakatos, P. L. (2007). Utility of serological markers in inflammatory bowel diseases: gadget or magic? World Journal of Gastroenterology: WJG, 13(14), 2028-36. Retrieved from http://www.ncbi.nlm.nih.gov/pubmed/17465443

Pender, S. L.-F., Chance, V., Whiting, C. V, Buckley, M., Edwards, M., Pettipher, R., \& MacDonald, T. T. (2005). Systemic administration of the chemokine macrophage inflammatory protein 1alpha exacerbates inflammatory bowel disease in a mouse model. Gut, 54(8), 1114-20. doi:10.1136/gut.2004.052779

Perone, M. J., Bertera, S., Tawadrous, Z. S., Shufesky, W. J., Piganelli, J. D., Baum, L. G., ... Morelli, A. E. (2006). Dendritic cells expressing transgenic galectin-1 delay onset of autoimmune diabetes in mice. Journal of Immunology (Baltimore, Md.: 1950), 177(8), 5278-89. Retrieved from http://www.ncbi.nlm.nih.gov/pubmed/17015713

Puthenedam, M., Wu, F., Shetye, A., Michaels, A., Rhee, K.-J., \& Kwon, J. H. (2011). Matrilysin-1 (MMP7) cleaves galectin-3 and inhibits wound healing in intestinal epithelial cells. Inflammatory Bowel Diseases, 17(1), 260-7. doi:10.1002/ibd.21443

Rabinovich, G. a, Baum, L. G., Tinari, N., Paganelli, R., Natoli, C., Liu, F.-T., \& Iacobelli, S. (2002). Galectins and their ligands: amplifiers, silencers or tuners of the inflammatory response? Trends in Immunology, 23(6), 313-320. doi:10.1016/S1471-4906(02)02232-9

Rabinovich, G. a, Rubinstein, N., \& Toscano, M. a. (2002). Role of galectins in inflammatory and immunomodulatory processes. Biochimica et Biophysica Acta, 1572(2-3), 274-84. Retrieved from http://www.ncbi.nlm.nih.gov/pubmed/12223275

Rabinovich, G. a, Toscano, M. a, Jackson, S. S., \& Vasta, G. R. (2007). Functions of cell surface galectin-glycoprotein lattices. Current Opinion in Structural Biology, 17(5), 513-20. doi:10.1016/j.sbi.2007.09.002

Rabinovich, G. A., Ariel, A., Hershkoviz, R., Hirabayashi, J., Kasai, K. I., \& Lider, O. (1999). Specific inhibition of T-cell adhesion to extracellular matrix and proinflammatory cytokine secretion by human recombinant galectin-1. Immunology, 97(1), 100-6. $\quad$ Retrieved from 
http://www.pubmedcentral.nih.gov/articlerender.fcgi?artid=2326819\&tool=pmc entrez\&rendertype $=$ abstract

Rabinovich, G. A., Daly, G., Dreja, H., Tailor, H., Riera, C. M., Hirabayashi, J., \& Chernajovsky, Y. (1999). Recombinant galectin-1 and its genetic delivery suppress collagen-induced arthritis via $\mathrm{T}$ cell apoptosis. The Journal of Experimental Medicine, 190(3), 385-98. Retrieved from http://www.pubmedcentral.nih.gov/articlerender.fcgi?artid=2195592\&tool=pmc entrez\&rendertype $=$ abstract

Rabinovich, G. A., Liu, F.-T., Hirashima, M., \& Anderson, A. (2007). An emerging role for galectins in tuning the immune response: lessons from experimental models of inflammatory disease, autoimmunity and cancer. Scandinavian Journal of Immunology, 66(2-3), 143-58. doi:10.1111/j.13653083.2007.01986.x

Rabinovich, G. A., Modesti, N. M., Castagna, L. F., Landa, C. A., Riera, C. M., \& Sotomayor, C. E. (1997). Specific inhibition of lymphocyte proliferation and induction of apoptosis by CLL-I, a beta-galactoside-binding lectin. Journal of Biochemistry, 122(2), 365-73. Retrieved from http://www.ncbi.nlm.nih.gov/pubmed/9378715

Rabinovich, G. A., Sotomayor, C. E., Riera, C. M., Bianco, I., \& Correa, S. G. (2000). Evidence of a role for galectin-1 in acute inflammation. European Journal of Immunology, 30(5), 1331-9. doi:10.1002/(SICI)15214141(200005)30:5\&\#60;1331::AID-IMMU1331\&\#62;3.0.CO;2-H

Rabinovich, G. A., \& Toscano, M. A. (2009). Turning "sweet" on immunity: galectin-glycan interactions in immune tolerance and inflammation. Nature Reviews. Immunology, 9(5), 338-52. doi:10.1038/nri2536

Rabinovich, G., Castagna, L., Landa, C., Riera, C. M., \& Sotomayor, C. (1996). Regulated expression of a 16-kd galectin-like protein in activated rat macrophages. Journal of Leukocyte Biology, 59(3), 363-70. Retrieved from http://www.ncbi.nlm.nih.gov/pubmed/8604014

Rabinowitz, K. M., Wang, Y., Chen, E. Y., Hovhannisyan, Z., Chiang, D., Berin, M. C., ... Mayer, L. (2013). Transforming growth factor $\beta$ signaling controls activities of human intestinal CD8(+)T suppressor cells. Gastroenterology, 144(3), 601-612.e1. doi:10.1053/j.gastro.2012.12.001

Rieder, F., \& Fiocchi, C. (2009). Intestinal fibrosis in IBD--a dynamic, multifactorial process. Nature Reviews. Gastroenterology \& Hepatology, 6(4), 228-35. doi:10.1038/nrgastro.2009.31

Roberts, A. A., Amano, M., Felten, C., Galvan, M., Sulur, G., Pinter-Brown, L., ... Baum, L. G. (2003). Galectin-1-mediated apoptosis in mycosis fungoides: the roles of CD7 and cell surface glycosylation. Modern Pathology: An Official Journal of the United States and Canadian Academy of Pathology, Inc, 16(6), 543-51. doi:10.1097/01.MP.0000071840.84469.06 
Royero Gútierrez, H. A. (2003). Enfermedad inflamatoria intestinal. Revista Colombiana de Gastroenterologia, 18(1), 24-41. Retrieved from http://www.scielo.org.co/scielo.php?script=sci_arttext\&pid=S0120$99572003000100006 \& \operatorname{lng}=$ en\&nrm=iso\&tlng=es

Rubinstein, N., Alvarez, M., Zwirner, N. W., Toscano, M. A., Ilarregui, J. M., Bravo, A., ... Rabinovich, G. A. (2004). Targeted inhibition of galectin-1 gene expression in tumor cells results in heightened $\mathrm{T}$ cell-mediated rejection; A potential mechanism of tumor-immune privilege. Cancer Cell, 5(3), 241-51. Retrieved from http://www.ncbi.nlm.nih.gov/pubmed/15050916

Rubinstein, N., Ilarregui, J. M., Toscano, M. A., \& Rabinovich, G. A. (2004). The role of galectins in the initiation, amplification and resolution of the inflammatory response. Tissue Antigens, 64(1), 1-12. doi:10.1111/j.00012815.2004.00278.x

Salatino, M., Croci, D. O., Bianco, G. A., Ilarregui, J. M., Toscano, M. A., \& Rabinovich, G. A. (2008). Galectin-1 as a potential therapeutic target in autoimmune disorders and cancer, 45-58.

Salatino, M., Dalotto-Moreno, T., \& Rabinovich, G. A. (2013). Thwarting galectininduced immunosuppression in breast cancer. Oncoimmunology, 2(5), e24077. doi:10.4161/onci.24077

Santucci, L., Fiorucci, S., Rubinstein, N., Mencarelli, A., Palazzetti, B., Federici, B., ... Morelli, A. (2003). Galectin-1 suppresses experimental colitis in mice. Gastroenterology, 124(5), 1381-1394. doi:10.1016/S0016-5085(03)00267-1

Schreiber, S., Nikolaus, S., \& Hampe, J. (1998). Activation of nuclear factor kappa B inflammatory bowel disease. Gut, 42(4), 477-84. Retrieved from http://www.pubmedcentral.nih.gov/articlerender.fcgi?artid=1727068\&tool=pmc entrez\&rendertype $=$ abstract

Sengupta, N., \& MacDonald, T. T. (2007). The role of matrix metalloproteinases in stromal/epithelial interactions in the gut. Physiology (Bethesda, Md.), 22, 401-9. doi:10.1152/physiol.00027.2007

Shi, F., Guo, X., Jiang, X., Zhou, P., Xiao, Y., Zhou, T., ... Han, G. (2012). Dysregulated Tim-3 expression and its correlation with imbalanced CD4 helper $\mathrm{T}$ cell function in ulcerative colitis. Clinical Immunology (Orlando, Fla.), 145(3), 230-40. doi:10.1016/j.clim.2012.09.001

Soldati, R., Berger, E., Zenclussen, A. C., Jorch, G., Lode, H. N., Salatino, M., ... Fest, S. (2012). Neuroblastoma triggers an immunoevasive program involving galectin-1-dependent modulation of $\mathrm{T}$ cell and dendritic cell compartments. International Journal of Cancer. Journal International Du Cancer, 131(5), 1131-41. doi:10.1002/ijc. 26498

Stowell, S. R., Karmakar, S., Stowell, C. J., Dias-Baruffi, M., McEver, R. P., \& Cummings, R. D. (2007). Human galectin-1, -2, and -4 induce surface exposure 
of phosphatidylserine in activated human neutrophils but not in activated $\mathrm{T}$ cells. Blood, 109(1), 219-27. doi:10.1182/blood-2006-03-007153

Strachan, D. P. (1989). Hay fever, hygiene, and household size. BMJ (Clinical Research Ed.), 299(6710), 1259-60. Retrieved from http://www.pubmedcentral.nih.gov/articlerender.fcgi?artid=1838109\&tool=pmc entrez\&rendertype $=$ abstract

Strober, W., \& Fuss, I. J. (2011). Proinflammatory cytokines in the pathogenesis of inflammatory bowel diseases. Gastroenterology, 140(6), 1756-67. doi:10.1053/j.gastro.2011.02.016

Strober, W., Fuss, I. J., Nakamura, K., \& Kitani, A. (2003). Recent advances in the understanding of the induction and regulation of mucosal inflammation. Journal of Gastroenterology, 38 Suppl 1, 55-8. Retrieved from http://www.ncbi.nlm.nih.gov/pubmed/12698873

Suzuki, A., Sugimura, K., Ohtsuka, K., Hasegawa, K., Suzuki, K., Ishizuka, K., ... Asakura, H. (2000). Fas/Fas ligand expression and characteristics of primed CD45RO+ T cells in the inflamed mucosa of ulcerative colitis. Scandinavian Journal of Gastroenterology, 35(12), 1278-83. Retrieved from http://www.ncbi.nlm.nih.gov/pubmed/11199367

Sylvester, K. G., Ling, X. B., Liu, G. Y., Kastenberg, Z. J., Ji, J., Hu, Z., ... Moss, R. L. (2013). A novel urine peptide biomarker-based algorithm for the prognosis of necrotising enterocolitis in human infants. Gut, 1-9. doi:10.1136/gutjnl-2013305130

Tibble, J. A., Sigthorsson, G., Bridger, S., Fagerhol, M. K., \& Bjarnason, I. (2000). Surrogate markers of intestinal inflammation are predictive of relapse in patients with inflammatory bowel disease. Gastroenterology, 119(1), 15-22. Retrieved from http://www.ncbi.nlm.nih.gov/pubmed/10889150

Toscano, M. a, Campagna, L., Molinero, L. L., Cerliani, J. P., Croci, D. O., Ilarregui, J. M., ... Rabinovich, G. a. (2011). Nuclear factor (NF)- $\kappa B$ controls expression of the immunoregulatory glycan-binding protein galectin-1. Molecular Immunology, 48(15-16), 1940-9. doi:10.1016/j.molimm.2011.05.021

Toscano, M. A., Bianco, G. A., Ilarregui, J. M., Croci, D. O., Correale, J., Hernandez, J. D., ... Rabinovich, G. A. (2007). Differential glycosylation of TH1, TH2 and TH-17 effector cells selectively regulates susceptibility to cell death. Nature Immunology, 8(8), 825-34. doi:10.1038/ni1482

Toscano, M. A., Commodaro, A. G., Ilarregui, J. M., Bianco, G. A., Liberman, A., Serra, H. M., ... Rabinovich, G. A. (2006). Galectin-1 suppresses autoimmune retinal disease by promoting concomitant Th2- and T regulatory-mediated antiinflammatory responses. Journal of Immunology (Baltimore, Md.: 1950), 176(10), 6323-32. Retrieved from http://www.ncbi.nlm.nih.gov/pubmed/16670344 
Uehara, F., Ohba, N., \& Ozawa, M. (2001). Isolation and characterization of galectins in the mammalian retina. Investigative Ophthalmology \& Visual Science, 42(10), 2164-72. Retrieved from http://www.ncbi.nlm.nih.gov/pubmed/11527926

Ullman, T. a, \& Itzkowitz, S. H. (2011). Intestinal inflammation and cancer. Gastroenterology, 140(6), 1807-16. doi:10.1053/j.gastro.2011.01.057

Vallabhapurapu, S., \& Karin, M. (2009). Regulation and function of NF-kappaB transcription factors in the immune system. Annual Review of Immunology, 27, 693-733. doi:10.1146/annurev.immunol.021908.132641

Van der Leij, J., van den Berg, A., Harms, G., Eschbach, H., Vos, H., Zwiers, P., ... Visser, L. (2007). Strongly enhanced IL-10 production using stable galectin-1 homodimers. Molecular Immunology, 44(4), 506-13. doi:10.1016/j.molimm.2006.02.011

Villanacci, V., Antonelli, E., Geboes, K., Casella, G., \& Bassotti, G. (2013). Histological healing in inflammatory bowel disease: a still unfulfilled promise. World Journal of Gastroenterology: WJG, 19(7), 968-78. doi:10.3748/wjg.v19.i7.968

Walzel, H., Blach, M., Hirabayashi, J., Kasai, K. I., \& Brock, J. (2000). Involvement of CD2 and CD3 in galectin-1 induced signaling in human Jurkat T-cells. Glycobiology, 10(2), 131-40. 1 Retrieved http://www.ncbi.nlm.nih.gov/pubmed/10642604

Walzel, H., Schulz, U., Neels, P., \& Brock, J. (1999). Galectin-1, a natural ligand for the receptor-type protein tyrosine phosphatase CD45. Immunology Letters, 67(3), 193-202. Retrieved from http://www.ncbi.nlm.nih.gov/pubmed/10369126

Wells, V., Davies, D., \& Mallucci, L. (1999). Cell cycle arrest and induction of apoptosis by beta galactoside binding protein (beta GBP) in human mammary cancer cells. A potential new approach to cancer control. European Journal of Cancer (Oxford, England: 1990), 35(6), 978-83. Retrieved from http://www.ncbi.nlm.nih.gov/pubmed/10533482

Westendorf, A. M., Fleissner, D., Hansen, W., \& Buer, J. (2010). T cells, dendritic cells and epithelial cells in intestinal homeostasis. International Journal of Medical Microbiology : IJMM, 300(1), 11-8. doi:10.1016/j.ijmm.2009.08.009

Wopereis, S., Lefeber, D. J., Morava, E., \& Wevers, R. a. (2006). Mechanisms in protein O-glycan biosynthesis and clinical and molecular aspects of protein Oglycan biosynthesis defects: a review. Clinical Chemistry, 52(4), 574-600. doi:10.1373/clinchem.2005.063040

Wu, B. W., Harley, P. H., Punt, J. A., Sharrow, S. O., \& Kearse, K. P. (1996). Identification of CD8 as a Peanut Agglutinin (PNA) Receptor Molecule on 
Immature Thymocytes. The Journal of Experimental Medicine, 325(August), 759-764.

Wullaert, A. (2010). Role of NF-kappaB activation in intestinal immune homeostasis. International Journal of Medical Microbiology: IJMM, 300(1), 49-56. doi:10.1016/j.ijmm.2009.08.007

Xavier, R. J., \& Podolsky, D. K. (2007). Unravelling the pathogenesis of inflammatory bowel disease. Nature, 448(7152), 427-34. doi: $10.1038 /$ nature 06005

Xu, X.-R., Liu, C.-Q., Feng, B.-S., \& Liu, Z.-J. (2014). Dysregulation of mucosal immune response in pathogenesis of inflammatory bowel disease. World Journal of Gastroenterology: WJG, 20(12), 3255-64. doi:10.3748/wjg.v20.i12.3255

Zúñiga, E., Gruppi, A., Hirabayashi, J., Kasai, K. I., \& Rabinovich, G. A. (2001). Regulated expression and effect of galectin-1 on Trypanosoma cruzi-infected macrophages: modulation of microbicidal activity and survival. Infection and Immunity, 69(11), 6804-12. doi:10.1128/IAI.69.11.6804-6812.2001 